\title{
THE ROLE OF ALGEBRA IN THE DEVELOPMENT OF' RELATIONAL THINKING
}

\section{Dissertation}

Presented in Partial Fulfillment of the Requirements for the Degree Doctor of Philosophy in the Graduate School of The Ohio State University

\section{By}

\author{
William Nichols Jackson, B.S., M.S. \\ The Ohio State University \\ 1952
}

Approved by:

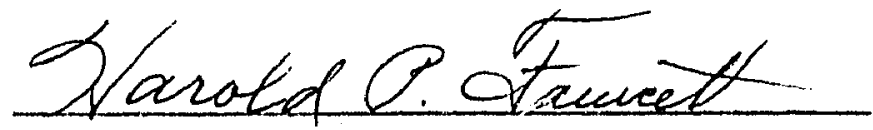




\title{
ACKNOWLEDGMENTS
}

It is with gratitude that I acknowledge the guidance given by my adviser, Dr. Harold P. Fawcett, in the planning and reporting of this study. The type of thinking which he stimulated was a frequent source of inspiration to me. The euggestions of Dr. Earl W. Anderson and Dr. G. P. Cahoon were unusually helpful to me in the preparation of the dissertation.

The untiring efforts of my dear wife, Dorwatha, in the typing of the first and final drafts of the dissertation merit my continuous thankfulness.

\author{
William N. Jackson
}


TABIE OF CONTENTS

CHAPTER

PAGE

ACKNOWLEDGEMENTS

I THE NATURE OF RELATIONAI THINKING AND ITS

RELATIONSHIP TO THE INTERPRETATION OF DATA $\ldots$.

Statement of the Problem $\ldots \ldots \ldots \ldots \ldots \ldots$ Plan of the Study

Need for and Importance of the Study ........ The Nature of Relational Thinking ......... Relational Thinling and Interpretation of Data

II PROBLEMS IN THE INTERPRETATION OF DATA $\ldots \ldots \ldots 16$

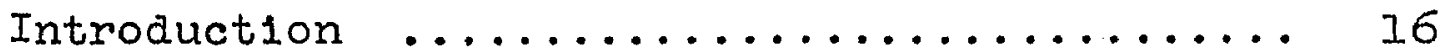

Definition and Analysis of the Ability ..... 19

Studies Related to Interpretation of Data ... 30

III SUGGESTED ALGEBRAIC CONTIENT AND TEACHING METIOD FOR DIGVELOPING ABILITY TO INTERPRET DATA $\ldots \ldots .47$

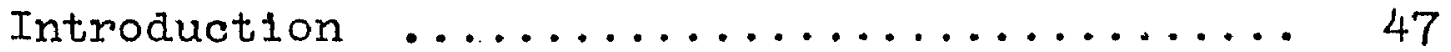

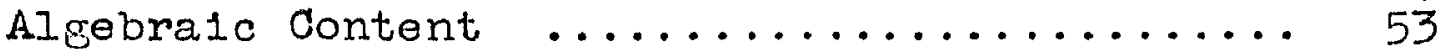

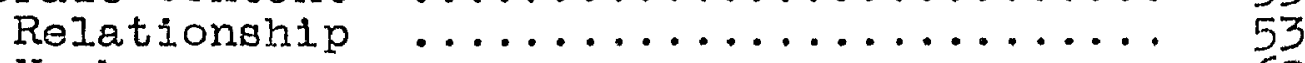

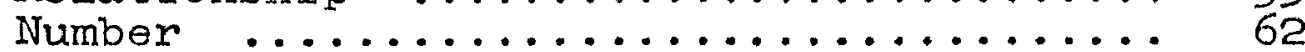

Measurement $\ldots \ldots \ldots \ldots \ldots \ldots \ldots \ldots \ldots \ldots$

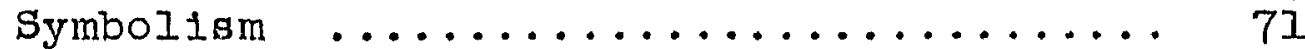

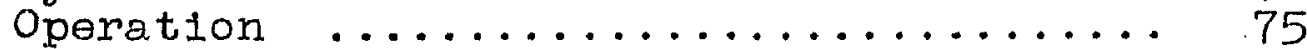

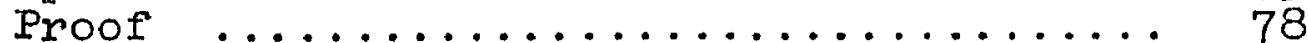

Basic èssumptions $\ldots \ldots \ldots \ldots \ldots \ldots \ldots \ldots \ldots$

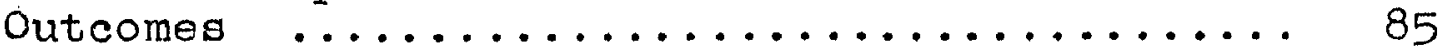

Teaching Method ................. 87

IV GENERAL, PROCEDURES AND EXPERIMINTAL CONDITIONS . 90

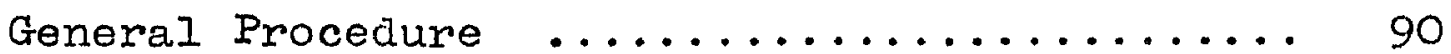

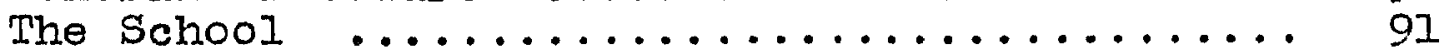

The Students $\ldots \ldots \ldots \ldots \ldots \ldots \ldots \ldots \ldots \ldots \ldots \ldots$. 92

V EXPERIMENTAL MATERIALS AND CLASSROOM PROCEDURES 101

Summary of Instructional Units .......... 101

The Study Gulde .................. 107

Unit One - The Language of Algebra ........ 110

Unit Two - Ixtend1ng the Number System ..... 126

Un1t Three - Approximate and Functional

Relationships $\ldots \ldots \ldots \ldots \ldots \ldots 151$ 
Unit Four - Extending Operations in the Number system

VI EVALUATING STUDENT ABILITIES TO INTERPRET DATA 209

Significance of Gaing in Ability to Interpret Data ................... 209 Apparent Influence of Intelilgence

on Interpretation of Data .......... 225 Apparent Influence of Reading Ability

on Interpretation of Data .......... 226 Apparent Influence of Sex on

Interpretation of Data ............. 233

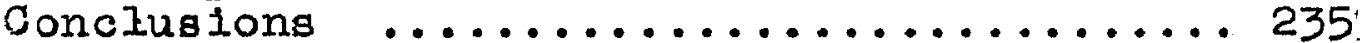
Discussion of Individual Students ....... 237 Inventory of Behaviors Evaluated ........241

.VII IMPLICATIONS FOR GENERAL EDUCATION $\ldots \ldots . .246$

General summary ................. 246 Recommendations .................. 247

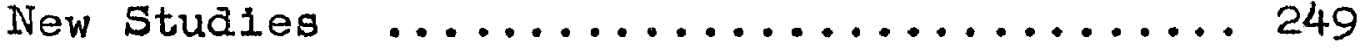

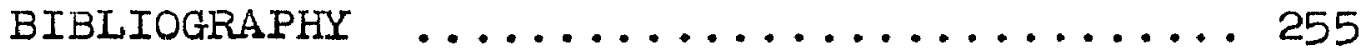

APPENDIX $\ldots \ldots \ldots \ldots \ldots \ldots \ldots \ldots \ldots \ldots \ldots$

AUTOBIOGRAPHY $\ldots \ldots \ldots \ldots \ldots \ldots \ldots \ldots \ldots$ 


\section{LIST OF TABLES}

TABLE

PAGE

1 SPEED AND REACTION DISTANCE $\ldots \ldots \ldots \ldots \ldots \ldots \ldots \ldots . \ldots 27$

2 graduates attending colltege $\ldots \ldots \ldots \ldots \ldots \ldots$

3 PARENTAL STATUS OF STUDENTS ............. 93

4 RESIDENTIAL STATUS OF STUDENTS $\ldots \ldots \ldots \ldots \ldots \ldots$

5 OCCUPATIONS OF PARENTS $\ldots \ldots \ldots \ldots \ldots \ldots \ldots \ldots . \ldots \ldots$

6 AGES OF STUDENTS $\ldots \ldots \ldots \ldots \ldots \ldots \ldots \ldots \ldots \ldots \ldots$

7 INTELLIGENCE QUOT IENTS OF STUDENTS IN SECTION 1 • 96;

8 INTELLIGENCE QUOTIENTS OF STUDENTS IN SECTION 2 • 97

9 READING PERCENTILES OF STUDENTS $\ldots \ldots \ldots \ldots \ldots . \ldots 9$

10 CLASS SCHEDULES $\ldots \ldots \ldots \ldots \ldots \ldots \ldots \ldots \ldots \ldots \ldots$

11 NEGATIVE RESPONSES IN LISTING OF ANTONYMS $\ldots \ldots \ldots 127$

12 FRIGQUENCY OF OPPOSITES SUGGESTED BY STUDENIS $\ldots$. . 128

13 FREQUENCY OF NUMBIR OPPOSITES SUGGESTED BY

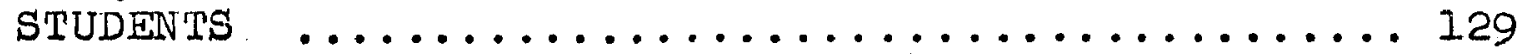

14 STUDENT RESPONSES TO PROBLEM $1 \ldots \ldots \ldots \ldots \ldots \ldots \ldots$

15 SIUDENT RESPONSES TO PROBLEM $3 \ldots \ldots \ldots \ldots \ldots \ldots$

16 RESPONSES OF STUDENIS TO PROBLEM $4 \ldots \ldots \ldots \ldots \ldots$

17 STUDENT RATINGS OF CONVERSE STATEMENTS $\ldots \ldots \ldots \ldots 177$

18 STUDENT RAT INGS OF STATEMENTS ILIUSTRATING

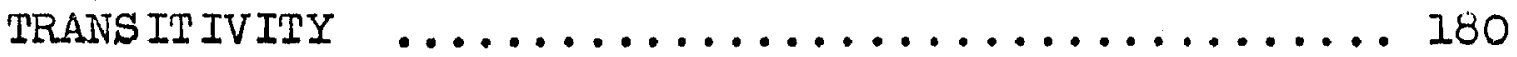

19 STUDENT RATINGS OF STATEMENTS IN STUDY GUIDE

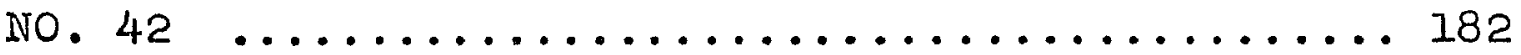

20 STATEMENTS CHECKED BY STUDENTS ON TEST $-5.4 \ldots \ldots .187$

21 STUDENT EVALUATION OF INTERPRETATIVE STATENENTS • 204 22 MEDIANS OF STUDENT RESPONSES TO TEST $5.5 \ldots \ldots \ldots 208$ 
23: SCORES ON INTERPRETATION OF DATA TEST..

FOR SEXTION 1, December, $1950 \ldots . . . . . . . . . .213$

24 SCORES ON INTERPRETATION OF DATA TEST

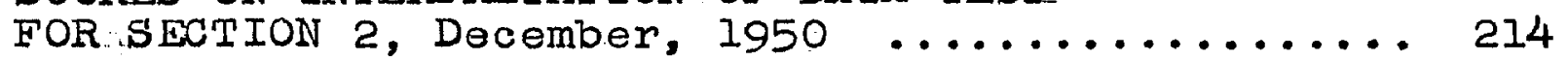

25 SCORES ON INTERPRETATION OF DATA TEST 1

FOR SECTION 1, June, 1951 .................. 215.

26 SCORES ON INTERPRETATION OF DATA TEST

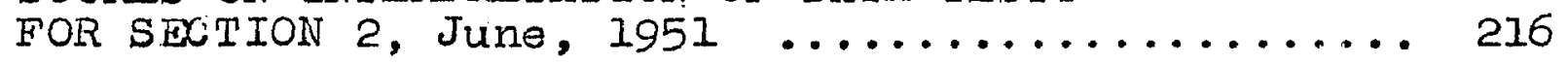

27 MEAN GAINS ON INTERPRETATION OF DATA TEST $\ldots . . . .217$.

28 SIGNIFICANCE OF DIFEERENCE IN MEANS ........... 219

29 SCORES ON INTERPRETATION OF DATA TEST BY

STUDENTS HAVING HIGHER INTELIIGENCE QUOTIENTS .. . 223

30 SCORES ON INTERPRETATION OF DATA TEST BY

STUDENTS HAVING LOWER INTELLIGEICE QUOTIENTS $\ldots . .224$

31 MEAN GAINS ON INTERPRETATION OF DATA TEST ..... 225

32 SIGNIFICANCE OF DIFFERENCE IN MEANS ........... 226

33. SCORES ON INTERPRETATION OF DATA TEST BY

STUDENTS HAVING BETTER READING ABILITY . . . . . . . 227.

34 SCORES ON INTERPRETATION OF DATA TEST BY

STUDENTS HAVING POOR READING ABILITY .......... 228

35: MEAN GAINS ON INTERPRETATION OF DATA TEST . ..... 229

36 SIGNIFICANCE OF DIFFERENCE IN MEANS ........... 230

37 SCORES ON INTERPRETATION OF DATA TEST BY BOYS ... 231

38 SCORES ON INTERPRETATION OF DATA TIST BY GIRIS . 232

39 MEAN GAINS ON INTERPRETATION OF DATA TEST $\ldots . . . .233$

40 SIGNIFICANCE OF DIFFERENCE IN MEANS $\ldots \ldots \ldots . \ldots . \ldots 234$

41 GAINS BY STUDENT F IN ABILITY TO INTERPRET DATA . 238

42... GAINS BY STUDENT A' IN ABILITY TO INTERPRET DATA • 240 


\section{IIST OF CHARTS}

CHART:

PAGE:

1 WEIGHT-HEIGHT RELAT ION FOR BABY BOY ........ 158

2... WEIGHT-HEIGHT RETATION FOR AVERAGE TYPE

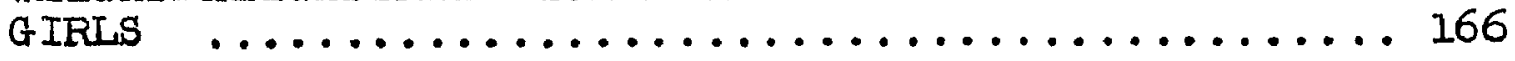

3. AREAS OF SQUARES . . . . . . . . . . . . . . 194 
THE ROLE OF ALGEBRA IN THE DEVELOPMENT:

OF REIATIONAI THINKING:

Chaptier 1

The Nature of Relational Thinking and its Relationship to the Interpretation of Data

Statement of the Problem

The problem invegtigated was concerned with the teaching of elementary algebra: The purpose of the study was to determine the extent to which the studentg in two ninth grade classeg: In the William Grant High School 10cated at Covington, Kentucky, can develop understandings: and abilities assoclated with the interpretation of data, through the study and use of algebra1c concepts. Since only those concepts are considered which, in the judgment of the writer seem to contribute to student facilities for Interpreting data, this involves the selection of appropriate content and teaching methods: An important aspect of the problem is the generalization of these understandings and abilities for use beyond the narrow confines: of elementary algebra. It is the writer's belief that the ability to interpret data is an integral part of one of the great fields of mathematics, relational thinking. Plan of the Study:

The plan for the discussion of this study follows. In the first chapter the characteriatics of relational 
thinking have been alscussed, and its intimate relationship with the interpretation of data have been shown. In chapter two, a detalled analysis has been made of the behaviors characteristic of the interpreter of data. Chapter three is concerned with the theory for planning a course in algebra designed to improve ability to interpret data.

In chapter four, a description has been given of the students and facilities involved in the experiment. A detalled description of the experimental course has been presented in chapter five. This description includes. teaching techniques, classroom materials, and summaries of the accomplishments of students.

The alxth chapter consists of an evaluation of student growth in the abilities involved in the interpretation of data. The final chapter is a discussion of the Implication for general education as sugested by the resultis of the study. Need for and Importance of the Study

Our environment is composed of many elements which are forever changing, but the changes in these elements: are determined by changes in related elements. To Ilve happily a person must be able to percelve these relations as they apply to his welfare and the welfare of his neighbors. Many of these elements are presented falsely through numerous communication devices in use today. 
Frequently the elements are so presented as to hide or distort the relationships between them. It is the common practice of some persons to emphasize the relations which favor an individual or group and to ignore or belittle those which are not favorable to them. In this world of advertisins, political platiorms, accidental deaths, and propaganda, young people need to become aware of the devious, as well as proper, ways to interpret relations between signiflcant elements in any situation.

To think at all is to think in terms of relations. For example, relational thinking is used no less by the carpenter as he decides to use white pine lumber because of such elements as humidity, wear, and type of finish desired, than by the physician who considers such elements as temperature, blood pressure, skin condition and other variables in the human body as he concludes that his patient suffers from a particular malady. Such thinking is used by the cook who knows that a "pinch of salt" along with varying amounts of other ingredients with proper baking will produce a certain type of delicacy; and by the truck driver who knows the relations between speed, the condition of the road surface and the braking system such that he can negotiate a highway curve safely at a speed which makes him neither an overcautious nor a reckless driver. Even a small child who has used data derived from the actions of his parents to 
make great demands of mother and few or none of father, has discovered certain relations to foster his wants: and desires as well as insure his comfort. Truly, relational thinking permeates all of life as is averred by Keyser::

The terms: father, mother, parent, ch1ld, nelghbor, partner, enemy, friend, greater, less, better, worse, and so on and on are familiar examples of relations. Each thing in the world has named or unnemed relations to everything else. Relations are infinite in number and in
kind. To be is to be related. I

Most mathematics teachers claim that the study of mathematics improves the student's thinking or reasoning abilities particularly in the field of relational thinking. Few educators would dispute the desirability of this objective, however, very little effort has been made to explore the validity of the proposition that reasoning abilities of students have improved because of studying algebra. Many research projects have been launched by educators since the turn of the century in an attempt to solve perplexing pedagogical problems facing the teacher of high school algebra. There has been comparatively little research relating to the extent to which the objectives of algebra are achleved and to the methods of teaching that should be emphasized in developing these

1. C. J. Keyser, Mole PhIlosophy and Other Essays. p. 94 . 
objectives. Without discounting the worth of such studies as those by Everett, Powell, Dally and others, most of the research has been concerned with determining ways to teach more efficiently the skills assoclated with algebra. The emphasis in research has been on such factors as ability grouplngs, analysis of pupil reading abilities, and the relation of intelligence ratings to achlevement in algebra, and even in these matters there seems to be some disagreement.

The references which follow do not refer to studies concerned with developing reasoning abilities, but to typlcal researches in algebra. They are cited to Bive the background demonstrating the need for this study. From an analysis of 317 separate studies between 1905 and 1935, Nren has shown that many conclusions and recommendations are contradictory to each other. The following conclusions are illustrative of this disagreement:

1 Intelligence is a $\mathbf{9 1 g -} 1$ Tests and grades show nificant factor in that ability in matheachievement in algebra.

2 There is a aignificant relationship between ability in aritbmetic and ability in algebra.

3 The adjusting of al- 2 gebraic instruction to ability levela. of pupils develops more individual inltiative, 3 creates better attitudes, and reduces the number of faliurea. matics is not as closely related to general intellectual capacity as we are likely to suppose. 2 Progress in beginning algebra is not dependent upon a good background in arithmetic. 3 The reaults do not favor ability grouping. 
4 The Orleans prognost1c 4: The Orleans prognostic test is effective for prognosis.

5 Group instruction in algebra produces: better resulta than indivtdual instruction.

test is not a satisfactory basis upon which to make a prognogis of abilities in algebra.

5 The Individualized unit method produced better achievement and retention in algebra than the traditional group method of instruction. 2

In the periodic issues of the Reviev of Educational Research which oummarize the research for the previous three years in sclence and mathematics education, there Is a paucity of reported research in the teaching of algebra. In the 1942 1ague only 7 of 31 references or 23 per cent were made to research in al febra. These studies dealt primarily with reading and vocabulary studies, and predicting success in algebra. In 1945 only 3 out of 38 or 8 per cent of the studies in high school and junfor college mathematics related to the teaching of algebra. In 1948 only 7 out of 74 or 9 per cent of the studies in methods and materials in the teaching of mathematics related to the teaching of algebra. None of the 44 siludies dealing with the alms of mathematics wa: concerned with algebra. In 1951, 5 out of 56; or 9 rer cent of the studiea reported in the

2. F. I. Wren, "A Survey of Research in the Teaching of Secondary Algebra", Journal of Educational Research, XXVIII (Apri1, 1935)., pp. 597-603. 
teaching of high school and college mathematics, , related to the teaching of elementary algebra. Not only has research in algebra been limited; it has also dealt with relatively unimportant 1 tems.

The focus of research in the teaching of algebra has been on those external conditions which do not exert a slenipicant influence on student-teacher relationships. Thls situation in whlch investigators have worked on similar problems and reached contradictory conclusions seems to suggest that we are emphasizing problems to which there can be no uniform answers applying to all students. The fact that first year algebra has been considered, even by mathematics teachers, as the "no man's land" of secondary education and the fact that the bulk of research has not been with method, have prompted the writer to believe that the teaching of algebra at the secondary level needs to be reconsidered. Can the teaching of algebra offer avenues of discovery and profitable work as do modernized versions of other secondary subjects? Are there not some more fundamental probleis concerning the teaching of algebra, problems dealing with the method and content of algebra, to which mathematics educators should give consideration? Specifically, for example, can the subject matter and method of alfebra be used as a basis for improving the reasoning of students? The claim is widely made that algebra develops reasoning 
ablifties but there is little evidence to support the claim. The writer suggests the hypothesis that algebra can be used to develop important understandings associated with relational thinking, and the investigation of this hypothesis is the end to which the present study. will be directed.

In its famous 1923 report the National Committee on Mathemat1cs. Requirements: recommended an emphasis. on objectives which are far-reaching and genuine in its listing of the following "disciplinery aims":

1. The acquisition, in precise form, of those ideas or concepts in terms of which the quantitative thinking of the world is done.

2. The development of ability to think clearly in terms of such ideas and concepts. This ability involves training in

a. Analysis of a complex situation into simpler parts. This includes the recognition of essential factors and rejection of the irrelevant:

b. The recognition of logical relations between intordependent factors and the understandins and, if possible, the expression of such relations in precise form.

c. Generalization; that 1s, the discovery and formulation of a seneral law and an understanding of its properties and applications. 3

The Joint Commission in 1ts 1940 report recommended

3. National Committee on Mathematical Requirements, The Reorganization of Mathematics in Secondary Education, p. 9 . 
a unification of secondary school mathematics. through seven broad categories or flelds: number and computation, geometric form and space pereaption, graphic representation, elementary analysig, logical thinking, symbolic representation and thinking, and relational thinking. The commission further emphasizes: in the following statement the need for teaching students to become thinkers:

Since one of the purposes of thinking is to gain conclusions, $1 \mathrm{t}$ is desirable for young people to have school experience with subjects in which the ideals of permanence and high precision are realized. Thig applies even for those persons whose main interest is in problems in which conclusions must involve doubt. The contrast thet one is thus: led to see may engender an attitude of wholesome caution. This experience may indeed leave a particularly vivid impression when opportunities are presented to study problems where a numerical measure of probability is assigned to a conclusion necessarily based on data somewhat contradictory or otherwige inadequate.

The I940 report of the Committee on the Function of Mathematics in General Education of the Progressive Education Association also recommends a uniting of the various branches of secondary mathematics through the major concepts of: formulation and solution, data, approximation, function, operation, proof, and symbolism. The Committee expresses a definite conviction relative to

4. Jolnt Commision of the Mathematical Association of America and the National Council of Teachers of Mathematics, The Place of Mathematics in Secondary Education, p. 24 . 
the importance of "scientific thinking":

Students who are in the habit of formulating real problems and of insisting on genuine solutions, who know how to judge, collect and interpret data, who are not misled by inaccurate or misleading statistics, and who know how to recognize valid proof, will not so easily be misled by propaganda, suppression of evidence, systematic calumny; demagoguery, ox mystical symbols. 5

The Nature of Relational Thinking

Mathemat1cs, defined by many mathematicians as: the science of relations has much to offer a teacher concerned with providing experience in relational thinking. Concerning this, Keyser says:

It: is evident that the understanding of relations is a major concern of all men and. women. Are relations a concern of mathematics? They are so much its concern that mathematics is sometimes defined to be the science of relations.

Relational thinking is a type of reasonilig which in volves the identifying of variables or elements among which there is dependence or interdependence. Hamley defines functional relation as follows: "We say that two variable classes are in functional relation when there is a determinate correspondence between the elements of the two classes, these elements being arranged

5. Progressive Education Association, Commission on Secondary Curriculum, Mathematics in General Education, p. 68 .

6. Keyser, op. cit., p. 94. 
in some prescribed order." 7 A person proficient in this ability should also be able to refute spurious claims of dependence between variables. The dependence may be functional or approximate. The statement that the "cost" depends upon the "price": or rate of the 1tem and tine "number of items" purchased, is an example of functional dependence. It is functional because there is. determinate correspondence between "cost" and "number of 1 tems" when "price" is a constant (e.g. is 0.30$)$. Thus the relation car be stated as a formula, $c=.30 \mathrm{n}$.

The variables may be measurable or non-measurable, mathematical or non-mathematical in nature. Hamloy makes the following comment concerning tire nature of functional relations:

The notion of function reed not be confined to numbers, or to the uses to which mathemaw ticians have accustomed us; it can be extended to all cases of one-many relations, and the 'father of $x$ " is just as lestimately a function of which $x$ is the argument; as is the "Ioganithm of $x "$.

On the other hand there and approximate and indefinite correspondences between variables determined through statistical computations. The "price" of fresin corn depends upon the "season" of the year, is an example of

7. Herbert R. Hamley, Reletional and Functional Thinking in Mathematics, p. 23 .

8. Ibid., p. 28 . 
approximate dependence. This relation cannot be statied precisely; it can only be stated that price varies as season, p s. According to Hamley::

Some of the correspondences of pure mathematics are definite and preaise, others: involve the factor of probability, leading us to what is known as 'statistical inference'. Correspondences: of both types are met with in life, from the unequivocal statement of fact, to the more hypothetical inductions from experience. 9

It can be seen that relationships range from mere inklings of dependence between two or more variables to those representing the ultimate ir functional dependence; for example, from the relationship that is suspected to exist between one's age and the intensity of appetite for sweets, to the linear function, $y=a x$, in which each value of $y$ can be predicted in terms of specific values of $x$, where $a$ is a constant. Countless relationships are found between these two extremes, the range being from the grosaest approximations to the most precise functional relationships.

Relational Thinking and Interpretation of Data

The end of all relational thinking, whether it be functional thinking or thinking in terms of approximate relations, is interpretation of relationships and the drawing of valid generalizations. Hamley says: ....... functional thinking Involves three

9. Ibid.,. p. 28 . 
abilities. First, the ability to recognize mutual dependence between variables and varying quantities; second, the ability to determine the nature of the dependence or relationship between variable quantities; and third, the ability to express and interpret quantitative relationships. In other words, the recognition, interpretation, and utilization of relationships. are the heart and soul of functional thinking. Io

When we examine these three abllities: recognizing mutual dependence, determining the nature of the dependence, and expressing and interpreting quantitative relationships, it becomes: evident that to exercise the first two abilities without proceeding to a use of the third would be to squander enerey and intelligence. What a mockery of our status as rational beings to train a student to recognize dependence and determine its nature, and yet the student be unable to put this knowledere to use in expressing and interpreting the inherent relationships. There has been too much of this type of instruction in our schools, for the development of the ability to express and interpret relationships is left to chance or to effortloss hope. There has been much theorlzing but these theories have not been put to sufficient use in the solution and interpretation of everyday problems. Relational thinking becomes a dynamic and purposeful process only when the climactic step of interpretation is exercised.

Relational thinking is activated from data or facts.

10. Ibid., p. 80. 
"Data may consist of any material used as a basis of discussion or inference" and it may be: incomplete. inaccurate, 1rrelevant, too extensive, pcoxly organized, or poorly presentied for the purpose at hand. Il Rielational thinking proceeds when one is able to reorganize, eliminate irrelevant data, secure additional data, and perform various tasks of refining in getting to the point of recognizing and characterizing various types of dependence and interpreting the inherent relationships. This process is: known as the interpretation of data. Hence, the essence of relational thinking is the ability to interpret data, because this ability implies a totality of the triad: recognition. characterization, and interpretation. To lilustrate this intimate relation between the interpreitation of data and relational thinking, suppose a person reads the following advertisement:

\section{Something to Think About}

\section{$1933 \quad 1951$ Increage}

I Ib. Pork Chops.

I 13. Coffee

Public Transportation

$\begin{aligned} 9 \phi & 81 \phi \\ 30 \phi & 80 \phi \\ 9 \phi & 15 \frac{1}{2} \phi\end{aligned}$

$800 \%$

$166 \%$

$72 \%$

Public Transportation Is St1l1 Your Best Buy! Instead of accopting the generalization that public transportation is the best buy, suppose the reader holds it in

11. M. I. Hartung, "Interpretation of Data", Bulletin No. 3, P.I.A., Evaluation in the Eight Year Study, p. 3 . 
abeyance, considering the data at hand and its relation to the generalization. He sees no relation between the price of two food commodities and the "best buy" in transportation. Hence, he discards it and seeks more relevant data, such as the per cent increase in taxi fares, and the per cent increase in the cost of owning and operating a car. Using these new data to identify relations between more relevant elements, he reaches a conclusion which efther substantiates or contradicts the given generalization. Throughout this process, relational thinking has proceeded and so has interpretation of data! Interpreting the data has stimulated relational thinking; seeing relations has stimulated further interpretations. The two processes are inseparable!

This study then deals with the role of algebra in the development of the ability to interpret data, the essence of relational thinking. Chapter Two of this discussion will therefore be concerned with a detalled analygis of the behaviors involved in the interpretation of data. 


\section{Chapter Two}

Problems: In The Interpretation of Data:

\section{Introduction}

Consciously or unconsciously the average citizen is: forced to interpret data dally. Via radio, television, newspapers and magazines he is frequently urged to conclude that " $X$ " brand of cigarettes must be his: brand because of "Impartial" surveys and experiments which have been performed showlng the superiority of this brand. During election campaigns he is given the past records of candidates and must decide for whom he must vote.

In buying a home he must decide whether it is more economical to build his home or renovate an old one to sult his specifications. He is presented with streamlined models of refrigerators, stoves; washing machines and other appliances, and he either chooses the models most. pleasing to the eye and the esthetic senses: or ignores these qualities to choose the model which does itg: intended task most effectively.

He must choose his foods by brands too and decide the merits of vitamin " $V$ " in "re" bread against vitamins in other brands. Problem in the home must also be daily reconciled. Should he, on the basis of facts at hand, rush his child to the hospitial or call his family doctor for advice? 
How seriously does he conglder data concerning deaths: due to various diseases, the precautions one should take in the home to prevent accidents, and the number of injuries and fatalities due to careless and irresponsible drivers of automobiles?

The average eitizen usually, "chooses: a side" in the many public controversies which arise or which are provoked by some individual or group. Was: the President. right or wrong in removing General MacArthur from his command? The citizen must decide whethor the data presented by each man are reliable and complete. Is either claimant withholaing evidence which would damage his position?. In one controversy a writer of a newspaper editorial accused a gtate university of paying $\$ 1,800$ of the "tax payers" money:" to a visiting lecturer who was believed to have Communistic leanings. Actually a total of $\$ 1,800$ was avallable in the fund for all visiting lecturers and other activities. This information was withheld by the editor and the new and misleading data were presented, thus arousing readers of the newspaper. What were the motives of the editor? Why did he use inaccurate data?

As another example of the withholding of data, the chlef medical examiner of a large city made the assertion that boxing is not the dangerous aport that it has been plctured to be. He listed the total number of deaths 
for the past 32 years in baseball, football and boxing. There were 43 deaths in baseball, 22 in football, and 21 in boxing. He then interpreted his data by concluding that baseball is most dangerous and that boxing caused fewer deaths in proportion to the number of participants than any other sport. The important data omitted were the total number of participants in each sport and the percentage of fatalities per season or year. Although his: conclusions may be valid, they cannot be properly evaluated by the reader. A different interpretation might: be made by readers with these additional facts.

Even on the international scene the citizen reaches conclusions--sometimes tentative, sometimes absolute, and of doubtful validity. Is Stalin the tyrant that he ia described to be?. Do the data concerning him support auch a conclusion? To have a sound conclusion there muat be reliable and sufficient data from which to draw it. Yet such questions are decided only on the basis of avallable information; seldom are decisions held in abeyance for further information.

The flood of advertising on the various communication media, the reputed Inefficlency of government administirators, the yearly increase in the number of accidentai deaths and injuries and the many other indications of his laissez-faire attitude, seem to show that the citizen must: become more sensitive to the need for becoming proficient 
in hig ability to interpret data.

A very preciour possession of a democratic culture is the freedom and privilege to interpret data. The ability to interpret data strikes at the heart of democracy, for citizens alert to the techniques of interpreting and evaluating evidence are democracy's bulwark. With a citizenry: apathetic to the wiles of those who would misinterpret data, democracy becomes ripe for plucking by any group with a consuming desire to replace democratic ideals with authoritarian or other anti-democratic ideals. The growth and development of a democracy may well be gauged in direct relation to the number and quality of persons sensitive to the validity of the many generalizations made in the daily press and other written materials. Definition and Analysis of the Ability

The ability to interpret data can be defined best through a description of the various behaviors one displays while engaged in this process. How would a person behave who knows how to interpret data? The following behaviors describe the sirilled interpreter:

1. Perceives and expresses possible relationships between items in a set of data.

2. Recognizes the Iimitations of the data.

3. Understands the fact that the validity of a statement depends on the values attached to the variables.

4. Evaluates conclusions and generalizations reached by others in their interpretation. 
of data.

5. Draws valia generalizations consistent with relationships recognized.

ProbabIy the most important behavior is represented In the action of perceiving and expressing possible relationships between items in a set of data. The data may be presented in tabular form, in graphic form, in a verbal statement, or in any form which conveys the relevant information. Aiperson in the act of interpreting data can see the existence or non-existence of a relation between elements or variables in a set of data and can make appropriate expressions of such relationships.

The term, variable, will be used with a much wider scope than its use in mathematics. The following references clarify its meaning:

Our third component of functionality is the variable which we have defined as an ageregate of mathematical elements. Thus the class of natural numbers constituties a: variable, which may be represented by a symbol identifiable with each and every element of the class. Similarly the word "man" is a variable symbol, by which one of the class of men may be identified. Names are symbols of the variables of human discourse. I

A variable is a symbol, which represents any one of a class of elements. The elements may or may not be numbers. 2

1. F. R. Hamley, Relational and Functional Thinking in Mathematics, p. 27 .

2. J. W: Young, Lectures on the Fundamental Concepts: of Algebra and Geometry, p. 193. 
The notion of variable need not be restricted to classical mathematics. Not only time and distance, but every measurable character, property, or quality may serve as a mathematical variable. ............ One may even extend the notion to qualities not usually thought of as numerically graded, such as taste, moral value, degree of discomfort, persistency, punctuality, and other characteristica personal or impersonal. 3

It is easy and customary, to pass from the usage in which the variable is a symbol to a second usage, in which one speaks of the variable symbol as referring to or signifying a variable object or variable element ........... So, too we come to speak of the temperature, the weather, the price of potatoes, the rate of progress of citilization, and many other things as variables dependent on variable conditions. 4

There are many supplementary skills required in order to perceive relationships in data efficiently. For example, In a functional relation involving two variables one should be able to compute the values of a variable from known value of a related variable. This includes an understanding of the changes in a variable when a related variable undergoes a change.

One must also be able to relate like characteristics in different types of data. Recognizing the relationship between the slope of a sraph and the constant differences between the values of the dependent varlable in a table, is an illustration of this ability.

3. Progressive Education Association, Commission on Secondary School Curriculum, Mathematics in General Education, p. 142 . p. 284.

4. A. A. Bennett and $\sigma$. A. Baylis, Formal Logic, 
The ability to do symbolic thinking such as attaching appropriate meanings to various symbols is a very important supplementary skill. Without this ability the interpreter of data would be in much the same predicament as the surgeon who plans to operate but has no instruments. Taba describes these skills as follows:

Several types of behavior are involved in interpreting data. First, students must be able to read given data, that is, to recognize the meaning of symbols used, and to understand the con-. ceptis necessary for seeing the relationships presented. These symbols vary according to the form of presentation. Thus, in verbal paragraphs the definition of terms is necessary. In graphic presentation, the student must be able to locate specific points on the graph, relate these to the base lines, recognize variations in length of bars or slope of graph lines, and so on. In the case of quantitative data, students must understand simple statistical terms (e.8., "average"), the units used, 5 and the conventional methods of pre-

Recognizing the limitations of data is a second characteriatic of the interpreter of data. With this ability he knows how far to go in drawing inferences from data. He uses procedures appropriate for ldentifying tendencies or trends in a given set of data. He makes proper qualifications of his statements when interpolating or finding and using intermediate values of the variables. The same may be said of his statements when extrapolating or predicting

5. Teaching Critical Thinking in the Social Studies, 13th Yearbook, National Council for the Social studies, p. 138 . 
values of varlables greater than the largest in a table of data or which lie beyond a given graph. Hence, he will use such terms as: "it is probable that", "some", "many", "almost", "it appears that", In making interpolations and extrapolations. He is also mindful of the type of sampling in the data, and considers its representativenesg as well as the amount of data preparatory to mairing interpretations. He recognizes the need for enlarging the data before stating or accepting some interpretations. Obviously, he must use data appropriate for the particular situation and consider the domain of the independent variable and the range of the dependent variable. Concerning this ability Smith and Tyler say:

A student who develops this ability recognizes what other information, in addition to that given, he must have in order to be reasonably sure of certain types of interpretations. He refraing from making judgments relative to implied causes, effects, or purposes until he has necessary facts at hand. He recognizes the error in allowing his emotions to carry him beyond the given facts. when he judges conclusions that affect him personally. If he holds rigidly to what is established by the data, the kinds of generalizations that he can make without qualification are limited. He recognizes that many interpretations must be regarded as almost completely uncertain because the facts given are insufficient to support such interpretations even with appropriately stated qualifications. These behaviors do not preclude the possibility of making qualified inferences when the situation warrants.......... Fundamentally, the objective involves making a distinction between what is established by the data alone, and what is being read into the data by the interpreter. 6

6. E. R. Smith and R. W. Tyler, Appraising and Recording Student Progress, pp. 38-39. 
In handing data the interpreter realizes that his inferences cannot apply to a single individual or item, that his inferences must be tempered with qualifying terms which inform others of the degree of uncertainty of his predictions or explanations. The interpreter of data must understand the difference between a scientific law, which applies in every instance, and statistical generalizationg which are rendered uncertain through probability. Concerning this the Commission on Secondary school Curriculum says:

Associations determined statistically are often phraged in much the same language as universal scientific "laws". In fact one sometimes mistakes what is intended to be merely a statistical generalization for an exact statiement of universal validity. But statistical generalizations are not intended for application for any given selected individual or even to an individual chosen at random.7

A third behavior often displayed as one interpreta data is a sort of open-mindedness on the part of the interpreter. He understands that, in many situations, $a b-$ solute interpretations cannot be made because of the changing factors or variables which are contained in the Interpretations. He understands that the degree of truth In a declaration is dependent upon the extent to which the related variables approach non-variability. Concerning this Thouless days::

\footnotetext{
7. Commisgion on Secondary Curriculum, op. c1t., pp. $131-132$.
} 
All over human Iife we find properties which show continuous variation and we find this property obscured by the use of words implying sharp distinctions. "Sane" and "insane"; "good" and "bad"; "intelligent" and "uninteli1gent"; "proletarian" and "capital1st", are pairs of opposites which ahow this property of continuous: variation ........Any artument, therefore, which begins in some such way as follows: "A' man must be elther sane or insane, and an insane person is absolutely incapable of reasonable thought........" is a danserous piece of crooked thinking, since it 1 gnores this fact of continuity. 8

The interpreter of data realizes that many relations: are propositional; they have neither validity nor invalidIty when the variables which compose them have no specific value. For example, the statement that "Catholics do not cooperate with Protestants": is a proposition-1t 1s: neither true nor false. When "Cathol1c" and "Protestant" are given specific values as: "John Baker does not cooperate with Albert Saunders", the statement may be rated as true or false, depending on the actions of the two men. Many: times we are led to rate such generalizations as true after one example is clted in which gpeciflc valueg are given to the variables. A person sensitive to the nature of propositional functions: w1ll, in his reading, recognize statements which actually are neither true nor false because they are generalizations with no gpecificity given to the variables. He will try to determine the writer's belief with respect to the statement and analyze the data given in

8. R. H. Thouless, How to Think Stra1ght, pp. 122- 
support of it.

The interpreter of data is not only open-minded, he is also critical-minded. A fourth behavior which he displays is the appraisal of generalizations drawn by others in their interpretation of data. Many citizens are gullible to the generalizations of others. To cite one example, a patent medicine company netted $\$ 1,500,000$ in 1950 through the sale of a product which was concocted of various minerals, vitamins, and a liberal smount of alcohol. An eight ounce bottle of the product retalling for $\$ 1.25$ was actually worth 21 cents. The medicine was conceived by a person having no medical training and it was claimed to be a panacea for ailments of men, women and children. The manufacturer capitalized upon the testimonials of users, offered bounties to physicians who would prescribe the medicine, and many people have comsumed the product in huge amounts without questioning the reliability of the data presented by the manufacturer?

A critical-minded person looks for the number of cases cited in an argument and for the variety of the sampling. In evidence produced through testimonials he considers the qualifications of the person testifying. He questiong the testimonials of well known athletes, movie stars, and other noted persons concerning products and ideas beyond their

\footnotetext{
9. J. D. Ratcliff, "The Hullabaloo About Hadacol", Reader's Digest, LIX (JuIy, 1951), pp. 1.1-14.
} 
particular fields of attainment.

Jepson staties that the value of a generalization depends upon::

1. the relative number of the unobserved instances;

2. Whether the instances observed form a fair and sufficient sample, and whether no exceptions are discoverable;

3. the degree of probability of the existence of such a general rule or law. 10

Finally, one skilled in the interpretation of data must be able to draw valid generalizations consistent with relationships which he recognizes. For example, Table 1

\section{TABLE: 1}

Speed and Reaction Distance

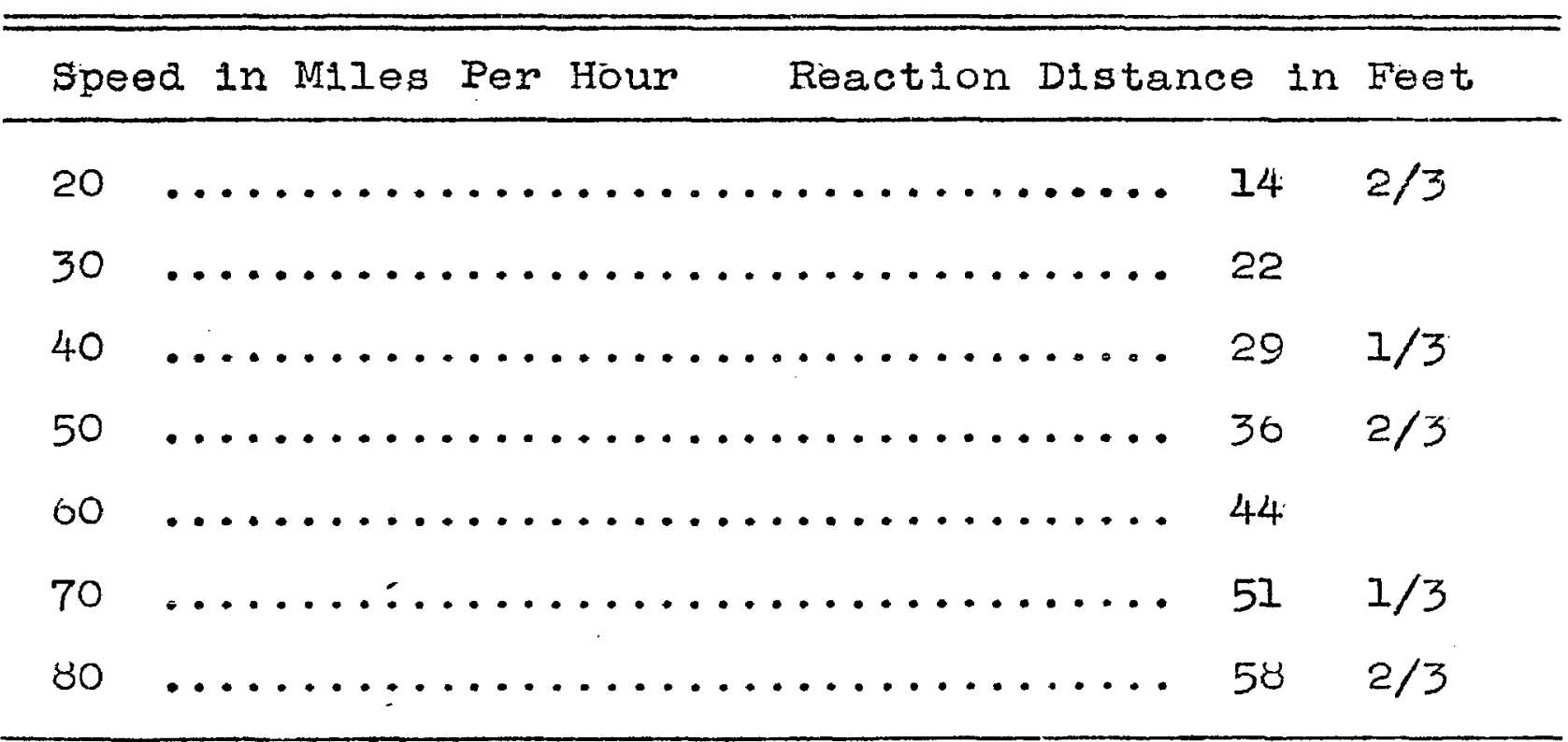

charts the distance a moving car will go between the inter-

10. R. W. Jepson, Glear Thinking, p. 22. 
val when the driver decides to apply the brakes and the actual application of the brakes. This interval is known as the "reaction time", and the table is based upon the average reaction time. which is one-half second. Suppose after ingpecting the table, a student notes the following relationships:

1. When the speed is increased from $20 \mathrm{mph}$ to 40 $\mathrm{mph}$, the reaction distance is doubled.

2. When the speed is increased from $30 \mathrm{mph}$ to 60 mph, the reaction distance is doublod.

3. When the speed is increased from $40 \mathrm{mph}$ to 80 mph, the reaction distance is doubled.

In making these observations he has recognized a specific relation between the variables, speed and reaction distance. However, if his analysis stops at this point, he has failed to generalize the relation which he has recognized. The climax in such an exercise is reached when the student is stimulated to state that, "The data indicate that whenever the speed is doubled, the reaction distance is doubled". The making of such generalizations, with necessary caution, is a characteristic of the student learning to exercise his intellectual powers to the maximum. Failure to encourage the practice of this important behavior would be a serious indictment againgt any mathematics teacher who desires to train young people to become competent members of a democratic culture.

The behaviors described with respect to the ability 
to interpret data, although applicable in the solution of mathematics problems, apply with as much force to any situation which could be resolved effectively through use of the ability. Whether the data be concerned with a basketball tournament or a sermon, an advertisement or a graph of * linear function, the behsviors apply in all situations. For this reason a teacher must provide a variety of situations in the classroom aimed at generalizing the behaviors involved in the "interpretation of data. The Jolnt Commission quotes the following statement by Orata concerning transfer of training which the writer considers syonymous with the generalizing of behaviors:

The various gubjects of the curriculum, most of all mathematics, cannot be expected to reault in automatic transfer to the social situation that confronts the child, unless by proper instruction and organization of the school, these subjects can be made a 'way of Iife' and be so regarded and used by the child himself. This is what we mean by 'humanizing education in the concrete". It is the kind of teaching that will promote intelifgent and functional learning". II

The Commisgion adds further emphasis to Orata's state-

ment in the following comment:

The question raised by the quotation from Orata is that of transfer of the results of mathematical study to social situations and to specific problems that confront persons throughout 11fe. Such a transfer is certainly an important concern, and a course of mathematical study should be planned so as to make it possible, and teachers should. teach in such a way as to achleve that goal. The 
thought that the transfer that is so earnestly desired may not be automatic is one to be kept constantly in mind. 12

Regardless of the desirability of the bohaviors needed for interpreting data, they cannot be "served" to the student to be siphoned off at will. The teacher must ever be planning ways to help students make genuine use of the behaviors in all situations--whether academic, personal, or social--where they can function for the benefit of the user. There must be persistent effort made to help young poople understand the value of their use in Iife situations. If interpretation of data becomes an objective of classroom instruction, then to no less degree should the generalizIng of behaviors asgociated with it also become an objective of instruction.

The brief review in chapter 1 of: the type of research conducted in secondary school algebra, the pervasiveness of relational thinking in the life of the world, and its dependence upon the interpretation of data, suggest that the courge in elementary algebra be so revised that its method and content will contribute to this important objective of general education, the interpretation of data. Studies Related To Interpretation of Data

The following two studies are Important because they

12. Joint Commission of the Mathematical Association of America and the National Council of Teachers of Mathematics, The Place of Mathematics in Secondary Education, p. 221 . 
Fepresent pioneer efforts that have been made to use the subject matter of algebra for developing thinking abilities: of students. In 1925 Benjamin W. Daily reportied a study designed to ascertialn the extent to which first-year high school students possess and exercise the ability to select from abundant data in a school problem those which are pertinent, and to organize them so that solving will produce a correct answer; or, when essential data are lacktng, to what extent students detect their absence and demand additional data. With two experimental groups, Dally noted the effect of the introduction of problems which contain auperfluous or insufficient data among problems with which children are famliar. As many as: one-third of the pupils were wholly unable to cope with the new aituation; fewer than one-third made sat1sfactory adjustments; the remaining pupils responded with varying degrees of succeas. The habit of attempting to solve a problem by using whatever data may be supplied without questioning their adequacy or relevance appears to be well-established amons pupils.

Daily reached the following conclusions as a result of the study:

1. Problems which contain more data than are needed to solve them and problems some of the data for which are lacking, seldom occur in textbooks and are not used commonly by teachers of high school algebra.

2. It is posgible, by means of specific instrua tion, so to teach pupils that they consciously exhibit the desirable function of exercising 
discrimination in the choice of data for the solution of algebra problems.

3. When pupils have been taught to select data: necessary for the solution of mathematical problems: they improve in ability to select data for problems: in other fields of learning.

4. Problems containing superfluous or insuficlent data should be used only after pupils have been definitely tola of their nature, and have received instruction and frequent practice in the technique of solving them. After such instruction pupils may be prepared to solve problems of the special type when they occur unannounced amomg other probIems. 13

W. M. Willits reported a study with ninth grade algebra students in 1944. The study emphasized the need for "new objectives in ninth grade mathematics". The following objectives guided Willits in his study:

There must be a unifyins concept, non-mathematical in nature, permeating the stream of mathematical concepts, recognized as educationally good, the values of which the learner himself can recognize, accept, and realize to a satisfying degree.

Mathematics, dealing with quantitative aspects of life, is admirably fitted for the role of helping the individual to solve his personal and group problems intelligently. This involves the problem-solving process.

The problem becomes the unit of learning, replacing the unit of subject: matter.

As a method, problem solving is inherently: a social process. It can also improve such social traits as cooperation, social-mindedness, and open-mindedness.

13. Benjamin W. Daily, The Ability of High School pupils to Select Essential Data In Solving Problems, p. 85 . 
Problem solving offers brighter prospects for transfer insofar as eneralization is a part of its process. 14

With two groups of students he considered a series of 24 "core" problems and a series of 10 problems sugsested by the students. Sample titles of "core" problems: were:

How does the federal income tax work?

What should I know about consumer credit?

How do the Fahrenheit and Centigrade thermometers compare?

How are parcel post rates computed?

How can algebra be used in making mixtures?

Examining evidence: Shall the town of Hudson, Wisconsin keep its toll bridge?

How $1 \mathrm{~s}$ the strength of floor beams computed?

Examlning evidence: Shall the calendar be changed? 15

Willits described three types of problems, all of which were considered by his pupils:

Problems in which the elements are few, concrete and fixed; all the facts are known or are readily at hand; solution is clear-cut, precise, and valid under test.

Problems in which the elements are so numerous or so varying that solution must be of necessity approximate, yet workable, acceptable; the best

14. W. M. Wilits, New Objectives for Minth Grade Wathematics", pp. 37-38. Unpublished Doctor's Dissertation, Temple University, 1944.

15. W. M. Willits, "New Objectives for Ninth Grade Mathematics: an Exposition and Appraisal", Journal of Experimental Education, XIII (Sept., 1944) pp. 31-45. 
possible solution.

Those problems involving little computation, whose quantitative aspects are probably not expressed in number, whose solution is based upon unprejudiced interpretation of all available evidence. 16

No textbook was used with the two groups, instead mimeographed sheets of instructions were issued.

The study was evaluated through five means:

1. The Columbia Research Bureau Algebra Test wa administered at the conclusion of the course and the two groups averaged 16 and 15 respectively; the norm for the test being 16 .

2. A pre-test and a final test on straight thinking were administered to the groups. "Five probIem situations of non-mathematical character were selected and developed as a measure of two aspects of the problem solvins process, namely, recognition of a problem situation and interpretation of evidence". The test was revised for use as a final test. Both groups averaged. higher on the final test.

3. A record was kept of applications of pupils' thinking.

4. Pupils were asked to comment on the values of the course. Only seven puplis expressed criticism of any kind.

5. An analysis was: made of pupil interestis in mathematics. In the beginning 14 of 76 pupils liked mathematics best. At the conclusion, 17 of 76 liked mathematics best.

A third study, The Eight Year Study which was launched by the Progressive Education Association in 1933 embracing thirty high schools gave high school faculties the opportunity to embark upon experimental teaching to accomplish

$$
\text { 16. Ib1a... p. } 31 .
$$


the things that they and their students considered important. Most of the schools mere concerned with the following objectives:

1. The development of effective methods of thinking

2. The cultivation of useful work habits and study skilis

3. The inculcation of social attitudes

4. The acquisition of a wide range of significant interests

5. The development of increased appreciation of music, art, IIterature, and other assthetic experiences

6. The development of social sensitivity

7. The development of better personal-social adjustment

8. The acquisition of important information

9. The development of physical health

10. The deyelopment of a consistent philosophy of $11 \mathrm{fe} .17$

The schools reallzed that most of the commercial tests dealt only with subject-matter goals. One of the most worthwhile contributions of the study was the development of techniques for measuring growth in many of the intangible objectives. The evaluation committee developed a number of instruments for measuring growth in methods of thinking. Interpretation of data was considered as one of the aspects of thinking and the committee developed two tests, one for senior high school and one for junior high school, for measuring this ability. According to the committee, abilIty to interpret data involves:

17. Wilford M. Aikin, The Story of the Eight Year Study, pp. 89-90. 
1. the ability to perceive relationships in data

2. the abifity to recognize the limitations of data. 18

The major queation to be answered in the Eight Year Study was, "W11l our graduates succeed in college despite the many curricular changes made in our schoola?" "A basis of comparison (with graduates of other schools) was established by matching, with utmost care, each graduate from the Thirty Schools with another student in the same college who had taken the prescribed courses, had graduated from some school not participating in the study, and had met the usual entrance requirements". They were matched on the basis of sex, age, race, scholastic aptitude scores, home and community background, interests, and probable future. 19

In the comparison of the 1475 matched pairs, the College Follow-up staff found that the graduates of the Thirty Schools::

1. earned a dightly higher total grade average;

2. earned higher grade averages in all subject flelds except foreign languages;

5. received slightly more academic honors in each year;

6. Were more often judged to be precise, systematic, and objective in their thinking;

18. E. R. Smith and R. W. Tyler, op. cit., p. 38. 19. Wilford M. Aikin, op. cit., p. 109. 
6. were more often judged to possess a high degree of intellectual curiosity and drive;

9. more often demongtrated a high degree of resourcefulness in meeting new situations.20

In the field of high school geometry many studies have been made on the transfer values of geometric beasoning to other situations involving similar reasoning and the teaching method necessary for achieving such transier. The well-known studies by Fawcett, Ulmer, Gadske, and Cooke, and the more recent study by Lewis are examples of the bype of research conducted for the benefit of high school geometry teachers. Most of these studies show that, through purposeful teaching, the deductive and inductive aspects. of reasoning necessary for an understandine of seometry will be used by the student in non-geometric problem situations. A summary of the Lewis study follows:

In a large high school of a city of about 400,000, (Dr. Lewis) and another teacher of comparable training and ability used an experimental class of 22, a "passing control" class of 35 and a "ialling control" Broup of 21. The experimental class used no textbook and experienced a course organized about the following topics: need of clear definitions, need of assumptions, direct deductive proof involving syllogisms, converses, contrapositives, etc., indirect proof, induction, and the interpretation of data. All but the first of these were introduced through geometric material. Then the logical ideas developed were applied to non-mathematical materials and situations, such as school happenings and controversies, advertising, news reportg, newspaper and magazine articles, selec-

20. Ibid., p. III. 
tions from the history of science and others. In the control classes the sequence followed was the one found in many textbooks. The emphases were on the application of reasoning principles to geometric problems sind to methods of attack on geometric "originals". The fact that geometry is not the only lilustration of the use of general principles of good reasoning was not brought out.

At the beginning and end of the school year all three groups were given tests of mental ability and reading, five of the Watson-Glaser Testa of Critical Thinking and the Cooperative Interpretation of Data Test.

Despite the fact that there was no statiaticolly signiflcant difference between the means of the experimental and "passing control" groups at the beginning of the year, the gains in critical thinking over the school year made by the experimental group exceeded those of the comparison group by a statistically gignificant amount. On the other hand, there. was no significant difference in the gains of the "passing control" and the "failing control" groups.......Furthermore, the difference in the amounts of seometry learned by the experimental and "passing control" groups was too small to be statistically significant. 21

Interpretation of data is an ablitty to which all teachers give alleglance more or less. There are studies in other subject fields which are related to this study. In the field of biology, for example, Leah Weisman made a very significant study.

21. Harry Lewis, "An Experiment in Developing Critical Thinking Through the Teaching of Plane Demonstrative Geometry":, Unpublished Doctor's Dissertation, New York University, 1950, summarized by

John J. Kinsella, "Research in Mathematics Education", The Mathematics Tëacher, XIII (December, 1950) pp. 4II412. 
She attempted to determine experimentally whethor or not the ability to interpret data can be improved by an experimental method in which the desired thinking outcomes are set up as definite aims of instruction. Six biology classes were taught by the Investigator using the experimental method, while six were taught by teachers considered equally good who thought that critical thinking would develop concomitantly a students followed the regular course of study. 22

It was found that pupilg in the experimental groups achieved reliably greater gains in the ability to interpret data as measured by the Interpretation of Data Test, than did pupils in the control groups. Pupils in the experimental groups also made significantly greatex gains in learning facts and principles of blology as measured by the Cooperative Blology Test. One year after the period of instruction, pupils in the experimental groups had retained their superiority over pupila in the control groups in the ability to interpret data and in knowledge of biological facts and principles.

In social studies the "Cornell Project" and the Stanford Soclal Education Investigation represent two major researches with results showing that teaching method determines to a great extent the degree to which students improve in their reasoning abilities. The Cornell Project was concerned with an evaluation of social studies curriculum materials and teaching procedurea designed to develop

22. Leah I. Weisman, "Some Factors Related to the Ability to Interpret Data in Biological Science," Unpublished Doctor's Dissertation, University of Chicago, 1946. reviewed by

N. E. Bingham and J. Y. West, "Aims and Purposes of Science Teaching", Review of Educational Research; XVIII (October, 1948) pp. $301-302$.

23. J.S. Richardson and J. D. Barnord, "Methods and Materials in the Teaching of Science", Review of EducationaI Research, XVIII (October, 1948) p. 334. 
abilities in critical thinking. Part of the experimental work was done with 14 pairs of seventh grade classes in 8 Iowa and New York cities. There were 962 pupils entolled in these classes and the work was done during the 1940-41 school year. The remainder of the experimental work was done with 12 pairs of tenth grade classes in 11 Iowa and New York cities with an enroliment of 838 pupils.

The procedure in the study was as follows:

1. Certain skills of critical thinking were identified.

2. Experimental materials for teaching these skills of critical thinking by two methods were developed.

3. Test materials and other procedures for evaluation of the skills were developed.

4. The cooperation of schools in Iowa and New York in the experimental use of "critical thinking" material was enlisted.

5. Results........were used in preparing improved materials for teaching certain skills of critical thinking. 24

Five problems were developed for use in seventh grade social studies classes (largely geography) and 5 others for the tenth srade classes (largely world history). Each problem was developed in two forms--"doing" and "telling". In the "telling" method a reading selection was provided and the way in which an expert would proceed in analyzine

24. H. C. Anderson, F. G. Marcham, and S. B. Dunn, "An Experlment in Teaching Certain Skilis of Critical Thinking", Journal of Educational Research, XXXVIII (December, 1944). pp. 241-25I. 
this content was explained in detail. In the "doing" method the problems contained the same basic selections as: in the "teli1ng" method, but pupils were left comparatively free to stuay and analyze content as they saw fit. The 5 experimental problems: were then used in each school during five 3-day periods: scattered at equal intervals over a 6month period.

A test on critical thinking was devised and administered to all classes at the beginning of the study and at the conclusion of the study. The tiest was concerned with the following abilities:

Test 1 Abstracting and organizing information Test 2 Drawing conclusions

The results showed that gains in all caterories of the test were about evenly divided between "doing" and "teling".

Tests were given to classes not using the critical thinking materials. In general, classes not using the materials did about a.s" well on Test $I$ as those who used them. On Test 2, the gains made by pupils not using the materials were decidedly lower. This fact suggests that critical thinking problems make their most important and distinctive contribution in developing skilis associated with the making of inferences and the drawing of conclusions. 25

One of the purposes of the Stanford Social Education Investigation was to provide evidence relative to the merits of the three methods commonly used in the teaching of social studies--the chronological, the topical, and the 
problems.

The participating teachers agreed that the superiority of one approach over the others should be judged primarily on it effectiveness in helping boys and girls grow in the behaviors considered desirable by social-studies teachers, regardless of the approach used. They agreed the following objectives are the behaviors necessary for effective participation in a democratic society.

A. Development of the ability to think critically. A person who has this ability:

1. Interprets data accurately

2. Uses logical arguments

3. Recognizes fallacies and sophistries: in the arguments of others

4. Draws sound generalizations

5. Applies accepted principles to new situations

B. Development of good work habits and study skilis.

C. Acquigition of a knowledge and understanding of our culture.

D. Development of desirable gocial attitudes.

E. Development of a broad pattern of interests and appregiation for the worth-while things in 1 ife.

Groups of pupils selected for participation in the study were selected on the following bases:

a. intelligence, reading ability, socio-econonomic background, age, grade level, and amount of social studies taken

b. similarity of school and community

c. teachers having similar backgrounds in ex-

26. I. J. Quilien and L. A. Hanna, Education for Social Competence, pp. 141-142 


\section{perience, training, teaching load, and saa- ceas.}

The study was Iimited to eleventh and twelfth grade students and a total of 532 students participated in the study. The groups were pajred so that the twelfth grade group using the problems approach was comparable to the twelfth grade group using the topical approach. The eleventh grade group using the problems approach was comparable to the eleventh grade group using the chronological approach.

Student growth in the many behaviors Iisted for effective participation in a democratic society, was evaluated through the administration of a series of tests at the beginning of the study, and the re-administration of the tests at the close of the study. This review will be concerned with only one behavior listed as a part of critical thinking-- the ability to interpret data. Growth in this behavior was determined through the changes in group means on forms 2.51 and 2.52 of the Progressive Eaucation Association Interpretation of Data Test. The conclusions drawn relative to this behavior were:

The students in the groups using the problem solving approach not only made significant growth in more aspects of critical thinking than the students usine the topical approach, but they also demonstrated superjor ability. The students in the group lalng the problems approach made significant growth in their ability to interpret data, to make qualified and unqualified judgments from the data, and to recognize the limitations of data in drawing generalizations. 
The students in neither of the junior groups using the problems or the chronological approach made growth which wa signiflcant in many aspects of critical thinking evaluated in the study. -While neither group significantly improved in the general accuracy with which they interpreted data, at the end of the year the problems group made significantly fewer errors as a regult of too great caution, and the chronological group was agnificantly more aware of the often insuffieiency of data for drawing any valid conclusions. The problems group, on the other hand, was legs accurate with interpretations where the data were in- $^{-}$ sufficient than they had been on the pre-test. 28

In the field of English an outstanding study was congucted by E. M. Glaser. The chlef purposes of the Glaser Study were:

1. to develop and present materials and 1liustrative teaching procedures which may be used effectively by the teacher of elementary, secondary, and college students to stimulate growth in ablilty to think critically.

2. to evaluate the effectiveness of these materIals and teaching procedures.

3. to ascertain whother or not there is a relationship between ability to think critically and certain other factors, wuch as intell1gence test scores, age, school srades, soc10economic status, and dominant interest values.29

Instruments were constructed to measure certain aspects of ability to think critically. (The Watson-Glaser Teats of Critical Thinking). The instruments were concerned with the following abilities:

1. Logical reasoning

28. Ibid., p. 171 .

29. E. M. Glaser, An Experiment in the Development of Critical Thinking, p. 10 . 


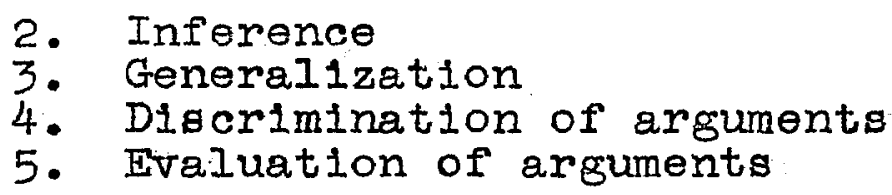

Two twelfth grade English clasges in each of two high schools were chosen as experimental groups. Each class was: taught by a different teacher. These four experimental groups were matched with four control English classes in the same two schools. Each control group was taught by a different teacher. It so happened that in both schools the syllabus for the twelfth grade included amons its objectives the development of ability to think aritically. The control teacherg using their own methods, taught the content outlined in their respective syllabi. The experimental teachers used both their own methods and the procedures suggested in the 8 units developed for the experimental classes by the director of the study. After ten weeks of work all classes were re-tested with the Watson-Glaser Tests of Critical Thinksng.

Following are some of the conclusions reached by Glaser:

The average gain on the critical thinking tests of of the four experimental classes after ten weeks was significantly greater than the average gain of the four control classes on the same tests.

The improvement in ability to think critically appears to be somewhat general in character. There is evidence for some students of improvement in general disposition to consider problems thoughtfully, and evidence of ability to think more critically in other classes in school, at home, in connection with personal problems, and in connection with speeches, advertisements, and 
arguments............................... attitude of wanting evidence for beliefs is most subject to general transfer.

The ability to comprehend language with accuracy and discrimination is one of the most important aspects of ability to think critically.

Among the factors measured in this study, intelligence, reading ability, and school marks are most closely related to scores made on the tests of critical thinking. 30

30. Ibid., pp. 175-177. 


\section{Chapter 3}

\section{Suggested Algebrais Content and Teaching Method For Developing Ability To Interpret Data.}

\section{Introduction}

Most of the attacks on the teaching of algebra in the high schools deal with the one-sided emphasis placed on manipulation an perfunctory operations with algebraic symbols and expressions. This is a criticism rightly deserved and the contention has become so widespread that algebra is: rapidly reaching the place that 1 is no longer a required subject. Many attempts of a "stop-gap" character have been made by mathematios teachers to retain ninth grade algebra by omitting complex topics and by placing more emphasis on the formula and equation. These attempts to prevent the abandonment of elementary algebra as a required subject have not resolved the difficulty for they do not deal with its cause.

To acquire a new concept or meaning one must relate it to meanings secured previously and the concept will be acquired more readily if it can be developed in a context close to one's daily living. Our practice of teaching algebraic concepts totally isolated from arithmetical operations has failed to give studentg a feeling for the practical character of algebra in daily living. We have ajo divorced algebraic operations from the context through 
which they were originally developed and continue to be developed by able mathematictans--relational thinking and irduction. In addition, we have neglected other concepts which lend enrlchment and deeper meaning to the concept of operation.

The succesg of students in an elementary algebra course with emphasis on the development of ability to interpret data undoubtedly will be influenced by the type of mathematical training which they have had prior to the nimtin grade. Students having elementary and junior high experiences in the unified program of mathematics would probably grasp the ideas with minimum difficulty. In a unified program the basic concepts which permeate all of mathematics are identified and most student activities are for the purpose of developing and giving meaning to these concepts. The writer views the mathematics program from grade one through grade twelve as a unified program in which a few basic concepts are to be developed through using varied approaches and through giving students many opportunities not only to formulate the principles but also to understand why a principle would be applied in a given aituation. The conceptis of number, relationship, measurement, proof, symbolism and operation would be developed with elementary students as zealously as with students at the secondary level.

The Commisaion on Secondary Curriculum makes the fol- 
lowing comment concerning the nature and number of major concepts in a mathematics program:

A: set of major concepts worthy of emphasis in the mathematics curriculum should serve to unify instruction in mathematics regarded not only as: a tool for problem-solving, but as a science considered apart from possible applications as well. The number of concepts. should be small in order that the list may be readily held in mind, and the concepts should have the property of systematic recurrence in diverse problems-or, stated negatively, they should not be the sort of concepts which, while necessary or at least useful in treating some problems, are not needed at all in many others. 1

With class activities at each level stemming from these concepts, continuity is provided in the mathematics curriculum from the very beginning of number study through the specialized work of the high school. At each level, experiences with the concepts would be an enlargement of previous experience. The unified program is a reasonable plan when we accept the thesis that child growth is a continuing process in which each stage in growth is dependent: on and is a part of all previous growth. It would seem reasonable to promote mental growth that is not "piece meal" but continuous. To quote the Joint Commission, learning should be "spaced" rather than "bunched".

A program based on unifying concepts cannot operate effectively without the cooperative planning of members of a

1. Progressive Education Association, Commission on Secondary Curriculum, Wathematics in General Education. p. 69 . 
school staff or system. In fact the very nature of the program requires continuous planning by professional groups and by individual teachers. A teacher coula not work effectively if he followed a plan made for him. The teacher must make his own plans in consultation with his colleagues. The use of a wide variety of references and equipment would also be required in this program. The extent to which these materials can be supplied would be another factor in determining the effectiveness of the program.

In planning a mathematics program for the elementary school, the members of the staff should consider or describe the abilitieg which they would expect the student to develop and decide upon the concepts which would receive continuing attention. Doubtless the concepts of number and operation should receive major emphasis, but without ignorIng the development of the other concepts.

Following are examples of the abilities that might be expected of the elementary student ready to enter junior high school. He should be able to analyze a problem situation appropriate for his maturity level and determine independently whether, for example, the operation of addition, the operation of division, or a combination of operations is required for its solution. He should be able to choose from a set of data, those relevant to the solution of a problem. Although the term might never be used with the student, he should be acqualnted with elementary ideas asso- 
51

ciated with inductive proof by having had the opportunity to reach his own generalizations using simple situations involving number. He should realize the usefulness of checking as a form of proof. These examples do not constitute a complete description of the ideal student ready to enter junior high school, for there are other abilities in mathematics as well as qualities requisite for a socially adjusted individual that would be equally desirable.

In the seventh and elghth grades the concepts of measurement, operation, and relationship should recelve continuing emphasia. A study of the relationships expressed in formulas, especially mensuration, should be one of the major considerations and students should have many opportunities to discover these relationships through discussions which stimulate inductive reasoning. An inductive approach to the principleg used in operating with fractions and mixed numbers is also a potential source material for cultivating good thinkers. Experience with simple measuring instruments should help students to appreciate the approximate character of measurement and in this respect the practice of estimating results when operating with approximate numbers should be encouraged. Improving the skill of estimating offers more for developing independent thinking than the use of crutches for placing decimalipoints in quotients and products. Maximum use should be made of models, measuring instruments, motion pictures, film strips, 
and slides in making student activity in mathematics an enjoyable and meaningful experience.

Students with such training prior to the ninth grade would have excellent preparation for a course in algebra with emphasis upon development of the ability to interpret data. In contradistinction, students trained in the uaval elementary and Junior high school mathematics progrem would experience some difficulty in becoming oriented to the ideas to be considered in such a course. Where they have previously been given a principle to use, now they will be expected to help in the development of the principles which they will apply. Where they have been taught unwittingly to note the differences between arithmetic, Informal geometry and algebra, now they may learn, for example, that the operations of algebra are extensions of arithmetical operations. Where they have been given specific directions to use a particular operation in the solution of a probiem, they may now have to choose the operations necessary to the solution of a problem. Where they have been given all of the data needed for the solution of a given problem, now the data may be insufficient or gome of the data may be superfluous, or they may be required to collect the data needed. Hence, a teacher malsing plans for such a course should survey carefully the student's mathematical training received prior to his enrollment in the course. 


\section{Algebraic Content}

The proposed content which follows carries with it the basic assumption that any activity in algebra must have for ita major purpose the development of ability to interpret data--an ability needed by every person, though often exercized in a manner considered to be very rudimentary and illogical.

A course in algebra with emphasis on the development of ability to interpret data should be based on the related mathematical concepts of relationship, number, symbolism, measurement, operation and proof. These concepts emphasized separately or jointly in the 1940 reports of the Joint Commission and the Progressive Education Association, can be developed while being oriented toward development of ability to interpret data.

\section{Relationship}

The concept of relationship, referred to by many as the function concept, permeates countless everyday activities a has been shown in Chapter Cne. Formulas and equations, graphs, tables of data, and verbal statements, each provides effective means for representing relationships between sets of variables. To heip students understand the advantages and limitations of each of these symbolic systems should be one of the teacher's major goals.

A genuine understanding of relationships includes a knowledge of dependence among variables whether the rela- 
tionship be functional or approximate. Functional relationships should be developed in such a manner that formulas and equations, for example, are an outgrowth of student thinking. The procedure might begin through considering approximate relationships in their characteristic crudeness. It would be the teacher's job to begin with sets of variables so related that only the approximate character of the relationship can be expressed by means of such terms as "changes as", "increases as." or "decreases: as" and move on gradually to a consideration of those relationshipg expresgible by meang of first degree equations and formulas, verbal statements and straight line graphs. Each of these two types of relationships will be approached through acquaintance with the techniques used by mathematiclans and statisticians: in assembling and arransIns data for the purpose of verifying or alsproving hypotheses which they have formulated. The use of elementary statistical notions in the study of approximate relationships would enable students to gain skill in processing such data for reaching conclusions. An understanding of the concepts of mean, median, mode, and range will be helpful to students in this respect as they seek trends in the data as the basis for reaching conclusions. Skill in "reading between the Iines" and in extending the limits of the data also can be a helpful tool in analyzing data. Such problems as the following represent areas of 
student interest which would provide data for study of approximate relationships::

1. Analysis of student purchases in school cafeterla.

2. Analysis of school attendance records.

3. Considering factors pertinent to prediction of winners in athletic contests.

4. Analysis of library book loans.

5. Analysis of local data on diseases, accidents, fires, crime and the like.

6. Relation between time and plant growth.

7. Study of normal variability. 2

A first stage in the development of any one of these areas should be that of defining the problem--formulating a specific statement of the question to be investigated.

As students make plang for gathering information on a problem the characteristics of the data to be gathered should be determined by the class. Such factors as relevance, representativeness, accuracy and reliability should be helpful considerations. 3

Practice in constructing various tables of data, including frequency tabulations, and in constructing statistical graphs should be another activity leading to an understanding of such concepts as mean, median and mode in making interpretations and reaching conclusions.

Class discussions on relationships between the variables encountered in the problems studied should bring out the fact that the relationships are approximate because of

2. Ibia., pp. 385-402.

3. Ibid., pp. 91-96. 
the many variables which cannot be controlled. For example, In a study of Iibrary book loans, the data might be interpretied so that the conclusion, "Only boys between the ages 13 and 15 read books on adventure and invention", would be drawn. Such variables as home life, after-school jobs, hobbies and interests, recreation, and associations with friends, would have a bearing on any conclusions to be drawn from the data.

At this stage problems might be sugsested which involve only two variables, the variables having a functional relation, as, for example, the relation between wages and number of working hours at a given hourly rate, or the relation between total cost and the number of articles purchased at a given rate. Students could arrange such data in the form of statigtical bar graphs. The regular increase in the lengths of the bara should lead students to question the difference between this graph and the graphs which they have constructed previously. A suggestion by the teacher that they connect the upper left corners of the respective bars $5 y$ a Iine would result in the group's discovery of another form for expressing relationships, the straight line graph. By considering the differences between variablag in the table of values and by comparing them with the aifferences between variables in a table repw resenting an approximate relationship, students could be led to formulate hypotheses concerning the difference be- 
tween a functional relationship and an approximate relationship.

Summarizing the table of values in the form of a verbal statement or principle which states the relation of one variable to the other, and suggesting that the statement be expressed concisely by substituting symbols for words or groups of words, would be one method for illustrating the relation between the formula, the verbal statement, the graph, and the table of values. This relation can be analyzed further by noting other characteristics which these four functional forms have in common, such as, the coefficient of the independent variable in the formula, the slope of the line graph, and the constant differences in the table of values. Students might also note that the formula and the verbal statement represent generalizations drawn from the data, and that the table of values and the graph have certain Iimitations which prohibit their use as generalizations. These limitations can be polnted out as the class attempts to interpolate or read between given values and to extrapolate or extend the data. 4

Considering another aspect of functional relationship, the aifferences resulting from changes in rates, would enlarge the students' conception of slope. For example, in the wage relation, $w=h r \quad$ ( $w=$ wages, $h=$ hours worked,

4. Ibid., pp. 151-152. 
$r$, the rate, is a parameter) questions might be asked concerning the change in the graph that would result when the wage rate is increased or decreased. The answers of students could be listed as hypotheses to be tested by the construction of additional graphs on the same set of axes. with the original graph. By observation of these graphs tentative conclusions could be reached concerning the signifjcance of coefficients of the independent variable in a formula and of the constant differences in the table of values in determinine the "steepness" of the graph.

Another phase of relationship offering promising possibilities is the study of propositional functions. Such statements as, "A coach is an athlete" or "The tree sheds its foliage in autumn" are examples of propositional functions. Neither of these statements can be rated as true or false unless specific values are stibstituted for the variables "coach" and "tree": When these variables are given specific values as "Coach Hayes is an athlete" or "The oak tree sheds: its follage in autumn", then the statements may be accepted or rejected. According to the Commission on Secondary Curriculum, "a propositional function is one whose value is a proposition, namely a concept, idea, or notion, which definitely is or is not true". 5

An elementary approach would consist of presenting stu-

5. Ib1d., p. 163 . 
dents with a series of statements for the pprpose of 1dentifying variables and constants. For example, in the statement, "Fruits tagte better than vegetables", the terms "fruits" and "vegetables" are variables. In the statement, "Oranges taste better than spinach", both "oranges" and "spinach" may be considered as constants. The student. should be helped to understand the fact that the latter statement can be evaluated definitely while the former cannot because of the wide range of values which may be assigned to "fruits" and "vegetables". In more sophisticated statements as "familiarity breeds contempt", knowledge of the many interpretations that may be given the term, "famillarity", may give the student inclined toward snobbery a more wholesome attitude toward his colleagues or cause him to weigh more carefully the meaning and signiflcance of the statement.

In mathematics, the statement that $A$ is related to $b$ is neither true nor false, but when it is specified that in a triangle, $A=5 b$, (where $A=$ area, $5=\frac{1}{2}$ the altitude, and $\mathrm{b}=$ base), the statement can be evaluated. Frequent references to propositional functions using mathematical and nonmathematical materials may help to generalize the behavior of weighing carefully the validity of statements which are purported to be sound generalizations.

Much of the voluminous editorial material in our daily newspapers is sprinkled with propositional functions with- 
out apecific values applied, yet the writer would have the reader accept the statements. For example, in connection with the recent fad for displaying the confederate flag, one writer concluded that "old animosities have been transmuted into sentinental memories". The variable in this btatement is "old animosities" and 1ts values include, for example, the animosity of a "southern" gentieman for a "Yankee" and that of a "Democrat" for a "Whig". The writer of the editorial would have the reader accept this conclusion in spite of the fact that old anlmosities shown in racial segregation have not been transmuted or changed. Students could derive much benefit from analyseg of editorials for propositional functions.

The discussion of reflexive, symmetric and transitive relations by the Commission on Secondary Curriculum should stimulate teachers of mathematics to recognize the possibilities for broadening the thinking of students from situations purely mathematical in nature to applications of the reasoning processes in life situations. The Committee con siders these relations as properties of propositional functions and defines them as follows:

Suppose that one has a relation $R$ between the arguments $x, y, z$ in a given common domain. This relation may be indicated by the symbol $x R y$, read " $x$ has the relation $R$. to $y$ ". A relation $R$ such that $x$ has this relation to itself $(x R x)$ is called reflexive. A relation such that $x R y$ implies that $\mathrm{yRx}$ is called symmetric. A relation such that $x R y$ and $y R z$ imply $x R z$ is called transi- 
tive. 6

The following examples illustrate these felations with mathematical and non-mathematical materials: The parallel relation is both symmetric and transitive, but not reflexive; $x$ is not parallel to itself. If $x$ is parallel to $y$, then $y$ is parallel to $x$. If $x$ is parallel to $y$ and $y$ is parallel to $z$, then $x$ is parallel to $z$.

The inequality relation is only transitive. Inequality may be expressed with many different terms: talier, shorter; greater, smaller; heavier, lighter; darker, lighter; hotter, colder; farther, nearer. John is not taller than himself. If John is taller than Henry, then Henry is not taller than John. If John is taller than Henry and Henry is taller than James, then John is taller than James.

The paternal relation is neither reflexive, symmetric nor transitive. A is not $A^{\prime}$ 's father. If $A$ is $B^{\prime} g$ father, then $B$ is not $A^{\prime} \cdot s$ father. If $A$ is $B^{\prime} s$ father and $B$ is $C^{\prime}$ s father, then $A$ is not $C^{\prime \prime} \mathrm{g}$ father.

The equality relation and the proportion relation (a special case of equality) possess each of the three properties.

The relations derived from the terms, "defeat" and "get" fair treatment from, are neither reflexive, symmetric nor transitive. Whether we are concerned with athletic

6. Ibida, p. 165. 
teams or nations at war it is eviaent that none of these relations can be derived from "defeat".

Through study guides, students may be given a series of propositions 1llustrating the property of symmetry. Assuming a given relation to be valid, they may be asked to evaluate a second relation which is the converse of the first. Through the use of many relational words, the group may decide whether certain relations possess the property of symmetry. Symmetric relations are used to a great extent in advertising and the advertiser frequently Implies the converse to be true or hopes that the reader acceptg the converge. Hence, knowledge of this relation is of practical importance to students because all of them are consumers.

The properties of reflexive and transitive relations can be investigated in a similar manner. Number

It is a common occurrence for a student to undergo one or more years of experience in algebra and emerge with vague notions concerning the purposes which various types of numbers serve. Usually he is confused because of the apparent disagreement between directed numbers and arithmetic numbers. Among other things, he has been persuaded to accept the mysterious statement that, "when you add a negative number to a positive number you must subtract"! Is there any wonder that students are muddled in their 
thinking? On the other hand with more consideration given to student derivation of generalizations and with an emphasis on the similarities, rather than differences, between arithmetic and algebraic numbers, students would develop the insights necessary for an understanding of the Internelationships in the number system.

The study of numbers can be initiated through a historical approach, the study beginnins with positive integral numbers. The class may consider what operations are possible in a number system so limited. Through appropriate discussion, students may conclude that the operations of subtraction and division are Iimited--the former to cases in which the minuend is larger than the subtrahend, and the latter to cases in which the divisor is contained in the dividend an integral number of times.

In attempting to angwer the question, "What kinds of numbers must be added to our number system in order to subtiract a positive number from any other positive number?", there could follow a consideration of a number system extended to include negative numbers, a system of integral numbers based on position and on direction from zero.

A comparison of number systems is also a helpful activity. For example, gtudents may solve simple problems. of addition using first Roman numerals, then Hindu-Arabic numerals. The concigeness of the Hindu-Arabic notation 
might be noted as students write and compare quantities in Roman numerals and then in the Hindu-Arabic, for example, 493 and 789 . Attempts to multiply quantities expressed in Roman numerals and then in the Hindu-Arabic may help to convince students of the efficiency of the present system. According to Cooley:

Important though conciseness is, it is not this characteristic that makes the Hindu-Arabic notation so greatly superior to others. It owes its pre-eminence to the fact that it greatly facilitates the operations of addition, subtraction, multiplication, and division. This greater ease in calculation is a result of the positional character of the notation and the presence of the number zero. 7

Students should also be able to analyze a number. For example, they should realize that the number 529 symbollzes the addition of 500, 20 and 9 . Multiplication problems also may be analyzed to the extent that students know why the partial products are shifted one column to the left of the preceding partial product.

So far the consideration has been with a number system dealing only with the concept of size and quantity and having one end-point, zero. When men begen to attach both the concept of size and direction to numbers the operation of subtraction was permisaible under all conditions. According to Everett, the invention of directed numbers introduced a "new measure of values" beginning not with zero,

7. H. R. Cooley, et. al., Introduction to Mathemat1cs, pp. 21-22. 
but "beginning anywhere we please. Only the place where a. number belongs, not its value, is conveniently reckoned from zero". 8

A digcussion and atuay of number "below zero" may be one tecinique for considering the further extension of the number system. Temperature and altitude readings, the measurement of time by the Gregorian calendar, elevator stops above and below the street level in bulldings, penalties in games, and other examples in which the new ldea will become an extension of the old, may help to stimulate student thinking in preparation for the idea of directed numbers.

A model number scale will also be a valuable teaching aid as students become oriented to the triple meaning implicit in directed numbers: (I) a sign of direction, (2) a sign of operation, and (3) a mark of identification. 9

The teacher should help students to develop the following principles concerning directed numbers:

Less lies toward one end of the (number) scale, more toward the other, but the scale has no beginning.

Fositively directed or negatively directed numbers cover the entire scale. With respect to any

p. 36 .

8: J.P. Everett, whe Fundamental Skilis of Algebra,

9. Ibid., pp. 36-58. 
given number of the scale, every other number that I1e et the left of the given number 1s: negatively directed; and to the right, positively directed.

The $s 1 g$ of the number to be added to another always indicates the direction of the addition on the number scale.

- The number to which a number is to be added indicates the point of departure for the addition. In this number the elgn is only a mark of identiflcation.

Subtraction means adding to the numker taken away a number sufficient to produce the other, and both direction and absolute value of the regult are eetermined by the relative positions of the two numbers on the number scale. The sign of the multiplier indicates whether the process of multiplication is to be thought of in terms of addition or of subtraction. I0

The inductive approach can be used in all considerations of operationg with directed numbers. For example, the number scale can be used to illustrate many apecific examples of addition from which the group can finally make generalizations concerning the addition of any set of directed numbers.

Appropriate study guides for first developing and then stating principles should utilize the inductive approach. The teacher ghould not just give the students rules to be memorized. Judd makes the following comment concerning memorizing in mathematics:

In the mathematics courses taught in secondary schools 1t ig easy for pupils to be fatrly successful as long as they are permitted by their teachers to follow rules blindly or repeat formal demonstrations which they have committed to memory.

10. Ibia., pp. 36-57. 
In algebra one can arrive at the sign which is appiopriate when two negative quantities are multiplied if one knows the rule governing signs. Even today most pupils who write a plug sign aftiar multiplying one negative quantity by another exhiblt not understanding but falth in the authority which taught them the appropriate rule.11

\section{Meagurement}

The most fundamental and characteristic concept in mathematics is the process of counting. The counting of discrete objects in a group is an exact process. When, however, the size or magnitude of an objecti is to be determined it ia never possible to be exact. It is possible under various conditions to approach the goal of exactness. The problem of counting units contained in, or determining the size of, an object is attacked through the use of measuring instruments and untts of measure. The facility with which the given instrument can be used and the choice of the proper unit of measure are both important factors for determining how near the ideal of exactness is reached. Any procedure used to determine the magnitude of an object is known as approximation or measurement.

The intelligent use of decimal numbers and mixed numbers is one phase of measurement which should receive continuing emphasis in the secondary school. The many crutches imposed upon students for use when placing decimal points in products and quotients belie our attempts to

11. C. H. Juda, Education as Cultivation of the Higher Mental Processes. p. 42 . 
develop thinking abilities of students. If they were taught to estimate products and quotients before performance of the operations, reasoning would replace rote when operating with decimal numbers If students are helped to understand such principles as the following, they should become independent in determining the extent to which one should round off products and quotients.

1. In determining the number of significant figures in mixed numbers and decimal numbers a count must be made of the units involved. For example, $83 / 16$ inches or $131 / 16$ inches has three significant figures. I pound 4 ounceg or 20 ounces has two significant figures. 5.001 containg four significant figures, while 5.010 contains three significant figures the unit of measure being .001 in both cases.

2. When measurements containing common fractions are converted to decimal numbers, the converted decimal number shoula contain no more significant figures than the original measurement. For example, $5^{\frac{1}{4}}$ inches or $21 / 4$ inches is equivalent to 5.2 inches rather than 5.25 inches.12

3. When operating with approximate numbers the results should be no more accurate than the less accurate factors involved. For example, the product of $32.5 \mathrm{~cm}$, and $2.7 \mathrm{~cm}$. shoula be rounded to $88 \mathrm{sq}$. $\mathrm{cm}$. Which containg two significant figures, the number contained in the less accurate factor, 2.7 .

In an attempt to datermine the value of pi and its role In circular measurement the principles listed above can be applied. Students can decide upon the unit to be used in

12. R. L. West and C.N. Shuster, "The Teaching of Approximate Computation", The Mathematics Teacher, XXXVI (April, 1942) p. I5I. 
actual measurement of circumferences and diameters of circular objecti. Their choice of units will determine the precigion of their value of p1. For example, if circles are measured to the nearest $1 / 8$ inch, then in a circle having a circuiference of $8 \quad 3 / 4$ inches and a diameter of $23 / 4$ inches, the value of $p 1$ is computed by first converting each measure to the number of units it contains, $e .8 ., 8 \frac{1}{2}=70 / 8$ and $23 / 4=22 / 8$. Each measure contains two significant figures, hence their ratlo can contain only two significant figures. The ratio $70 / 22=3.18$ must be rounded to 3.2 . Students have other opportunities to understand the nature of measurement in deriving formulas for areas and volumes respectively of plane and solid geometric figures. As these generalizations or formulas are derived inductively the use of model square inches, cubic inches and other units. of measure can be used a the basis for developing an understanding of the arbitrary character of our units of measure. Use of such statigtical concepts as, mean, median and mode and the study of approximate relations among related variables have been suggested earlier in the discussion of relationships. Much experience with measurement can be obtained when appropriate data are procegsed for curve-fitting. A study of normal variation in heights and weights of adolescents is one relation offering possibilities for meaningful experiences in elementary curve-fitting. The commission on Secondary Curriculum makes the following suggestions 
relative to curve fitting:

In cases where there appears to be a relationship between two or more variables, the students may undertake some simple curve-fitting. The coefficient of linear correlation between height and weight is usually about .87 . It is possible to obtain a IInear formula which may be used to predict the welght corresponding to a given height. This work may be done without making any extensive use of correlation or more advanced curve-fitting methods, such as least squares. As. an 1llustration a brief discussion of the development of a height-weight formula for tall slender girls ranging in age from 12 to 18 years will be given. Assume the data (in the following table) are at hand.

The graph is approximately linear and the first differences are approximately constant. Assume a formula of the type, $w=a h+b$, where $a$ and $b$ are to be determined from the data. If we arbitrarily. choose the line which pasges through the first five points, the slope a is 5 by inspection. Then

Height-Weight Table For Tall Slender Girls

\begin{tabular}{c|c|c|c|c}
\hline \hline Height & Av. Weight & $\boldsymbol{\Delta}$ & $\mathrm{w}$ & $\mathrm{d}$ \\
\hline 60 & 95 & 5 & 95 & 0 \\
61 & 100 & 5 & 100 & 0 \\
62 & 105 & 5 & 105 & 0 \\
63 & 110 & 5 & 110 & 0 \\
64 & 115 & 5 & 115 & 0 \\
65 & 121 & 6 & 120 & 1 \\
66 & 127 & 6 & 125 & 2 \\
67 & 133 & 6 & 130 & 3 \\
68 & 136 & 3 & 135 & 1 \\
69 & 140 & 4 & 140 & 0 \\
\hline
\end{tabular}

$\Delta=$ tabular difference in welght; $a=$ difference between tabular weight and $w$.

Substituting the pair $(60,95)$ we have and $b=205$; hence

$$
95=5.00+b
$$

$\mathrm{w}=5 \mathrm{~h}-205$

would be one approxinate formula. In the table w 
has been computed by this formula, and the discrepancles or residuals a between values of $w$ as predicted by the formula and those given in the original data have been calculated. It happens in this case that these are all positive, although in eeneral some will be positive and some negative. By choosing certain other pairs of values, formulas with different coefficients may be obtained. Various tests of 300 aness of fit may then be ap-plied. For high school students the best-fitting curve may be defined as the one which yields the minimum value of $A$, where $A=\frac{\Sigma|a|}{n}$. Or the rootmean-square test may be used, although it is more difficult to compute. Then $A=\frac{\sqrt{E a^{2}}}{n}$. other more refined methods of finding a suitable formule may
also be used. Symbol1sm

Algebra is one of the many mediums used to communicate lieas, but $1 t$ employs a symbolism radically different from the previous experiences of students in the communication of ideas. As a consequence, the teacher who is sengitive to this condition w11l be obligated to use procedures designed to orient students to this new language. In discussing the "practical aims" of secondary mathematics, and after referrins to the importance of understanding the fundamental processes. of arithmetic, the National Committee says: "Of almost equal importance to every educated person is an understanding of the language of alsebra and the ability to use this language intelligently and readily in the expression of such simple quantitative relations as occur in

13. Commisaion on Secondary Curriculum, op. cit., pp. $396-398$. 
everyday life and in the normal reading of the educated. person". 14

As in other languages, the thinking of people usires the language of mathematics can become distorted. The mystical powers asgigned to such numberg as: 7 and 13 are well known to even the young child. Progress in thinking has been and will be hampered by the many emotional and unfounded beliefs which we attach to words and terms. Hogben illustrateg. how unwarranted conclusions interfered with the early development of mathematics:

The idealistic teaching which brought large audiences to hear Pythagoras is illustrated by the ways he invested numbers and figures with moral qualitieg. One, being regarded as the source of all numbers rather than a number ltself, stood for reason, two for opinion, four for justice, five for marriage, because it is formed by the union of the first male number, 3 and the first female number, 2. 15

Many superstitions relative to numbers continue to guide our thinking even today, as for example, the omisgion of 13 in numbering the floors and rooms of many office buildings and hotels. Hence, the student must be helped to realize that numbers are "hothing but useful symbols to fill gaps in meaning and communication........Mathematics can do no more, explain no more, than the tangible things to which its

14. National Committee on Mathematics Requirements, The Reorganization of Mathematicg in Secondary Education. $p .7$. p. 195.

15: Lancelot Hogben, Mathematics for the Milition. 
symbols are hitched permit... In the language of mathematics no less than in ordinary language we must find the referent for the symbols". 16

On this problem Fawcett makes the following comment:

The symbols of mathematics are the creation of the human intellect. They were invented for the purpose of expressing ideas and, as teachers of mathematics, it is well to recognize that the ldea was clearly understood before it was symbolized. We have tended to reverse the process and have all too frequently introduced students to a symbol rather than to the idea behind the symbol. They have been encouraged to use the names of ideas which they do not possess and they have been called upon to use symbols for ldeas which they do

Betz also has definite convictions concerning the improper use of symbols:

....... if a concept for which the symbol is supposed to stand does not correspond to anything that has been experienced, the symbol has no meaning. But a symbol which does not symbolize something is useless. It is "empty". At best, it may serve as a form of amusement, but educationally it is barren. In like manner, when a pupil uses the technical symbols of algebra, before he understands what they symbolize, or how he can apply them, he is indulgine in a blind game that has no intrinsic educational value whatever. 18

The teacher of algebra might direct the attention of students to the ways in which symbols encompass our daily

16. Stuart Chase, The Tyranny of Words. pp. 159, 162.

17. Harold Fapett, "Language and Mathematics", Educational Method, XXI (March, 1942) p. 294.

I8. William Betz, "Whither Algebra?--a Challenge and a Plea", Mathematics Teacher, XXIII (February, 1930) p. 114. 
living. Students will enjoy listing symbols and discussing their role in everyday affairs. The symbols used by manufacturers, by directors of highway safety, by athletic contestants, by welfare organizations, and by political parties are illustrative of the many situations. which would provide fruitful discussions. The purposes of symbols should be one of the outgrowths of thig preliminary study.

In like manner, students will be benefited when they contrast the Iimited and precise meanings of mathematical symbols with the "indefinite meanings of some non-mathematical symbols". A study of the evolution of number symbols and gigns of operation wili contribute to developing an appreciation of modern symbolic notation in mathematics.

The preceding discussion (Relationships) on the condensing of verbal statements into formulas provides a striking illustration of the efficiency of mathematical symbolism. Students should also become acquainted with some of the different meanings attached to a particular mathematical symbol. For example, the term "billion" has a meaning for the English and German people that differs from the meaning it symbolizes in this country and in France. The number 56 symbolizes the addition of 50 and 6 while the term ax symbollzes the product of $a$ and $x .19$

19. Commission on Secondary Curriculum, op. cit., pp. 214-237, and Mary I. Webster, "Elementary Algebra with an Emphasis on Symbol1c Thinking". Unpublished Master's Thesis, Ohio State University, 1943. 
Operation

Previous reference has been made to the emphasis that: has been placed upon manipulation of algebraic terms without providing opportunities for pupils to understand the meanings associated with each operation. The National Committee made the following observation on the situation:

Extreme emphasis upon the mere manipulation of symbolg which does not have meaning and significance to the pupil, together with poorly sellected content and material of Iittle value even in later courses in mathematics, constitute the two pronounced indictments of the standard algebra of the ninth grade.

Everett: says that, "the element of interpretation of meanings is of as great importance as manipulative ability. The ability to perform an operation demandines manipulative skill is slight evidence that the performance is necessariIy attended by a sense of its significance." 21

An understanding of the relations between the four fundamental operations is indispensable if students are to achieve command of the operations to the extent that they will be able to make correct choices of operations in the solution of problems. These interrelations are listed by the Committee on the Function of Mathematica in General Education as follows:

\footnotetext{
20. National Committee on Mathematics Requirements, op. cit., p. 189.

21. Everett, op. cit., p. 12
} 
3. Addition may be regarded as a short method of counting.

2. Multiplication is a short method of finding the sum of a group of numbers all of which are the same.

3. Subtraction is the inverse process of addition.

4. Division is the inverse process of multiplication. It may be regarded as a short method of performing repeated subtraction. 22

Solving many aimple exercises of the following type would provide experiences through which students might be led to reach generalizations 3 and 4 above: $58+17-17$; $397+48-397 ; \quad a+c-a ; \quad(75 \times 5) \div 5 ; \quad(428 \times 22) \div 22 ;$ $(\mathrm{r} x \mathrm{y}) \div \mathrm{y}$

The relation between a.Igebraic and arithmetic conceptis should not be overlooked. Most operations with numbers in algebra are extengions of arithmetical operations. Again, we can approach each new idea in algebra through arithmetic. For example, the adition of fractions in arithmetic is performed as foljows:

$$
\frac{1}{3}+\frac{3}{4}=\frac{4 \cdot 1+3 \cdot 3}{3 \cdot 4}=\frac{4+9}{12}=\frac{13}{12} \text {. }
$$

Several examples of this type would enable the pupil finally to generalize the process. as follows:

$$
\frac{a}{i}+\frac{c}{d}=\frac{a d+c b}{b d} \text {. }
$$

As one inspects this example and other algebraic expressions it is evident that from any standpoint elementary

22. Commission on Secondary Curriculum, op. cit., p. 271. 
algebra may be considered as seneralized arithmetic. Most. algebraic expressions indicate operations and can be used to illustrate and explain the many ideas which were not generalized in the study of arithmetic.

Students should participate in the formulation of the assumptiong which are used in the solution of equations. The ideas resulting from the use of such expressions as, "transpose" and "cancel" so distort the thinking of students with regard to the relation between the members of an equa:tion that their use is inadvisable. We should use the following expressions instead:

It is permissible to add (or subtract) equal amounts to both sides of an equation without destroying the equality.

It is permissible to aivide (or multiply) both sides of an equation by the same quantity without destroying the equality. (Zero excepted)

It is permisgible to multiply (or divide) both terms of a fraction by the same quantity without changing its value. (Zero excepted).

If students are to understand why they perform various operations in the solution of an equation, they should be introduced to the inverse character of the operations involved in the formulation of an equation and in its solution. For example, in the equation, $2 n+4=8$, the unknown term has been: (a) multiplied by 2 and (b) this product has been incread by 4 which yields the answer 8 . To solve for the value of $n$ which satisfies the equation, the processes which are the inverse of multiplication and addition must be per- 
formed, that is, both members must be decreased by 4 and finally divided by 2 .

As study progresses, it should be developed that in every operation performed during the solution of a cond1tional equation, the relation between the members of the original equation must be preserved. Further, the process of solving an equation is a matter of un-doing the operations previously performed on the unknown.

Usually the relation between the roots of an equation and the coefficients of the variable and constant terms is: not considered before pupils study quadratic equations and systems of Iinear equations. This relation might well be considered in the study of conditional first degree equations with one unknown. For example, the solution of the equation, $2 n+4=8$, could be left in the following form: $n=\frac{8-4}{2}$. Other equations carrying specific values for the constant terms and the coefficient of the unknown might be solved in a similar manner. From these specific answers a generalized solution could be listed for equations of the form $a x+b=c$, the solution being, $x=\frac{c-b}{a}$.

\section{Proof}

Throughout this discussion much has been said of the concentration on the use of the inductive method. In addition students should have frequent experiences. with nonmathematical situations which use or require the use of in- 
duction in their solution. Materials are readily avaliable in such current reading matter as magazines and the editorlal and advertising sections of newspapers.

Public opinion polls, a popular feature of most daily papers, use the inductive method for arriving at generalizations which are claimed to be held by the American public. In a recent article the editors of Time ralsed the question, "Do polls follow the voters or do voters follow the polls?" In the discussion, the evils of the "straw ballot" were pointed out and the authors concluded that "they (the polls) can find what the people, who rule a democracy, think and want. But a democracy also needs leadership by men who must frequently tell the people why a popular notion--no matter how widely held--can be wrong." 23

The recently published Kinsey report on male sexual behavior reached the generalization that the majority of men at some time in their lives followed some abnormal sexual practice. Many readers are interpreting these conclusions to the effect that many sexual practices long held in abhorrence mugt now be acceptable.

Should the teacher of algebra accept the responsibility for discussing and analyzing reports of this type? It i. possible that this specific report will not toubh the lives of youngsters, but suppose it does? Murder and robbery and

23. 23. "Gallup Poll", Time, II (May 3, 1948) pp. 21, . 
other crimes are prevalent also in our society but we do not consider them as normal for the best interests of society. Frequently comparisons and analogies as in the paragraph above are useful in showing the fallacies that can be committed when the inductive method is used erroneously. The characteristics of induction as a method of thinking should be studied by the class from time to time and samples of inductive reasoning should be analyzed and criticized by gtudents. However, the maturity level of the student 1s important and must be recognized in the selection of learning materials. Many situations can be framed from the pasing conversations of students. For example, the statement often overheard in conversations, "Every Saturday 1 t rains, so I don't plan to so skating next Saturday", could be presented for class discusgion. "How many rainy saturdays should thers be before one could reach such a conclusion with certainty3.", is an 111ustration of the type of question which could be raised from the statement. The discussion might be coneluded with the generalization that such a decision becomes more valid as the number of ratny saturdays increases, or, the more cases of rainy Saturdays, the more reliable the conclugion. A point deserving emphasis is that even twentyfive succesgive rainy Saturdays would be insufficient to prealct saturday weather. It might also be shown that the data from which the conclusion was drawn is 1 rrelevant and that Friday's data from the UnIted States Weather Bureau 
woula be more relevant to the question.

Discussions and study of situations similar to the preceding illustration could accompany the exercises involving the discovery by induction of various algebraic principles. It is evident that there are many down-to-earth situation which are potential sources for exercising proper use of inductive reasoning. Stimulating students to develop sound Generalizations from their experiences should be an integral part of the plan for developing the ability to interpret data. With regard to algebraic materials, students should be shown the value of checking their solutions of problems. Checling solutions is one of the more reliable types of proof, since it represents one of the tests to which one subjects a hypothesis.

The fact that the "related concepts" have been discussed separately does not imply that they should be treated separately. There should be a maximum of interplay between them and it is concervable that, occasionaliy, experlences in all the concepts will proceed simultaneously. Basic Assumptions

This discussion of teaching method and content makes the following basic assumptions to be used as guides by a teacher concerned with developing the ablilty to interpret data through a course in algebra based on the mathematical concepts which have been treated in this chapter:

1. Adolescents achieve best when given the oppor- 
tunity to work with materials which interest them--materials which are taken from life about them.

Most mathematics teachers can give vivid descriptions of the spontaneous response of students to mathematics problems which are based on situations that are of interest to the student. In Iike manner, the spiritless and disinterested response of students to abstract problems lacking concrete backgrounds, can be listed also among the experiences of the mathemat1cs teacher.

2. There 1s more than one acceptable order or plan to arrange the sequence of concepts in alpebra.

Secondary school teachers have shown that the definitions, assumptions, and theorems of geometry can be arranged in many different sequences, each sequence belng logically sound. Further, it has been shown that definitions, assumptions and theorems are interchangeable in these different sequences, 1.e. a definition in one sequence may be a theorem in another sequence, etc. In the fleld of algebra a system of logic can be developed which may differ from another algebraic system in the sequence and number of seneralizations reached.

3. Many topics and concepts of traditional algebra have nelther interest nor utilitarian value to students:

Complex exercises dealing with factoring, operations with complex algebrats fractions and algebraic long division are three examples of algebralc subject matter which should be 
presented to students only after careful and deliberate planning by the teacher, if they are to have interest or utilitarian value.

4. Learning proceeds best when a few concepts are repeatedly experienced in varied settings.

Understanding and thinking are components of learning. Neither of these is developed when we drill students or present one situation repeatedly. Only when we change or vary the elementa in a situation, do we stimulate understanding and thinking, and thus, learning.

5. Many hikh school students have acquired prejudices against algebra before beginning study of $1 t$.

The difficulty and arabness of elementary algebra have been emphasized by students who have emerged as algebraic successes or failures after a year of ninth grade mathematics. These student evaluations of algebra are passed on to younger students with astounding enlargements of the difficulties which were experienced. Should the mathematica teacher wonder at the nervous reactions and frightened expressions of some students upon beginning their study of algebra?

6. The mathematics teacher must consider the child with hig complete background if he would plan activities that will stimulate maximum intellectual growth.

This assumption is related closely to Assumption (I). The interests, the aptitudes and weaknesses, the personal problems, and the aspirations of the student $\operatorname{compose}$ the sources 
from which every teacher should plan classroom experlences.

7. Supervised study encourages independent work by the student and offers more opportunities for teaching and analysis of study habits than do home assignments.

The evils attendant to homework are well known to most mathematics teachers. The "perfect" papers of slow learners and thoge who have not grasped the work for the day, seem to indicate that homework for all encourages dishonesty. If there were assurances of adequate and proper help in doing home assignments, there would be no problem. Apparently the best solution is that of supervised classroom study, where the teacher concerned guides each student to the extent the teacher believes is sufficient.

8. We must teach for the outcomes we expect students to gain. (Tranafer of trainine is not automatic).

This assumption has been supported through evidence presented by researchers in the teaching of geometry and in other secondary subjects. The attention of the student must be directed to the Iong-range objectives which we wish to achleve. roreover, classroom activities must be oriented definitely toward these objectives.

9. Algebra can make as great a contribution to general education through application of its method as through application of its subject matter.

Most educators agree that the development of reasoning abilities should be the great objective of all secondary subjects. It is obvious that emphasis on the method of algebra 
is more promising for the development of this objective then is algebraic subject matter alone.

Outcomes

In the preceding discussion, the following outcomes have been illustrated and should typify the major purposes of a teacher interested in developins the ability to interpret data through the channel of algebra:

I. Relationship

1.1 Understanding the relation between the formula, the equation, the graph, the table, and the verbal statement.

1.2 Abliity to perceive the dependence among related variables in both mathematical and nonmathematical situations.

1.3 An understanding of the relations in propositional functions Iimited to two variables.

1.4 Ability to distinguish between functional and approximate relationships.

2. Number

2.I An appreciation of the ever-widening scope of number.

2.2 Understandine the propertieg of directed numbers and irrational numbers.

3. Measurement

3.1 An understanding of the arbitrary character of units of measure.

3.2 An understanding of the approximate character of values which are secured through measurement.

3.3 Ablitty to apply principles of approximate computation

3.31 Ability to determine the number of signif- 
icant figures in measurements, where the unit of measure is given.

3.32 An understanding of procedures to be followed in securing sums and differences of approximate numbers.

3.33 Ability to estimate products and quotients involving approximate numbers.

$3.34^{\circ}$ Ability to round off products and quotients involving approximate numbers, to proper accuracy.

4. Symbolism

4.I Improvement in ability to read mathematical materials.

4.11 Ab1lity to interpolate and extrapolate in readine tables of data.

4.2 An appreciation of the value of symbolism in promoting discavery and prosress.

4.21 Recognition of the fact that well-selected symbols promote intellectual power.

4.3 Ability to translate the relationships of life into the language of algebra, 1.e., functional familiarlty with the language of algebra.

5. Operation

5.1 Ability to generalize each of the fundamental operationg in arithmetic through algebraic symbols.

5.2 An understanding of the interrelationship between the operations of algebra.

6. Proof

6.I Ability to make sound generalizations through induction.

6.2 Recognition of the fact that solutions are hypotheses or possible answers which must be tested. (Checking solutions)

6.3 Recognizes the fact that many generalizations have only probability in their favor. 
Teachins Method

The outcome, "ability to make sound generalizations through induction" is closely related to the ability to interpret data. It cannot be developed over night. The teacher's efforts must be directed persistently and consciously toward the development of this ability as students acquire algebraic concepts. The method of induction must so permeate each problem aituation that the student becomes conscious of its use and is sensitive and critical of its use by himself as well as by others. Thus, instead of giving students the rules for operating with exponents or reading the rules from a book, students should be allowed to discover these principles and generalizations for themselves. In the solution of algebraic problems the emphasis would be placed on the process of solution, as well as securing an answer. Every opportunity would be used to seneralize the process, in preference to emphasizing a unique number, as an answer. The Joint Commission makes the following statement relative to teaching students the use of inductive reasoning:

Any formal discusgion of epistemology can hardly find place in secondary instruction, but there should be conscious experience with both inductive and deductive reasoning. The character and requisites of these two procedures should be so clearly Erasped that appropriate behavior on the part of the pupil is brought about in the direction both of understanding and of making applications. In solving problems the pupil should develop the habit of asking whether he is starting from general premIses and is seeking consequences, or, by examining 
particular instances, is aiming at universal conclusions............Proper attention must be Given to generalizing these behaviors and understandings. We may then hope that pupils will apply them to situations arising in many different
fields of thought. 24

An important problem related to method is concerned with the choice of problem materials. Does it matter whether the problem will recur in aituations outside of the algebre clagsroom on that it does not interest students? If the main concern is to be development of thinking ability, can that desirable outcome be realized through the use of fletitious data applied to nebulous and fantastic problems? It is the writer's belief that, in choosing teaching materials, the teacher must be sensitive to student interests and to those problems having applications to Iife outside the clasaroom. Certainly, materials so chosen and used discriminately would accelerate the learning cycle. Hence, the teacher who uses a textbook must exercise good judgment in choosing problems which will conform to the two criterla of Interest and practlcal application.

The use of a textbook is also related to method. A. teacher having earnest and sincere convictions concerning the need of developing thinking abilities will probably decide to minimize the use of a single textbook. In fact,

24. Joint Commisgion of the Mathematical Association of America and the National Council of Teachers of Mathematics, The Place of Mathematics in Secondary Education, $p .24$. 
89

the use of a textbook, where the rules are all given, would not be consistent with the plan proposed herein for development of atudent abilities for interpreting data. Only references should be used which contain materials that show potentialities in promoting student growth in the desired. abilities. In most instances it would be more desirable for the teacher to plan his own learning guides as a result of his observations of class trajts and abilities. 


\section{Chapter Four}

General Procedures: And Experimental Conditions:

\section{General Procedure}

This study is concerned with the extent to which elementary algebra can contribute to student growth in ability to interpret data. Although mathematics materials were used and progress was made in objectives peculiar to mathematics, the study is Iimited to an accounting of changes in the ability of the student to interpret data. Two groups of ninth grade algebra students in the William Grant High School, Covingtion, Kentucky were taught for the express: purpose of improving their ability to interpret data. Intellisence quotients and reading abilities of the students were obtained through the administration of standard tests, and an inventory was secured of abilities in the interpretation of data.

Study guides designed to promote student command of the behaviors associated with the ability to interpret data were constructed for use w1th the groups and no textbook was used. Students were stimulated to discover the rules and general1-. zations which are usually given to them through textbooks as well as generalizations associated with their environment. Frequent discussions were conducted to gensitize students to the importance and utility of interpreting data properly. 
91

Toward the close of the year, the test on interpretation of data wos re-administered to the groups.

The Scihool

Willam Grant High School is a division of the IincolnGrant School, a school rebulit by the Clty of Covingtion in 1931 to serve more effectively the educational needs of the city's Negro youth. Constructed of reinforced concrete and brick, the bullding occuples three stories and a basement. It contains 32 classrooms, two libraries, an auditorium, a: Bymnasium, a cafeteria and a model apartment. The physical plant is maintained in excellent condition by the Board of Education. The average enroliment for the thirteen grades, kindergarten through grade 12, is 500 studenta and requires a staff of 32 teachers. The bullaing is so arranged that the elementary, funior high and senior high departments are housed on geparate floors.

William Grant High School, comprising grades 9 through 12, is the only public high school for Negroes in Northern Kentucky. Although operated by the Board of Education of the fity of Covington, the school serves three counties, Campbell, Boone and Kenton. The Negro population in the three counties numbers no more than 4,000, and the school and ataff 1 a ample for those persons who accept public educational provisiong on a segregated basis. The average yearly enrollment is 125 students with a staff of 13 teachers. Although coming from families with incomeg senerally 
meager, within recent years approximately 35 per cent of the graduates go to colleges; and trade and technlcal schools to further their education. The following table gives this information in more detail:

\section{TABLE 2}

Graduater Attending College

\begin{tabular}{l|c|c|c}
\hline Year & $\begin{array}{c}\text { Number of } \\
\text { Graduates }\end{array}$ & $\begin{array}{c}\text { Number Going } \\
\text { to College }\end{array}$ & Per Cent \\
\hline 1941 & 16 & 4 & 25 \\
1942 & 19 & 7 & 37 \\
1943 & 32 & 14 & 44 \\
1944 & 15 & 5 & 33 \\
1945 & 23 & 12 & 52 \\
1946 & 25 & 6 & 24 \\
1947 & 25 & 11 & 44 \\
1948 & 17 & 4 & 24 \\
1949 & 21 & 7 & 33 \\
1950 & 22 & 7 & 32 \\
1951 & 20 & 6 & 30 \\
\hline
\end{tabular}

The students

The group of ninth grade students who participated in this study was composed of 34 individuals, divided into two sections of 16 and 18 respectively. Of the 34 students, 19 were boys and 15 were girls. Both perents of 26 students were living, although only 13 students were living with both of their parents. The parents of two students were deceased and gix students either lived with a friend of the family or with relatives. Fifteen of the students lived with one of their parents. In most instances, when the family was broken, the child Iived with the mother who was the only means: 
of support. In Täbles. 3 and 4 below, where parental and residential status of each section are listed, only 33 per cent of the students in section 1 having both parents alive, lived with both parents. In section 2, 64 per cent of the students having both parents al1ve, Iived with both parents.

\section{TABIE 3}

Parental Status of students

\begin{tabular}{|c|c|c|}
\hline Parenta玉 Status & $\begin{array}{l}\text { Number in } \\
\text { Section } 1\end{array}$ & $\begin{array}{l}\text { Number in } \\
\text { Section } 2\end{array}$ \\
\hline $\begin{array}{l}\text { Both Parentis Living } \ldots \ldots \ldots \ldots \\
\text { One Parent Iiving } \ldots \ldots \ldots \ldots \ldots \\
\text { Both Parents Deceased } \ldots \ldots \ldots \text {. }\end{array}$ & $\begin{array}{r}15 \\
1 \\
0\end{array}$ & $\begin{array}{r}11 \\
5 \\
2\end{array}$ \\
\hline
\end{tabular}

TABIE 4

Residential Status of Students:

\begin{tabular}{l|c|c}
\hline \hline Residential Status. & $\begin{array}{c}\text { Number in } \\
\text { Section 1 }\end{array}$ & $\begin{array}{c}\text { Number in } \\
\text { Section 2 }\end{array}$ \\
\hline Living With Both Parents $\ldots \ldots$ & 6 & 7 \\
Living With Mother $\ldots \ldots \ldots \ldots$ & 6 & 4 \\
Living With Father $\ldots \ldots \ldots \ldots$ & 1 & 4 \\
Living With Relatives $\ldots \ldots \ldots$ & 3 & 3 \\
\hline
\end{tabular}

The occupations Iisted in Table 5 indicate that domegtic or day work, janitorial, construction and railroad work were the chief occupations of the parents. 
TABLE 5

Occupations of Parents:

\begin{tabular}{|c|c|}
\hline Occupation & Employed \\
\hline 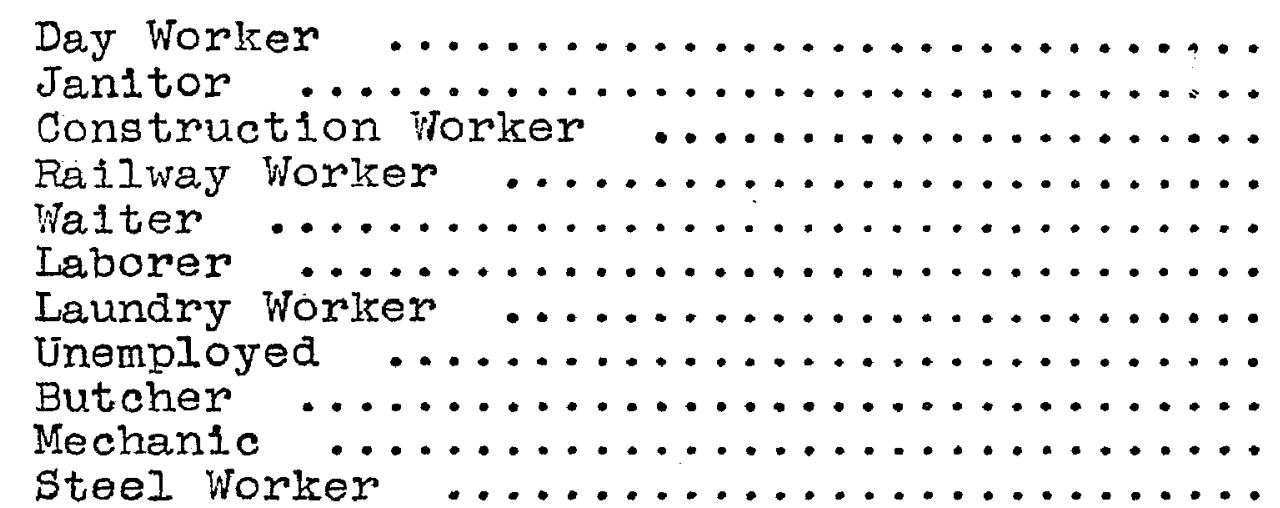 & $\begin{array}{l}8 \\
5 \\
5 \\
5 \\
2 \\
2 \\
2 \\
2 \\
2 \\
1 \\
1 \\
1\end{array}$ \\
\hline
\end{tabular}

The ages of students were distributed as shown in Table 6 and were computed to the birtrday preceding september 5 , 1950:

\section{TABIE 6}

Ages of Student:

\begin{tabular}{|c|c|c|c|}
\hline Age in & Years & Number of $\mathrm{S}$ & Students \\
\hline $\begin{array}{l}18 \\
17 \\
16 \\
15 \\
14 \\
13\end{array}$ & $\begin{array}{l}\ldots \ldots \\
\ldots \ldots \\
\ldots \ldots \\
\ldots \ldots \\
\ldots \\
\ldots\end{array}$ & $\begin{array}{l}\ldots \ldots \ldots \ldots \\
\ldots \ldots \ldots \ldots \\
\ldots \ldots \ldots \ldots \\
\ldots \ldots \ldots \ldots\end{array}$ & 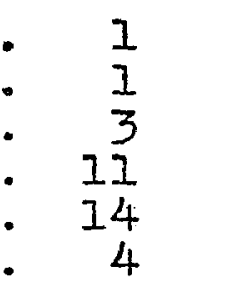 \\
\hline
\end{tabular}

The median intelifgence quotients and reading percentiles shown in Tables 7,8 and 9 indicate that both classes were of "Iow average" Intelligence and that the reading 
abilities were low in comparison with national norms. Additional data concerning intelligence quotients and reading abilities may be found in Tables 7,8 and 9 .

The behaviors involved in interpreting data were evaluated through the administration of Interpretation of Data Test. Lower Leve1, an evaluation ingtrument of the Eight Year Study. I The median scores made by the two groups on the various categories of this test shown in Tables 20 and 21, Chapter 6, indicate that the outstanding weakness among these students was their general failure to recognize the limitations of data. Generally students were not overcautious as shown in Column 4, but they had a tendency to go beyond the data or "to ascribe more truth or falsity to an interpretation than the data would justify". (Column 5).

Table 10 shows that all students followed practically the same daily schedule, with the exception of industrial work. The girls took either clothing or foods and the boys took either woodwork or auto mechanics. Al. periods were forty-five minutes long, except the first which was a fifteen minute period. Section 1 studied Health for the first half of the school year, then History for the last half. Section 2 studied History for the first half of the school year, then Health for the last half.

1. Published by Cooperative Test Division, Educational Testing Service, Princeton, N. J. 
TABLE 7

Intelligence Quotients of Students in Section 1

\begin{tabular}{|c|c|c|c|c|}
\hline student & Sex & $\begin{array}{c}\text { Chronolog- } \\
\text { ioal Age }\end{array}$ & $\begin{array}{l}\text { Mental } \\
\text { Age } \\
\end{array}$ & $\begin{array}{c}\text { Intelligence } \\
\text { Quotient }\end{array}$ \\
\hline $\begin{array}{l}A \\
B \\
C \\
D \\
E \\
F \\
G \\
H \\
I \\
J \\
T \\
I \\
M \\
N \\
O \\
P\end{array}$ & $\begin{array}{l}\text { Female } \\
\text { Female } \\
\text { Male } \\
\text { Female } \\
\text { Female } \\
\text { Male } \\
\text { Male } \\
\text { Male } \\
\text { Male } \\
\text { Male } \\
\text { Female } \\
\text { Male } \\
\text { Male } \\
\text { Male } \\
\text { Female } \\
\text { Female }\end{array}$ & $\begin{array}{l}167 \\
184 \\
173 \\
171 \\
180 \\
171 \\
191 \\
173 \\
192 \\
175 \\
182 \\
174 \\
190 \\
182 \\
178 \\
177\end{array}$ & $\begin{array}{l}181 \\
143 \\
186 \\
163 \\
157 \\
169 \\
161 \\
169 \\
173 \\
173 \\
149 \\
178 \\
145 \\
157 \\
143 \\
157\end{array}$ & $\begin{array}{r}108 \\
78 \\
108 \\
95 \\
87 \\
99 \\
84 \\
98 \\
90 \\
99 \\
82 \\
102 \\
76 \\
86 \\
80 \\
89\end{array}$ \\
\hline \multicolumn{2}{|c|}{ Highest Score $\ldots .$. . } & 191 & 186 & 108 \\
\hline \multicolumn{2}{|c|}{ Group Median } & 178 & 162 & 90 \\
\hline \multirow{2}{*}{\multicolumn{2}{|c|}{$\begin{array}{l}\text { Group Mean } \ldots \ldots \ldots \ldots \\
\text { Lowest score } \ldots \ldots \ldots\end{array}$}} & 180 & 163 & 91 \\
\hline & & 167 & 143 & 76 \\
\hline
\end{tabular}


TABIE: 8

Intelligence Quotients of Students in Section 2

\begin{tabular}{|c|c|c|c|c|}
\hline student: & Sex & $\begin{array}{l}\text { Chronolog- } \\
\text { Ical Age }\end{array}$ & $\begin{array}{l}\text { Mental } \\
\text { Age }\end{array}$ & $\begin{array}{c}\text { Intelilgence } \\
\text { Quotient }\end{array}$ \\
\hline $\begin{array}{l}A \\
B \\
C \\
D \\
E \\
F \\
G \\
H \\
I \\
J \\
K \\
I \\
M \\
N \\
O \\
P \\
Q \\
R\end{array}$ & $\begin{array}{l}\text { Female } \\
\text { Male } \\
\text { Female } \\
\text { Male } \\
\text { Female } \\
\text { Male } \\
\text { Female } \\
\text { Male } \\
\text { Male } \\
\text { Female } \\
\text { Female } \\
\text { Male } \\
\text { Female } \\
\text { Male } \\
\text { Male } \\
\text { Male } \\
\text { Female } \\
\text { Male }\end{array}$ & $\begin{array}{l}178 \\
192 \\
171 \\
188 \\
169 \\
192 \\
192 \\
163 \\
182 \\
183 \\
192 \\
169 \\
167 \\
187 \\
162 \\
192 \\
173 \\
188\end{array}$ & $\begin{array}{l}119 \\
155 \\
159 \\
137 \\
149 \\
160 \\
154 \\
189 \\
175 \\
155 \\
137 \\
146 \\
157 \\
130 \\
163 \\
183 \\
137 \\
162\end{array}$ & $\begin{array}{r}67 \\
81 \\
93 \\
73 \\
88 \\
83 \\
80 \\
116 \\
96 \\
85 \\
71 \\
86 \\
94 \\
70 \\
101 \\
95 \\
79 \\
86\end{array}$ \\
\hline \multicolumn{2}{|c|}{ Hibhest score ... } & 192 & 189 & 116 \\
\hline \multicolumn{2}{|c|}{ Group Median .... } & 183 & 155 & 86 \\
\hline \multicolumn{2}{|c|}{ Group Mean ..... } & 180 & 154 & 86 \\
\hline \multicolumn{2}{|c|}{ Lowest Score .... } & 162 & 119 & 67 \\
\hline
\end{tabular}




\section{TABIE 9}

Reading Percentiles of Students

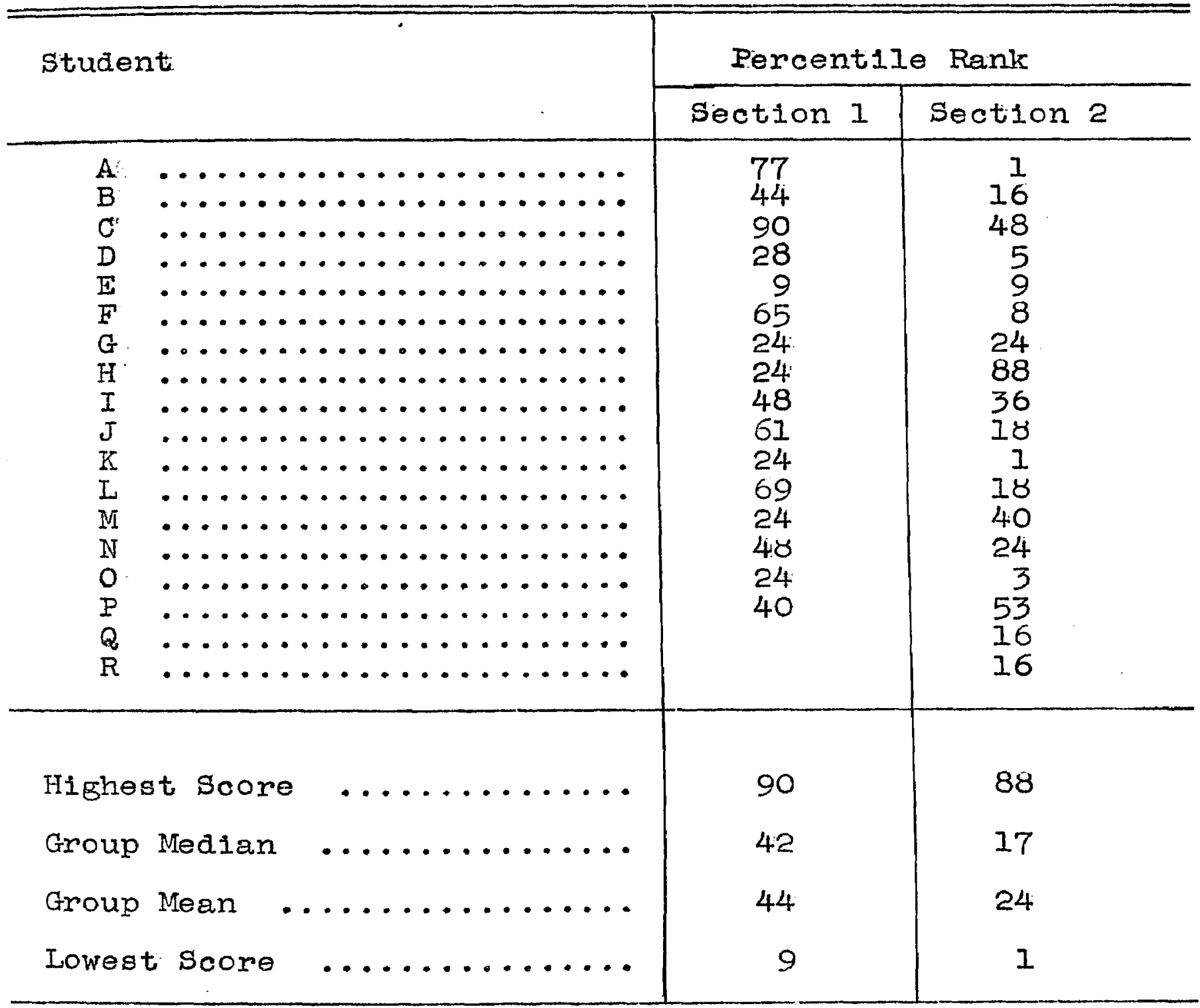


TABIE 10

Class Schedules

\begin{tabular}{|c|c|c|}
\hline Peric & Sehedule of Section 1 & schedule of section 2 \\
\hline 1. & Homeroom & Homeroom \\
\hline 2. & Hea.Ith & Englioh \\
\hline 3 & $\begin{array}{c}\text { Physical Education } \\
\text { Boys: M-W } \\
\text { Girls: T-Th } \\
\text { Study } \text { Friday }\end{array}$ & $\begin{array}{cl}\text { Physical Education } \\
\text { Boys: } & M-W \\
\text { Girls: } & T-T h \\
\text { Study } & \text { Friday }\end{array}$ \\
\hline 4 & Algebra & History \\
\hline 5 & English & Algebra \\
\hline 6 & Recess & Recess \\
\hline 7 . & Cho1r or Band & Choir or Band \\
\hline $8-9$ & $\begin{array}{l}\text { Woodwork } \\
\text { or Foods: }\end{array}$ & $\begin{array}{l}\text { Auto Mechanics } \\
\text { or Clothing }\end{array}$ \\
\hline
\end{tabular}

The school year consiated of 40 weeks or 200 days, however the classes in algebra met only 190 times due to holidays or school assemblies. All of the periods in the first week were congumed in administering the intelligence test (language and non-language forms), and the reading test. The test on ability to interpret data was administered in December, due to Itis: late delivery by the publishers.

The classes met in the lecture room and laboratory deslgned for physics and chemistry classes. The lecture room was equipped with a large demonstration desk and 28 movable arm chatrs. Successive rows of chairs were on a platform 
with graduated levels. The laboratory was equipped with 24 Iincoln school type laboratory desks. Both rooms as well as all laboratory apparatus and supplies were available for use at the time each class met. In most instances the laboratory room was used when students worked on study guides or assembled any data required for their work. The lecture room was used when the ingtructor presented demonstrations or when the period was devoted to group discus:sions. 


\section{Chapter Five}

\section{Experimental Materials And Classroom Procedures}

\section{Summary of Instructional Units}

The work for the school year consisted of four units: and the principal teaching devices. used throughout the year were study guides. The emphasis in each study guide was on the development of 1deas through inductive reasoning and an expected outcome of each guide was the formulation of a generalization by the student based on specific problems previously solved in the study guide. The first unit titled, "The Language of Algebra" was concerned with helping stur dents to gain an appreciation of the role of symbolism in the communication of ldeas and the following were the unit objectives:

1. Appreciation of the role of symbolism in the communication of ideas.

2. Ability to recognize and predict linear relationships

2.I In tables of value through computing first differences in dependent variables.

2.2 In graphs by computing slope.

3. Ability to distinguish between approximate and functional relations.

4. Ability to interpret data which is presented in. graphical or tabular form.

4.I To "read between the Iines" (Interpolate) with caution. 
4.2 To "go beyond the data" (extrapolate) with caution.

4.3 To relate the domain of independent varlables to the range of corresponding dependent varlables.

4.4 To evaluate conclusions and eeneralizations reached by others in their interpretation of data.

4.5 To relate changling slopes to corresponding changes in tables ard formulas.

5. Ablilty to subst1tute values of independent vartables in formulas and equations in order to find corresponding value of dependent var1able.

6. Ability to change the subject of a formula or equation.

7. Ablilty to reach conclusions inductively.

The second unit titlea, "Extending the Number System", illustrated the power of Hindu-Arabic numbers especially when compared with the clumsy Roman aystem. The inadequacy of a number system involving only positive integers was considered and it was expanded to meet the demands of subtraction in all aituations. The fundamental operations were developed with directed numbers and their use was demonstrated through conditional equations. The following were the undt objectives:

1. Understandine of relations between the following operationg:

1.I Addition and countine

1.2 Addition and subtraction

I.3 Multiplication and addition

1.4 Subtraction and diviaion

1.5 Multiplication and division 
2. Appreciation of the efficiency of Hindu-Arabic notation in comparison with Roman notation.

3. Appreciation of the wider utility of directed numbers in comparison with arithmetical numbers.

4. Understanding of the fundamental operations with directed numbers.

5. Ability to reach conclusions inductively.

6. Understanding of the assumptions used in the solution of conditional equations.

7. Ability to give general solutions for equations of the forms: $a x=b$ and $a x+b=c$.

The third unit titled, "Approximate and Functional Relationships" was an enlargement of unit one. Through demonstrations and discussions, students were helped to develop inductively a number of formulas Involving areas and volumes of common geometric figures. Problems were Introduced in which the data were to be assembled and the data processed through the application of certain elementary statistical concepts. The conclusions and generalizations drawn from these data represented approximate relationships. Class work proceeded from problems which by nature produced limited and inaccurate generalizations to those which produced nearly-linear relationships. Linear relationships were considered through many. situations fllustrating applied mathematics. Such items as the relation between the table, graph, verbal statement and formula, especially the relation between the slope of a graph, the constant differences in the corresponding table of values, and coefficlent of the 
Independent variable in the formula, were points of major emphasis. Simultaneous linear equations were approached through an analysis of the fares charged by two taxi-cab companies.

The study of relations was extended to include symmetric, transitive and reflexive relations.

The fourth unit titled, "Extending Operations in the Number System" was concerned with developing an understanding of the principles relating to the use of exponential quantities and the simple quadratic functions, $y=a x^{2}$, $y=a x^{2}+b$ and $y=a x^{2}+b x$. The principles relating to the multiplication and division of exponential quantities were derived by students inductively. Constant second differences In a table of values and a curve of second degree were compared with constant first differences in a table and the corresponding Iinear function. Applications of quadratic functions were made in the study of stopping distances required for moving vehicles. The objectives of this unit were similar to those of units one and two, extending and enriching the same major 1deas:

1. Ability to recognize and predict quadratic relationships

1.I In tables of values through computing second differences in dependent variabies.

2. Ablity to perform the operations of multiplication and division with exponential quantities. (Including positive, negative and fractional exponents).

3. Ability to interoret data which are presented in 
graphical or tabular form.

3.1 To "read between the Iines": (interpolate) with caution

3.2 To "go beyond the data" (extrapolate) with caution

3.3 To relate the domain of independent variables to the range of corresponding dependent vartables

3.4 To evaluate conclusions and seneralizations reached by others in their interpretation of data

4. Ability to substitute values of independent variables in formulas and equations in order to find corresponding value of dependent variable.

5. Ability to reach conclusions inductively.

From a survey of the objectives listed for the four units ore sees several duplications of objectives. Those concerning the ability to interpret data and the ability to reach conclugions inductively are examples of this repetition. These two objectives represent the overall purposes of the study and operated in any activity where the instructor saw an opportunity to provide experience toward their development. Actually, all other objectives were subsidiary and were developed for the purpose of giving a more profound meaning to the ability to interpret data and the ability to reach conclusions inductively. The writer's efforts were directed constantly and persistently toward the development of these two abilities.

The four units were selected according to the following criteria: 
1. Are the algebraic subject matter and other learning materials adaptable for use in developing inductive reasonine or any of the behaviors involved in the interpretation of data?

2. Is the material of a type which will contribute information of practical use to the student as a future consumer?

The sequence of the units was decided ugon through logical as well as psychological considerations. Mathematics is a cumulative subject, Ior every principle mastered is used as the foundation for understanding or discovery of more complex principles. Thus, the study of exponents and quadratic functions would of necessity follow, rather than precede, a study of directed numbers and linear functions. According to the Joint Commission:
Wodern psychology has proved the effectiveness of "spaced learning". That is, "bunched learning" is not so productive of lasting values as "spaced learning". "ifth slow pupils, especially, the idea of a periodic return to the same topic, providing For its growing mastery and enlarged appication, is of utmost importance, Experience shows that we cannot expect "one hunared per cent mastery" after a single, brief exposure. I

The translation of this Important idea into actual classroom practice is responsible for the fact that the treatment of symbolism and relationship in Unit 1, "The Language of Alsebra", was again constdered and enlarged in Unit 3, "ADproximate and Functional Relations".

1. Joint Commission of the National Council of Teachers of Nathematics and the liathematicel Association of America, The Place of Mathematics in Secondary Education, $v$. 57 . 
The Study Guide

Before discussing each unit in detall the construction and use of the study guide will be considered, since the study guide was one of the principal teaching devices used in the study. The purpose of the study guide is to promote independent thinking by the student. To plan an effective study suide is no easy task especially if students have reading difficulties or if the teacher cannot adjust his Writing to the level of the reader. The use of words beyond the range of the readers' vocabulary make fruitless the effort of constructing any study guide. One word wrongly placed or omitted may give a meaning to the reader which is entirely different to the meaning intended by the teacher. It is of primary importance that the teacher refrain from introducing or bringing to culmination in one study Guide too many nev ldeas or principles. In fact, most study suides must be planned so that they can be completed by the stuaent within a class period and only one new principle, or even part of a principle on occasions, can be treated effectively.

The questions end problems shoula proceed from simple to more complex statements and from specisic statements to more seneral ones. Every stuay guide should contain a final sumarizing question--one which consolidates the answers to speciflc questions in a general statement to be made by the student. 
In using the study guides the teacher cannot remain seated blandly at his desk while the students "study". During directed study, many on-the-spot suggestions can be made which will steer the student toward the goal envisioned by the teacher. In fact it is necessary that the teacher move from student to student noting the progress made by each. Frequently the student can detect an error in his responses when asked to read a question aloud. Other errors can be detected by the student when the teacher reads the student's responses to him.

After students have completed a study guide and after the teacher has checked the work, the study guide should be discussed with the class. Common errors can be pointed out and a class conclusion or generalization asreed upon.

It is obvious that the study guide cannot be used exclustvely in teaching. There are many ldeas which cannot be treated effectively by means of this teachins device, and besides, a variety of experiences is highly desirable. The teacher demonstration and discussions can both be used effectively in promoting the ability to interpret data and to stimulate inductive thinking. Then, too, the continued use of study guides with no change in daily routine will often cause students to become bored and disinterested.

In summary:

1. The study guide constitutes only one phase of teaching and must be supplemented with explanations, demonstrations and oral suggestions. 
2. The wording of guiding questions and statements must be done with understanding by the student as the main consideration.

3. In general, the development of one magor 1dea per study guide will yield mogt fruitful results.

4. The study guide should contain a final summarizing question--a question which directs the thinking of students toward a generalization.

All work on study guides completed by students was filed in chronological order in personal folders which were available in the classroom. Generalizations reached through class aiscussions of study guides were called agreements. Each student was required to keep in his notebook a record of all agreements reached by the class. These notebooks were inspected periodically by the instructor on the following bases:

1. Does the statement make sense? (Are there omisgions of words or phrases which make the statement unintell1glble?)

2. Does the student spell correctly and use proper punctuation marks, enabling him to keep a clear record of class agreements?

Twenty-two copies of the textbook, First Year Algebra by Betz, were avallable for class use, and coples of many other algebra books were avallable in the classroom library. These references were consulted frequently after reaching generalizations relative to some algebraic idea, for the purpose of comparing student agreements with those stated by authorities in the field. The textbook was used also to secure problems which were applications of principles derived 
by students.

\section{UNIT ONE -- THE IANGUAGE OF ALGEBRA}

Unit 1, "The Language of Algebra", began with study guides lliustrating the use of symbols in daily life such as highway symbols, punctuation signs, abbreviations, sound and light symbols, numerals and formulas, and students were guided to a consideration of how symbolism is involved in all communication (Study Guide No. 1).2 In class discussions after work on the study guide one of the students concluded that man uses symbols:

a. To keep a record of his thoughts

b. To send and receive messages over a great distance

c. To save time, effort and money.

Attention was next focused upon multi-valued symbols (Study Guide No. 2). Pairs of sentences were presented in which a word had different meanings and each gtudent was asked to record any observations that he could make concerning the meaning of the underlined word in the pairs of sentences. Portions of the study guide are reproduced below:

$$
\begin{aligned}
& \text { Study Guide lTo. } 2 \\
& \text { The Meaning of Symbols }
\end{aligned}
$$

In previous discussions we have agreed that words are one of man's most ugeful symbols. Consider the following statements noting how the underlined word is used in each sct of statements.

1. a. We cast away useless things.

b. Her face has a bluish cast.

2. Portions of most of the study guides are presented in this chapter. A complete reproduction of all stuciy guides used in the study may be found in the Appendix. 
8. a. This hosiery is of fine quality.

b. Each club member must pay a fine when late to a meeting.

A. What observations can you make concerning the use or meaning of the underlined word in each set of statements?

B. For the following words, construct at least two statements for each to show the different meanings that the word can convey.

$\begin{array}{lllll}\text { vice } & \text { plot } & \text { kind } & \text { mark } & \text { long } \\ \text { hail } & \text { lock } & \text { light } & \text { rent } & \text { hide }\end{array}$

c. What conclusions can you make concerning the uses that can be made of word symbols?

Although, individually, no fruitful conclusions were reached, in class discussions the following observations were made:

1. A word symbol may be used in many different ways.

2. A word symbol may have many different meanings.

3. The meaning of a word is usually determined by the situation in which it is used.

A study of relations expressed through word symbols was another activity of the groups (Study Guide ivo. 3). Seven statements illustrating dependence in various situations were presented for analysis by students. The student was asked to underline the word whose meaning or value depended upon the meaning of another word. Following are excerpts from the study guide:

Study Guide No. 3

Using Symbols To Express Relations

We have seen that a symbol. (word) may serve many purposes and that its meaning is determined by the situation in which it is used as well as many other factors. The meaning of a word may change within a situation because of the changed meanings of other words. 
Hence, its meaning may depend upon the meaning of another word. Consider the following lllustrations of dependence:

a. Blood pressure depends upon age. (As one increases in age blood pressure increases).

8. The amount of floor area in a room depends upon its dimensions (1ts length and widh).

1. In the statements above, underline the words whose meanings are dependent as has been done in statement a.

2. Give other illustrations of dependence.

3. In a short paragraph give your ideas concerning the importance and value of dependence in our everyday living.

Students experienced difficulty in identifying the words and in constructing statements which illustrated dependence. Nany ồ their statements had no meaning because of language difficulty. Following are typical statements constructed by students. In most cases the statements have been edited by the writer:

1. The cost of a thing depends upon its quality.

2. The amount of heat in a room depends upon the size of the heater and type of fuel used.

3. The quality of our education depends upon the type of school and the preparation of our teachers.

4. Taking a good picture depends upon the amount of sunlight and where it's taken.

5. The size of a circle depends upon its radius.

5. A farmer's harvest depends upon the veather and the tyoe of soll.

7. A boy's weight depends upon his e.ge. 
8. Whe styling of a person's clothes depends upon his age.

9. The amount of light in a room depends upon the amount of sunlight and the color of the walls.

10. The size of a bottle depends upon its: helght and the size of its base.

11. The ability of a baby to walk depends on its age.

12. That I study in school depends upon what I plan to do after finishing school.

13. The price of a building depends on the cost of materials and the amount of labor required to build it.

When asked to give their ideas concerning the importance and value of dependence in their everyday living, most of the students attempted to make statements concerning the importance of interdependence among people. One student wrote: "Whether we are sick, tired, hungry, happy, sad or healthy usually depends upon something else". Many statements were made concerning life in relation to such factors as health, a good job, and the passage of time (night and day). One student saw a relation between current events and events of the past.

Some were concerned with the relation between getting a job and such factors as age and health. Others made statements concerning health as being dependent on quality of food, cleanliness and abstinence from smoking. Many statements were made concerning the dependence of a child upon his parents and the dependence of a student upon his teacher. The following statements are illustrative: 
"Students depend upon teachers for education".

"Quality of teaching depenas upon learning":

"Getting my lunch money depends upon my father".

Safety and occupations were considered by two students:

"stopping a car to prevent a collision depends upon the ariver's skill, the speed and the car's brakes."

"An industry depends upon other industries for 1ts progress".

The attention of the group was next directed to the use of variables in different situations. The instructor gave several examples in which the variables could not be measured and others in which the variables could be measured or predicted accurately. Pupils then suggested other illustrations. Tabular data on school accidents (Study Guide No. 4) were presented and students were asked to list conclusions based upon the data. The student's attention was drawn to the fact that most of the conclusions must be narrow or limited in their scope because of the irregular variation in the number of accidents.

The same set of date. was used by students to make bar graphs. (Study Guide No. 5). They were again asked to list conclusions based on the data in their graphs.

As a concluding task each student was asked to decide which form of data (table or graph) he could use best for making interpretations. Wost of the students preferred using the graph and gave as reasons for their choice:

1. The ease with which a graph is read

2. The use of a scale makes for rapid reading

3. The pictorial qualities of the graph 
Those preferring the table gave the following reasons:

The exactiness of the table is preferred to the approximate numbers of a graph.

No computation is necessary in reading a table, whereas it is necessary on a graph and mistakes can be made, especially in using the correct scale.

Students were introduced to the use of mathematical symbols in the interpretation of tabular data. A table of data on housing in the city of Covington was presented to the students. The data was arranged by wards and by years. (Study Guide No. 6). Through discussion, symbols were suggested to designate the number of dwelling units in a ward for a given time period. Students then assigned symbols for other wards for other time perlods. Conclusions were stated. by students as a series of formulas expressing what per cent the number of dwelling units in a given ward was of the total in the city during a given time period. The study guide is reproduced below:

Study Guide No. 6

Reaching Conclusions

The data below give information concerning the number of dwelling units in Covington and the years in which they were built.

Dwelling Units in Covington By Year Built

\begin{tabular}{l|r|r|r|r|r}
\hline \multirow{2}{*}{ Year Bullt } & \multicolumn{4}{|c|}{ Waras } & \multirow{2}{*}{ Totals } \\
\cline { 2 - 6 } & \multicolumn{1}{|c|}{1} & 2 & 5 & 6 & \\
\hline 1899 or earl1er & 865 & 1406 & 1313 & 1862 & 8159 \\
1900 to 1919 & 243 & 290 & 2572 & 1819 & 5627 \\
1920 to 1929 & 29 & 52 & 1558 & 914 & 2867 \\
1930 to 1940 & 3 & 13 & 236 & 110 & 416 \\
\hline Totalg & 1140 & 1761 & 5679 & 4705 & 17069 \\
\hline
\end{tabular}


1. Make appropriate graphs of the data given in the table or portions of 1 t.

2. What observations can you make concerning dwelling units in the entire city and in the various wards? (Is Covington a city of old homes or new homes?)

3. We can also reach conclusions by making a series of statements in the following manner:

Before 1900 the number of dwelling units in ward 1 was $10.6 \%$ of the total dwelling units in covington. $w_{1 a}=.106 n_{1}$, where $w_{l a}^{o r}=$ the number of dwelling 1900 .

$$
\begin{aligned}
n_{1}= & \text { the total number of } \\
& \text { dwelline units in Covins- } \\
& \text { ton before } 1900 .
\end{aligned}
$$

Using this system of symbol1sm, what would the followlng symbols represent? " $I b$ ' $w_{2 c}$, $n_{2}$

4. Make a few conclusions of the type described in question 3 above.

A bar graph on the number of private and government employees in the United States was used by the instructor to formulate a series of interpretative statements. (Study Guide No. 7). Some of the statements were reasonable interpretations and the others were unreasonable statements because of unwarranted extrapolations or interpolations or because of irrelevance.

Both groups made creditable evaluations of all statements with the exception of those involving ratios, those which were interpolations, and an irrelevant statement. About 45 per eent of the students accepted absolute statements involving interpolation and 66 per cent accepted an 
Irrelevant statement as a valid interpretation of the data. The statements were discussed extensively with the groupg and the dangers of accepting interpolations and irrelevant statements were noted.

A series of circle graphs on "How the Consumer spent His Dollar" was presented to the students for free interpretation. (Study Guide No. 8). The interpretations were summarized for each group and the refined statements from group 1 were given to group 2 about two weeks later for student evaluation. (Study Guide No. 17). In like manner, the statements from group 2 were given to group 1. About half of the statements were extrapolations and in most instances students considered the amounts spent by the consumer for various 1tems as prices. Many attempted to assign causes to increases or decreases in amounts spent for an item, as the following statements attest:

Food prices went down until the shortage, then they went up again.

Due to rent control there were very little changes in rent.

The average man spent most of his money for food in 1949, so he had no money to buy clothing for his family.

Attempts were made to help students understand the characteristics of tabular data with respect to rate of change. (Study Guide No. 10). They were first given a set of data on accidental deaths due to motor vehicles by five year periods. Studenta computed the change in years and the 
change in number of deaths. They were then asked to compute the change per year assuming that the frequency of deaths was evenly distributed over each five year period. They were shown that the change per year was equivalent to the rate of change. After tabulating the rate of change for each interval and identifying decreases by means of negative signs, students were guided in using the rates of change as a basis for reaching conclusions concerning accidental deaths due to motor vehicles. The study guide is shown below:

$$
\begin{aligned}
& \text { Study Guide No. } 10 \\
& \text { Studying Data }
\end{aligned}
$$

The table below gives information on accidental deaths from motor vehicles in the United States.

\begin{tabular}{|c|c|}
\hline Year & Deathsis \\
\hline $\begin{array}{l}1913 \\
1918 \\
1923 \\
1928 \\
1933 \\
1942\end{array}$ & 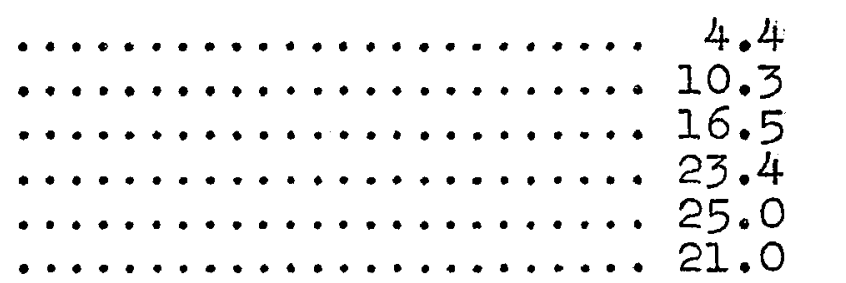 \\
\hline
\end{tabular}

Accidental Deaths From Motor Vehicles

* Rate per 100,000 people

Ve can study the table by comparing the change in time with the change in the number of deaths. For example, from 1913 to 1918 there is a change, which is an increase of 5 years. The corresponding change in deaths is $5.9(10.3-4.4)$. Is this change an increase or decrease?

Find the other changes in years and the corresponding change in deaths. Record your results in the table below, placing a plus $(t)$ sign before numbers which represent increases and 
a minus: (-) sign before numbers which represent decreases:

\begin{tabular}{c|c|c|c}
\hline Years & $\begin{array}{c}\text { Change in } \\
\text { Yeaxs }\end{array}$ & $\begin{array}{c}\text { Change in } \\
\text { Deathe }\end{array}$ & $\begin{array}{c}\text { Rate of } \\
\text { Change }\end{array}$ \\
\hline 1913 to $1918 \ldots \ldots \ldots$ & 5 & 5.9 & \\
\hline 1918 to $1923 \ldots \ldots$ & & & \\
\hline 1923 to $1928 \ldots \ldots \ldots$ & & & \\
\hline 1928 to $1933 \ldots \ldots$ & $\ldots$ & & \\
\hline 1933 to $1938 \ldots \ldots$ & & & \\
\hline 1938 to $1942 \ldots \ldots \ldots$ & & & \\
\hline
\end{tabular}

At the end of the firgt 5 years (in 1918) there was an increase of 5.9 deaths over the number of deaths in 1913. Assuming that the number of deaths increased redularly each year, what is the change per year during this period? This increase is called "rate of change".

Find the rate of change for the other periods and record them in the last column of the table above.

What conclusions can you make concerning the rates of change in accidental deaths due to motor vehicles?

Most of the students confined their conclusions to statements concerning the variation in the rate of change. One student stated the per cent that the death rates for one period were of another period. Several students extrapolated by assigning causes for the increase in rates of change:

There are a lot of careless drivers.

Drivers should be more careful and people should look twice before crosing the streets.

The death rate increased because there were more motor vehicles on the road between 1913 and 1928 and then decreased with the coming of traffic and safety laws from 1928 to 1942 and then increased because of a greater number of vehicles. 
The increased rate of accidents was due to the lact of an increased production of automobiles causing more reckless drivers.

I think the people who have accldents are mostly drunk or don't have good brakes.

In class discussion, attention was directed to the lack of a basis in the data for supporting the proposed causes. Students were reminded thet the conclusions must be limited to their observation concerning rates of change in accidental deaths. The conclusions above were analyzed by the class to determine whether or not they were within the prescribed limits. With this direction most of the students saw that the statements were irrelevant since no facts were presented In the data to substantiate the conclusions.

For contrast, a set of data was presented on wages earne ed by the hour. (Study Guide No. 11). After computing tine rate of change over 5 hour intervals, students were asked to express the relation between hours worlred and wages earned. The study guide was presented as follows:

\section{Study Guide No. II}

Studying Data

The following table shows the relation between wages recelved by a worker and the number of hours he works:

\begin{tabular}{c|c|c|c|c}
\hline Hours & Wages & $\begin{array}{c}\text { Change in } \\
\text { Hours }\end{array}$ & $\begin{array}{c}\text { Change in } \\
\text { Wages }\end{array}$ & $\begin{array}{c}\text { Rate of } \\
\text { Change }\end{array}$ \\
\hline 0 & Wo.00 & & & \\
\hline 5 & 4.50 & & & \\
\hline 50 & 45.00 & & & \\
\hline
\end{tabular}


Compute the change in hours for each interval and record in the table above.

Compute the change in wages for each interval and record in the table above.

Compute the rate of change for each interval and record in the table above.

You will note that the rate of change for the first interval is multiplied by the total number of hours, the answer

( 4 . 40) represents the total wages. Is this true for every interval in the table?

What is the relation between hours worked and wages earned? Most of the students stated that the wages earned increased as the number of working hours increased. Some' stated that the wage always equalled the product of the rate of change and the number of hours worked. One student decided that the wages were "reasonable for the number of hours worked". In class discussion it was shown that a formula could be used to express the relation because of the constant rate of change. This was compared with the previous work on accidental deaths where no formula could be used because of the irregular rates of change.

The work on these two setg of data (on deaths due to motor vehicles and on wages) was further clarified when the students drew bar graphs for each set, noting the irregular changes in lengths of the bars representing deaths due to motor vehicles and the regular, stair step arrangement of the bars representing wroses. (Study Guide No. 12)

When asked how the graphs differed, students gave various answers. Following are some selected statements: 
The two graphs differ in appoarance.

The graph on wages has even steps; the graph on deaths has uneven steps and they are out-of-order.

The accident graph increases and then decreases, but the wage graph goes up step by step.

The wage graph increases all the way up, but the accident graph has an increase and then a decrease.

The graph on wages is like a set of even steps, and the graph on accidental deaths is like uneven houses, side by side.

Most students noted that:

(1) The lengths of the bars for the graph on accidental deaths varied in the same manner and at the same points as the rate of change.

(2) The bars for the graph on wages increased by the same amount and that the rate of change "remained the same".

In a plackboard discussion the instructor suggested that a line graph be used instead of the bars by connecting the upper corners of successive bars. The response of the group to the straight line of tike wage graph was one of pleasant surprise. The group was then shown that in instances where a constant rate of change was obtainable from the data a definite generalization expressed as a formula could be obtained.

The terms variable, dependent variable and independent variable were clarified as the groups studied a table of data on reaction distance when applying the beakes of a car. (Study Guide No. 13). The effect of doubling the independent variable was derived inductively. After answering specific questions involving the doubling of speeds, (e.8., "when the 
speed is increased from 20 to $40 \mathrm{mph}$, what happene to reaction distance?") pupils were asked to generalize the relation between reaction distance and the doubling of speed. Most of the students stated that, "If speed is doubled, then: reaction distance is also doubled": Three students concluded that reaction distance "Increased" when speed is doubled. One student could only conclude that "speed increased". Five students could reach no conclusions. The term slope was substituted for rate of change and students were able to further confirm the conclusions previously reached concerning straight Iine graphs and functional relations in the guise of formulas.

Additional study guides $(14,15,16)$ were used to give further practice in distinguishing between approxinate relations and functional relations through computing rates of change in tables of data. Further practice was obtained in

1. Identifyins independent and dependent variables

2. Deriving formulas and verbal statements or conclusions from data.

3. Interpolation and extrapolation.

4. Determining the effect on the dependent variable by doubling or halving the independent variable.

Study Guide No. 15 was concerned with a study of the relation between the diameter and the circumference of a circle. Although most of the students were familiar with the values 3.14 and $31 / 7$ as used in junior high school textbooks, none of them considered these numbers as ratios. 
There was preliminary discussion in which the groups decided upon the type of data needed to solve the problem (the relation between the distance around a circle and the distance across a circle) and the method to be used in securing the data. No one seemed to have any ideas for securing the needed data until the instructor suggested using a ruler to find the greatest distance across a number of circular discs of various sizes. For securing the distance around each disc one pupil suggested using a string. Another suggested using a tape: measure. The instmuctor suggested as a third method that a mark be placed at some point on the outer edge of the disc and that the disc be rolled along the desk top, marking the point at whith the mark touched the desk top two successive times. The distance between the two marks on the desk would be the distance around the disc.

Each student measured such objects as jar tops, tobacco cans and fruit juice cans. The data were recorded in a table and finally each was agked to compute the ratio of the "distance around" to the "distance across". Most of the students experienced difficulty with the problems which involved reducing ratios of the following types to decimal numbers: $6: 17 / 8 ;$ i3 : $4 \frac{1}{3} ; .153 / 4: 5$ 1/8; $15 \frac{1}{4}: 43 / 4 ; 245 \%:: 73 / 4$. After reducing the ratios, the average ratio was computed and was found to range from 2.7 to 3.5. For the final value, the instructor, in the blackboard discussion, recorded each student's average. The 
average of the values was computed by the group. For group 1, the average value was 3.1 and for group 2, 3.2.

The many types of errors in measurement were discussed and the following possible sources of error were listed:

1. Differences in elasticity of string.

2. Differences in stress applied to tape measure or string.

3. Errors in reading scales.

4. Errors in division when computing ratios.

5. Errors in addition and division when computing average ratio.

When asked to use the average ratio in reaching conclusions concerning the relation between "distance around" and "distance across", the following typical statements were made:

The distance around equals 3.2 times the distance across.

The ratio of the distance around to the distance across is 3.2 .

The distance across times 3.1 will give you the distance around.

The distance around divided by the distance across will give you 3.2 .

Divide the distance around by the distance across each time and you will get about the same value.

The distance around can be found by multiplying 3.2 times the distance across.

The distance around a circle is three and a fraction times the distance across the circle.

The symbol, $\pi$, was substituted for the value 3.2. The 
terms diameter and circumference were substituted for the terms "distance across" and "distance around" and the conclusions were restated uging the new terms. Finally the general, verbal statements were condensed to formulas.

Students were also given some information on the historical aspects of pi. The accepted value 3.14 was discussed, as well as: (I) the value used during Biblical times, 3; (2) the value which an Indiana legislator attempted to legalize in 1897, 3.2; and (3) the value commonly used in junior high textbooks, $31 / 7$.

UNIT .TWO --EXTENDING THE NUMBER SYSTEM.

The second un1t, "Extending the Number System" was concerned with giving students command of the fundamental operations with directed numbers and a knowledge of the procedure followed in solving condttional equations. One of the first considerations of the students was a study of opposites (Study Guide No. 18). The purpose of this study was to give students a sensitivity for opposites and to set the stage for the introduction to directed numbers. It also helped to give the feeling that directed numbers are not isolated and theoretical abstractions but are real and necessary components in the vocabulary of today's citizen. In a study guide developed for the study of opposites, students were given 10 sets of antonyms. They then were asked to give the opposite to each word in another series of words. Following are examples of negative responses by some of the stu- 
dents in: listing word having opposite meanings to the given: word in the left column of Table II.

TABLE II

Negative Responses In Listing of Antonyms

\begin{tabular}{|c|c|c|c|c|c|c|}
\hline \multicolumn{2}{|c|}{ Given Word } & Words & Suggested & \multicolumn{2}{|r|}{ s Opposite } & In Meaning \\
\hline Grief ... & ... & take & heavy & & slow & sorrow. \\
\hline Stupid & ... & nice & foolish & & aumb & deficient \\
\hline Hole & $\ldots$ & $\begin{array}{l}\text { level } \\
\text { filled }\end{array}$ & $\begin{array}{l}\text { solid } \\
\text { ditch }\end{array}$ & & $\begin{array}{l}\text { part } \\
\text { hollow }\end{array}$ & $\begin{array}{l}\text { half } \\
\text { let go }\end{array}$ \\
\hline Apology & $\cdots$ & $\begin{array}{l}\text { reject } \\
\text { fable }\end{array}$ & $\begin{array}{l}\text { angry } \\
\text { purposely }\end{array}$ & & $\begin{array}{l}\text { right } \\
\text { silence }\end{array}$ & $\begin{array}{l}\text { not sorry } \\
\text { sorry }\end{array}$ \\
\hline Reward & $\cdots$ & $\begin{array}{l}\text { giving } \\
\text { bad }\end{array}$ & $\begin{array}{l}\text { keep } \\
\text { withdraw }\end{array}$ & & $\begin{array}{l}\text { gift } \\
\text { receive }\end{array}$ & $\begin{array}{l}\text { receive nothing } \\
\text { money }\end{array}$ \\
\hline withdraw & $\cdots$ & $\begin{array}{l}\text { draw: } \\
\text { keep }\end{array}$ & $\begin{array}{l}\text { continue } \\
\text { add }\end{array}$ & & $\begin{array}{l}\text { Bive } \\
\text { quit }\end{array}$ & $\begin{array}{l}\text { hold } \\
\text { take away: }\end{array}$ \\
\hline Divide & - & take half & part & & whole & keep \\
\hline Reverse & & $\begin{array}{l}\text { don't move } \\
\text { start over }\end{array}$ & $\begin{array}{l}\text { mportant } \\
\text { r backward }\end{array}$ & & $\begin{array}{l}\text { change } \\
\text { straight }\end{array}$ & $\begin{array}{l}\text { turm around } \\
\text { stand still. }\end{array}$ \\
\hline Mianight & - & daylight & morning & & dawm & \\
\hline
\end{tabular}

From the responses it is apparent that these students. were troubled with a number of vocabulary problems:

1. The term "opposite" was often mistaken for "similar", e.8., grief-sorrow, stupid-foolish, stupid-dumb, reward-gift; withdraw-quit, reverse-turn around.

2. Weaknesses in spelling probably accounted for some responses (e.8. hole-part; hole-let go).

3. Lack of a complete understandins of the meaning of "oppositeness" is seen in the following pairs: reverse-don't move or stand still; reward-receive 
nothing; apology-silence; midnight-daylight or morning.

4. Lack of understanding of meaning of the given word 1s indicated in such pairings as: reverse-important; grief-heavy; apology-fable. These different types of errors were discussed with the two classes and the proper opposites were listed.

When asked to list their own pairs of words having opposite meanings the students listed the following pairs. Pairings listed by less than five students are not included: TABLE: 12

Frequency Of Opposites Suggested By Students

\begin{tabular}{|c|c|}
\hline Opposites & Frequency \\
\hline 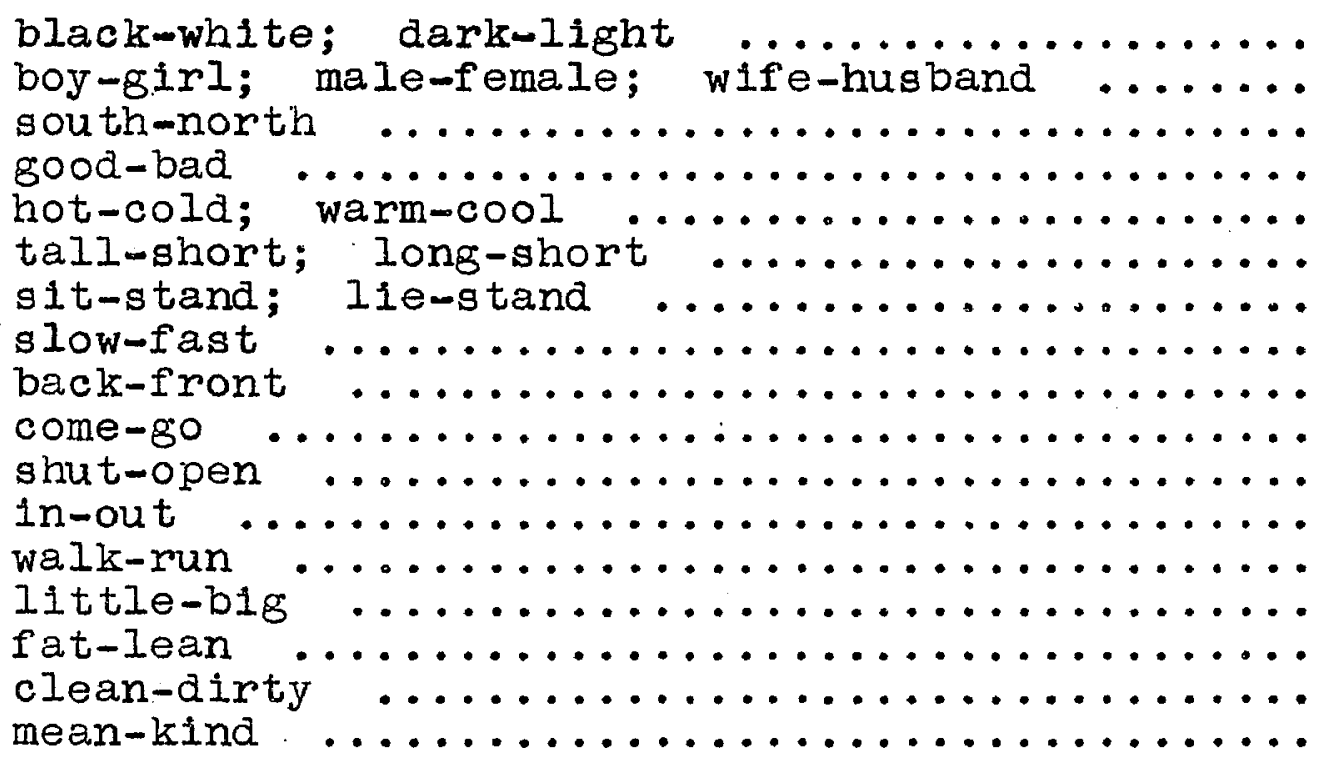 & $\begin{array}{r}30 \\
25 \\
10 \\
10 \\
10 \\
8 \\
7 \\
7 \\
7 \\
7 \\
6 \\
6 \\
6 \\
6 \\
5 \\
5 \\
5\end{array}$ \\
\hline
\end{tabular}

Very few students were able to suggest pairs of numbers having opposite meanings. Nine students gave no response. Most responses were limited to yearly and hourly time as shown in Table 13. 
TABLE 13 ,

Frequency of Number Opposites Susgested By.. Students

\begin{tabular}{|c|c|}
\hline Opposites & Frequency \\
\hline 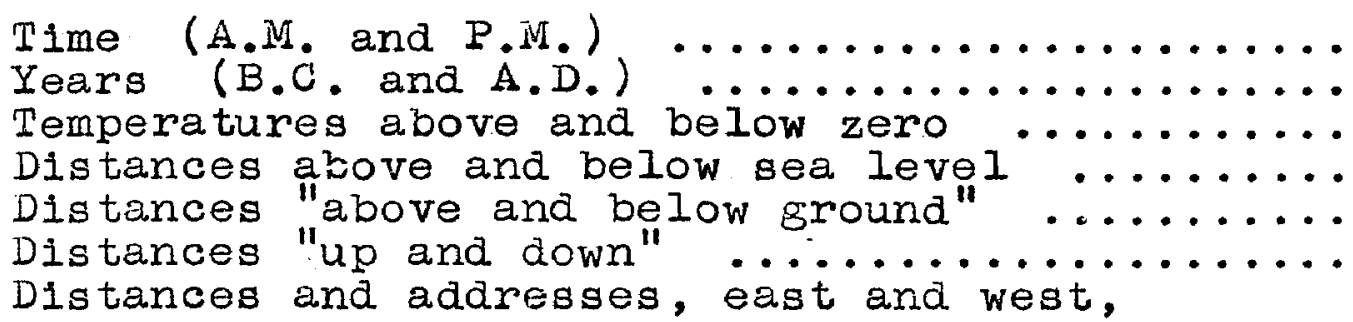 & $\begin{array}{r}12 \\
10 \\
4 \\
2 \\
5 \\
2\end{array}$ \\
\hline $\begin{array}{l}\text { north and south } \ldots \ldots \ldots \ldots \\
\text { Pounds overweight and underweight }{ }_{\text {taller }} \text { than" } \ldots \ldots \ldots\end{array}$ & $\begin{array}{l}4 \\
2 . \\
2\end{array}$ \\
\hline
\end{tabular}

Some students considered the following compinations as having opposite meanings:

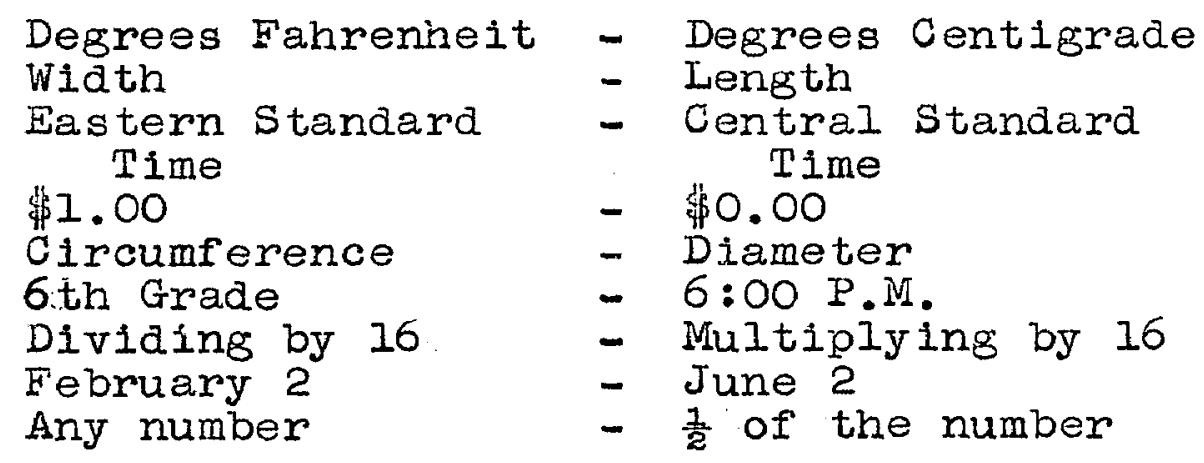

To help students appreclate the power of well-selected symbols, they were given a set of exercises in addition, subtraction, multiplication and division using Hindu-Arabic numerals (Study Guide No. 19). They then were asked to do the same exercises using Roman numerals. The subtraction problem and the two multiplication problems using Roman numerals were hardest to fathom. To subtract XXXV from LXXXII, required converting the latter to the form, XXXXXXXVVII. To multiply XVII by VIII, XVII was written 
eight times and the numbers added. In like manner the multiplication of LXI by XIIX was performed, but most students saw the labor involved and stated what would be necessary to solve the problem.

In answer to the question as to whether they believed Roman children could work problems as easily as we, most students did not believe that they could. As reasons they cited the following:

1. Too many symbols are used in the Roman system.

2. Too much time is required for multiplication.

3. Short cuts are impossible (multiplication).

4. Addition must be used instead of multiplication.

5. Numbers can't be placed in columns.

6. Some larger quantities require few symbols and some small quantities require many symbols.

Eleven students believed that Roman children could work problems with as much ease because it (the Roman system) was the only one with which they were acquainted.

In a series of problems, ldentical amounts were added to and subtracted from a given number (Study Guide No. 20). In another series a given number was first multiplied, then divided by identical amounts. From these exercises students reached the following generalizations concerning the relation between the operations of addition and subtraction and between divigion and multiplication.

1. Addition is the opposite of subtraction.

2. Division is the opposite of multiplication. 
To further orient students before actual introduction to directed numbers, they were given a few novel problem situations as shown in Study Guide No. 21. In answer to the first question concerning James' score who previously had 5 points and lost 6 points, the following scores were Iisted:

TABIIT 14

Student Responses To Problem 1

\begin{tabular}{|c|c|}
\hline Score & Frequency \\
\hline 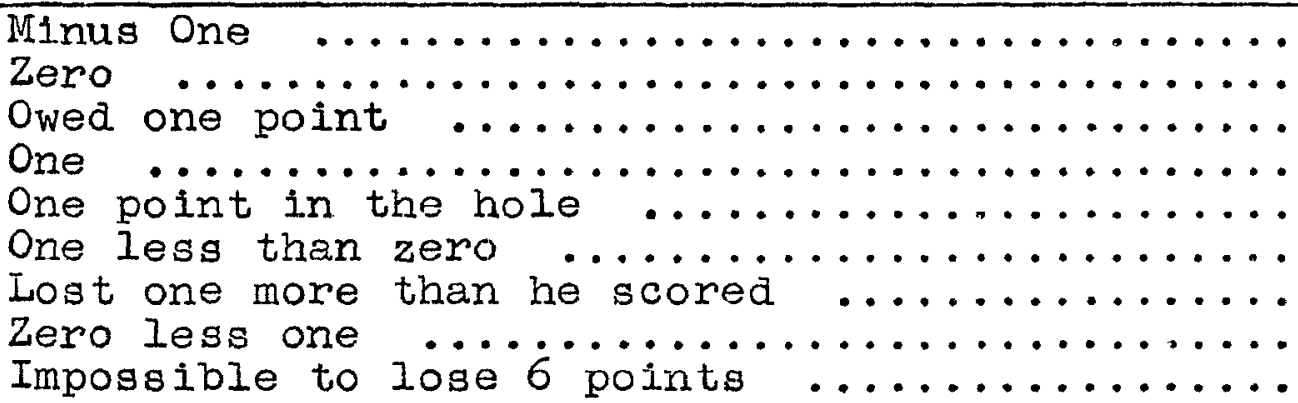 & $\begin{array}{r}10 \\
8 \\
8 \\
6 \\
2 \\
1 \\
1 \\
1 \\
1\end{array}$ \\
\hline
\end{tabular}

Apparently the students were familiar with thermometer readings, since most of them stated that a drop of $12^{\circ}$ from

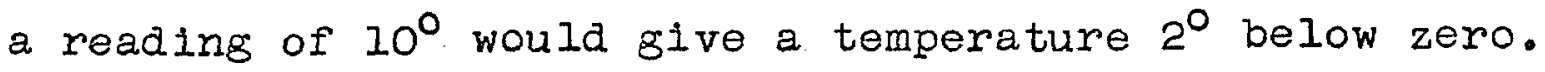
However, 6 students gave the temperature as $2^{\circ}$.

The third problem concerning the bank balance of a depositor who was allowed to withdraw $\$ 100$ from an account of \$75, educed varied responses as is showed in Table 15: One of the students declaring the balance to be zero, explained that the $\$ 75$ had earned 25 per cent interest. This was an example of unwarranted extrapolation, as was shown in class discussion. The conclusion that the "transaction was not 
TABLE: 15

Student Responses to Problem 3

\begin{tabular}{|c|c|}
\hline Depositor's Balance & Frequency \\
\hline 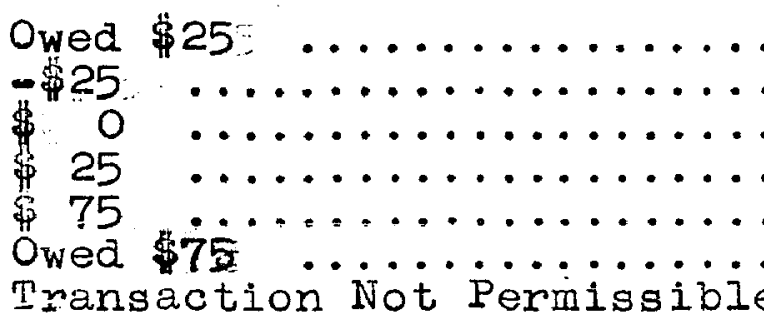 & $\begin{array}{r}20 \\
6 \\
4 \\
5 \\
1 \\
2 \\
1\end{array}$ \\
\hline
\end{tabular}

permissible" was also cited as an illustration of denial of the data.

The fourth query concerning the floor at which an elevator would stop after moving down 8 floors from the sixth floor, elicited the responses as shown in Table 16 (The floor at street level was assumed to be floor ivo. 0):

TABLE 16

Responses of Students to Problem 4

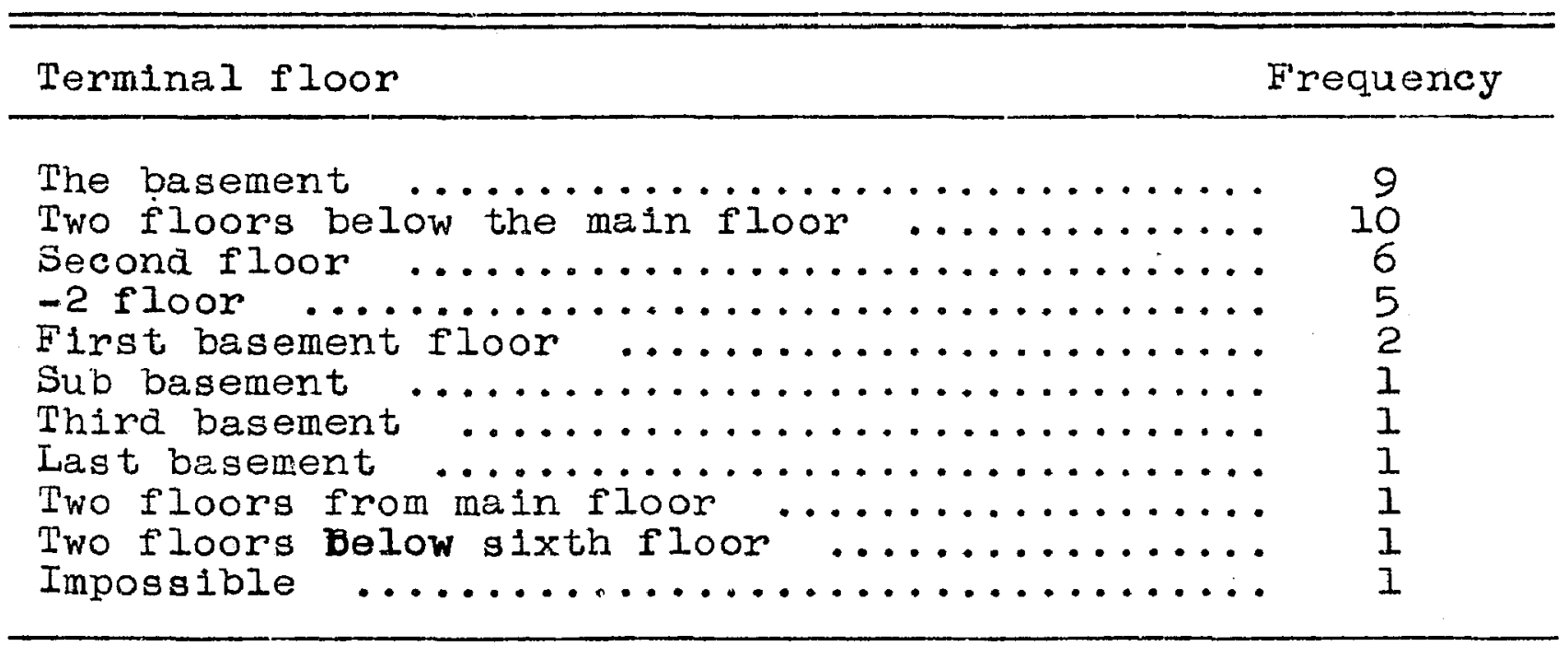

The problem on the date for introduction of circular 
coins which first appeared 2250 years ago, prompted 20 students to give the date as 300 B.C., 2 to say "300 years before the flrst century", and 2 to decide upon the year "300". The following years were listed by individual students: $700,1600,1650,1690$ A.D. and -1770. One student subtracted as follows: $1950-2250=700$. Another subtracted twice: $2250-1950=300 ; 1950-300=1650$. One student decided upon "300 years ago"." and two students gave the year, "300":

In the subtraction problems of question 6 where the subtrahend was larger than the minuend, 26 students either placed a negative sign before the difference or stated that the result was "below zero". Six students made no differentiation between this difference and the differences between a minuend and a smaller subtrabend. Two students considered zero as the difference. Four students gave no response. Fourteen students denied the possibility of always subtracting one number from another although several had answered correctly all of the questions which preceded. The others agreed that subtraction is always possible and explained that when the subtrahend is larger the remainder will be below zero or "minus".

Much discussion centered around the use of negative signg and when asked to give an explanation for the negative signs used, most of the students stated that they indicated amounts that were below zero. 
Another study guide almed at acquainting students with the many uses of directed numbers involved such activities as:

1. Arranging sample thermometric readings, (above and below zero) in order from highest to lowest reading.

2. Arranging a set of historical dates (A.D. and B.C.) in order beginning with the most recent date listed.

3. Arranging a set of gtreet addresses (east and west) in order beginning with the one farthest east.

4. Arranging a set of altitude readings (above and below sea level) in order beginning with the one highest above sea level. (study Guide No. 22).

The most prevalent errors made on this study guide, occurred in the latter part of each arrangement. For example, in arranging temperatures from high to low, the student would arrange all readinga above zero correctly but the "zero" reading and "below zero" readings were arranged in reverse order. Sixteen students made such errors. A second error made by six students was that of arranging the numbers in order from high to low without regard to direction.

The concluding discussion on this study guide gave opportunity for the introduction and illustration of the following terms: positive direction; negative direction; negative number; positive number and absolute value. Each student was also asked to construct a cardboard number scale.

One of the basic understandings with respect to directed numbers is that of quantity or size in relation to position and direction from zero. (Study Guide No. 23). This understanding was developed through a series of specific problems 
in which the student was to select the greater of two given directed numbers and give the position of the larger number with respect to the smaller. Each student used his number scale in solving these problems. Another series of problems directed the attention of students to the smaller of a pair of directed numbers. In this series, the student was asked to give the position of the smaller number with respect to the larger number. Through these gpecific problems, an attempt was made to help students see how position is related to size generally. Although much individual advice was sought by students as they worked on the general statements, very few were able to make general statements concerning the "larger of two numbers generally". Only a few students made statements of the following type:

The larger of two numbers generally is:

1. The one on the right side of zero.

2. The positive number.

3. The one on the right.

4. The number farthest to the right.

Most alleged general statements discussed the largeness of such specific numbers as 5 or 4 with respect to speciflc negative numbers.

Similar difficulty in generalizing was shown when students were asked to describe the smaller of two numbers generally.

The elevator analogy was used to help students develop 
generalizations relative to the addition of positive numbers and positive and negative numbers. (Study Guides 24 and 25). In addition each student used his number scale to check each problem, it being agreed that moving to the right signified addition of positive numbers and moving to the left signified addition of negative numbers. A demonstration number scale was used by the instructor to develop generalizations concerning the addition of negative numbers. In class discussiong on study guides 24 and 25 and as a result of the demonstration on adding negative numbers, the following generalizations were reached:

To add two positive numbers, find the sum of their absolute values and affix a positive sign.

To add a positive number and a negative number, get the difference between their absolute values and affix the sign of the addend having the greatest absolute value.

To add two negative numbers, find the sum of their absolute values and affix a negative sign to the answer.

Subtraction of directed numbers was considered by the additive method. For example, to subtract 5 from 9 , students were asked, "What number added to 5 gives 9?". This method is more reasonable especially when the student is confronted for the first time with the problem of subtraction involving negative numbers. Several examples were illustrated on the demonstration number scale and emphasis was placed upon the assoclation of direction on the number scale with the sign of the number representing the difference between the two numbers. Then, students were given a group 
of 30 problems in subtraction, involving all combinations or directed numbers. To help students reach generalizations concerning the subtraction of directed numbers they were asked to consider the various classes or combinations of numbers (both positive, both negative, a negative and positive) noting for each class the sign of the answer and showing how the absolute value of the answer was obtained. Excerpts from this study guide are given below:

Study Guide No. 26

Subtracting Directed Numbers

We have reached agreements concerning the addition of directed numbers. Suppose we have a given number (say 49 ), and a second number $($ say +4$)$ and we want to know how much must be added to +4 to give us +9 . The number is +5 . This number represents the difference between +9 and +4 .

Using the number scale, we can locate the +4 and count the number of units required to reach +9 and note the direction in which we go. The direction from +4 to +9 is positive, so the difference is +5 .

Using the number scale, answer the following questions: Answer Indicated Operation:

1. What number added to +3 gives +8 ?

7. What number added to +9 gives -1 ?

13. What number added to -6 gives +5 ?

17. What number added to -7 gives -10 ?

21. What number added to +5 sives +2 ?

30. What number added to -12 gives -8 ? 
Some of the problems on the preceding page involve only positive numbers, some involve only negative numbers, while: others involve a positive number and a negative number. Study carefully the results for each class and complete the table below:

\begin{tabular}{l|l|l}
\hline Class & Sign of Result & $\begin{array}{c}\text { Absolute Value } \\
\text { of Result }\end{array}$ \\
\hline Positive Numbers & & \\
\hline $\begin{array}{l}\text { Negative Numbers } \\
\text { Positive Number } \\
\text { and } \\
\text { Negative Number }\end{array}$ & & \\
\hline
\end{tabular}

Using information in the table above write a general statement concerning the nature of the result when finding the difference between:

(a) Two positive numbers

(b). Two negative numbers

(c) A positive number and a negative number

Seventeen students were able to complete the summarizing table in the study guide and in most instances tnis information enabled them to make correct generalizations concerning the method to be used in gettins the difference between any two directed numbers. The following group generalizations (or agreements) were made after much class discussion and illustrations of the problems listed in the study guide:

1. To subtract a negative number from a negative number find the difference between absolute values of the two numbers and affix a positive sign if the subtrahend has the larger absolute value and a negative sign if the minuend has the larger absolute value. 
2. To subtract a positive number from a positive number find the difference between absolute values of the two numbers and affix a positive sign if the minuend has a larger absolute value and a negative sign if the subtrahend has the larger absolute value.

3. To subtract a negative number and a positive number find the sum of the absolute values of the two numbers and affix the sign of the minuend to the answer.

After using these generalizations in the solution of problems, the instructor raised the question of short cuts that could be used in subtracting directed numbers. The conventional mile of changing the sign of the subtrahend and proceeding as in addition of directed numbers was compared with their generalizations. About half of the students used these textbook rules in later problems while the others preferred their own generalizations.

The study guide on subtraction was confusing to some students because of the wide variety of problems included. It probably would be improved if it were presented in two sections-one section to be concerned with subtraction of positive numbers and subtraction. of negative numbers, and a second section to be concerned with the subtraction of a negative number from a positive number and the subtraction of a positive number from a negative number.

To apply their own knowledge of addition and subtraction with directed numbers students were introduced to the conditional equation. This was done through the use of a trip scale. The platforms were balanced with sets of weights and 
then the scale was thrown out of balance by removing a welght from one of the platforms. The instructor asked the group to indicate what was necessary to bring the platforms. back into balance. It was emphasized that an identical weight must be removed from the other platform to restore the balance. Then a small bag of marbles and a two-ounce weight were balanced with a set of weights totaling 8 ounces. This. demonstration was recorded by writing, on the blackboard, the equation, $x+2=8$, where $x$ represented the weight of the bag of marbles. After removing the two ounce weight from the platform supporting the bag, the class was asked to indicate how the scales could be brought back into balance. It was emphasized that identical amounts must be removed from each platform to maintain balance. This was expressed on the blackboard as follows:

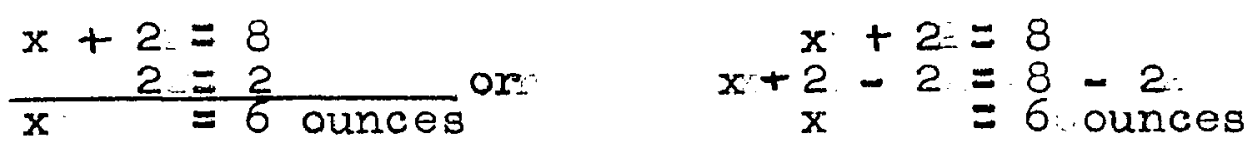

It was emphasized that statements of this type were called conditional equations and that steps similar to those taken in the blackboard demonstration could be followed in solving the equation or finding the value of the unknown term. It was further emphasized that the equality of $x$ and 6 , was the condition necessary for $x+2$ to equal 8 . Students were then given a study guide which repeated the ldeas considered during the blackboard demonstration. (Study Guide No. 27). Three of the questions on this study. 
guide directed the attention of students to a comparison of the operation performed upon the unknown before solution with the operation necessary for solution of the equation. The purpose of this comparison was to show that the operation required to solve the equation was the opposite or inverse of the operation performed on the unknown in the siven equation. Portions of the study guide are reproduced below:

$$
\begin{aligned}
& \text { Study Guide No. } 27 \\
& \text { Using Signed Numbers }
\end{aligned}
$$

Imagine that you have a set of platform scales with the pans balanced by the sets of weights listed below. What would you have to do in order to find the value of the unknown weight and yet keep the pans balanced in each

\begin{tabular}{|c|c|c|c|c|c|c|c|c|}
\hline $\begin{array}{c}\text { Weights } \\
\text { On Left } \\
\text { Pan }\end{array}$ & $\begin{array}{c}\text { Weights } \\
\text { On Right } \\
\text { Pan }\end{array}$ & $\begin{array}{c}\text { Statement } \\
\text { of } \\
\text { Equality }\end{array}$ & $\begin{array}{l}\text { Value of } \\
\text { Unknown } \\
\text { Weight }\end{array}$ & $\begin{array}{l}\text { Opera } \\
\text { Order } \\
U_{Y}\end{array}$ & & c. & $\begin{array}{l}\operatorname{ary} \\
\text { lue } \\
\text { ht }\end{array}$ & $\begin{array}{l}\text { In } \\
\text { Of }\end{array}$ \\
\hline • & - & - & - & - & - & - & 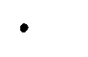 & - \\
\hline $\begin{array}{l}\text { p-gram } \\
5 \text {-gram }\end{array}$ & 10-gram & & & & & & & (d) \\
\hline • & • & - & - & • & - & - & • & - \\
\hline 7 -gram & $\begin{array}{l}\text { X-gram } \\
\text { 3-gram }\end{array}$ & & & & & & & (f) \\
\hline • & • & • & - & - & - & ${ }^{\circ}$ & - & - \\
\hline $21-g \mathrm{ram}$ & $\begin{array}{r}11-8 \mathrm{ram} \\
r-8 \mathrm{ram}\end{array}$ & & & & & & & $(\mathrm{h})$ \\
\hline
\end{tabular}
case?

I. What operation has been performed on the unknown weight in examples $d, f, b$, and $h$ above?

2. When weights are removed from one pan of the balance to find the value of the unknown weight, what else must be done in order to keep the pans balanced?

3. To what mathematical operation does the removal of the welght correspond-addition, subtraction, multiplication or division? 
4. How do your answers to questions 1 and 3 compare?

5. In equations (statements of equality) like $d, 8, f$ and $h$ above, what must be done to find the value of the unknown term?

In response to question No. 5, the following statements typify the thinking of the majority of the students:

1. "Subtract the two known numbers to get the unknown":

2. "You subtract to find the value of the unknown".

3. "Subtract the amount that has been added to the unknown number, from the known number".

4. "Subtract the Ieft member from both members of the equation".

5. "Subtract equal amounts from both sides of the equation".

6. "Subtract as much from both sides as has been added to the unknown".

In class discussion of the statements above, and through blackboard demongtrations of the solution of equations as directed by each $\mathrm{statement,} \mathrm{students} \mathrm{saw} \mathrm{the} \mathrm{inadequacy} \mathrm{of}$ the first five statements. Statement 6 , was considered adequate and it was restated as the following arreement:

To solve equations of the type, $x+5=9$, take as much from both members of the equation as has been added to the unknown term.

Conditional equations of the type, $x-a=b$, were illustrated through a number of word problems which were consiciered in a class discussion. Following are sample problems: "What number with three taken away equals 10?" "John has a number of marbles. He gave away 6 and had 8 remaining. How many did he have before giving away the $6 ?$ 
As students quickly answered the questions, the corresponding equations and their solutions were written on the blackboard:

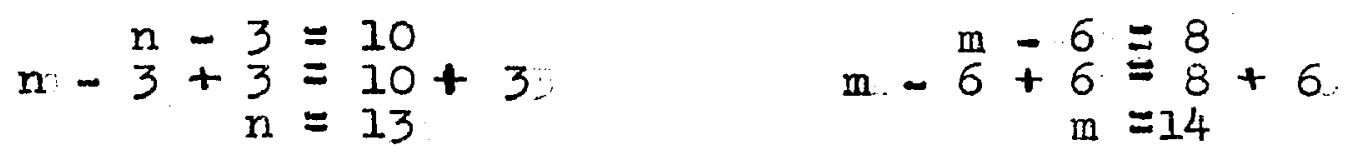

Students were reminded of the fact that they were again dealing with an equation where the "balance" must be maintained and that in this situation equal amounts must be added to both sides of the equation.

Finally the following problem was Given: "What number with "a" taken away equals "b"? " Bewilderment subsided for some as the teacher reminded the class of the steps taken in the solution of the other equations. A more alert student stated that " $a$ " must be added to both members of the equation. The solutions were written on the black board:

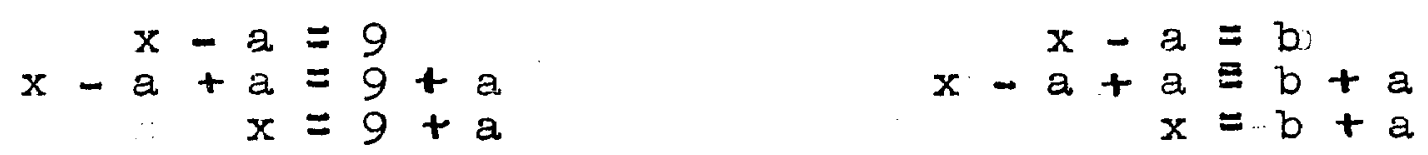

From these solutions the group was guided by the instructor to make the following generalizations:

"To solve equations of the type $x-3=8$, add the amount that was subtracted from the unknown to each side of the equation".

Multiplication of directed numbers was considered as a special phase of addition of directed numbers. For example, if +4 is multiplied by +3 it is equivalent to adding +4 to zero, three times, or the multiplication of -3 by +2 is equivalent to adding -3 to zero, two times. Students were 
given seven problems each involving the multiplication of a positive number by a positive number and a negative number by a positive number. (Study Guide No. 28). They were asked to state the equivalent addition and the product. They were asked then to generalize the multiplication of these numbers. The study guide was presented as follows:

Study Guide No. 28 Multiplying Signed Numbers

When we multiply +4 by +3 we are really adding +4 three times beginning at zero. In fact multiplication is rapld addition. Starting at zero on the number scale, we ada +4 once by moving over to +4 . Adaing +4 two more times, we move to +8 and then to +12 , which is the product of $(+4) \times(+3)$.

Similarly what does $(-3) \times(+2)$ mean? Starting at zero on the number scale, we add __ once by moving over to __. Adding ___ one more time, we move to which is the product of $(-3) \mathrm{x}(+2)$.

Using the number scale try to solve the following problems. The first problem has been solved as an illustration of what you are to do. Equivalent Pró- Explanation Addition uet

1. $(+4) x(+3)$ or $4+4+4=+124$ has been added to 0 , 3 times.

2. $(+6) \times(+3)$

$\dot{6} \cdot(\dot{n}) \cdot x(+\dot{5}) \cdot$

7. $(+n) \times(+m)$

i2. $(-3 j x \dot{x}(\dot{6}) \cdot$

13. $(-n) \times(+7)$

14. $(-n) x(+m)$

Study the results in the problems above and try to make general statements concerning a rapid method for multipliting: 
(a) Two positive numbers

(b) A negative number by a positive number

Twenty-three students made the generalization that "The product of two positive numbers is positive". However, only eighteen students correctly generalized the multiplication of a negative number by a positive number. General statements of the other students directed one to affix to the product "The sign of the number having the greater absolute value", "The sign of the number that has been added" and "The sign of the top number".

In considering the multiplication of a positive number by a negative number, and the product of two negative numbers, the equivalent reault by subtraction was demonstrated to the groups. For example, multiplying +4 by -3 is equivalent to subtracting +4 from 0 , three times. This operation was illustrated on the number scale by moving left from 0 to -4 (the first subtraction), thence to -8 , (the second subtraction), and finally to -12 (the third subtraction). Which represented the product of +4 and -3 .

In I1ke manner the product of -4 and -3 was considered as equivalent to subtracting -4 from 0 , three times. For subtraction on the number scale one would move to the right, opposite the direction for adding negative numbers. Students then solved twelve specific problems using their number scales. (Study Guide No. 29). Although the majority of the class solved these problems correctly, only fourteen 
146.

were able to generalize their results.

In class discussion of this study guide the following agreements were reached:

"When a positive number is multiplied by a negative number, the product is negative". $(+a) \times(-b):=-a b$.

"When two negative numbers are multiplied, the product is positive". $(-a) x(-b)=+a b$.

The demonstration number scale was used to review our agreements concerning addition and subtraction of signed numbers. A summary was made with the following diagram: On The Number Scale

\begin{tabular}{c|c}
\hline \multicolumn{1}{c|}{ Left } & \multicolumn{1}{c}{ Right } \\
\hline Add negative $(-)$ numbers & Add positive $(+)$, numbers \\
$\begin{array}{l}\text { Subtract positive }(+) \\
\text { numbers }\end{array}$ & $\begin{array}{l}\text { Subtract negative }(-) \\
\text { numbers }\end{array}$
\end{tabular}

The four cases of multiplication were again illustrated with the following examples:

$$
\begin{aligned}
& (+5) \times(+3)=0+(+5)+(+5)+(+5)=+15 \cdot(+a) x(+b)=+a b \\
& (-5) \times(+3)=0+(-5)+(-5)+(-5)=-15 \cdot(-a) x(+b)=-a b . \\
& (+5) \times(-3)=0-(+5)-(+5)-(+5)=-15 .(+a) \times(-b)=-a b . \\
& (-5) \times(-3)=0-(-5)-(-5)-(-5)=+15 .(-a) \times(-b)=+a b .
\end{aligned}
$$

Through an ingpection of the general identities, ( $+a) x$ $(+b)=t a b$, etc., the classes' previous generalizations concerning multiplication of signed numbers were revised as follows:

When two numbers with like signs are multiplied, the product is positive. 
When two numbers with unlike signs are multiplied, the product is negative.

After generalizations were reached in the study of each operation, students were assigned problems from a textbook (Betz, First Year Algebra) which were applications of their generalizations.

Division of directed numbers was considered as a check upon multiplication or as the inverse of multiplication. It was approached through class discussion in a manner similan to the beginning paragraph of study Guide ivo. 30:

We have agreed that $(+5) \mathrm{x}(+3)=+15$. From this it follows that if we divide the product, $(+15)$ by either of the two factors, $(+5)$ or $(+3)$, our quotient will be the other factor. That is, $+15=+5$ or $\frac{+15}{+5}=+3$.

After solving a group of 32 problems as checks on 16 mult1plication problems, nineteen students were able to generalize their work in division in four statements:

1. Dividing a positive number by a positive number

2. Dividing a negative number by a positive number

3. Dividing a positive number by a negative nuraber

4. Dividing a negative number by a negative number

Seven students correctly made three general statements or less, and seven students made no attempt to generalize.

Solutions of equations of the type $a x=b$ and $x / a=b$ were studied through demonstrations on a set of platform balances. For the former type, sets of identical weights were balanced by a single weight. Questions of the following type were asked the group: "If five identical weights weigh 100 grams, how much does one of them weigh? The question 
and the answer were symbolized as follows:

$$
\text { If } 5 x=100 \text {, then } x=20 \text {. }
$$

For the latter type of equation, a transparent plastic box graduated in fifths was balanced on the scales. It was then filled one-fifth full of sand and the sand was weighed. The following question: was asked: If one-fifth of a box of sand weighs 125 grams, how would you determine the weight of a full box without adding more sand? The question and the answer were symbolized as follows:

$$
\text { If } 1 / 5 x=125 \text {, then } x=625 \text {. }
$$

After many demonstrations, the following generalizations were reached:

When solving equations of the type $a x=b$, divide the number multiplying the unknown, into both sides of the equation.

When solving equations of the type, $x / a=b$, multiply both sides of the equation by the number dividing the unknown.

$$
\begin{array}{rlrl}
a x & =b & \frac{x}{a}=b \\
\frac{a x}{a}=\frac{b}{a} & \frac{a x}{a}=a b . \\
x=\frac{b}{a} & x=a b .
\end{array}
$$

This unit on the use of numbers was concluded with a study of conditional equations whose solution required two or more operations. In class discussion equations of the following types were presented for solution:
(a) $2 x+5=13$
(b) $3 x-6=18$

The class was first asked to name the things that had 
been done to the unknown in equation (a). (It has been multiplied by two, and five has been added to it). By review of the solutions for $x / a=b$ and $a x=b$, it was suggested that 5 be subtracted from both sides and that the resulting nembers be divided by two. These suggestions were listed as follows:

$$
\begin{aligned}
2 x+5-5 & =13-5 \\
2 x & =8 \\
\frac{2 x}{2} & =\frac{8}{2} \\
x & =4
\end{aligned}
$$

Equation (b) was discussed in like manner, After two class periods devoted to solving equations similar to (a) and (b) above, the solutions of equations of the type, $\frac{x}{a}+b=c$, were considered. The work on conditional equations was summarized through study Guide Nio. 31, where the equation $\frac{5}{4} n+2=12$ was "built" by the student. The operations required for its construction were identified and the inverse of each of these operations was listed. Through performing these inverse operations in reverge order upon the members of the equation, the value of " $n$ " was found. The study guide is shown below:

Study Gulde No. 31 The Conditional Equation.

Consider an unknown term "n".

1. Multiply $\mathrm{n}$ by 5 .

2. Divide this expression by 4

3. Add 2 to the expression in (2)

4. Let the expression in (3) be equal to twelve. 
5. The expression in (4) represents a conditional equation. The conditions are expressed in statements (I) timrough (4) above. The conditions are that $\frac{5 n}{4}+2$ has a value of twelve provided we do certain things to $n$. What are these things? a.

$$
\text { c. }
$$

6. In order to determine the value of " $n$ " we would have to perform the inverses (opposites) of those operations listed in (5) above. What are the inverses of the operations which you listed above?

The inverse of 5 a.

The inverse of $5 \mathrm{~b}$.

The inverge of $5 \mathrm{c}$.

7. Try to perform the inverse operation of " $\mathrm{c}$ " on the equation listed in (4). (Note: You must perform the same operation to both members, if the relation between the two members is to be preserved).

8. Perform the inverse of $5 \mathrm{~b}$ on the above answer.

9. Perform the inverse of 5 a on the above answer.

10. What then is the value of $n$ ?

11. What general statement can you make concerning the procedure to follow in solving a conditional equation?

From this illustration 24 students were able to generalize the solution of equations of this type. The usual generalization made by students was that the solution of equations of the type $\frac{5 n}{4}+2=12$, requires the use of operations Which are the opposite or inverse of those already performed on the unknown term. One student decided that. "when you have a conditional equation, you subtract, divide and multiply if the unknown has been divided, multiplied and added to 
151

previously". This statement was the basis for enlarging tine conclusion of the group to the statement that the solution of a conditional equation requires the performance preferably in reverse order of the operations which are the opposite of the operations already performed upon the unknown.

UNIT THREE - APPROXIMATE AND FUNCTIONAL RELATIONSHIPS

In the tinird unit titled, "Approximate and Functional Relationships", students were given further opportunities to understand the methods used for assembling and processing data in order to make valid and useful interpretations. The relations expressed in mensuration formulas were discovered in group discussions following teacher demonstrations. The statistical concepts: mean, median and mode were used in processing raw data on such topics as student attendance and weights and heights of adolescents. Certain raw data were used in curve-fltting and in deriving Iinear equations. Group discussions of geometric figures were the first activities in this unit. The purpose of the discussions was to use group thinking to derive inductively the formulas for areas and volumes of common geometric figures. At the outset students were given opportunities to derive formulas for areas of squares, rectansles, parallelograms, triansles and dircles. Units of measure for length were illustrated and students read such pamphlets as "How Long Is A Rod" 3 and

3. Distributed by the Ford Motor Company, Detroit, Mich. 
152

"The Amazing Story of Measurement" 4 to understand how the different units of length were secured. Students noted the arbitrary manner in which each unit was formulated. A square-inch piece of cardboard was shown and it was explained that mathematicians and others interested in measurement have agreed that any figure occupying an equivalent area has an area of one square inch.

Several rectangles were shown and students were asked to find the area of each. When a pupil suggested that the "square inch" be laid on each figure a number of times, the rectangles were turned over to show the number of squares already drawn on each figure. After one effort at counting the number of squares pupils recalled the more efficient method of multiplying the length by the width.

A similar procedure was followed with several squares. In discussing how to find the area of a parallelogram one pupil suggested measuring the length of the base and the length of a slanting side, and getting the product of their lengths. However, when 1 ts area was compared with a rectangle having the same base and length, the areas were not the same.

A second pupil suggested getting the product of the diagonals, and a third suggested cutting off each end, thus getting two rectangles. Then the teacher suggested cutting Michigan. 
off only one end and placing it adjacent to the other end of the figure.

To find the area of a triangle, several students suggested cutting and rearranging the triangle as follows:
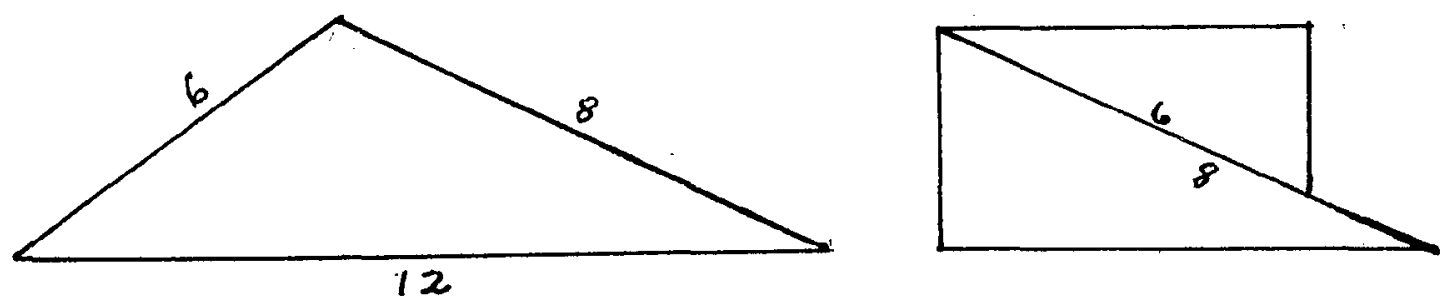

No one could decide what to do with the triangular "tip" which was projecting from the figure. The teacher then suggested using another triangle of the same size and shape to form a parallelogram. It was readily seen that the area of the triangle was one-half the area of the parallelogram having the same base and height.

To derive the formula for the area of a circle, two cardboard discs of equal radii were used. One of the discs was divided into twenty equal segments as shown below and the formula for the circumference of a circle was reviewed.
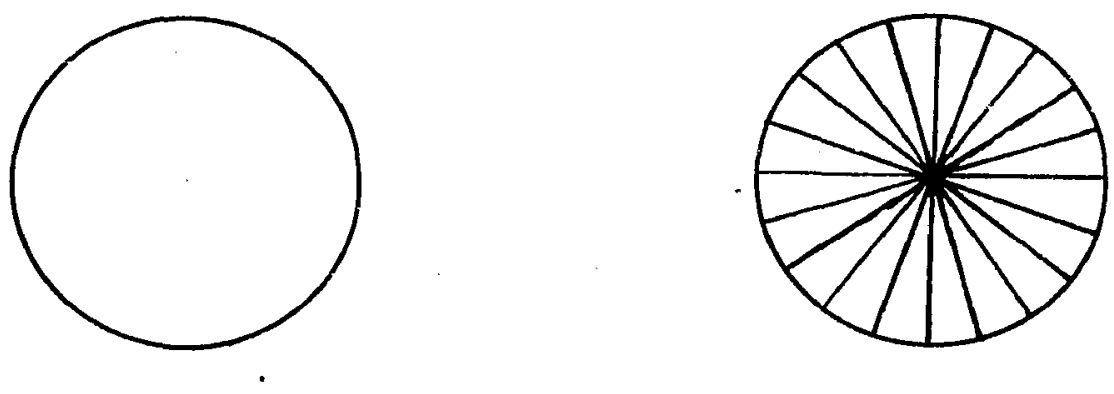
The segments were arranged in the shape shown below and students were asked to compare its shape with other figures that they had studied. Its similarity to the shape of a parallelogram was quickly noted, and it was sugrested that its area be gotten in the same manner as for the parallelogram.

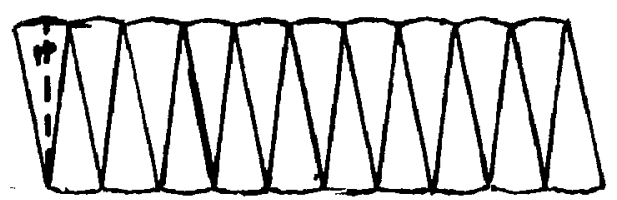

$\frac{1}{2} c$ or $\pi r$

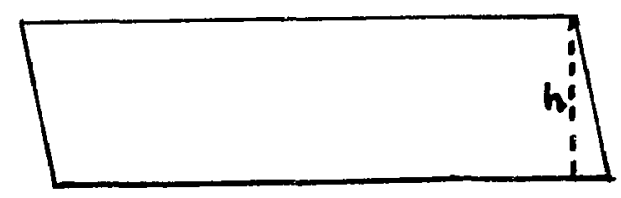

b

The teacher then made the following substitutions in the formula with appropriate explanations.

$$
\begin{aligned}
& A=b h . \\
& A=\pi \cdot r \cdot r \\
& A=\pi r^{2}
\end{aligned}
$$

Formulas for the volumes of cubes, rectangular solids, pyramids, cylinders, and cones were next derived. A plastic cubical box with open top and a paper model of a "cubic inch" were shown to the class. To find the volume, the class inst suggested counting the number of inch-cubes required to fill the box, but quickly changed to the sugsestion that the three dimensions be multiplied.

For the rectangular solid it was pointed out that we were really getting the volume by multiplying the area of the base by the height. 
The volume of a cylinder was derived by substituting in the formula, $V=B h$. A metal cylindrical cup and a conlcal cup of the same base and height were available for study of the volumes of the cone and the cylinder. The cone was filled with water and the contents were transferred to the cylinder. To fill the cylinder, three fillings of the cone were required and from this the group derived the formula, $V=1 / 3 \pi r^{2} h$.

A cardboard model of a pyramid having the same base and height as the cube, was filled with sand and the contents were transferred to the cube. To fill this cube required three fillings of the pyramid. From this the formula, $V=1 / 3$ lwh was derived.

The work on deriving formulas and accompanying practice exercises required tinree weeks.

The study of approximate relationships was initiated through questions dealing with the method used to compute a pupil's general scholastic average. Nost of the pupils were acquainted with the method for computing an average and they were eager to answer such questions as:

What is the average weight of the pupils in this class?

What is the average foot-length of the pupils in this clasa?

What is their average arm-length?

What is their average height?

The terms: mean, median and mode were explained through textbook references (especially Mathematics and Life, Book 3 
by Ruch, Knight and Hawkins).

Each pupil was weighed; his height and the length of his right foot were measured. Weights were rounded to the nearest 10 pounds; heights were rounded to the nearest inch; foot-lengths were rounded to the nearest inch. The data were used by each pupil: to answer the questions above, to gain practice in securing the mean, median and mode, and to note similarities and differences between the three concepts.

A second project dealt with the question, "Which class in our school has the best attendance record?". Attendance data for the months of October and February were presented to each pupil and the question was answered through the following computations:

$$
\begin{aligned}
& \text { Average number of days present } \\
& \text { Average number of days absent } \\
& \text { Average number of times tardy } \\
& \text { Median number of days present } \\
& \text { Median number of days absent } \\
& \text { Median number of times tardy } \\
& \text { Modal number of days present } \\
& \text { Modal number of days absent } \\
& \text { Modal number of times tardy }
\end{aligned}
$$

Much of today's communication is carried on through the display of graphs and tabular data. The various governmental bureaus and departments, manufacturing concerns and other business firms frequently present reports in graphic or tabular form with accompanying interpretations. This indicates that the consumer must become alert to the techniques 
used for presenting and intexpreting data. One of these techniques is that of expressing approximate relations between variables through the derivation of an empirical equation. The purpose of Study Guides 32 through 36 was to introduce this technique. Students had their first experiences in curve fitting through a set of data presenting the monthly weights of a baby boy from birth to age $2 \frac{1}{2}$ years. (Study Guide No. 32). A portion of the study guide follows: Study Guide No. 32 The Relationship Between Age and Weight

The following data give the actual monthly weight in pounds of a baby boy from birth until he is $2 \frac{1}{2}$ years of age:

\begin{tabular}{|c|c|c|c|}
\hline $\begin{array}{l}\text { Age in } \\
\text { Mionths }\end{array}$ & $\begin{array}{l}\text { Weight in } \\
\text { Pounds }\end{array}$ & $\begin{array}{l}\text { Increase } \\
\text { in Weight }\end{array}$ & $\Delta \mathrm{w} / \Delta \mathrm{a}$ \\
\hline 0 & $7 \frac{1}{3}$ & & \\
\hline 1 & $8 \frac{3}{3}$ & & \\
\hline 2 & $10^{\circ}$ & & \\
\hline 3 & $11 \frac{1}{2}$ & & \\
\hline 4 & $13^{\circ}$ & & \\
\hline 5 & $14 \frac{1}{3}$ & & \\
\hline 6 & 16 & & \\
\hline 7 & $16 \frac{1}{3}$ & & \\
\hline 8 & $17^{\frac{1}{2}}$ & & \\
\hline 9 & $18 \frac{1}{3}$ & & \\
\hline 10 & $19 \frac{1}{2}$ & & \\
\hline 11 & $20 \frac{1}{2}$ & & \\
\hline 12 & 21 & & \\
\hline 13 & $21 \frac{1}{2}$ & & \\
\hline 14 & $22^{\sim}$ & & \\
\hline 15 & $22 \frac{1}{2}$ & & \\
\hline 16 & $23^{2}$ & & \\
\hline 17 & $23^{\frac{1}{3}}$ & & \\
\hline 18 & 24 & & \\
\hline 19 & $24 \frac{1}{2}$ & & \\
\hline 20 & $25^{2}$ & & \\
\hline 21 & $25 \frac{1}{2}$ & & \\
\hline 22 & $26^{\circ}$ & & \\
\hline$\cdot$ & 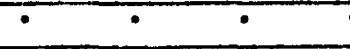 & $\cdot$ & 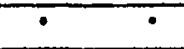 \\
\hline 30 & 30 & & \\
\hline
\end{tabular}


Students graphed the data in the manner shown in Chart 1.

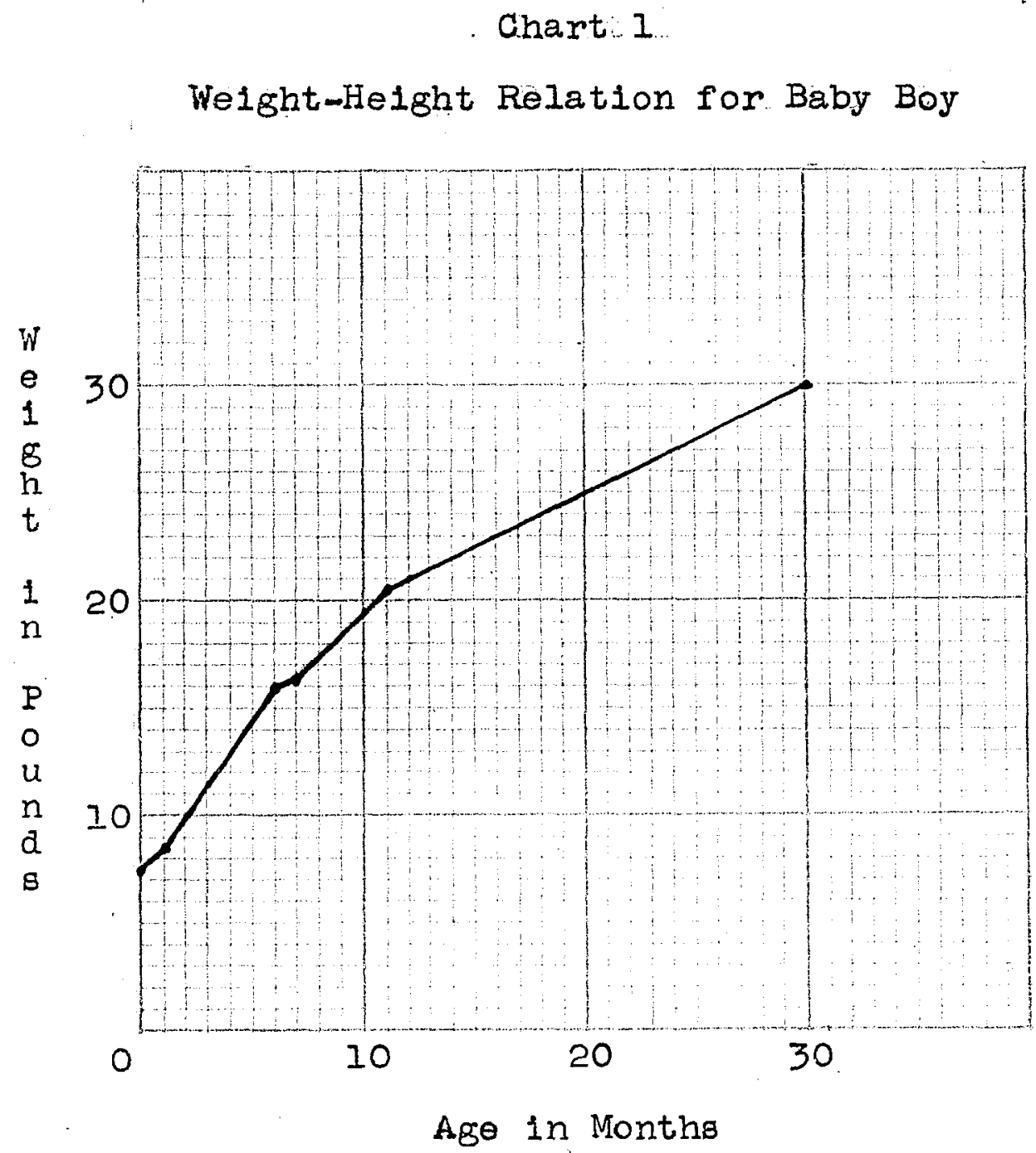

The next step was to help students understand the signiflcance of rate of change and slope. This was done through written explanations and exercises as follows:

2. Add two columns to the table and record opposite the weight, $8 \frac{1}{2}$ pounds, the increase in weight during the first month. (Give this column heading:: Increase in weight).

3. In like manner record the increase in weight for each month. 
4. Between what months are the increases constant (the same)?.

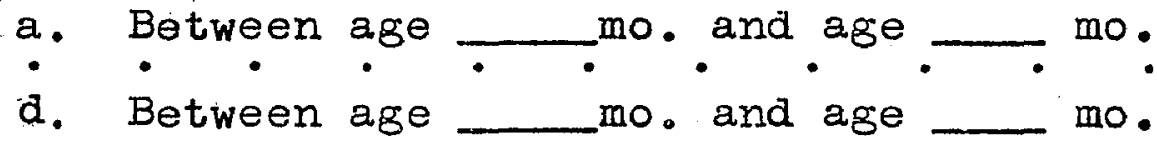

5. How does the graph appear in each of these intervals?

6. In problem 2, what is the ratio of the increase in weight to the increase in age? Record this ratio in the last column. (Give this column the heading, aw/sa, where $\Delta w . . s t a n d s$ for increase in weight and $\Delta a$, increase in age.

7. In like manner, record the corresponding ratios for the other ages.

8. Mathematiclans often analyze data by computing ratios similar to those which you have computed. When dealins with tables of values, they define such ratios as rates of change, and they broaden the definition as follows:

Rate of change $=$ ratio of change of dependent variable to corresponding change of independent variable.

Which of the variables in the table (weight and age) is dependent on the other for its value?

9. When dealing with line graphs, the mathematician also denotes the rate of change by another term. This term is "slope". He defines slope in exactly the same way that he defines rate of change.

Using your graph, note that when "a" changes from two to three, w changes from 10 to $11 \frac{1}{2}$. This can be illustrated by, first, drawing a line parallel to the " $a$ " axis between 1 and 2 and intersecting the line graph. Label this segment, $\Delta a$. Second, draw a line parallel to the $w$ axis between the graph and the end point of $a$. Label this segment, $\Delta w$. Note that $\Delta w / \Delta a$ equals $1 \frac{1}{2} / 1$ or $3 / 2$. Compare this value with the corresponding value of $\Delta \mathrm{w} / \Delta \mathrm{a}$ in the table.

10. Illustrate on the graph how jou would determine the slope between the following points on the a axis:

a. Between 2 and 3. Computed value of slope

b. Between 3 and 4. Computed value of slope 
c. Between 4 and 5. Computed value of slope

d. Between 5 and 6 . Computed value of slope

e. Between 7 and 11. Computed value of slope

f. Between 11 and 30. Computed value of slope

11. What can you conclude about the slope of the graph between 1 and 6 on the "a" axis?

Twenty-eight students were able to state the formula for the interval 1--6, $w=1 \frac{1}{2} a+7$; seventeen for the interval $7--11, w=a+9 \frac{1}{2}$; and fiftewn for the interval $11--30, w=\frac{1}{2} a+15$.

A number of questions were asked which related to extrapolation and interpolation. The questions followed by summaries of student responseg are listed below:

19. Would you be able to predict the weight of this baby boy when he becomes 3 years old? Why?

Eight students replied "15o" and gave the following reasons:

1. The data given in the table only accounta for 30 months.

2. The weight increase varies at different ages.

3. His appetite may increase and thus he may gain more weight per month.

Fourteen students replied "Yes" and gave the following reasons:

4. The table is the guide.

5. He will increase in weight at the same rate as between 12 and 30 months.

6. The graph can be read:

7. We have the increases for every month he has lived. 
In class discussion students agreed that Reason $I$ was the most acceptable reason. Reasons 2,3 , and 5 were equivalent to adding new data for which they had no conclusive evidence. Reasons 4, 6 and 7 were equivalent to extending the given data. The questions which follow were also discussed and the reasons given were evaluated.

20. Would you be able to predict the weight of any 3 year old boy? Why?

Sixteen students replied "No" and gave the following reasons:

1. There is no information on the weight of a.l 3 year old boys.

2. Some babies don't gain weight like others.

3. All babies do not weigh the same at birth.

4. The weight of another 3 year old could be different. Seven students replied "Yes" and gave the following reasons:

5. The data is given in the table.

6. It can be determined by his height.

7. Find how much he gains per month and multiply.

8. If you know the increase in weight according to age.

21. What was the age of the baby when he weighed 20 pounds?

Most students gave $10 \frac{1}{2}$ months as the age.

23. Is the age of any baby the same at 20 pounds? Why?

The 24 students who answered this question responaed "No". As reasons two students stated that the given weights were not for any baby--but for a particular baby. Twelve students stated that "some babies weigh more than others at $10 \frac{1}{2}$ 
months". Six averred that "some babies weigh more at birth": Four students referred to such variables as home, food and inheritance.

24. To what extent should one use caution when using a table of data to determine values of a dependent variable not given in the table?

The following statements were typical responses to this question:

1. It is not wise to guess.

2. Use such words as "approximately", "about", "almost", and "nearly".

3. Do not go beyond the data given.

4. The answers will not be exact.

5. Be certain that the number predicted is not larger than the second number and not smaller than the first number. (Apparently this student was sensitive to values secured by "reading between the Iines".).

6. You shoula be very cautious.

7. Compute the values not given in the table.

25. Would these same restrictions apply to the use of a graph?

Most students responded "Yes", because they believed that a graph gives the same information as a table.

26. Would these same restrictions apply to the use of a formula?

Following are typical student responses:

1. A formula is derived from a table or graph so the same restrictions would apply.

2. The same restrictions should not apply because the formula is more exact than the table or graph. 
Three class periods were required to complete this study guide and many students lost interest. When asked why they did not complete the guide, such responses as, "I didn't like this work" were made. When asked to clarify this statement, such statements as "You have to think too much" or "It was too hard" were given. These reasons were given frequently even on other study guides. On occasions students were given practice exercises to do outside of class. In most cases the work was done on a high level of accuracy even by the dull students regardless of the aifficulty. This led the teacher to suspect that much of the work outside the class was done by a few students who allowed others the benefit of their thinking. Doing assignments outside of class was a procedure to which these students had become accustomed throughout the upper elementary grades and junior high school, hence these supervised study periods were forcing them to think--to which they rebelled. Many students did not enjoy reading, hence any written explanations were ignored and it was necessary either to have a student read the explanations aloud for class discusgion or through individual conferences the teacher would ask the student to read the explanations aloud. When this was done, usually the student understood what was expected. Question 13, which required the statement of a formula to express the relations in the table and graph, was explained to the class through demonstration of the method 
used for deriving a formula from a similar set of data. The rate of change was multiplied by a given value of the independent variable and an amount was added to the product which was sufficient to equal the corresponding value of the dependent variable. When this procedure gave correct values of the dependent variable for every given value of the independent variable, the relation was expressed using appropriate symbols for each variable.

This study guide probably should be shortened or presented as three separate guides, one for each interval of growth which gave a straight line graph.

Study of curve fitting was continued in a series of four study guides--33 through 36. This study dealing with normal variability was particularly appropriate at this point because students had earlier shown unusual interest in learning how their foot lengths and heights compared with the "average" for their age. These study guides were designed to help each student derive an empirical formula for predict-ing the weights of adolescents of a certain body build. The study guides were developed from the suggestions given in Chapter 3, pages 70-71.

In Stuay Guide No. 33, students chose the particular relationship in which they were interested, e.8. relation between height and weight of: "tall-glender girls", "average type boys" or "short-stocky boys", and the like. From height-weight tables compiled by the American Public Health 
Association, the student computed the average weight, in the age range 12--18, for each height. These variables, height and weight, were graphed using height as the independent variable. The slope of the graph was estimated and the point at which the extended graph would interest the vertical axis was estimated by extending the graph. These two items were used to assemble an approximate formula for the data. Following is a specimen of work done by student "x":

Approximate slope of graph: $\frac{61}{15}=4.1$ (Chart 2, p. 166), Point at which extended graph would probably intersect vertical axis: $(0,-144)$

Approximate formula: $\quad w=4$. Ih -144 .

In this study the graph was used as the basis for determining $a$ and $b$ in the general equation $w=a h+b$. In Study Guide No. 34, the table was used as the basis for arriving at a formula. The study guide is reproduced on page 167 and the responses of student " $x$ " are recorded in it. In this study guide the average difference between successive weights was computed and the value was assumed as the coefficient of the independent variable in the general equation, $w=a h+b$, which gave the equation, $w=3.8 h+b$. Having values for $w$, $h$ and $a$, the student substituted successive weight-height values and solved for $b$. The average of the values for $b$ was substituted in the equation, $w=3.8 h+b$, thus siving the formula, $w=3.8 \mathrm{~h}-127$. This formula was compared with the formula developed in the 


\section{CHART 2}

Weight - Helght Relation For Average Type Girla Ages 12-18

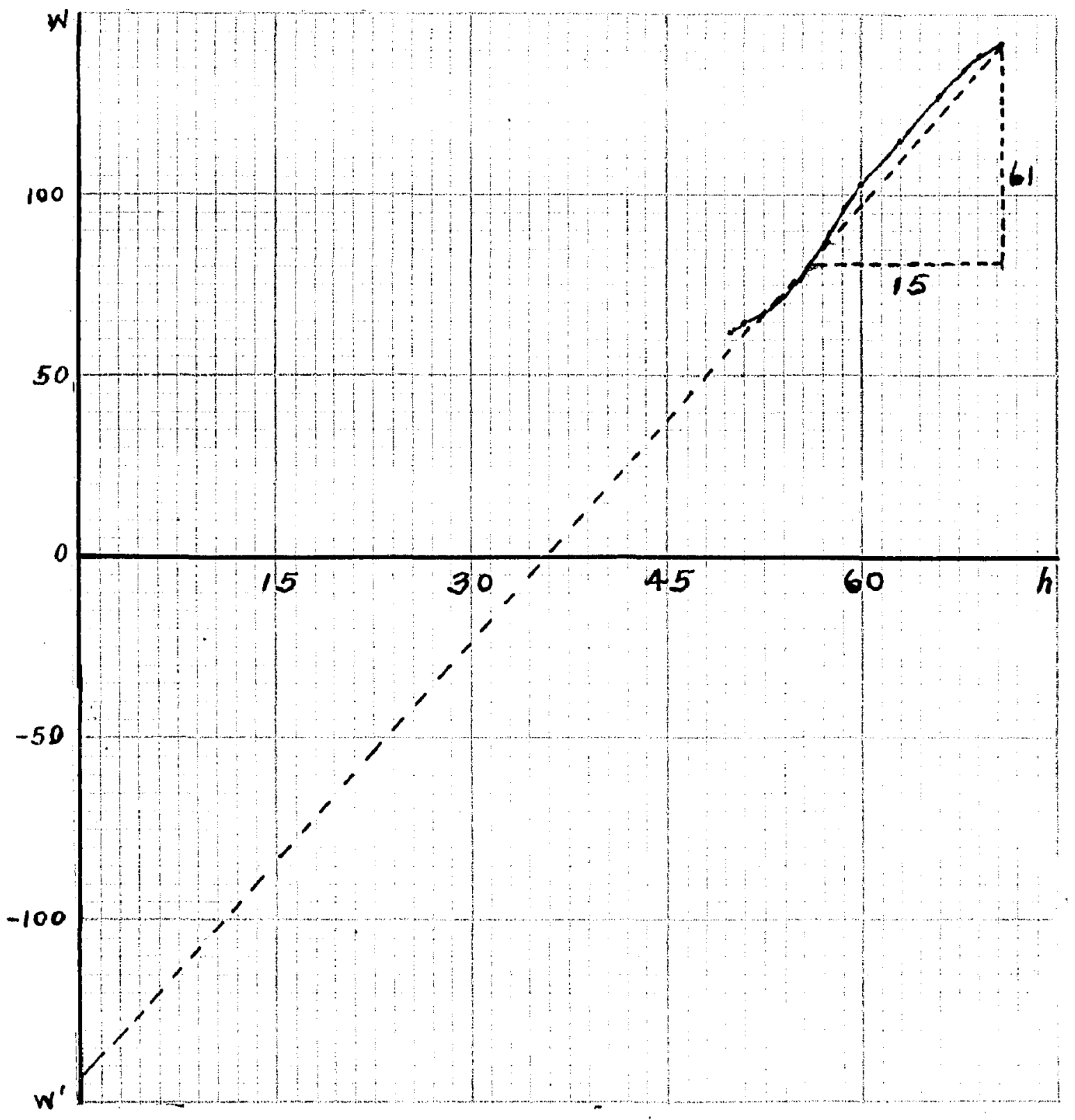


preceding study guide for accuracy.

Study Guide No. 34

Comparing Püpils By Type Of Body Build

Your equation on Study Guide No. 33 for predicting weights gave a rough estimate. You can derive a more precise equation by studying the average weight differences. Transfer the data from sheet 33 to columng 1 and 2 in the table below:

Average Weight-Height Table for Average Type Girls, Ages 12-18

\begin{tabular}{|c|c|c|c|c|c|c|c|}
\hline Height & $\begin{array}{l}\text { Average } \\
\text { Welght }\end{array}$ & $\Delta$ & $\mathrm{b}$ & Height & $\begin{array}{l}\text { Average } \\
\text { Weight }\end{array}$ & $\Delta$ & $b$ \\
\hline 50 & $621 b$. & & -128 & 61 & $108 \mathrm{Ib}$ & 4 & -124 \\
\hline 51 & $65 \mathrm{Ib}$. & 3 & -129 & 62 & $1121 b$. & 4 & -124 \\
\hline 52 & $67 \mathrm{Ib}$ & 2 & -131 & 63 & $115 \mathrm{lb}$ & 3 & -124 \\
\hline $53:$ & $70 \mathrm{Ib}$ & 3 & -131 & 64 & $1191 \mathrm{~b}$ & 4 & -124 \\
\hline 54 & 72 Ib. & 2 & -133 & 65 & $1221 b$. & 3 & -135 . \\
\hline 55 & 77 1b. & 5 & -132 & 66 & $127 \mathrm{Ib}$ & 5 & -124 \\
\hline 56 & $811 b$. & 4 & -132 & 67 & $132 \mathrm{lb}$ & 5 & -123 \\
\hline 57 & $871 b$. & 6 & -130 & 68 & 13516. & 3 & -123 \\
\hline 58 & 93 Ib. & 6 & -127 & 69 & $138 \mathrm{Ib}$ & 3 & -124 \\
\hline 59 & 98 Ib. & 5 & -126 & 70 & 14010. & 2 & -126 \\
\hline 60 & $104 \mathrm{lb}$. & 6 & -124 & 71 & $1421 b$. & 2 & -128 \\
\hline
\end{tabular}

1. Compute the differences between successive weights and record the results in Column 3. We customarily use the symbol, $\Delta$, (pronounced delta) to denote such differences.

2. What is the average difference between successive weights? 3.8

3. How does the average compare with the slope of the line graph that you made in sheet 33 ? The slope is almost the same. 
4. State the general linear equation using $w$ as the dependent variable and $\mathrm{h}$ as the independent variable. $3.8 \mathrm{~h}+\mathrm{b}=\mathrm{w}$.

5. For which terms in this equation do we have values? Height and weight.

6. Knowing these values, find the corresponding values of the unknown term. Use a separate sheet for these computations.

7. List these values in column 4 of the table.

8. What is the average of these values? Place this average in the table at the bottom of column 4 .

9. What does this indicate as to the best equation for showing the relation between height and weight? $3.8 \mathrm{~h}-127=\mathrm{w}$.

10. Use this equation to predict the weight of a friend who is of the proper sex and body build. Use a separate sheet of paper.

11. How precise is it in comparison with the equation used in sheet 33? Are your answers more or less accurate? It $1 \mathrm{~s}$ mors precise on sheet 33 , because it was 1 1b. off on sheet 33 and it is 3 lbs. off on this sheet.

Study Guide No. 35 was designed for studentg who had done creditable work on the three preceding guides. (In the following explanation the formula developed by student " $x$ " is used). In this guide four values of $b$ were selected to determine first the extent to which computed weights using the equation $w=3.8 \mathrm{~h}+\mathrm{b}$, differed from the average weight.g when each selected value of $b$ was used in the equation. The sums of the squares of the differences resulting from each value of $b$, were used to determine which value of $b$, gave the smallest value in the formula, $A=\frac{\sqrt{\Sigma a^{2}}}{N}$. This value of $b$ was to replace whatever value was used in 
Study Guide No. 34. The study guide is reproduced below.

Study Guide No. 35

Comparing Pupils By Type of Body Build

You can further test the precision of your equation by the plan which follows:

1. Transfer the data from the sheet 34 to the first four columns of the table below:

Average Weight-Height Table For Average Type Girls, Ages 12-18

\begin{tabular}{|c|c|c|c|c|c|c|c|c|c|c|c|c|c|c|c|}
\hline 1 & 2 & 3 & 4 & 5 & 6 & 7 & 8 & 9 & 10 & 11 & 12 & 13 & 14 & 15 & 16 \\
\hline \multirow[b]{2}{*}{ Ht. } & \multirow{2}{*}{$\begin{array}{l}\text { Av. } \\
W t .\end{array}$} & \multirow[b]{2}{*}{$\Delta$} & \multirow[b]{2}{*}{ b } & Fo: & \multicolumn{2}{|c|}{$b=-123$} & \multicolumn{3}{|c|}{ For $b=-128$} & \multicolumn{3}{|c|}{ For $b=-131$} & \multicolumn{3}{|c|}{ For $b=-126$} \\
\hline & & & & W: & d & $\mathrm{a}^{2}$ & w & d & $a^{2}$ & w & d & $\mathrm{d}^{2}$ & $\mathbf{W}$ & a & $a^{2}$ \\
\hline 50 & 62 & & -128 & 67 & 5 & 25 & 62 & 0 & 0 & 59 & -3 & 9 & 64 & 2 & 4 \\
\hline 51 & 65 & 3 & -129 & 71 & 6 & 36 & 65 & 0 & 0 & 62 & -3 & 9 & 68 & 3 & 9 \\
\hline & & & & & & & & & & & & & & & \\
\hline 70 & 140 & 2 & -126 & 143 & 3 & 9 & 138 & -2 & 4 & 135 & -5 & 25 & $1+0$ & 0 & 0 \\
\hline 71 & 142 & 2 & -128 & 147 & 5 & 25 & 142 & 0 & 0 & 139 & -3 & 9 & 144 & 2 & 4 \\
\hline Su & & & & & & 570 & & & 259 & & & 607 & & & 220 \\
\hline
\end{tabular}

2. Using one value of $b$ with each value of $h$ and the equation of problem 4, sheet 34 , solve for $w$.

3. Record your answers in column 5 of the table.

4. How do these computed values for $w$ compare with the average $w$ in column 2 ? They are almost the same.

5. Find the differences, $d$, between the $w^{\prime} s$ in columns 2 and 5 and record them in column 6 . If the computed $w$ (column 5) is greater than the average w (column 2), assume the difference to be positive $(t)$. If it is less, assume it to be negative $(-)$.

6. Now complete column 7 .

7. Repeat steps $2-6$ for the other values of $b$. Record your results in table, labeling your columns.

8. The method for testing the exactness of your equation is concluded by using the formula, $A=\frac{\sqrt{E d^{2}}}{N}$ to find the set of $a^{2}$ 's giving the smallest value f'or $A$. The value for $b$ giving this smallest answer is the one that will be used in the equation of problem 9 , sheet 34. The symbol, $\Sigma$, (pronounced sigma) means the 
"sum of" and $N$ equals the number of $w ' s$ in column. 2. Use the formula to find the value of $\mathrm{A}$ for each set of $\mathrm{d}^{2 !} \mathrm{s}$. Record your results in the table below:

\begin{tabular}{c|c|c|c}
\hline $\begin{array}{c}\text { When b is } \\
\text { equal to }\end{array}$ & $\begin{array}{c}\Sigma d^{2} \\
\text { equals }\end{array}$ & $\begin{array}{c}N \\
\text { equals }\end{array}$ & $\begin{array}{c}A \\
\text { equals }\end{array}$ \\
\hline-123 & 570 & 22 & $\frac{24}{22}=1.08$ \\
\hline-126 & 220 & 22 & $\frac{15}{22}=.68$ \\
\hline-128 & 259 & 22 & $\frac{16}{22}=.72$ \\
\hline-131 & 607 & 22 & $\frac{25}{22}=1.13$ \\
\hline
\end{tabular}

9. For what value of $b$ is A smallest? -126

10. What change would you make in your equation of problem 4, sheet 34 ? $\quad w=3.8 \mathrm{~h}-126$.

11. Use this equation to predict the weight of some one who is of the proper body build ard sex.

12. Use the equation to predict the weight of any person in the group which you studied. (As a check, use the table of average weights for the entire country).

13. What is your per cent of error?

The work on curve fitting was summarized tinrough Study Guide No. 36 in which each student used his refined formula to write a verbal statement of the relation between height and weight and to note the domain and range of the variables. A table of values was constructed and the pairs of variables plotted and graphed. Each of the four forms then was used to find the weight which corresponded to a given height.

Students seemed to enjoy this series of study guides. Many of them selected friends of proper body build and pre- 
dicted their weights using the formula which had been. aeveloped. To produce a more accurate formula with each succeeding study guide seemed to be a source of satisfaction. Another specific ability required for interpreting data is the ability to relate like characteristics in different types of data. Examples of like characteristics in different types of data are:

1. The slope of a straight line graph and the coefficient of the independent variable of the corresponding equation.

2. The constant term in a linear equation of the form, $y=a x+b$, and the point at which the corresponding sraph intersects the vertical axis.

Through graphing a series of equations on the same set of axes the students were stimulated to make these comparisons. (Study Guide No. 37). The study guide is reproduced below:

Study Guide No. 37

\section{Slopes and Intercepts}

1. On one set of axes graph the following formulas:
(a) $c=308$
(b) $c=708$
(c) $c=108$

2. On one set of axes graph the following formulas:
(a) $c=30 g$
(b) $c=308+10$
(c) $c=30 g-20$

3. On one set of axes graph the following formulas:
(a) $d=40 t$
(b) $d=-40 t$
(c) $d=-10 t$
(a) $a=-80 t$
(Assign only negative values to $t$ in $b$, $c$ and $d$ ).

4. Which graph has the greatest slope?

5. Which graph has the least slope?

6. Which graphs pass through the origin? 
7. How can you find out from a formula whether its graph will pass through the origin?

8. Give an example of a formula whose graph crosses the vertical axis below the origin?

Above the origin?

9. When the slope of a formula is negative how does its graph slant-----from lower left to upper right or from upper left to lower right?

After students had worked on the guide, the work was illustrated by the teacher in a blackboard demonstration. Although 26 students made the graphs, only 13 gave intelligible responses to the questions concerning them. In answering the questions concerning slope ( 4 and 5) students seemed to be undecided about the significance of the negative coefficients in the formulas. About half of the students selected $c=70 \mathrm{~g}$ as the graph having greatest slope, while the others chose $d=-80 t$. The same was true in their selections of graphs with least slopes, the choices being equally divided between $c=10 g$ and $\bar{a}=-10 t$. In class discussion it was decided that the absolute value of the coefficient of the independent variable determined the degree of alope and the gign determined the direction of slope. In response to question 7 , the following statements typify student thinking:

1. "A graph will pass through the orifin if nothing has been added to or taken away from the independent variable".

2. "A graph will not pass through the origin if it has positive and negative numbers".

3. "If a number is added to or subtracted from the independent variable the graph will pass 'above 
or below' ".

4. "If a formula has an extra number, it will pass either above or below zero".

Four of the 13 students responding to question 9 , interpreted their data to conclude that a negative slope indicates a slant from lower left to upper right.

In a second study guide, attention of students was directed to the relation between slopes of graphs and rates as given in formulas. (Study Guide ivo. 38). A portion of the study guide is reproduced below:

\section{Study Guide No. 38}

Relating Change In Slope To Change In Rate

This graph represents the income of John, who sells newspapers for Dally Tattler. According to the graph, he receives a basic salary of $\$ 2.00$ per week plus a commission of $1 \phi$ per paper sold.

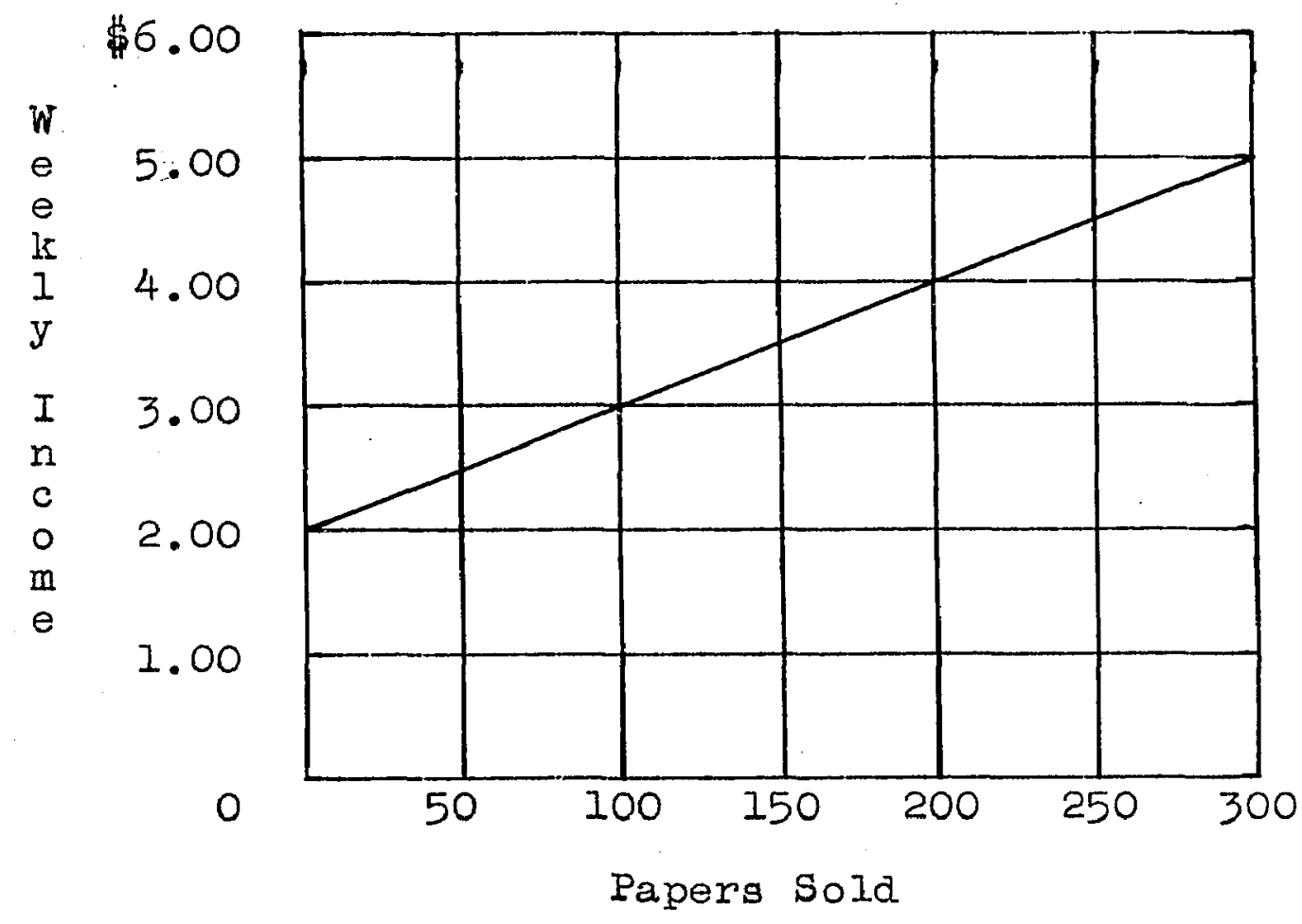


1. Construct a table to accompany the graph.

2. State the formula which gives the same information as the graph.

3. Suppose John's employer decides to raise his basic salary to $\$ 3.00$ per week giving him the same commission on the number of papers sold. Would a sraph of John's new salary (using the same scale) be any different from

If so, how?

Where would the graph begin?

Four other situations similar to question 3 were described where the basic salary and the commission rate were changed. Students did creditable work on this study guide; most of them graphed each situation on the original chart in order to arrive at conclusions concerning the changes in the graph.

In Study Guide No. 39, students were stimulated to identify like characteristics in the graph, the table and the formula.

Three graphs, three tables and three formulas each representing the price of tomatoes at a particular season of the year were presented in random order.

Students were asked to indicate the season of the year to which each graph corresponded and to give their reasons for matching as they did. Following are typical reasons given by students:

There is a relation between cost and plentifulness of tomatoes. 
The more there is of a product, the cheaper.

Prices are higher in the fall and winter than they are in spring and summer.

If they are "in season", the price is low.

I comparea the slope with the cost.

Tomatoes are plentiful in summer and are hard to get in winter; this makes them high in winter.

Price depends upon the amount of tomatoes in each season.

In graph No. 3 you get one pound for $10 \%$, and they are cheapest in summer, and $10 \not$ is the lowest price on the graphs.

Students were then asked to match each sraph with the formula to which it corresponded and to explain why they matched as they did. In explaration students stated that:

1. In each formula there is a number corresponding to a number on the graph.

2. The graph and formula tell the same thing.

3. The cost of one pound on the graph equals the amount stated in the formula.

4. For graph No. 1 the cost per pound is $20 \not$, so $c=20 n$.

5. You get the same answer when you use a particular pair.

6. The figure in each formila told you how much the tomatoes were per pound.

In like manner students were asked to: match each sraph with the appropriate table; explain why they natched as they did. Although students matched correctly, many of their reasons were not intelligible or they were irrelevant. 
For example, many students continued to explain the relation between season and cost.

Symmetric, transitive and reflexive relations were considered in a series of three study guides. Symmetric relations were introduced as follows:

\author{
Study Guide No. 40 \\ Symmetric Relations
}

As we read advertisements and listen to the radio or make decisions on various problems we often do not consider the relations between wariables. Frequently we overlook the additional relations which are not stated but which are implied in a statement.

Consider the following as a true statement: Covington is the second largest city in Kentucky". Is it true that: "The second largest city in Kentucky is Covington"!?

Now consider this statement as valid: "If Jane uses Bond's Cold Cream her skin will be beautiful". Is the following statement valid? "If Jane has beautiful skin, then she uses.Bond's Cold Cream".

From the two illustrations above, it has probably occurred to you that we of ten rate false statements as true when they are reversed or "turned around". In fact many merchants want us to rate such gtatements as true, then we will purchase only one particular brand of face cream or cereal, and the like.

In the statements which follow assume that the first atatement of each pair is tme. Rate the second statement as true ( $T$ ), false $(F)$, or insufficient $\operatorname{data}(I)$.

1. John is Tom's nephew. Tom is John's nephew.

3. Ice is lighter in weight than water. water is lighter in weight than ice.

12. $a$ is greater than b. $b$ is greater than a. 
Fifteen statements and their converses were presented thus : for student evaluation of the converses, assuming the original statements to be true. Students had no difficulty in rating statements containing such relational expressions as: "1s north of"; "is Iighter than"; "is less than"; "is married to"; "is the tallest" and "is taller than". Five of the statements were rated by students as is shown in Table 17. These responses are reported because of their unusual distribution. Such obviously true converse stateTABLE 17 .

Student Ratings of Converse Statements

\begin{tabular}{|c|c|c|c|}
\hline \multirow{2}{*}{ Statements } & \multicolumn{3}{|c|}{$\begin{array}{c}\text { Number of Students } \\
\text { Rating Converses }\end{array}$} \\
\hline & True & False & $\begin{array}{l}\text { Insuff } 1- \\
\text { cient Data }\end{array}$ \\
\hline $\begin{array}{l}\text { 9. Mary loves Harry. } \\
\text { Conv. Harry loves Mary. }\end{array}$ & 8 & 11 & 9 \\
\hline $\begin{array}{l}-8+4=-7+3 \\
\text { Conv. }-7+3=-8+4\end{array}$ & 18 & 8 & 2 \\
\hline $\begin{array}{l}\text { Workers are treated } \\
\text { fairly by employers. } \\
\text { Conv. Employers are treated } \\
\text { fairly by workers. }\end{array}$ & 3 & 16 & 9 \\
\hline $\begin{array}{l}\text { 14. m equals } r . \\
\text { Conv. } r \text { equals } \mathrm{m} \text {. }\end{array}$ & 17 & 8 & 3 \\
\hline $\begin{array}{l}\text { 15. MacArthum disagrees } \\
\text { With Truman's policy. } \\
\text { Conv. Truman disagrees with } \\
\text { MacArthur's policy. }\end{array}$ & 15 & 8 & 5 \\
\hline
\end{tabular}


ments as (10) and (14) were rated false or uncertain by over one-third of the students, showing either over-caution or a lack of understanding of meanings implied in mathematical symbols. Yet such converse statements as (9), (11) and (15), which should be rated uncertain, were accepted naively by about 2 out of 7 and rejected by about 3 out of 7 students. These rejections again represented over-caution, the outstanding weakness revealed in the initial results on the interpretation of data test.

Students were also asked to construct five sets of statements which were converses of each other and to evaluate the converse statements. Following are examples of statements suggested by students and their ratings of the converses:

1. If the sun is shining the day is bright.

T If the day is bright the sun is shining.

I or $\mathrm{F}$. The Red Cross helps some needy people.
Some needy people help the Red Cross.

3. Cotton is softer than coal.

F. Coal is softer than cotton.

4. Covington is larger than Newport.

$F$ Newport is larger than Covington.

5. Bill looks like Jimmy.

T. Jimmy looks like Bill.

6. Shirley is prettier than Judy.

F: Judy is prettier than Shirley.

7. GIycerine is a pure drues.

F Any pure drug is glycerine.

8. The liver is opposite the gall bladder.

T... The gall bladaer is opposite the liver. 
9. Some enzymes produce chemical changes in the body.

T: Some chemlcal changes produce enzymes in the body.

10. Potatoes weigh heavier than tomatoes. F. Tomatoes weigh heavier than potatoes.

In class discussions of the statements listed by the instructor on the study guide and those written by students, statements containing similar relational words or expressions were analyzed. From this analysis the following conclusions were reached:

If a comparative is used in a true statement, its converse is false.

If a superlative is used in a true statement, its converse is true.

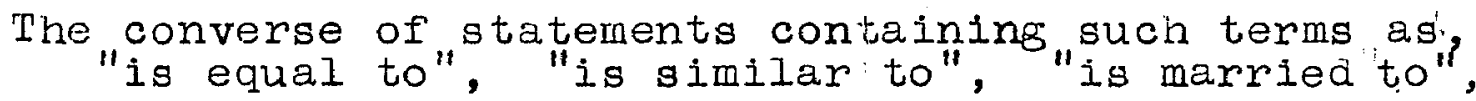
are true.

Sixteen statements illustrating transitive relations were presented in study guide No. 41. Student evaluations of eight of these statements are summarized in Table 18 . The responses to statements (3), (10), (14) and (15) -..(which should be ratied respectively $I, F, T$, and $F$ ) indicate careless and uncritical reading by about one-third of the students. Evaluations of statements $(4),(11),(13)$ and (16)--(all of which are true except (16) which is false) by about 3 of every 8 students, showed either over-caution or a lack of understanding of the meanings conveyed by mathematical symbols. Lack of understanding of the terms "parallel" and "perpendicular" was evident particularly in 
class discussion of statements (13) and (16). In the study guide a diagram was placed beside each of these two statements as an illustration.

TABLE 18

Student Ratings of Statements Illustrating Transitivity

\begin{tabular}{|c|c|c|c|}
\hline \multirow{2}{*}{ Statements } & \multicolumn{3}{|c|}{$\begin{array}{l}\text { Number of Students } \\
\text { Rating Statement }\end{array}$} \\
\hline & True & False & cient Date \\
\hline $\begin{array}{l}\text { 3. If James is in the same class } \\
\text { as John and John is taller than } \\
\text { Albert, then James is taller } \\
\text { than Albert. }\end{array}$ & 5 & 9 & 18 \\
\hline $\begin{array}{l}\text { 4. If } c=n \text { and } n=b \text {, } \\
\text { then } c=b \text {. }\end{array}$ & 17 & 9 & $6 i$ \\
\hline $\begin{array}{l}\text { 10. If Arthur is Hector's father } \\
\text { and Hector is Mortimer's father, } \\
\text { then Arthur is Mortimer's father. }\end{array}$ & 7 & 24 & $1 \ldots$ \\
\hline $\begin{array}{l}\text { II. If }-2=2-4 \text { and }-4+2= \\
-1 \div a \text {, then }-1 \div a=-2 .\end{array}$ & 19 & 5 & 5 \\
\hline $\begin{array}{l}\text { Ij. If a is parallel to } b \text { and } b \\
\text { is parallel to } c \text {, then } c \text { is } \\
\text { parallel to a. }\end{array}$ & 23 & 7 & 1 \\
\hline $\begin{array}{l}\text { 14. If } X \text { is east of } Y \text { and } Z \text { is } \\
\text { east of } X \text {, then } Z \text { is east of } Y \text {. }\end{array}$ & 22 & 7 & 2 \\
\hline $\begin{array}{l}\text { 15. If Mary's books are Ijghter } \\
\text { than John's books and John's are } \\
\text { lighter than Paul's, then Paul's } \\
\text { are lighter than Mary's. }\end{array}$ & 12 & 20 & 0 \\
\hline $\begin{array}{l}\text { 16. If a is perpendicular to } b \\
\text { and e is perpendicular to } b \text {, then } \\
\text { a is perpendicular to } c \text {. }\end{array}$ & 11 & 19 & 2 \\
\hline
\end{tabular}

Students were able to construct many transitive statements which were logically sound. The following relational 
words and expressions were used by most students:

$\begin{array}{lll}\text { better } & \text { longer } & \text { lives with } \\ \text { darker } & \text { lighter } & \text { loves } \\ \text { defeated } & \text { later } & \text { equals } \\ \text { fatter } & \text { older } & \text { east of } \\ \text { faster } & \text { prettier } & \text { aest of. } \\ \text { greater } & \text { shorter } & \text { is father of } \\ \text { heavier } & \text { smarter } & \text { la brother of } \\ \text { larger } & \text { wider } & \text { is uncle of }\end{array}$

Through class discussion and analysis of statements constructed by students and those given on the study guide the following conclusions were reached:

When two things are compared with a third thing through. such relational words as lighter, longer, wider, taller, and richer, then they have the same relation to each other in the same order.

When the positions of two things are compared with the position of a third thing through such relational words as north, south, east and west, then they have the same relation to each other in the same order.

If two things are equal to a third thing, they are equal to each other.

The following study guide developed by Helen. L. Green, was a very helpful instrument in making students sensitive to reflexive relations. 5

\section{Study Guide No. 42 Reflexive Relations}

Sometimes, we do not realize what relations we are assuming when we solve problems and make decisions. The following questions and statements are designed to make you more conscious of some simple relations. Fill in the blanks and answer the questions.

5. Helen L. Green, Developing an Understanding of the Nature of Relationshies throush the Medium of Elementary Alsebra, pp. 133-134. Unpublished Master's Thesis, Ohio State University, 1946. 
1. To solve the equation, $4 \mathrm{y}=16$, both members of the equation must be divided by. - This is a valid procedure because __ equals___. Thus, both members of the equation are divided by equals.

2. If $a$ is greater than $b$, then $a+c$ is greater than $b+c$. This statement is valid because $c$ equals Thus equals are beins added to unequals and the relationship still holds.

3. Does $5+9$ always equal $9+5$ ?

4. If your principal excuses you from school to go to see a doctor this Thursday afternoon, will he excuse you to do the same thing next Thursday afternoon?

5. The claim that Mary Ann Evans wrote whatever George Eliot wrote is valid if

6. If John Brown, alias Jim Smith, was arrested last night, was Jim Smith, alias John Brown, arrested last night?

7. Does $a+b$ always equal $b+a$ ?

8. If Mark Twain is the pseudonym of Samuel Clements, is Samuel Clements the pseudonym of liark Twain?

9. If the cost of mailing two packages to the same place was six cents each, did the packages have identical weights?

The responses to statements 6 and 8 as shown in Table 19 indicate varying degrees of understanding of the terms TABLE 19

Student Ratings of Statements in Study Guide No. 42

\begin{tabular}{c|c|c|c}
\hline \multirow{2}{*}{ Statement } & \multicolumn{2}{|c|}{ Number of Students Responding } \\
\cline { 2 - 4 } & Yes & No & Uncertain \\
\hline No. 6 & 28 & 4 & \\
\hline No. 8 & 15 & 17 & \\
\hline No. 9 & 15 & 12 & 5 \\
\hline
\end{tabular}

"alias" and "pseudonym". The preponderance of acceptance of 
statement (6) and the division of opinion in evaluating statement, (8) reflect a general acquaintance with the meaning of the term "alias" and a lack of acquaintance with the term "pseudonym". Students accepting statements 6 and 8 usually explained that the terms (John. Brown and the like) referred to the same person. Students not accepting statement 9 explained that the packages could have been mailed from different places.

Thls brief study of symmetric, transitive and reflexive relations was concluded by having pupils to analyze ten statements for symmetry, transitivity and reflexiveness. The statements were listed under the following captions: Relation and Its Converse Comparing Two Things With a Third Thing Relating a Thing to Itself

The following words were listed by the teacher as suggestions for constructing the statements:

$\begin{array}{lll}\text { equals } & \text { father } & \text { heavier } \\ \text { married } & \text { shorter } & \text { darker } \\ \text { parallel } & \text { wider } & \text { north } \\ \text { uncle } & \text { hotter } & \text { loves }\end{array}$

Pupils were asked to indicate those statements which were true in two or more situations. One general conclusion was that the equality relation is true in all cases.

Simultaneous equations were introduced through a comparison of the fares charged by two taxi cab companies:

The $A$ and $B$ Cab Company computes its fares per trip by the following statement: $25 \not$ for the first tenth of a mile and $5 \phi$ for each additional tenth of a mile.. 
Fares for the XYZ Cab Company are computed by charging $15 \phi$ for the first tenth of a mile and $10 \phi$ for each aditional tenth of a mile.

The teacher did most of the work in re-writing these statements as formulas: :

$$
\begin{array}{cc}
f=25+5(m-1) & f=15+10(m-1) \\
\text { or } & \text { or } \\
f=5 m+20 & f=10 m+5 \\
\begin{array}{c}
\text { (where } m \text { is equal to or greater than } 1 \text { and } \\
\text { represents the number of tenths of a mile.) }
\end{array}
\end{array}
$$

The group formulated the accompanying tables:

\begin{tabular}{l|c|c|c|c|c|c|c|c}
\hline $\mathrm{m}($ tenths of a mile) & 2 & 3 & 4 & 6 & 8 & 10 & 12 \\
\hline $\mathrm{f}$ (fare in cents) & 30 & 35 & 40 & 50 & 60 & 70 & 80 \\
\hline
\end{tabular}

\begin{tabular}{l|l|l|l|l|l|l}
\hline $\mathrm{m}$ (tenths of a mile) & 2 & 3 & 4 & 6 & 8 \\
\hline $\mathrm{f}$ (fare in cents) & 25 & 35 & 45 & 65 & 85 \\
\hline
\end{tabular}

The two formulas were graphed on the blackboard chart on the same set of axes. The following questions were asked the class:

When is the fare the same for the same distance traveled in either cab?

Which cab is cheapest when the distance traveled is less than .3 mile?

It was shown that the answer to the first question was also siven at the point where the two graphs intersected. 
It was explained that this point represents the solution of the two equations. Each pupil was then asked to follow: a similar procedure with a second set of fares:

The Blue Cab Company charges $35 \%$ for the first tenth of a mile and $10 \not$ for each additional tenth of a mile.

The Red Cab Company charges $20 \not$ for the first tenth of a mile and $15 \phi$ for each adaitional tenth of a mile. The other methods for solving linear equations simultaneously, (addition or subtraction, substitution) were introduced through these taxi fare formulas.

The following problems were devised by a student teacher who observed and participated in the class activities beginning with the study of transitive, symmetric and reflexive relations:

John sells magazines for the Kentucky Magazine Company and his salary is $20 \%$ of his sales plus \$15 a week. James sellg handkerchiefs for the Ohio Handkerchief Cowpany; his salary is $40 \%$ of his sales plus $\$ 5$ a week.

1. State a formula that could be used by each boy to compute his salary.

2. Make a graph of each formula.

3. If John sold no magazines one week what would his salary be?

4. How many sales will both have to make in order to recelve the same amount of pay?

Mary selis $I$ pound boxes of candy for the Kentucky Candy Company and her salary is $25 \%$ of her sales plus 25 a week. Jane sells nail polish for the Five and Ten Cent store and her salary is $5 \%$ of her sales plus $\$ 35$ a week.

1. State a formula that could be used by each girl to compute her salary. 
2. Make graphs of the formulas.

3. If Mary sold no candy, what would be her salary?

4. How much must each girl sell in order to recelve the same amount of pay?

In adition to the study guides in this unit, several testg were used as teaching devices. One of the preliminary: tests developed by the Eight Year Study, Test 5.4 (Problems Relating to Functional Thinking) was administered and the results were discussed with the students. In this test the four functional forms were uged to present data on reaction. distance for automobile drivers. Students did very well in solving the various problem situations presented on the test, but in explaining their choice of a form for solving a problem they frequently gave irrelevant and inconsistent reasons. For example, some students chose reasons supporting the use of a graph to justify their use of a formula.

Portions of the test are presented below:

a. Verbal Statement:

The distance traveled during reaction time in feet is equal to one and a half times the speed in miles per hour.

The police instructor went on to investigate more completely the relationship of speed and the distance traveled durins the reaction time. He said, "Suppose your speed doubles, what happens to the aistance?"

Of the possible answers given below, check the one you would make.

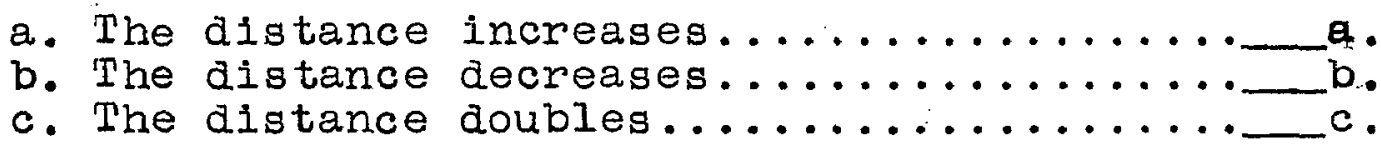


d. The distance is twice as great...............

e. Not enough information is given to decide-e.

$f$. The distance remains the same......... f.

g. The distance is one-half as great.......

In the course of your lecture you wished to give an illustration of the way in which the distance changed with speed. You chose the following problem. If the speed is increased by one-half of itself, how does the distance change?

Which of the possible answers listed below do you think to be the correct one?

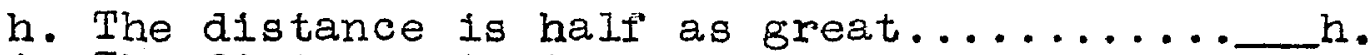

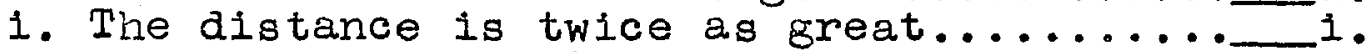
j. The distance is $1 \frac{1}{2}$ times as great......... k. The distance remains unchanged............ 1. The distance is 3 times as great............

Following is a summary of student responses to these statements:

\section{TABLE 20}

Statements Checked By Students On Test 5.4

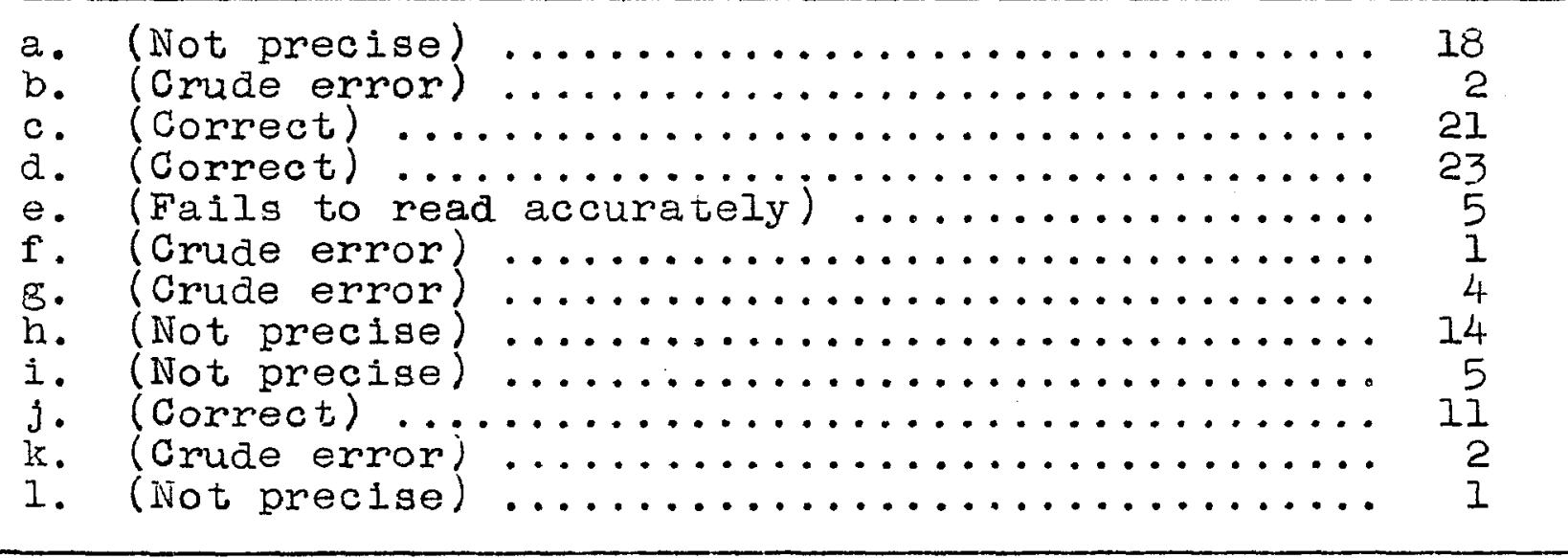

Another instrument presented by Hartung and Fawcett 
was also used as a teaching device. 6 The exercise is presented below with the number of students making the specified responses listed at the left of each statement.

The students in a health class were studying the number of hours of sleep needed by boys and sirls. One student brought in the table at the right showing the number of hours of sleep needed at different ages. The students noticed some definite relationships between pairs of numbers.

Directions: Study the table and the statements below. Suppose the facts in the table are true. If you agree with a statement which follows, put $A$ on the line by the statement. If you disagree with a statement, put $D$ on the Iine. If

\begin{tabular}{c|c}
\hline $\begin{array}{c}\text { Age } \\
(\mathrm{A})\end{array}$ & $\begin{array}{c}\text { No. of } \\
\text { Hours } \\
(\mathrm{H})\end{array}$ \\
\hline 6 & 14 \\
\hline 8 & 13 \\
\hline 10 & 12 \\
\hline 12 & 11 \\
\hline 14 & 10 \\
\hline 16 & 9 \\
\hline
\end{tabular}
you can neither agree nor disagree, but are uncertain, put $U$ on the line by the statement.

\begin{tabular}{|c|c|c|c|c|}
\hline A & $D:$ & $\mathrm{U}$ & & \\
\hline 2 & 28 & 1 & & $\begin{array}{l}\text { As the age increases from } 6 \text { to } 16 \text {, } \\
\text { the number of hours of sleep needed } \\
\text { increases. }\end{array}$ \\
\hline 2 & 25 & 4 & & $\begin{array}{l}\text { The number of hours of sleep needed } \\
\text { at any are is greater than the are.. }\end{array}$ \\
\hline 15 & 14 & 2. & & $\begin{array}{l}\text { number of hours of sleep to the age: } \\
\text { is constant. }\end{array}$ \\
\hline 5 & 5 & 21 & 4. & $\begin{array}{l}\text { A four-year-old should have } 15 \text { hours } \\
\text { of sleep. }\end{array}$ \\
\hline 5 & 26 & 0 & & $\begin{array}{l}\text { A twelve-year-old only needs half as } \\
\text { much sleep as a six-year-old. }\end{array}$ \\
\hline 25 & 6 & 0 & & $\begin{array}{l}\text { From age } 6 \text { to age } 16 \text {, for every } 2 \\
\text { years that your age increases you } \\
\text { need one hour less sleep. }\end{array}$ \\
\hline 4 & 7 & 20 & & $\begin{array}{l}\text { A person } 30 \text { years old needs very few } \\
\text { hours of sleep. }\end{array}$ \\
\hline
\end{tabular}

6. M. L. Hartung and H. P. Fawcett, "The Measurement of Understanding in Secondary School Mathematics", 45 th Yearbook, N.S.S.E., Part 1, The Measurement of Understandins, 


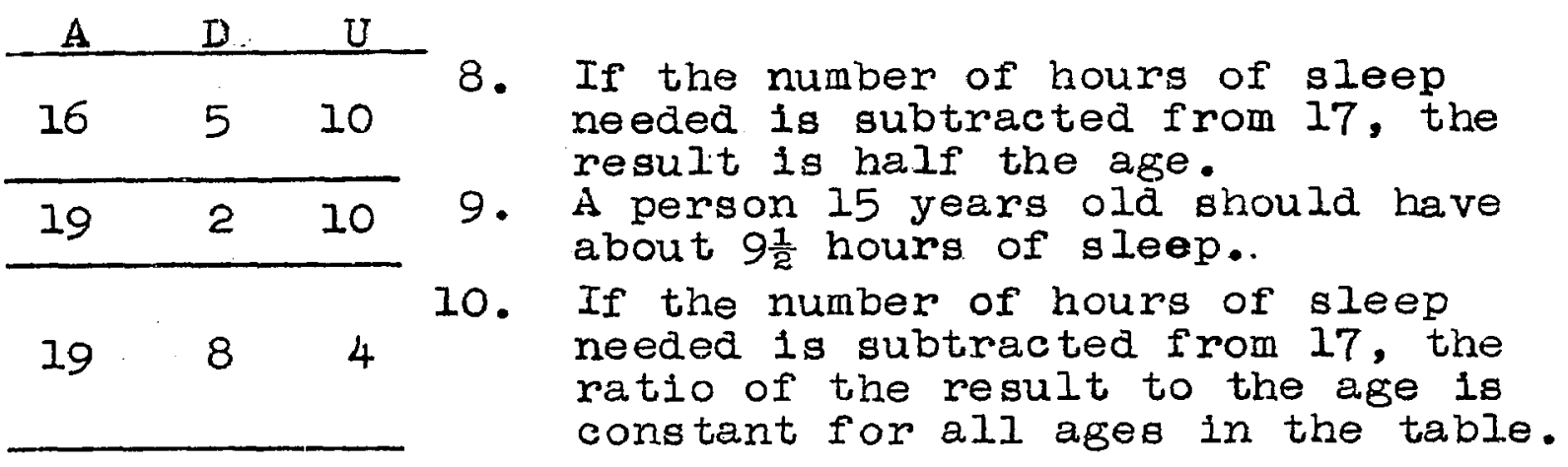

It is interesting to note that about two-thiras of the students were uncertain about the validity of statements 4 and 7. Both statements are extrapolations and were evaluated properly by this portion of the students. Statement 9 which is an interpolation stated with caution, was accepted by about two-thirds of the students and rated as uncertain. by abmost one-third of the students. The latter group were over-cautious. Responses to statements 3, 8 and 10 reflect difficulties encountered by about one-half of the students with understanding and using ratios, as well as other difficulties.

UNIT FOUR -- EXTENDING OPERATIONS IN THE NUMBER SYSTEII.

The fourth unit titled, "Extending Operations in the Number System" "was concerned with helping students to develop principles relating to involution and to understand certain applications of simple quadratic equations.

The study of exponents was introduced through a review. of area and volume formulas for the rectangle, the square, the rectangular solid, and the cube. The following black- 
board diagrams were discussed: :
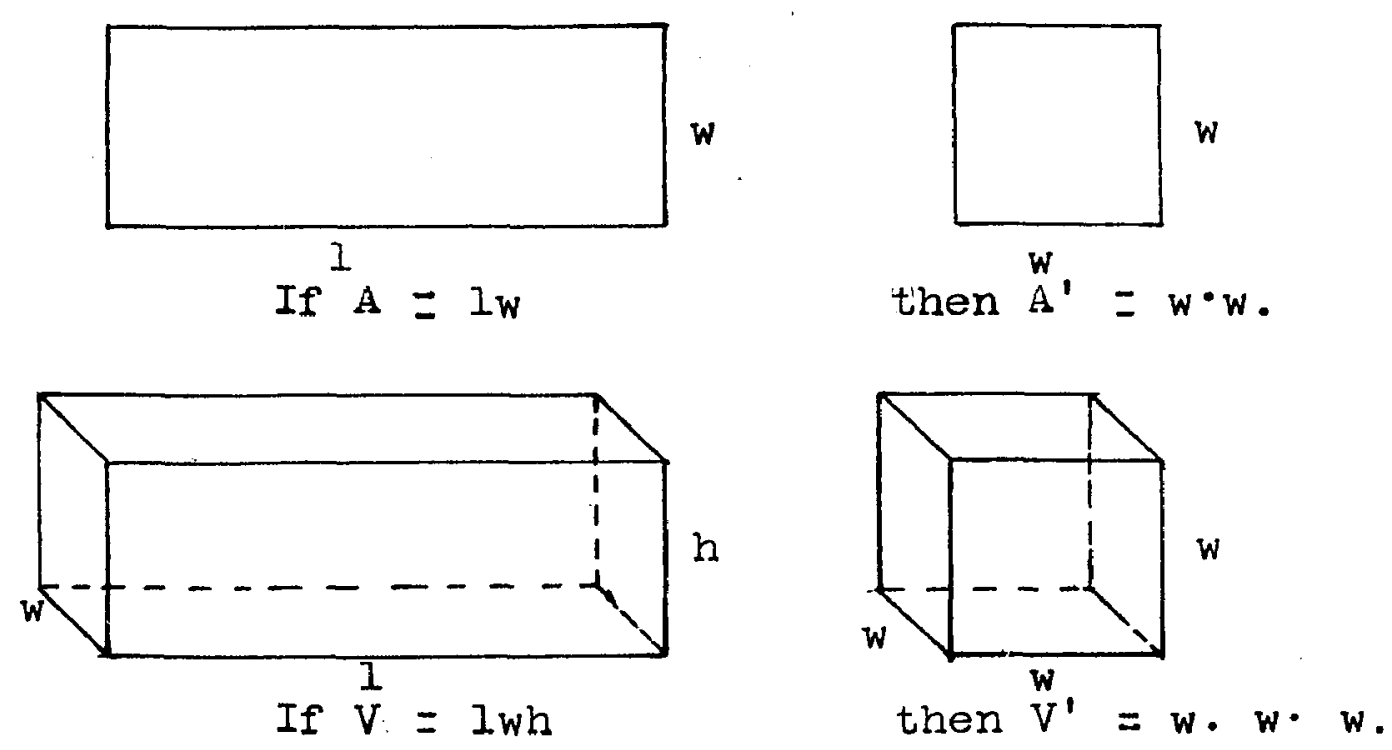

The class was reminded of the economy of writing w.w as w? and $w \cdot w \cdot w$ as $w^{3}$. The following derinitions were an outgrowth of the discussion:

1. When a number is squared it is taken as a factor two times.

2. When a number is cubed it is taken as a factor tinree tines.

3. When a number is raised to the fourth power it is taken as a factor four times.

4. When a number is raised to the nth power it is taken as a factor $n$ times.

Products of numbers with the same base were considered through study guide number 44. A portion of the study guide follows.

Study Guide No. 44
Products Of Numbers With The Same Base

1. a. What is the product of 1000 and 100 ? 100000

b. Express the factors and the product above in powers 
of 10. $\quad 10^{3} \cdot 10^{2}=10^{5}$

In like manner solve the following problems:

2. (a) The product of 216 and (b) Factors and product 36 . in powers of 6 .

9. (a) The product of 27000 and 810000 . (b) Factors and product in powers of 30 .

11. Notice carefully the "b" answers above, studying the relations between the exponents. What is this relation?

Twenty-one out of 30 students attempted to generalize, and the following types of statements were made by these students in expressing the relation between factors to the same base and their product:

I. In order to multiply, ada the exponents.

2. When two numbers with the same base are to be multiplied, add the exponents.

3. If you find the sum of the exponents of the factors, the sum is the exponent of the product.

Quotients of numbers with the same base were considered in a similar manner. The following statements typify student thinking concerning the relation between exponents when dividing numbers to the same base:

1. In order to find the quotient, take one exponent from the other.

2. When numbers with the same base are divided, you subtract their exponents. 
3. You subtract the exponent below the line from the exponent above the line.

4. If you subtract the exponent of the number that is the divisor, from the exponent of the number that is to be divided, you will get the quotient's exponent.

Negative exponents were introduced in the following examples solved through supervised atudy and group discussion:

Reduce the following fractions to lowest terms, then convert them to the indicated base.

Common Base
1. $\frac{100}{10000}=\frac{1}{100}=\frac{1}{10^{2}}$

$$
\frac{10^{2}}{10^{4}}=10^{2-4}=10^{-2}
$$

2. $\frac{9}{729}=$

6. $\frac{100}{100}=$

10. $\frac{16}{16}=$

As problems were solved the instructor recorded results on the blackboard separating the problems giving quotients equal to 1 from those less than 1. The ensulng discussion resulted in the following conclusions:

1. A number raised to a negative power is the same as its reciprocal to same power but the sign of the exponent is positive.

2. Any number raised to the zero power is equal to 1 .

These generalizations relative to exponents were applied 
as students solved algebraic problems involving products and quotients.

Students had their first experiences with quadratic equations in working on atudy guide number 46. The guide is reproduced below:

Study Guide No. 46

A Study of Squares

1. Draw squares having sides respectively: 1 inch, 2 inches, 3 inches, 4 inches, 5 inches, and 6 inches long.

2. Record the area of each square in the table below:

\begin{tabular}{l|l|l|l|l|l|l}
\hline s (Iength of s1de) & 0 & 1 & 2 & 3 & 4 & 5 \\
\hline A (area) & & & & & & \\
\hline
\end{tabular}

3. Graph the data above, plotting "s" on the horizontal axis.

4. Describe the graph.

This type of graph is known as a parabola.

5. In the table below record the changes in area of the squares. Label the column as " $\Delta A$ ". Are the changes regular or varying?

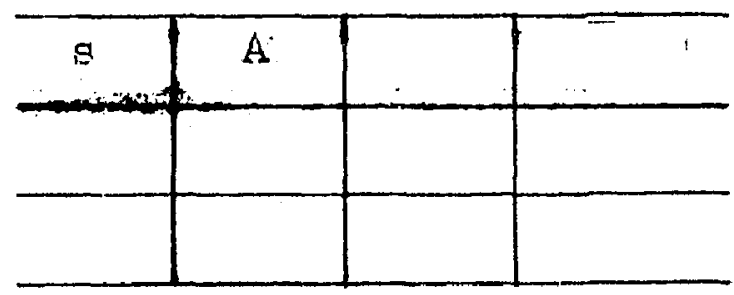

6. Record the second differences by finding the changes in $\Delta A$. Label the column " $\Delta^{2} A$ ".

8. Wen the second differences are constant the equation for the graph is a quadratic equation.--The dependent variable equals the square of the independent variable. 
What is the independent variabje?

What is the dependent varlable?

9. State the equation using statement (8) as a guide.

Students gave varled descriptions of the graph, the terms, "curved", "crooked" and "broken" being used most frequently. In class discussion of this guide the instructor with a blackboard diagram of the squares (as in Chart 3 ) illustrated the fact that doubling the sides of a square quadruples its area, ........, and that makins the sides of a square six times as long increases its area 36 times.

\section{CHART 3}

Areas of Squares

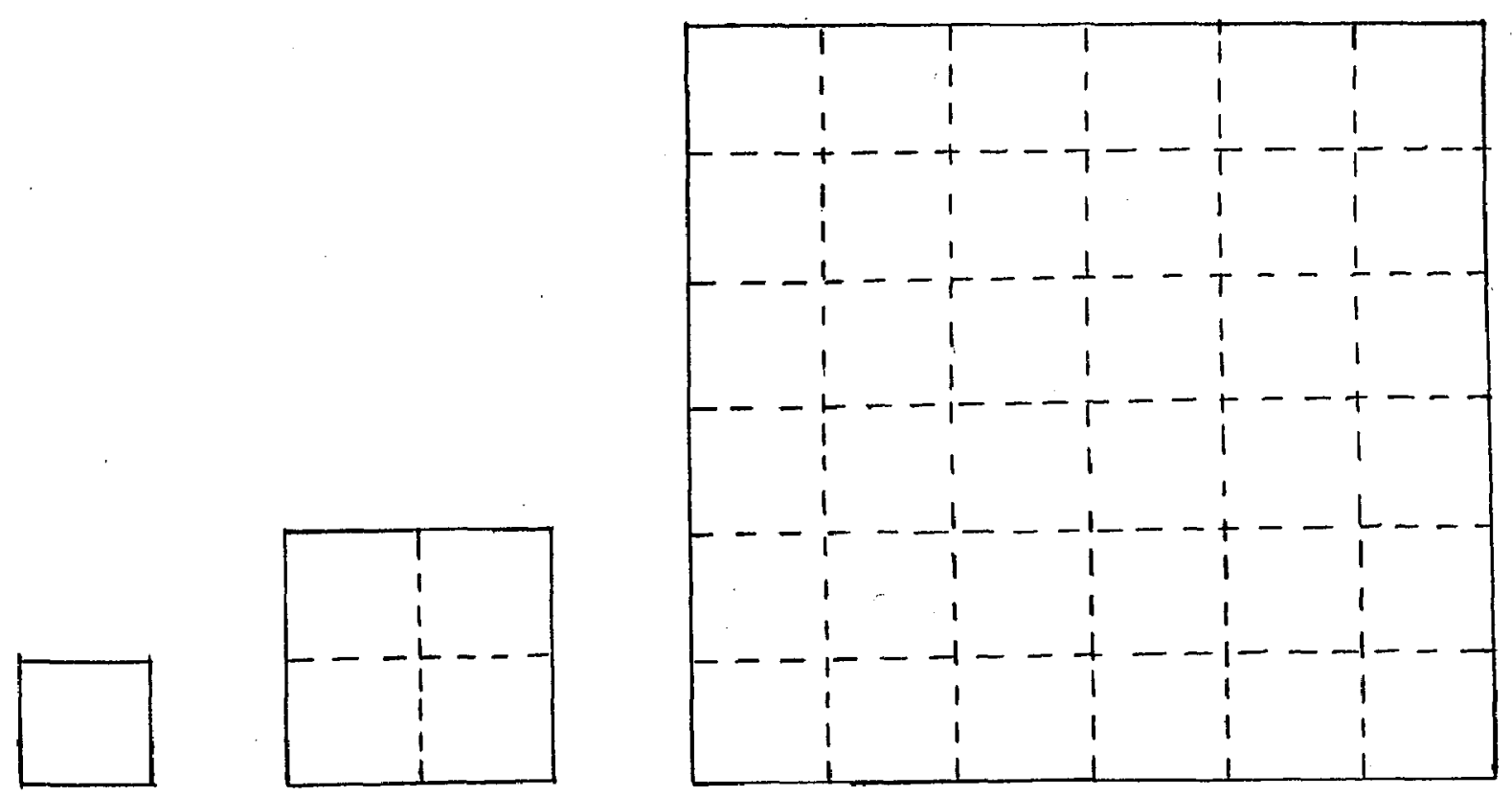

The consequences resulting from doubling the lengths of sides of the classroom were discussed. These facts were broadened to include any second degree relationship, whether 
concerned, with lengths and areas, time and velocity, or other related varlables.

This study guide was followed with a study of the area of surface of a cube and the resultant changes in surface area when the sides were increased in length.

The study of second degree equations shifted to studies of the relation between time and velocity in the next two study guides. Study guide number 47 follows:

\section{Study Guide No. 47 \\ The Crash of A Speeding Car}

"If a moving automobile hits a stationary object, such as a solid wall, a tree, or a telephone post, the force of the impact is equivalent to that force with which it would strike the ground when falling from a certain height. If s represents this height in feet and $r$ is the speed of the car in miles per hour, then

$$
s=.0336 r^{2} . "(17 \text { th Yearbook N.C.T.M.) }
$$

1. Using the formula complete the following table of values:

\begin{tabular}{l|l|l|l|l|l|l|l}
\hline When $r$ equals & 0 & 10 & 20 & 30 & 40 & 50 & $60 \mathrm{mph}$ \\
\hline Then s equals & & & & & & & \\
\hline
\end{tabular}

2. Plot and graph these values in the chart at the right.

3. Suppose the speed of a car is doubled from 20 miles per hour. How does the height change?

4. How does the height change when the speed is tripled from 20 miles per hour?

5. Suppose the speed of another car is halved from 60 miles per hour. How does the helght change?

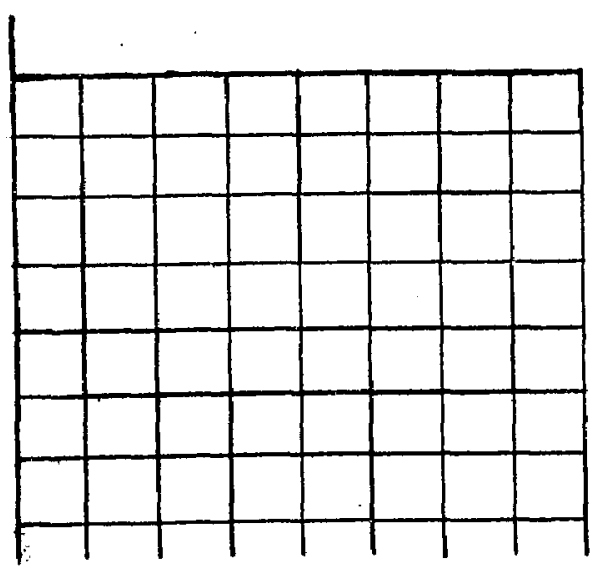


6. What is the equivalent force of impact of a car moving at the rate of 45 milea per hour?

7. If a motorist is driving at the rate of 90 miles per hour, the crash of his car would be equivalent to the car falling how many feet?

8. What conclusions can you make conoerning speed and force of impact?

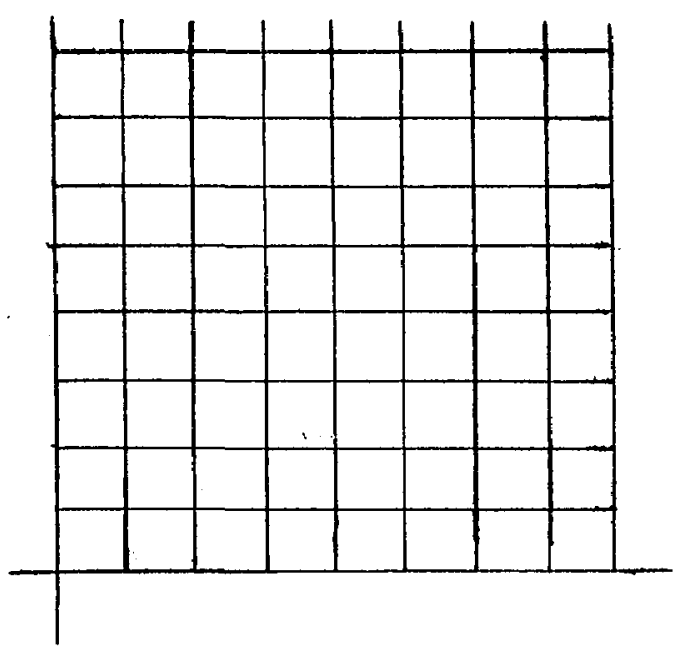

There were more incorrect responses to question (5) than to any other question. Only 15 of the 28 students working on this guide answered "4 timeg legs" or "i as great". The following conclusions were listed by students:

1. If speed is doubled or tripled the force of impact is squared or raised to the third power.

2. The greater the speed, the greater the force of impact.

3. One should travel no faster than 20 miles per hour.

4. The faster the speed, the greater the equivalent.

5. The slower one drives, the surer he is of preventing accidents.

6. When the speed increases, danger increases at a much higher rate.

7. When the speed increases 6 times its original amount, danger increases 36 times.

8. If a moving object hits a stationary object, the equivalent height depends upon the speea of the object.

9. As speed Increases, the equivalent force of impact doubles. 
Most of the conclusions were similar to conclusion (6) and the statement, in class discussion, was altered to read:

"When the speed increases, the force of impact increases more rapialy",

the students noting that the data were not concerning danger per se.

Another relationship brought out in class discussion was that, "regardless of the amount of increase in speed, the resulting force of impact is the square of the original force of impact". This statement was derived through individual students computing other relations after a demonstration of the following relation:

As speed increases from 30 to 40 miles per hour or 1.33 times, the force of impact increases from 30.2 to 53.8 feet or 1.78 times. 1.78 is the square of $1.33 . \quad\left(1.78=1.33^{2}\right)$

Portions of study guide number 48 are presented below:

Study Guide No. 48

Stopping Distance And Speed

"How soon can a car be stopped in the face of danger? The answer to this question depends upon the speed at which the car is being driven, the length of time necesary to start applying the brakes, and the rate at which the car slows down after the brakes are applied. For a car being driven at the rate of $r$ mileg per hour the minimum number of feet, $d$, necesgary for stopping the car atter danger is realized, is given approximately by the formula,

$$
\mathrm{d}=.045 \mathrm{r}^{2}+1.1 \mathrm{r} \text {. }
$$

This is for a dry road with the best of braking conditions." It $1 \mathrm{~s}$ also assumed that the average reaction time necessary before a driver can get his foot on the brakes is .75 second. (Adapted from 17 th Yearbook, N.C.T.M., p. 95) 
Using the formula complete the following table to show the stopping distance for cars moving at the indicated rates.

Using the table congtruct a graph to show the relation between speed and stoppins distance.

1. How many feet are required to stop a car moving at the rate of 55 miles per hour? (Dry road, good brakes, average reaction time)

2. If a ariver's reaction time is 0.9 second or above the average, what is his stopping distance when moving at the rate of 40 miles per hour?

4. What is the stopping digtance of a car moving at the rate of 35 miles per hour on a wet road?

Questions (2) and (4) are of particular interest since they require data different from that given in the study guide. Most of the students were alert to this situation and stated that "no data were given" on the problems. No student suggested that the stopping distance in each case would probably be sreater than the amount computed with the given formula. This reluctance again represented overcaution and the students were convinced through class discussion that such a response would be valid.

One outgrowth of this study guide was student learning: of the skill of simple factoring. The method for evaluating $a$ in the formula, $d=.045 r^{2}+1.1 r$ was reviewed. "When $r=10$, we found d as follows:

$$
\begin{aligned}
a & =.045 \times 10^{2}+1.1 \times 10 \\
& =.045 \times 100+11 \\
& =4.5+11=15.5
\end{aligned}
$$


We first multiplied and finally added. Can we reverse the operations--add first and then multiply?"

"In the equation, $m=n^{2}+n$, when $n=5, m=5 x 5+5$

$=25+5$ or 30 .

This means add one 5 and five 5 's. Could it also mean multiply 5 by $(5+1)$ ? If so, then $m=n(n+1)$."

After other illustrations, the formula was re-written as:

$$
\begin{aligned}
a & =r(.045 r+1.1) . \\
\text { or } .045 r^{2}+1.1 r & =r(.045 r+1.1) \\
\text { Hence, } a r^{2}+b r & =r(a r+b)
\end{aligned}
$$

In class discussion the characteristics of equations were summarized with the following lllustration: Linear Equation: $\mathrm{y}=8 \mathrm{x}+2$

\begin{tabular}{c|r|r}
$x$ & $y$ & $\Delta y$ \\
\hline 0 & 2 & \\
1 & 10 & 8 \\
2 & 18 & 8 \\
3 & 26 & 8 \\
4 & 34 & 8
\end{tabular}

Quadratio Equation: $y=8 x^{2}+2$

\begin{tabular}{c|r|r|r}
$\mathrm{x}$ & $\mathrm{y}$ & $\Delta \mathrm{y}$ & $\Delta^{2} \mathrm{y}$ \\
\hline 0 & 2 & & \\
1 & 10 & 8 & \\
2 & 34 & 24 & 16 \\
3 & 74 & 40 & 16 \\
4 & 130 & 56 & 16
\end{tabular}

Cubic Equation: $y=x^{3}$

\begin{tabular}{c|r|r|r|r}
$\mathrm{x}$ & $\mathrm{y}$ & $\Delta \mathrm{y}$ & $\Delta^{2} \mathrm{y}$ & $\Delta^{3} \mathrm{y}$ \\
\hline 0 & 0 & & & \\
1 & 1 & 1 & & \\
2 & 8 & 7 & 6 & \\
3 & 27 & 19 & 12 & 6 \\
4 & 54 & 37 & 18 & 6 \\
5 & 125 & 61 & 24 & 6
\end{tabular}

Students agreed on the following concluaions:

1. In equations of first degree the first differences in the dependent variable are 
constant.

2. In equations of second degree the second differences in the dependent variable are constant.

3. In equations of third degree the third differences in the dependent voriable are constant.

A final study guide was concerned with determining the value of $\pi$ through a consideration of areas of circles. The purpose of this study guide was to acquaint students with a method used for fitting data to a curve of second degree. The study guide is reproduced below:

\section{Study Guide No. 49 \\ The Value of PI}

Earlier in the year we computed the value of P1. ( $\pi$ ), by finding the ratio of the distance around (circumference) to the distance across (diameter) in a number of circles. We can use a second method by studying the relations between the areas of circles of varying radil.

On the piece of graph paper which has been given to you is drawn a circle. If we agree that each smal. block has an area of 1 square unit, how could you set the area of the circle?

What is the length of each small block?

What is the length of the radius of the cirole? What is the area of the circle? 
Class Results

\begin{tabular}{c|c|c|c}
\hline $\begin{array}{c}\text { Radius } \\
(\mathbf{r})\end{array}$ & $\begin{array}{c}\text { Area } \\
(\mathbf{A})\end{array}$ & $\Delta \mathrm{A} / \Delta \mathrm{r}$ & $\Delta^{2} \mathbf{A}$ \\
\hline 0 & 0 & & \\
\hline 4 & 51 & 12 & \\
\hline 8 & 200 & 37 & 25 \\
\hline 12 & 452 & 63 & 26 \\
\hline 16 & 806 & 88 & 25 \\
\hline 20 & 1254 & 112 & 24 \\
\hline 24 & 1810 & 136 & 24 \\
\hline
\end{tabular}

Compute the first and second differences and record them in the above table.

From the data in the table, what is the approximate formula for the area of a circle? $A=\mathrm{kr}^{2}$

We can find the value of $P$ i by substituting values in the formula from the table. Do this and find the average of the answers which you get from the substitution.

$$
\begin{aligned}
16 k=51 ; & k=3.2 \\
64 k=200 ; & k=3.1 \\
144 k=452 ; & k=3.1 \\
256 k=806 ; & k=3.1 \\
400 k=1254 ; & k=3.1 \\
576 k=1810 ; & k=3.1
\end{aligned}
$$

What is the relation between the area and radius of a circle? $\quad A=3.1 r^{2}$

Satigfactory results were not obtained with this stuay guide because the counting of squares by students was not accurate. Only after the instructor made a count of the squares were the students able to proceed with their work. 
The table as completed in the study guide is a specimen of student work done on the guide.

In using this study guide it is suggested that:

1. The counting of squares be closely supervised.

2. That graph paper containing one-eighth-inch squares or smaller be used.

Exercises on interpretation of data which were developed by the Eight Year Study were also used. 7 Three situations each considering a quadratic relationship in a different

form (table, graph, verbal statement) were presented with interpretative statements to be evaluated or exercises to be performed by students. The first section is presented below and correct responses are given for each statement: Interpretation of Data and Application of Principles

Statement: During a campaign to reduce automobile accidents, a class in the Lincoin School was studying some of the factors involved. Data were studied to find out whether there is a relationship between speed and the number of accidents. A question arose as to how far a car travels before coming to a stop after the brakes are applied. The following data were found in a magaine article. The speed is given in miles per hour and the distance required for a car to come to a stop after the brakes are applied is measured in feet:

$\mathbf{s}=$ speed in miles per hour

$\mathrm{d}=$ aistance in feet

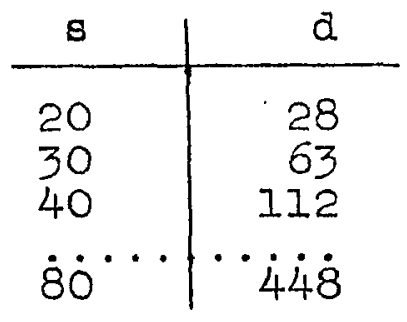

7. Materials developed by participants of the Mathematics Group, P.E.A. Workshop, Ohio State University, 1936. 
It was decided to study these data in order to understand more completely the way in which stopping distance depends upon speed.

Directions: Assuming that the data given in the aforementioned table are correct, mark in accordance with the following statements:

Mark with an $R$ - every statement which is a reasonable interpretation of lata.

Mark with a U - every statement which may be true but for which ingufficient facts are given to justify the interpretation.

Mark with an F - every statement which cannot be true because it is contradicted by the data.

F 1. The number of feet in which a car can be stopped after the brakes are applied has no relationship to the speed of the car.

R 2. The distance in which a car can be brought to a stop when going at a speed of 30 miles an hour is the same for all cars.

R 3. The distance in which any car can be stopped after the brakes are applied has some relationship to the square of the speed at which the car is traveling.

R 4. If the speed of the car is increased from 30 to 60 miles an hour, the distance required to stop a car is then approximately four times as great.

F 5. A car going 50 miles an hour can be stopped in less than twice the distance required when going 30 miles an hour.

U 6. There is no relationship between the distance required to stop a car going at 40 miles an hour and its weight.

U 7. High speeds cause accidents.

F 8. The distance required to stop a car when the speed is increased from 40 to 70 miles an hour does not increase any more than when the speed is increased from 30 to 60 miles an hour. 
204

R 9. A car moving at 45 miles an hour can be stopped in about 142 feot.

F 10. A car moving at the rate of 100 miles an hour can be stopped after the brakes are applied in less than 600 feet.

F 11. The increase in the distance required to stop a car when the speed is doubled from 40 to 80 miles an hour, is not any greater than the increase in distance when the speed is doubled from 30 to 60 miles an hour.

Thirty-two students evaluated the statements as shown in Table 21 .

TABLE 21

Student Evaluation of Interpretative Statements

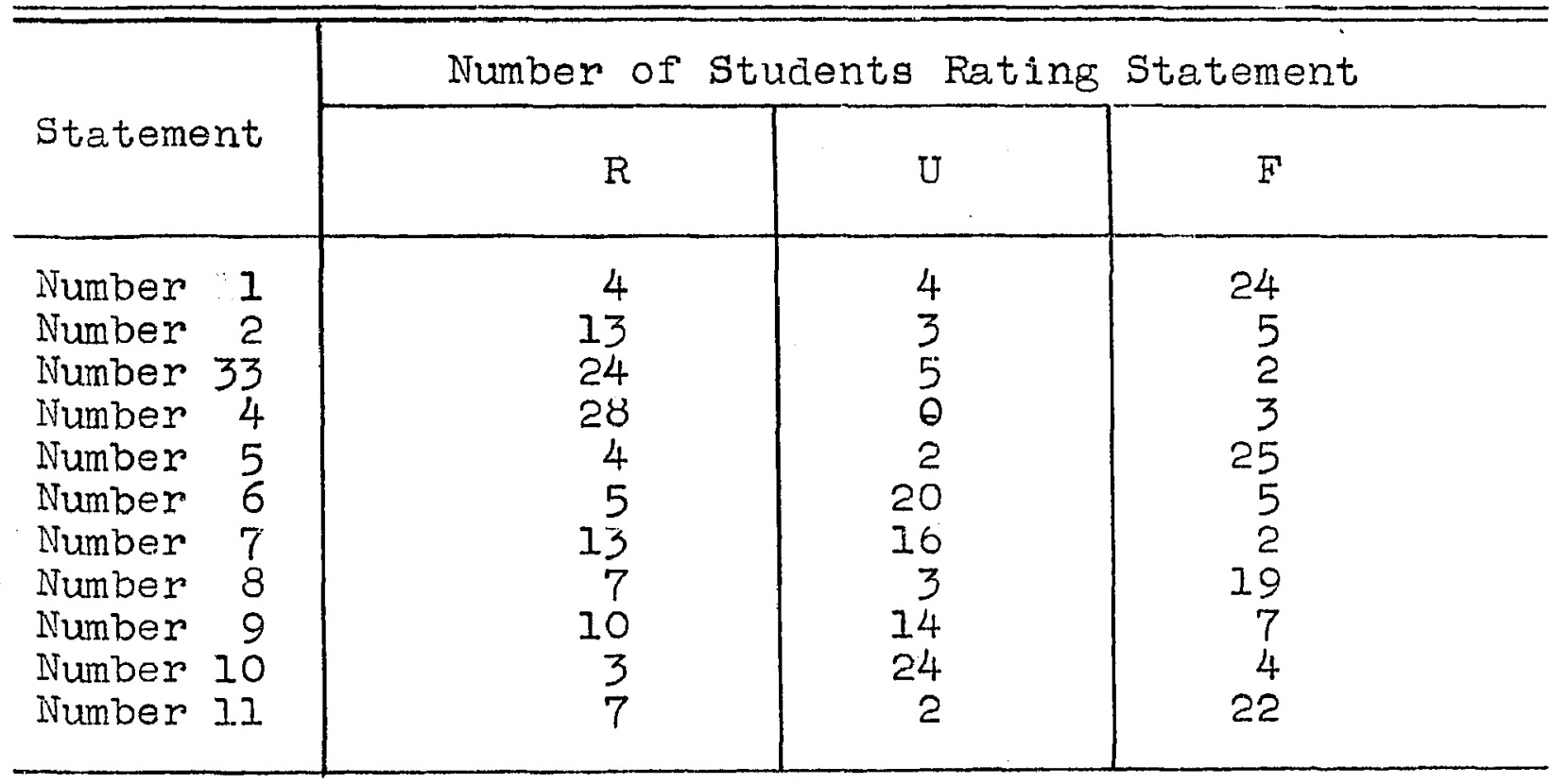

About three- $\theta$ ighth of the students rated statements 2 and 9 and three-fourths of them rated statement 10 as insufficient data, showing over-caution. Three-eighths of the students rated statement 7 as a reasonable interpre- 
205

tation, thus going beyond the data. Doubtless, the failure of these students to respond correctly to statements 9 and 10, was due to their inability to use appropriate computations to check the accuracy of the statements. Section 2 of the Progressive Education Association Test 5.5 (applying principles of variation) was also used. This section is reproduced below:

The following quotation is taken from an article printed in a daily newspaper:

"..........George I. Smith, an automotive engineer of the national capital, has made a study of the (automobile) brake situation in relation to speed fatalities and is far from being content.

"He points out tinat 10 years ago the usual stock passenger automobile sold to the general public rarely had a speed capacity in excess of 50 miles an hour. That, of course, is a high rate of speed, and the sreat weight of a motor car, striking at such a speed, creates an impact which is bound to cause severe results. But Mr. Smith asserts that while today the speed of stock motor cars has been stepped up to 70 miles an hour, there has not been a comparable advance in braixing power. The destructive power of a car going 70 miles an hour is almost exactly twice that of the same car going $50 \mathrm{miles}$ " --.Columbus Dispatch

The "destructive power" referred to in the article comes from the kinetic energy of the car, and this may be computed from the formula:

$$
K=\frac{1}{2} m V^{2}
$$

where $K=$ kinetic energy

$\mathrm{m}=$ mass (sometimes called "weight") of the car

$\mathrm{V}=$ velocity or speed of the car

The article says "the destructive power of a car going 70 miles an hour is almost exactly twice that of the same car going 50 miles. Note that. 70 is 1.4 times as great as 50 . 
Check $(\checkmark)$ any of the following statements with which you asree.

10. The article is incorrect. The destructive power of a car going 70 miles an hour cannot be almost twice that of the same car going 50 miles an hour.

11. The destructive power of a certain car bought ten years ago was less than it would be today.

12. If one of two cars of the same weight is mov1ng twice as fast as the other, its kinetic enerey is four times as great.

13. If one of two cars is $10 \%$ heav1er than the other, its destructive power will be 10\% greater provided both are moving at the same speed.

14. Since 70 is not twice 50 , the "destructive power" at 70 miles per hour cannot be twice as great.

15. Since $70^{2}$ is almost twice $50^{2}$, the kinetic energy of a car going 70 miles an hour will be about twice that of one going 50 miles per hour.

16. The kinetic energy of a car moving 50 miles an hour is 100 times as great as that of the same car moving 5 miles an hour.

17. The article is correct. The destructive power of a car going 70 miles an hour is almost exactly twice that of the same car going only 50 miles an hour.

18. Not enough information has been iven to enable one to decide whether the newspaper article is accurate or not.

19. The destructive power of two cars with the same "horsepower" will be the same.

20. The kinetic energy of a car moving 40 miles an hour will be four times as great as that of the same car moving 20 miles an hour.

21. The destructive power of a car weighing 4000 pounds will be twice as great as that of a car weighing 2000 pounds.

22. If the weight of one car is twice that of a second car, the "destructive power" of the first is four 
times that of the second.

23. The destructive power of a car does not depend upon its weight.

24. The destructive power of one car which

is 1.4 times as heavy as a second car will. be 1.4 times as great.

25. Car A is twice as heavy as car B, but is moving only half as fast when it strikes. How will the destructive power of the two cars compare?

-a. It will be the same.

b. Car A will be twice as destructive as car B.

c. Car A will be half as destructive as car $B$.

d. No definite answer is possible.

Fourteen of these statements represent multiplicative variations and four of them are general statements representing crude errors or extrapolations. One statement illustrates an additive variation. Medians of student responges to the three types of statements are shown in Table 22. 
TABLE 22

Medians of Student Responges to Test 5.5

\begin{tabular}{|c|c|c|}
\hline Type of Variation & Median & Maximum \\
\hline $\begin{array}{l}\text { Additive } \\
\text { Right } \ldots \ldots \ldots \ldots \ldots \\
\text { Wrong } \ldots \ldots \ldots \ldots \ldots\end{array}$ & $\begin{array}{l}1 \\
0\end{array}$ & $\begin{array}{l}1 \\
0\end{array}$ \\
\hline $\begin{array}{l}\text { Multiplicative } \\
\text { Fractions } \\
\text { Right } \ldots \ldots \ldots \ldots . \\
\text { Wrons } \ldots \ldots \ldots \ldots\end{array}$ & $\begin{array}{l}0 \\
1\end{array}$ & $\begin{array}{l}2 \\
3\end{array}$ \\
\hline $\begin{array}{l}\text { Whole Numbers } \\
\text { Right } \ldots \ldots \ldots \ldots \\
\text { Wrong } \ldots \ldots \ldots \ldots\end{array}$ & $\begin{array}{l}4 \\
1\end{array}$ & $\begin{array}{l}6 \\
3\end{array}$ \\
\hline $\begin{array}{l}\text { General } \\
\quad \text { Right } \ldots \ldots \ldots \ldots \ldots \\
\text { Wrong } \ldots \ldots \ldots \ldots\end{array}$ & $\begin{array}{l}0 \\
2\end{array}$ & $\begin{array}{l}0 \\
4\end{array}$ \\
\hline
\end{tabular}

The work for the year culminated in the re-administration of the Interpretation of Data Test.

Although this description has been given in great detail, 1t is not complete. To include all of the discussions and activities would be a formidable undertaking. Since the study guide was the principal teaching device, the writer feels that the essential and characteristic activities of the course have been recorded in the descriptions of the study guides.

Chapter 6 will include an evaluation of these activities in terms of their contribution to promoting growth in the ability to interpret data. 


\section{Chapter Six}

Evaluating Student Ab1lities To Interpret Data

\section{Significance of Gains in Ability to Interpret Data}

The principal means of determining student growth in ability to interpret data was through an analysis of the scores made on the two administrations of the Interpretation of Data Test (Lower Level). The Initial administration of the test occurred in December, over three months after the experimental work had begun. An order for the tests was placed during the Summer of 1950 and delivery was promised in september. However, due to delays in printing, the tests were not delivered until December.

The following description of the test is Elven by the publishers:

The ability to interpret data includes two main aspects: (I) the ability to perceive relationshipg in data which are assumed to be new to the student, and (2) the ability to recognize certain Iimitations of data. The Interpretation of Data Tests were developed to measure these abilities.

The first type of behavior sampled by these tests involves the ability to make comparisons, to see common elements in data, and to recognize prevailing tendencies in the data. This behavior is dependent on the ability to read the siven data, to make simple computations, and to understand the symbolism used. These operations vary somewhat. for different types of data.

The second type of behavior measured by the tests is the ability to recognize the limitations of given data which are asgumed to be dependable. A student who develops this ability recolnizes 
what other information, in adiltion to that which is given, is necessary in order to be reasonably sure of certain types of interpretations. He refraing from making judgments relative to implied. causes, effects, or purposes until he has necessary facts at hand.

The achievement of the student as revealed by the test may be analyzed by means of the data sheet in terms of two related questions (Table 23 may be used for reference as the following analysis is read):

(1) To what extent does the student recognize the IImitations of the data?

In general, one may reach some tentative conclusions about this question chiefly on the basis of the scores on General Accuracy (Col. 1), Over-caution (Col. 4), and Golng Beyond Data (Col. 5). The General Accuracy score is the per cent of the statements in which the student's judgment agreed with the key, that is, the student judged as true those statements keyed as true, insufficlent data as insufficient data, and the like..... ... The scores shown in columns 4,5 , and 6 reveal the types of errors that the student made when he failed to be accurate in his judgments. Thus in Column 4, the per cent of statements in which the student tended to require more qualifications than necessary on the basis of the given data is indicated. This score gives some measure of the student's tendency to call true or false statements uncertain. In column 5 is shown the per cent of statements in which the student tended to ascribe truth or falsity to interpretations which the data would not justify. A high score here is usually considered undesirable because it indicates the tendency of the student to go beyond the limita of the given data and to make definite judgments about statements for which information is insufficient.

1. Manual of Directions, Interpretation of Data Test - - Lower Level, p. 2 . 
(2) How accurately does the student percelve various types of relationghips in the data?

By examining the scores in columns 2,3 , and 6, some tantative conclusions about this question may be reached. As stated above, the score in Column 1 gives the per cent of accuracy with which the student is able to judge limitations of interpretations dealing with all types of relationships. Scores in Columns 2 and 3 are sub-scores of the General Accuracy score. Each sub-score refers to the accuracy with which the student judges certain of the relationships involved in the interpretation.

Column 2 gives the score on the student's per cent accuracy in recognizing those statements which are true or false. A high score indicates that the student is able to judge accurately statements that involve comparison of points in the data, and recognition of or comparison of trends. The score on "Crude Errorg" (Col. 6) Indicates errors in judgment in which the student marked as true, statements that are false, and vice versa. Such errors may be due to vocabulary difficulties, to carelessness; or to almost complete inability to identify the relationships involved.

Column 3. gives the per cent of accuracy in judging statements which cannot be justified without the use of information from other sources. These statements include relationships such as cause, effect, purpose, and analogy. ${ }^{2}$

As was stated in Chapter 4, the outstanding weakness of most students was their tendency to extrapolate or to go beyond the limits of the data in reaching conclusions. This is shown in Tables 23 and 24, by the high median and mean scores in column 5. From the data, the instructor of these classes concluded that students at this stage, generally had a tendency to ascribe truth or falsity to inter- 
pretations which the data would not justify.

An inspection of the Desember (1950) scores and the June (1951) scores on the Interpretation of Data Test as shomn in Tables 23 and 25, indicates that the students of section 1 improved in general accuracy (col. 1), ability to evaluate atatements involving insufficient data (col. 3), and ability to evaluate statements which involved going beyond the limitg of the data (col. 5). There was no apparent growth in the ablilty to evaluate statements. Which, on the basis of the data, were definitely true or definitely false. (col. 2). The tendency to require more qualifications than necessary on the basis of the given data was not improved as shown in column 4. There was no change in the mean score on crude errors--true statements marked false, and vice versa (column 6).

Students in section 2 improved in all categories of the test except "crude error" (Tables 24 and 26).

The changes in mean scores for the two sections are shown in Table 27. The greatest mean gaing for both sections were registered in the categories. "insufficient data" and "beyond data". The latter category was the outstanding weaknegs in both sections according to the data secured from the first administration of the test. It is evident that several of these gains are statistically insignificant, e.s. the changes in "crude error" scores for both sections and the changes in "true-falss" and "over- 
TABIE 23

Scores On Interpretation Of Data Test For Section 1 December 1950

\begin{tabular}{|c|c|c|c|c|c|c|}
\hline \multirow{2}{*}{$\begin{array}{l}\text { Stud- } \\
\text { ent }\end{array}$} & \multicolumn{3}{|c|}{ Percentage of Accuracy } & \multicolumn{3}{|c|}{ Percentage of Errors } \\
\hline & $\begin{array}{c}\text { General } \\
(1)\end{array}$ & $\begin{array}{c}\text { True- } \\
\text { False } \\
(2)\end{array}$ & $\begin{array}{c}\text { Insuffi- } \\
\text { cient } \\
\text { Data(3) }\end{array}$ & $\begin{array}{c}\text { Over- } \\
\text { Caution } \\
(4)\end{array}$ & $\begin{array}{l}\text { Beyond } \\
\text { Data } \\
(5) \\
\end{array}$ & $\begin{array}{c}\text { Crude } \\
\text { Error } \\
(6) \\
\end{array}$ \\
\hline $\begin{array}{l}A \\
B \\
C \\
D \\
E \\
F \\
G \\
H \\
I \\
I \\
J \\
K \\
I \\
M \\
N \\
D \\
P\end{array}$ & $\begin{array}{l}60 \\
80 \\
62 \\
38 \\
42 \\
66 \\
28 \\
68 \\
50 \\
52 \\
44 \\
74 \\
30 \\
56 \\
64 \\
48\end{array}$ & $\begin{array}{l}60 \\
68 \\
72 \\
40 \\
56 \\
80 \\
56 \\
68 \\
60 \\
56 \\
52 \\
72 \\
56 \\
64 \\
76 \\
48\end{array}$ & $\begin{array}{l}60 \\
92 \\
52 \\
36 \\
28 \\
52 \\
0 \\
68 \\
40 \\
48 \\
36 \\
76 \\
4 \\
48 \\
52 \\
48\end{array}$ & $\begin{array}{r}16 \\
16 \\
8 \\
24 \\
12 \\
0 \\
0 \\
8 \\
8 \\
20 \\
8 \\
0 \\
8 \\
4 \\
12 \\
16\end{array}$ & $\begin{array}{r}40 \\
8 \\
48 \\
52 \\
72 \\
48 \\
100 \\
32 \\
60 \\
52 \\
64 \\
24 \\
96 \\
44 \\
48 \\
52\end{array}$ & $\begin{array}{l}24 \\
16 \\
20 \\
28 \\
32 \\
20 \\
44 \\
24 \\
32 \\
24 \\
40 \\
28 \\
36 \\
28 \\
12 \\
36\end{array}$ \\
\hline $\begin{array}{l}\text { Highest } \\
\text { Score }\end{array}$ & 80 & 80 & 92 & 24 & 100 & 44 \\
\hline Median & 54 & 60 & 48 & 8 & 50 & 28 \\
\hline Mean & 54 & 62 & 46 & 10 & 52 & 28 \\
\hline $\begin{array}{l}\text { Lowest } \\
\text { Score }\end{array}$ & 28 & 40 & 0 & 0 & 8 & 12 \\
\hline
\end{tabular}


TABLE 24

Scores On Interpretation Of Data Teat For Section 2 December 1950

\begin{tabular}{|c|c|c|c|c|c|c|}
\hline \multirow{2}{*}{$\begin{array}{l}\text { stud- } \\
\text { ent }\end{array}$} & \multicolumn{3}{|c|}{ Percentage of Accuracy } & \multicolumn{3}{|c|}{ Percentase of Errors } \\
\hline & $\begin{array}{c}\text { General } \\
(1)\end{array}$ & $\begin{array}{c}\text { True- } \\
\text { False } \\
(2)\end{array}$ & $\begin{array}{l}\text { Insuffic } \\
\text { cient } \\
\text { Data (3) }\end{array}$ & $\begin{array}{c}\text { Over- } \\
\text { Caution } \\
(4)\end{array}$ & $\begin{array}{l}\text { Beyond } \\
\text { Data } \\
(5)\end{array}$ & $\begin{array}{l}\text { Cruae } \\
\text { Error } \\
(6)\end{array}$ \\
\hline $\begin{array}{l}A \\
B \\
C \\
D \\
E \\
F \\
G \\
H \\
I \\
J \\
K \\
L \\
M \\
N \\
O \\
P \\
Q \\
R\end{array}$ & $\begin{array}{l}30 \\
62 \\
52 \\
42 \\
44 \\
32 \\
42 \\
38 \\
62 \\
62 \\
20 \\
34 \\
64 \\
32 \\
78 \\
68 \\
28 \\
56\end{array}$ & $\begin{array}{l}40 \\
44 \\
56 \\
40 \\
52 \\
56 \\
76 \\
68 \\
72 \\
68 \\
32 \\
28 \\
64 \\
36 \\
72 \\
80 \\
32 \\
64\end{array}$ & $\begin{array}{r}20 \\
80 \\
48 \\
44 \\
36 \\
8 \\
8 \\
8 \\
52 \\
56 \\
8 \\
40 \\
64 \\
28 \\
84 \\
56 \\
24 \\
48\end{array}$ & $\begin{array}{r}24 \\
28 \\
20 \\
12 \\
12 \\
8 \\
0 \\
8 \\
4 \\
8 \\
12 \\
32 \\
8 \\
16 \\
16 \\
8 \\
20 \\
12\end{array}$ & $\begin{array}{l}80 \\
20 \\
52 \\
56 \\
64 \\
92 \\
88 \\
92 \\
48 \\
36 \\
88 \\
60 \\
36 \\
72 \\
16 \\
44 \\
68 \\
52\end{array}$ & $\begin{array}{l}36 \\
28 \\
24 \\
48 \\
36 \\
36 \\
20 \\
24 \\
24 \\
16 \\
56 \\
40 \\
28 \\
44 \\
12 \\
12 \\
48 \\
24\end{array}$ \\
\hline $\begin{array}{l}\text { Highest } \\
\text { Score }\end{array}$ & 78 & 80 & 84 & 32 & 92 & 56 \\
\hline Median & 43 & 56 & 42 & 12 & 58 & 28 \\
\hline Mean & 47 & 54 & 40 & 14 & 59 & 31 \\
\hline $\begin{array}{l}\text { Lowest } \\
\text { Score }\end{array}$ & 20 & 28 & 8 & 0 & 16 & 12 \\
\hline
\end{tabular}


TABLE 25

Scores On Interpretation of Data Test For Section 1 June 1951

\begin{tabular}{|c|c|c|c|c|c|c|}
\hline \multirow{2}{*}{$\begin{array}{l}\text { Stud- } \\
\text { ent }\end{array}$} & \multicolumn{3}{|c|}{ Percentabe of Accuracy } & \multicolumn{2}{|c|}{ Percentage of } & Errors \\
\hline & $\begin{array}{c}\text { General } \\
(1)\end{array}$ & $\begin{array}{l}\text { True- } \\
\text { Falge } \\
(2)\end{array}$ & $\begin{array}{l}\text { Insuffi- } \\
\text { cient } \\
\text { Data (3) }\end{array}$ & $\begin{array}{c}\text { Over- } \\
\text { Caution } \\
(4)\end{array}$ & $\begin{array}{l}\text { Beyond } \\
\text { Data } \\
(5)\end{array}$ & $\begin{array}{l}\text { Crude } \\
\text { Error } \\
(6)\end{array}$ \\
\hline $\begin{array}{l}\mathrm{A} \\
\mathrm{B} \\
\mathrm{C} \\
\mathrm{D} \\
\mathrm{E} \\
\mathrm{F} \\
\mathrm{G} \\
\mathrm{H} \\
\mathrm{I} \\
\mathrm{J} \\
\mathrm{K} \\
\mathrm{L} \\
\mathrm{M} \\
\mathrm{N} \\
\dot{P} \\
\mathrm{P}\end{array}$ & $\begin{array}{l}72 \\
78 \\
58 \\
44 \\
58 \\
84 \\
28 \\
68 \\
66 \\
54 \\
46 \\
84 \\
18 \\
50 \\
68 \\
72\end{array}$ & $\begin{array}{l}76 \\
68 \\
76 \\
56 \\
52 \\
72 \\
52 \\
56 \\
64 \\
56 \\
64 \\
72 \\
20 \\
52 \\
64 \\
64\end{array}$ & $\begin{array}{l}68 \\
88 \\
40 \\
32 \\
64 \\
96 \\
4 \\
80 \\
68 \\
52 \\
28 \\
96 \\
16 \\
48 \\
72 \\
80\end{array}$ & $\begin{array}{r}12 \\
12 \\
12 \\
20 \\
12 \\
8 \\
8 \\
16 \\
20 \\
12 \\
0 \\
8 \\
24 \\
4 \\
8 \\
12\end{array}$ & $\begin{array}{r}32 \\
12 \\
60 \\
68 \\
36 \\
4 \\
96 \\
20 \\
32 \\
28 \\
68 \\
4 \\
84 \\
52 \\
28 \\
20\end{array}$ & $\begin{array}{l}12 \\
20 \\
12 \\
24 \\
36 \\
20 \\
40 \\
28 \\
16 \\
32 \\
40 \\
20 \\
56 \\
44 \\
24 \\
24\end{array}$ \\
\hline $\begin{array}{l}\text { Highest } \\
\text { Score }\end{array}$ & 84 & 76 & 96 & 24 & 96 & 56 \\
\hline Median & 62 & 64 & 66 & 12 & 32 & 24 \\
\hline Mean & 59 & 60 & 58 & 12 & 40 & 28 \\
\hline $\begin{array}{l}\text { Lowest } \\
\text { Score }\end{array}$ & 28 & 20 & 4 & 0 & 4 & 12 \\
\hline
\end{tabular}


TABIE 26

Scores On Interpretation of Data Test For Section 2 June 1951

\begin{tabular}{|c|c|c|c|c|c|c|}
\hline \multirow{2}{*}{$\begin{array}{l}\text { Stud- } \\
\text { ent }\end{array}$} & \multicolumn{2}{|c|}{ Percentage of } & \multirow{2}{*}{$\begin{array}{l}\text { Accuracy } \\
\text { Insuffi- } \\
\text { cient } \\
\text { Data (3) }\end{array}$} & \multicolumn{2}{|c|}{ Percentase of } & Errors \\
\hline & $\begin{array}{c}\text { General } \\
(1)\end{array}$ & $\begin{array}{l}\text { True- } \\
\text { False } \\
(2)\end{array}$ & & $\begin{array}{c}\text { Over- } \\
\text { Gaution } \\
(4)\end{array}$ & $\begin{array}{c}\text { Beyond } \\
\text { Data } \\
\text { (5) }\end{array}$ & $\begin{array}{c}\text { Oruae } \\
\text { Error } \\
(6)\end{array}$ \\
\hline $\begin{array}{c}A \\
B \\
C \\
D \\
\text { E } \\
\text { F } \\
G \\
\cdot H \\
I \\
J \\
K \\
L \\
M \\
N \\
O \\
P \\
Q \\
R\end{array}$ & $\begin{array}{l}46 \\
62 \\
60 \\
48 \\
66 \\
52 \\
58 \\
76 \\
68 \\
68 \\
26 \\
46 \\
66 \\
58 \\
76 \\
68 \\
28 \\
70\end{array}$ & $\begin{array}{l}52 \\
44 \\
64 \\
56 \\
72 \\
44 \\
84 \\
88 \\
64 \\
68 \\
28 \\
44 \\
52 \\
56 \\
64 \\
76 \\
48 \\
64\end{array}$ & $\begin{array}{c}40 \\
80 \\
56 \\
40 \\
60 \\
60 \\
32 \\
64 \\
72 \\
68 \\
24 \\
48 \\
80 \\
60 \\
88 \\
60 \\
8 \\
76\end{array}$ & $\begin{array}{r}12 \\
16 \\
20 \\
8 . \\
0 \\
24 \\
0 \\
8 \\
12 \\
0 \\
12 \\
8 \\
4 \\
4 \\
4 \\
12 \\
8 \\
8\end{array}$ & $\begin{array}{l}60 \\
20 \\
44 \\
60 \\
40 \\
40 \\
68 \\
36 \\
28 \\
32 \\
76 \\
52 \\
20 \\
40 \\
12 \\
40 \\
88 \\
24\end{array}$ & $\begin{array}{l}36 \\
40 \\
16 \\
36 \\
28 \\
32 \\
24 \\
4 \\
24 \\
32 \\
60 \\
48 \\
40 \\
40 \\
32 \\
12 \\
44 \\
28\end{array}$ \\
\hline $\begin{array}{l}\text { Highest } \\
\text { Score }\end{array}$ & 76 & 88 & 88 & 24 & 88 & 60 \\
\hline Median & 59 & 60 & 60 & 8 & 40 & 32 \\
\hline Mean & 58 & 59 & 56 & 9 & 43 & 32 \\
\hline $\begin{array}{l}\text { Lowegt } \\
\text { Score }\end{array}$ & 26 & 28 & 8 & 0 & 12 & 4 \\
\hline
\end{tabular}


TABLE 27

Mean Gains On Interpretation of Data Test

\begin{tabular}{l|c|c|c|c|c|c}
\hline \multirow{2}{*}{ Students } & \multicolumn{2}{|c|}{ Percentage of Accuracy } & \multicolumn{2}{c|}{ Percentage of Errors } \\
\cline { 2 - 6 } & $\begin{array}{r}\text { General } \\
\text { Accuracy }\end{array}$ & $\begin{array}{r}\text { True } \\
\text { False }\end{array}$ & $\begin{array}{c}\text { Insuf- } \\
\text { ficient } \\
\text { Data }\end{array}$ & $\begin{array}{r}\text { Over } \\
\text { Caution }\end{array}$ & $\begin{array}{c}\text { Beyond } \\
\text { Data }\end{array}$ & $\begin{array}{c}\text { Crude } \\
\text { Error }\end{array}$ \\
\hline Section 1 & $\begin{array}{r}5.4 \\
\text { Section 2 }\end{array}$ & $\begin{array}{r}-2.0 \\
4.9\end{array}$ & $\begin{array}{r}12.0 \\
16.9\end{array}$ & $\begin{array}{r}-2.0 \\
4.9\end{array}$ & $\begin{array}{r}12.0 \\
15.8\end{array}$ & $\begin{array}{r}0 \\
-1.0\end{array}$ \\
\hline
\end{tabular}

caution" scores for section 1 . To determine the significance of the differences between means, values of $t$ were computed by the following formula for small samples which are paired and correlated:

$$
t=\frac{M_{d}}{\sqrt{\frac{\sum x_{d}^{2}}{N-1)}}}
$$

where $M_{d}=\begin{aligned} & \text { mean of the } N \text { difference of paired } \\ & \text { observations. }\end{aligned}$

$$
x_{\mathrm{d}}=\begin{aligned}
& \text { deviation of a difference from the } \\
& \text { mean of the differences.3 }
\end{aligned}
$$

According to Guilford, "Is defined as the ratio of a deviation to a standard error" 4 To the writer, the $t$ ratio in this situation is, roughly, the ratio of the total

3. J. P. Guilford, Fundamental Statistics in Psycholoxy and Education, pp. 228-229.

4. Ibid., p. 208 
change (the product of the number of students and the mean change) to the sum of the absolute values of deviations (of differencer) from the mean (of the differences). When the sum of the deviations increases the value of $t$ decreases and the chances for the value of $t$ to occur from random sampling are increased. Then the sum of the deviations decreases, the value of $t$ increases, and the chances for the value of $t$ to occur from random sampling are decreased. In the latter statement the smallness of deviations from the mean represents a trend toward uniform change and may be due to a specific cause. In the former statement dhange is unordered and may reflect a multiplicity of causes.

Gullford states the following concerning confidence levelg for $t$ :

The larger the $t$, the less likely it is that it could occur by random samplins. There is general agreement that when $t$ is as large as 1.96 (in normal sampling distributions) we may regard $t$, and the deviations for which it stands, as 'sienificant'. In a normal distribution, a $t$ that deviates more than 1.96 (in either direction) from the mean would occur only 5 times in 100. This criterion is often referred to as 'significant at the .05 level of confidence', ....... We could reject the null hypothesis with confidence that only 5 times in 100 would we be wrong in so doing. .......... A more confident criterion of rejection requires a $t$ as large as 2.58, at which value there is less than 1 chance in 100 that a $t$ as large or larger could have occurred by chance. 5

The problem is to determine whether the mean of the difterences for each behavior in the interpretation of data,

5. Ibid., pp. 208-209. 
is significantly different from a change of zero. The null hypothesis in this case is the assumption that the mean of the differences is zero.

TABLE 28

Significance of Difference in Meang

\begin{tabular}{|c|c|c|c|c|}
\hline \multirow{2}{*}{ Behaviors Evaluated } & \multicolumn{2}{|c|}{ Section 1} & \multicolumn{2}{|r|}{ Section 2} \\
\hline & $\begin{array}{l}\text { Value } \\
\text { of } t\end{array}$ & $\begin{array}{l}\text { Level of } \\
\text { Confldence* }\end{array}$ & $\begin{array}{l}\text { Value } \\
\text { of } t\end{array}$ & $\begin{array}{l}\text { Level of } \\
\text { Confidence }\end{array}$ \\
\hline $\begin{array}{l}\text { General Accuracy } \\
\text { True-False } \\
\text { Ingufficient Data } \\
\text { Over-Caution } \\
\text { Beyond Data } \\
\text { Crude Error }\end{array}$ & $\begin{array}{l}2.19 \\
\text { Neg: } \\
2.88 \\
\text { Neg. } \\
2.73 \\
0\end{array}$ & $\begin{array}{l}5 \%+ \\
-\overline{1 \%} \\
-\overline{1 \%} \\
--\end{array}$ & $\begin{array}{l}3.8 \\
1.8 \\
3.97 \\
2.25 \\
3.58 \\
\text { NeB. }\end{array}$ & $\begin{array}{l}0.1 \%- \\
10 \%+ \\
0.1 \%+ \\
5 \%+ \\
0.1 \%- \\
---\end{array}$ \\
\hline Number of Students & \multicolumn{2}{|r|}{16} & \multicolumn{2}{|r|}{18} \\
\hline
\end{tabular}

The values of $t$ for the various categories of the test are summarized in Table 28. The levels of confidence were secured from Fisher's Table of $t$ which gives values of $t$ appropriate for small samples. 6

In terms of this study, it must be determined whether or not student abilities for interpreting data were significantly better in June, 1951 than they were in December, 1.950. According to the values of $t$ listed in Table 28, the null p. 360 .

6. Palmer 0. Johnson, Statistical Methods in Research, 
hypothesis is rejected for section 2 at about the $0.1 \%$ level of confidence in three categories of the teat and at better than the $5 \%$ level in one category. In other words for section 2, the mean of the differences is significantly different from zero in:

I. general accuracy when interpreting data. (The probability that the mean difference in general accuracy occurred by random sampling is about 1 chance in 1000).

2. abil1ty to evaluate statements which involve going beyond the limits of the data.

3. ability to evaluate statements involving ingufficient data.

4. Improvement in the tendency to require more qualifications than necessary on the basis of the given data (over-caution).

For section 1 , the null hypothesis is rejected at something better than 5\% level of confidence for one category and at almost the $1 \%$ level for two categorles. That is, the mean of the differences is significantly different from zero in:

1. general accuracy when interpreting data.

2. ability to evaluate statements involving insufficient data.

3. ability to evaluate statements which involve going beyond the limits of the data.

It is evident that the null hypothesis cannot be rejected in the "crude error" category for both sections. Neither can 1 t be rejected for section $I$ in the categories of "truefalse" and "over-caution". For section 2, chances are too 
high (1:10) for its rejection in the "true-falso" catesory .

The question arlses now concerning the reasons for lack of pupil growth in the categories of true-false and crude error. A possible answer to the question lies in the reliability of the various scores. The following comment is given by Smith and Tyler concerning the reliability of Test 2.71 (Interpretation of Data Test, Lower Level):

For these 15 populations the reliability coefficlents of the beyond data and insufficient data scores are of the same order of magnitude as are those of the general accuracy score. The reliability of the other scores analogous to those of Form 2.52 are a little lower with the exception of those for crude errors which, as one might expect, are erratic and tend to be rather low. This same general pattern is found for each grade. 7

No reliability coefficients were presented by Smith and Tyler for the true-false score. However--descriptions of procedures for constructing Test 2.71 and Test 2.52 (Interpretation of Data Test, Upper Level) were almost 1dentical except for simplifications in vocabulary and responses, and selection of problem situations for test 2.71 . The following statement is made by Smith and Tyler concerning true-false statements in Test 2.52: ".... for these populations the reliability coefficients for all scores except crude errors and accuracy with true-and-false statements are sufficiently

7. E. R. Smith and R. W. Tyler, Appraising and Recordins Student Progress, p. 65. 
high for group interpretation": 8

From this information it is obvious that conclusions cannot be reached relative to student growth in the crudeerror category. Any conclusions relative to stadent growth in the true-false category would be uncertain because of lack of data relative to rellability coefficients.

Another point to be considered is that students generally are alert to interpretations which are drawn from sufficient facts (e.g. true-false statements). Teaching, especially in mathematics, is based on problemituations which present sufficient data for solutions. Rare indeed Is the teacher who uses problem situations which have superfluous data or insufficient data for solution of the situation. It is quite feasible that these students had had much experience in earlier grades with definitely true or false statements. The teacher of these classes was also inclined toward an emphasis in teaching which would reduce the general tendency to go beyond the limits of the data, the weakness discovered from an analysis of the intial test results.

The changes in all categories represent Erowth over a 7 month period, since the Interpretation of Data Test was first administered in December--3 months after the beginning of the school year. It is possible that the

8. Ibid., p. 75 . 
TABLE 29

Scores On Interpretation of Data liest

By Students Having Higher Intelligence quotients

December 1950 and June 1951

\begin{tabular}{|c|c|c|c|c|c|c|c|c|c|c|c|c|}
\hline \multirow{3}{*}{$\begin{array}{l}\text { Stu- } \\
\text { dent }\end{array}$} & \multicolumn{6}{|c|}{ Percentage of Accuracy } & \multicolumn{6}{|c|}{ Percentage of Errors } \\
\hline & \multicolumn{2}{|c|}{$\begin{array}{c}\text { General } \\
\text { (1) }\end{array}$} & \multicolumn{2}{|c|}{$\begin{array}{l}\text { True- } \\
\text { False } \\
\text { (2) }\end{array}$} & \multicolumn{2}{|c|}{$\begin{array}{l}\text { Insuff'i- } \\
\text { cient } \\
\text { Data (3) }\end{array}$} & \multicolumn{2}{|c|}{$\begin{array}{l}\text { Over- } \\
\text { Caution } \\
(4\rangle)\end{array}$} & \multicolumn{2}{|c|}{$\begin{array}{c}\text { Beyond } \\
\text { Data } \\
\text { (5) }\end{array}$} & \multicolumn{2}{|c|}{$\begin{array}{c}\text { Crude } \\
\text { Error } \\
(6)\end{array}$} \\
\hline & D & $\mathrm{J}$ & $D$ & $\mathrm{~J}$ & D & $J$ & $D$ & $J$ & D & $\mathrm{J}$ & D & $\mathrm{J}$ \\
\hline $\begin{array}{l}A \\
C \\
D \\
F \\
H \\
J \\
I \\
I \\
N \\
P \\
C: \\
C ! \\
E ! \\
H ! \\
I ! \\
J ! \\
L ! \\
M ! \\
O \\
R ! \\
P ! \\
D\end{array}$ & $\begin{array}{l}60 \\
62 \\
38 \\
66 \\
68 \\
52 \\
50 \\
74 \\
56 \\
48 \\
52 \\
44 \\
38 \\
62 \\
62 \\
34 \\
64 \\
78 \\
56 \\
68 \\
42\end{array}$ & $\begin{array}{l}72 \\
58 \\
44 \\
84 \\
68 \\
54 \\
66 \\
84 \\
50 \\
72 \\
60 \\
66 \\
76 \\
68 \\
68 \\
46 \\
66 \\
76 \\
70 \\
68 \\
58\end{array}$ & $\begin{array}{l}60 \\
72 \\
40 \\
80 \\
68 \\
56 \\
60 \\
72 \\
64 \\
48 \\
56 \\
52 \\
68 \\
72 \\
68 \\
28 \\
64 \\
72 \\
64 \\
80 \\
56\end{array}$ & $\begin{array}{l}76 \\
76 \\
56 \\
72 \\
56 \\
56 \\
64 \\
72 \\
52 \\
64 \\
64 \\
72 \\
88 \\
64 \\
68 \\
44 \\
52 \\
64 \\
64 \\
76 \\
52\end{array}$ & $\begin{array}{l}60 \\
52 \\
36 \\
52 \\
68 \\
48 \\
40 \\
76 \\
48 \\
48 \\
48 \\
36 \\
8 \\
52 \\
56 \\
40 \\
64 \\
84 \\
48 \\
56 \\
28\end{array}$ & $\begin{array}{l}68 \\
40 \\
32 \\
96 \\
80 \\
52 \\
68 \\
96 \\
48 \\
80 \\
56 \\
60 \\
64 \\
72 \\
68 \\
48 \\
80 \\
88 \\
76 \\
60 \\
64\end{array}$ & $\begin{array}{r}16 \\
8 \\
24 \\
0 \\
8 \\
20 \\
8 \\
0 \\
4 \\
16 \\
20 \\
12 \\
8 \\
4 \\
8 \\
32 \\
8 \\
16 \\
12 \\
8 \\
12\end{array}$ & $\begin{array}{r}12 \\
12 \\
20 \\
8 \\
16 \\
12 \\
20 \\
8 \\
4 \\
12 \\
20 \\
0 \\
8 \\
12 \\
0 \\
8 \\
4 \\
4 \\
8 \\
12 \\
12\end{array}$ & $\begin{array}{l}40 \\
48 \\
52 \\
48 \\
32 \\
52 \\
60 \\
24 \\
44 \\
52 \\
52 \\
64 \\
92 \\
48 \\
36 \\
60 \\
36 \\
16 \\
52 \\
44 \\
72\end{array}$ & $\begin{array}{r}32 \\
60 \\
68 \\
4 \\
20 \\
48 \\
32 \\
4 \\
52 \\
20 \\
44 \\
40 \\
36 \\
28 \\
32 \\
52 \\
20 \\
12 \\
24 \\
40 \\
36\end{array}$ & $\begin{array}{l}24 \\
20 \\
28 \\
20 \\
24 \\
24 \\
32 \\
28 \\
28 \\
36 \\
24 \\
36 \\
24 \\
24 \\
16 \\
40 \\
28 \\
12 \\
24 \\
12 \\
32\end{array}$ & $\begin{array}{r}12 \\
12 \\
24 \\
20 \\
28 \\
32 \\
16 \\
20 \\
44 \\
24 \\
16 \\
28 \\
4 \\
24 \\
32 \\
48 \\
40 \\
32 \\
28 \\
12 \\
36\end{array}$ \\
\hline High & 78 & 84 & 80 & 88 & 84 & 96 & 32 & 20 & 92 & 68 & 40 & 48 \\
\hline Median & 56 & 66 & 64 & 64 & 48 & 68 & 8 & 12 & 48 & 32 & 24 & 24 \\
\hline Mean & 56 & 65 & 62 & 64 & 50 & 66 & 12 & 10 & 49 & 34 & 25 & 25 \\
\hline Low & 34 & 44 & 28 & 44 & 8 & 32 & 0 & 0 & 16 & 4 & 12 & 4 \\
\hline
\end{tabular}




\section{TABLE 30}

Scores On Interpretation of Data Test

By Students Having Lower Intelligence Quotients December 1950 and June 1951

\begin{tabular}{|c|c|c|c|c|c|c|c|c|c|c|c|c|}
\hline \multirow{3}{*}{ student } & \multicolumn{6}{|c|}{ Percentage of Accuracy } & \multicolumn{6}{|c|}{ Percentage of Errors } \\
\hline & \multicolumn{2}{|c|}{$\begin{array}{c}\text { General } \\
\text { (I) }\end{array}$} & \multicolumn{2}{|c|}{$\begin{array}{l}\text { True- } \\
\text { Falge } \\
\text { (2) }\end{array}$} & \multicolumn{2}{|c|}{$\begin{array}{l}\text { Inguffi- } \\
\text { cient } \\
\text { Data(3) }\end{array}$} & \multicolumn{2}{|c|}{$\begin{array}{l}\text { Over- } \\
\text { Caution } \\
(4)\end{array}$} & \multicolumn{2}{|c|}{$\begin{array}{c}\text { Beyond } \\
\text { Data } \\
\text { (5) }\end{array}$} & \multicolumn{2}{|c|}{$\begin{array}{c}\text { Crude } \\
\text { Error } \\
(6)\end{array}$} \\
\hline & D & $\mathrm{J}$ & $\mathrm{D}$ & $J$ & D & $\mathrm{J}$ & D & $\mathrm{J}$ & $D$ & $\mathrm{~J}$ & $\mathrm{D}$ & $\mathrm{J}$ \\
\hline $\begin{array}{l}B \\
G \\
G \\
K \\
M \\
O \\
A^{\prime} \\
B^{\prime} \\
D^{\prime} \\
F^{\prime} \\
G^{\prime} \\
K^{\prime} \\
N^{\prime} \\
Q^{\prime}\end{array}$ & $\begin{array}{l}80 \\
28 \\
44 \\
30 \\
64 \\
30 \\
62 \\
42 \\
32 \\
42 \\
20 \\
32 \\
28\end{array}$ & $\begin{array}{l}78 \\
28 \\
46 \\
18 \\
68 \\
46 \\
62 \\
48 \\
52 \\
58 \\
26 \\
58 \\
28\end{array}$ & $\begin{array}{l}68 \\
56 \\
52 \\
56 \\
76 \\
40 \\
44 \\
40 \\
56 \\
76 \\
32 \\
36 \\
32\end{array}$ & $\begin{array}{l}68 \\
52 \\
64 \\
20 \\
64 \\
52 \\
44 \\
56 \\
44 \\
84 \\
28 \\
56 \\
48\end{array}$ & $\begin{array}{r}92 \\
0 \\
36 \\
4 \\
52 \\
20 \\
80 \\
44 \\
8 \\
8 \\
8 \\
28 \\
24\end{array}$ & $\begin{array}{r}88 \\
4 \\
28 \\
16 \\
72 \\
40 \\
80 \\
40 \\
60 \\
32 \\
24 \\
60 \\
8\end{array}$ & $\begin{array}{r}16 \\
0 \\
8 \\
8 \\
12 \\
24 \\
28 \\
12 \\
8 \\
0 \\
12 \\
16 \\
20\end{array}$ & $\begin{array}{r}12 \\
8 \\
0 \\
24 \\
8 \\
12 \\
16 \\
8 \\
24 \\
0 \\
12 \\
4 \\
8\end{array}$ & $\begin{array}{c}8 \\
100 \\
64 \\
96 \\
48 \\
80 \\
20 \\
56 \\
92 \\
88 \\
88 \\
72 \\
68\end{array}$ & $\begin{array}{l}12 \\
96 \\
68 \\
84 \\
28 \\
60 \\
20 \\
60 \\
40 \\
68 \\
76 \\
40 \\
88\end{array}$ & $\begin{array}{l}16 \\
44 \\
40 \\
36 \\
12 \\
36 \\
28 \\
48 \\
36 \\
20 \\
56 \\
44 \\
48\end{array}$ & $\begin{array}{l}20 \\
40 \\
40 \\
56 \\
24 \\
36 \\
40 \\
36 \\
32 \\
24 \\
60 \\
40 \\
44\end{array}$ \\
\hline $\begin{array}{l}\text { Highest } \\
\text { Score }\end{array}$ & 80 & 78 & 76 & 84 & 92 & 88 & 28 & 24 & 100 & 96 & 56 & 60 \\
\hline Median & 32 & 48 & 52 & 52 & 24 & 40 & 12 & 8 & 72 & 60 & 36 & 40 \\
\hline Mean & 41 & 47 & 51 & 52 & 31 & 42 & 13 & 10 & 68 & 57 & 36 & 38 \\
\hline $\begin{array}{l}\text { Lowest } \\
\text { Score }\end{array}$ & 20 & 18 & 32 & 20 & 0 & 4 & 0 & 0 & 8 & 12 & 12 & 20 \\
\hline
\end{tabular}


changes in all categories would be more significant if the first administration could have been in september. Apparent Influence of Intelizence on Interpretation of Data

The writer believed that students having higher intelligence quotients made more progress than those having lower intelligence quotients. To test this hypothesis the scores of students from both sections were arranged in two groups:

1. a set of scores for those having "low average" or better, intelligence quotients (i.e.,85 and above). This group will be called the "superior" group.

2. a set of scores for those having intelligence quotients below 85. This group will be called the "infertor" group.

There were 21 students in the "superior" group, the range of I. Q.'s being 116--85. The "inferior" group was 13 students with an I. Q. range of 84--67. (See Tables 7 and 8 , Chapter 4). The mean and median reading percentiles of the superior group were respectively 42 and 40 , and for the inferior group, 18 and 24. The December-June scores for

$$
\text { TABLE } 31
$$

Mean Gaing on Interpretation Of Data Test

\begin{tabular}{|c|c|c|c|c|c|c|}
\hline \multirow{2}{*}{ Students } & \multicolumn{3}{|c|}{ Percentage of Accuracy } & \multicolumn{3}{|c|}{ Percentage of Errors } \\
\hline & $\begin{array}{l}\text { General } \\
\text { Accuracy }\end{array}$ & $\begin{array}{l}\text { True } \\
\text { False }\end{array}$ & $\begin{array}{l}\text { Insuf- } \\
\text { Pacient } \\
\text { Data }\end{array}$ & $\begin{array}{c}\text { Over } \\
\text { Caution }\end{array}$ & $\begin{array}{c}\text { Beyond } \\
\text { Data }\end{array}$ & $\begin{array}{l}\text { Crude } \\
\text { Error }\end{array}$ \\
\hline $\begin{array}{l}\text { High } I . Q . \\
\text { Low I.Q. }\end{array}$ & $\begin{array}{l}9.4 \\
6.3\end{array}$ & $\begin{array}{l}2.0 \\
1.0\end{array}$ & $\begin{array}{l}16.6 \\
11.4\end{array}$ & $\begin{array}{l}2.0 \\
2.2\end{array}$ & $\begin{array}{l}15.2 \\
10.8\end{array}$ & $\begin{array}{l}0 \\
-2.0\end{array}$ \\
\hline
\end{tabular}


these two groups are shown in Tables 29 and 30 . The mean gains for the two groups are shown in Table 3I. It is evident that the superior group registered greater mean gains in all categories of the test, except for "over-caution", and in this category the gains are practically the same.

The significance of these gains is summarized in Table 32.

TABLE 32

Significance of Difference In Means

\begin{tabular}{|c|c|c|c|c|}
\hline \multirow[b]{2}{*}{ Behaviors Evaluated } & \multicolumn{2}{|c|}{ Superiór Group } & \multicolumn{2}{|c|}{ Inferior Group } \\
\hline & $\begin{array}{l}\text { Value } \\
\text { of } t\end{array}$ & $\begin{array}{l}\text { Level of } \\
\text { Confidence }\end{array}$ & $\begin{array}{l}\text { Value } \\
\text { of } t\end{array}$ & $\begin{array}{l}\text { Level of } \\
\text { Confidence }\end{array}$ \\
\hline $\begin{array}{l}\text { General Accuracy } \\
\text { True-False } \\
\text { Insufficient Data } \\
\text { Over-Caution } \\
\text { Beyond Data } \\
\text { Crude Error }\end{array}$ & $\begin{array}{l}4.08 \\
- \\
4.58 \\
- \\
3.84 \\
0\end{array}$ & $\begin{array}{l}0.1 \%+ \\
- \\
0.1 \%+ \\
0.1 \% \\
-\end{array}$ & $\begin{array}{l}2.17 \\
- \\
2.2 \\
- \\
2.09 \\
\operatorname{Neg} .\end{array}$ & $\begin{array}{l}5 \%- \\
- \\
5 \% \\
5 \%- \\
-\end{array}$ \\
\hline Number of Students & & 21. & & 13 \\
\hline
\end{tabular}

From Table 32 one would conclude that the gains made by the superior group were more significant statistically than those by the inferior group. Apparent Influence of Readins on Interpretation of Data Another possible factor affecting ability to interpret data is reading ability. To compare the growth of good 
TABLE 33

Scores On Interpretation Of Data Test

By Students Having Better Reading Ability December 1950 and June 1951

\begin{tabular}{|c|c|c|c|c|c|c|c|c|c|c|c|c|}
\hline \multirow{3}{*}{ S tudent } & \multicolumn{6}{|c|}{ Percentage of Accuracy } & \multicolumn{6}{|c|}{ Percentage of Errors } \\
\hline & \multicolumn{2}{|c|}{$\begin{array}{c}\text { General } \\
\text { (I) }\end{array}$} & \multicolumn{2}{|c|}{$\begin{array}{l}\text { True- } \\
\text { False } \\
\text { (2) }\end{array}$} & \multicolumn{2}{|c|}{$\begin{array}{l}\text { Insuff1- } \\
\text { cient } \\
\text { Data(3) }\end{array}$} & \multicolumn{2}{|c|}{$\begin{array}{c}\text { Over- } \\
\text { Caution } \\
(4)\end{array}$} & \multicolumn{2}{|c|}{$\begin{array}{c}\text { Beyond } \\
\text { Data } \\
(5)\end{array}$} & \multicolumn{2}{|c|}{$\begin{array}{c}\text { Crude } \\
\text { Error } \\
(6)\end{array}$} \\
\hline & D & $J$ & $D$ & $J$ & D & $\mathrm{J}$ & $D$ & $\mathrm{~J}$ & $D$ & $\mathrm{~J}$ & D & $\mathrm{J}$ \\
\hline $\begin{array}{l}C \\
A \\
B \\
F \\
F \\
I \\
J \\
I \\
N \\
P \\
C \\
H^{\prime} \\
H^{\prime} \\
I^{\prime} \\
M^{\prime} \\
P^{\prime}\end{array}$ & $\begin{array}{l}62 \\
60 \\
80 \\
66 \\
50 \\
52 \\
74 \\
56 \\
48 \\
52 \\
38 \\
62 \\
64 \\
68\end{array}$ & $\begin{array}{l}58 \\
72 \\
78 \\
84 \\
66 \\
54 \\
84 \\
50 \\
72 \\
60 \\
76 \\
68 \\
66 \\
68\end{array}$ & $\begin{array}{l}72 \\
60 \\
68 \\
80 \\
60 \\
56 \\
72 \\
64 \\
48 \\
56 \\
68 \\
72 \\
64 \\
80\end{array}$ & \begin{tabular}{|l|}
76 \\
76 \\
68 \\
72 \\
64 \\
56 \\
72 \\
52 \\
64 \\
64 \\
88 \\
64 \\
52 \\
76
\end{tabular} & $\begin{array}{r}52 \\
60 \\
92 \\
52 \\
40 \\
48 \\
76 \\
48 \\
48 \\
48 \\
8 \\
52 \\
64 \\
56\end{array}$ & $\begin{array}{l}40 \\
68 \\
88 \\
96 \\
68 \\
52 \\
96 \\
48 \\
80 \\
56 \\
64 \\
72 \\
80 \\
60\end{array}$ & $\begin{array}{r}8 \\
16 \\
16 \\
0 \\
8 \\
20 \\
0 \\
4 \\
16 \\
20 \\
8 \\
4 \\
8 \\
8\end{array}$ & $\begin{array}{r}12 \\
12 \\
12 \\
8 \\
20 \\
12 \\
8 \\
4 \\
12 \\
20 \\
8 \\
12 \\
4 \\
12\end{array}$ & $\begin{array}{r}48 \\
40 \\
8 \\
48 \\
60 \\
52 \\
24 \\
44 \\
52 \\
52 \\
92 \\
48 \\
36 \\
44\end{array}$ & $\begin{array}{r}60 \\
32 \\
12 \\
4 \\
32 \\
48 \\
4 \\
52 \\
20 \\
44 \\
36 \\
28 \\
20 \\
40\end{array}$ & $\begin{array}{l}20 \\
24 \\
16 \\
20 \\
32 \\
24 \\
28 \\
28 \\
36 \\
24 \\
24 \\
24 \\
28 \\
12\end{array}$ & $\begin{array}{r}12 \\
12 \\
20 \\
20 \\
16 \\
32 \\
20 \\
44 \\
24 \\
16 \\
4 \\
24 \\
40 \\
12\end{array}$ \\
\hline $\begin{array}{l}\text { Highest } \\
\text { Score }\end{array}$ & 80 & 84 & 80 & 88 & 92 & 96 & 20 & 20 & 92 & 60 & 36 & 44 \\
\hline Median & 61 & 67 & 66 & 66 & 52 & 68 & 8 & 12 & 48 & 32 & 24 & 20 \\
\hline Mean & 59 & 68 & 66 & 67 & 53 & 69 & 10 & 11 & 46 & 31 & 24 & 21 \\
\hline $\begin{array}{l}\text { Lowest } \\
\text { Score }\end{array}$ & 38 & 50 & 48 & 52 & 8 & 40 & 0 & 4 & 8 & 4 & 12 & 4 \\
\hline
\end{tabular}


TABLE 34

Scores On Interpretation of Data Test By Students Having Poor Reading Ability December 1950 and June 1951

\begin{tabular}{|c|c|c|c|c|c|c|c|c|c|c|c|c|}
\hline \multirow{3}{*}{ Student } & \multicolumn{6}{|c|}{ Percentage of Accuracy } & \multicolumn{3}{|c|}{ Percentage } & of & \multicolumn{2}{|c|}{ Errors } \\
\hline & \multicolumn{2}{|c|}{$\begin{array}{c}\text { Genera } 1 \\
(1)\end{array}$} & \multicolumn{2}{|c|}{$\begin{array}{l}\text { True- } \\
\text { False } \\
(2)\end{array}$} & \multicolumn{2}{|c|}{$\begin{array}{l}\text { Insuffi- } \\
\text { clent } \\
\text { Data (3) }\end{array}$} & \multicolumn{2}{|c|}{$\begin{array}{c}\text { Over- } \\
\text { Caution } \\
(4)\end{array}$} & \multicolumn{2}{|c|}{$\begin{array}{c}\text { Beyond } \\
\text { Data } \\
\text { (5) }\end{array}$} & \multicolumn{2}{|c|}{$\begin{array}{l}\text { Cruae } \\
\text { Error } \\
(6)\end{array}$} \\
\hline & $D$ & $\mathrm{~J}$ & $D$ & $J$ & $\mathrm{D}$ & $J$ & $\mathrm{D}$ & $J$ & $D$ & $J$ & $\mathrm{D}$ & $\mathrm{J}$ \\
\hline 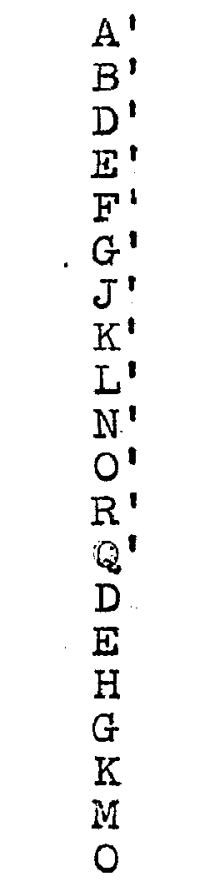 & $\begin{array}{l}30 \\
62 \\
42 \\
44 \\
32 \\
42 \\
62 \\
20 \\
34 \\
32 \\
78 \\
56 \\
28 \\
38 \\
42 \\
68 \\
28 \\
44 \\
30 \\
64\end{array}$ & $\begin{array}{l}46 \\
62 \\
48 \\
66 \\
52 \\
58 \\
68 \\
26 \\
46 \\
58 \\
76 \\
70 \\
28 \\
44 \\
58 \\
68 \\
28 \\
46 \\
18 \\
68\end{array}$ & $\begin{array}{l}40 \\
44 \\
40 \\
52 \\
56 \\
76 \\
68 \\
32 \\
28 \\
36 \\
72 \\
64 \\
32 \\
40 \\
56 \\
68 \\
56 \\
52 \\
56 \\
76\end{array}$ & $\begin{array}{l}52 \\
44 \\
56 \\
72 \\
44 \\
84 \\
68 \\
28 \\
44 \\
56 \\
64 \\
64 \\
48 \\
56 \\
52 \\
56 \\
52 \\
64 \\
20 \\
64\end{array}$ & $\begin{array}{r}20 \\
80 \\
44 \\
36 \\
8 \\
8 \\
56 \\
8 \\
40 \\
28 \\
84 \\
48 \\
24 \\
36 \\
28 \\
68 \\
0 \\
36 \\
4 \\
52\end{array}$ & $\begin{array}{r}40 \\
80 \\
40 \\
60 \\
60 \\
32 \\
68 \\
24 \\
48 \\
60 \\
88 \\
76 \\
8 \\
32 \\
64 \\
80 \\
4 \\
28 \\
16 \\
72\end{array}$ & $\begin{array}{r}24 \\
28 \\
12 \\
12 \\
8 \\
0 \\
8 \\
12 \\
32 \\
16 \\
16 \\
12 \\
20 \\
24 \\
12 \\
8 \\
0 \\
8 \\
8 \\
12\end{array}$ & $\begin{array}{r}12 \\
16 \\
8 \\
0 \\
24 \\
0 \\
0 \\
12 \\
8 \\
4 \\
4 \\
8 \\
8 \\
20 \\
12 \\
16 \\
8 \\
0 \\
24 \\
8\end{array}$ & $\begin{array}{l}80 \\
20 \\
56 \\
64 \\
92 \\
88 \\
36 \\
88 \\
60 \\
72 \\
16 \\
52 \\
68 \\
52 \\
72 \\
32 \\
100 \\
64 \\
96 \\
48\end{array}$ & $\begin{array}{l}60 \\
20 \\
60 \\
40 \\
40 \\
68 \\
32 \\
76 \\
52 \\
40 \\
12 \\
24 \\
88 \\
68 \\
36 \\
20 \\
96 \\
68 \\
84 \\
28\end{array}$ & $\begin{array}{l}36 \\
28 \\
48 \\
36 \\
36 \\
20 \\
16 \\
56 \\
40 \\
44 \\
12 \\
24 \\
48 \\
28 \\
32 \\
24 \\
44 \\
40 \\
36 \\
12\end{array}$ & $\begin{array}{l}36 \\
40 \\
36 \\
28 \\
32 \\
24 \\
32 \\
60 \\
48 \\
40 \\
32 \\
28 \\
44 \\
24 \\
36 \\
28 \\
40 \\
40 \\
56 \\
24\end{array}$ \\
\hline $\begin{array}{l}\text { Hishest } \\
\text { Score }\end{array}$ & 78 & 76 & 76 & 84 & 84 & 88 & 32 & 24 & 100 & 96 & 56 & 60 \\
\hline Median & 42 & 55 & 54 & 56 & 36 & 48 & 12 & 8 & 64 & 46 & 36 & 36 \\
\hline Mean & 44 & 52 & 52 & 54 & 35 & 49 & 14 & 10 & 63 & 51 & 33 & 36 \\
\hline $\begin{array}{l}\text { Lowest } \\
\text { Score }\end{array}$ & 20 & 18 & 28 & 20 & 0 & 4 & 0 & 0 & 16 & 12 & 12 & 24 \\
\hline
\end{tabular}


readers and poor readers, In ability to interpret data, the scores of students were grouped in relation to the mean reading percent1le (32) for all students. Interpretation of data scores of students having a reading score above this mean were compiled in one group. Scores of students having a reading score below the mean percentile were compiled in another group. The mean and median reading percentiles for the "good readers" were reapectively 65 and 51 and for the poor readers, 16 and 17 respectively. The mean I. Q. for the good readers was 97 and for the poor readers, 83. The scores of these "good readers" and "poor readers" are shown in Tables 33 and 34, and the mean gains are shown in Table 35.

\section{TABLE 35}

Mean Gains On Interpretation Of Data Test:

\begin{tabular}{l|c|c|c|c|c|c}
\hline \multirow{2}{*}{ Studints } & \multicolumn{2}{|c|}{ Percentage of Accuracy } & \multicolumn{2}{|c|}{ Percentage of Errors } \\
\cline { 2 - 7 } & $\begin{array}{l}\text { General } \\
\text { Accuracy }\end{array}$ & $\begin{array}{l}\text { True } \\
\text { False }\end{array}$ & $\begin{array}{l}\text { Insuf- } \\
\text { ficient } \\
\text { Data }\end{array}$ & $\begin{array}{c}\text { Over } \\
\text { Caution }\end{array}$ & $\begin{array}{c}\text { Beyond } \\
\text { Data }\end{array}$ & $\begin{array}{c}\text { Crude } \\
\text { Error } \\
\text { Good } \\
\begin{array}{l}\text { Readers } \\
\text { Poor } \\
\text { Readers }\end{array}\end{array}$ \\
\hline
\end{tabular}

The good readers gained slightiy more than the poor readers in all categories, except "True-false" and "Overcaution". Apparently the poor readers gained, while the 
good readers were static in reducing the tendency to require more qualifications than necessary when evaluating interpretative statements (Over-Caution). The significance of these gains 1s shown in Table 36.

TABLE 36

Significance of Difference In Means

\begin{tabular}{|c|c|c|c|c|}
\hline \multirow{2}{*}{ Behaviors Evaluated } & \multicolumn{2}{|c|}{ Good Readers } & \multicolumn{2}{|c|}{ Poor Readers } \\
\hline & $\begin{array}{l}\text { Value } \\
\text { of } t\end{array}$ & $\begin{array}{l}\text { Level of } \\
\text { Conf1dence }\end{array}$ & $\begin{array}{l}\text { Value } \\
\text { of } t\end{array}$ & $\begin{array}{c}\text { Level of } \\
\text { Confidence }\end{array}$ \\
\hline $\begin{array}{l}\text { General Accuracy } \\
\text { True-False } \\
\text { Insufficlent Data } \\
\text { Over-Caution } \\
\text { Beyond Data } \\
\text { Grude Error }\end{array}$ & $\begin{array}{l}2.75 \\
-\overline{3} \\
3.16 \\
\text { Neg. } \\
2.93 \\
1.1\end{array}$ & $\begin{array}{l}2 \%+ \\
\overline{1} \%+ \\
- \\
1 \%- \\
30 \%\end{array}$ & $\begin{array}{l}3.70 \\
3.68 \\
1.70 \\
3.11 \\
\text { Neg. }\end{array}$ & $\begin{array}{c}0.1 \%- \\
0.1 \%- \\
10 \%- \\
1 \%+\end{array}$ \\
\hline Number of Students & & 14 & & 20 \\
\hline
\end{tabular}

Gains by both groups were statiatically aignificant in the categories of General Accuracy, Insufficient Data and Beyond Data. The levels of confldence for the two groups are about the same in the "Beyond Data" category. In the other two categories the gains of the poor readers are more significant. The differences in these levels suggest that students with poor reading ability made more progress in interpreting data than those with good reading ability. 
TABLE 37

Scores On Interpretation Of Data Test By Boys December 1950 and June 1951

\begin{tabular}{|c|c|c|c|c|c|c|c|c|c|c|c|c|}
\hline \multirow{3}{*}{ Student } & \multicolumn{6}{|c|}{ Percentage of Accuracy } & \multicolumn{6}{|c|}{ Percentage of Errors } \\
\hline & \multicolumn{2}{|c|}{$\begin{array}{c}\text { General } \\
\text { (1) }\end{array}$} & \multicolumn{2}{|c|}{$\begin{array}{l}\text { True- } \\
\text { Falso } \\
\text { (2) }\end{array}$} & \multicolumn{2}{|c|}{$\begin{array}{l}\text { Insuffi- } \\
\text { cient } \\
\text { Data }\end{array}$} & \multicolumn{2}{|c|}{$\begin{array}{c}\text { Over- } \\
\text { Caution } \\
(4)\end{array}$} & \multicolumn{2}{|c|}{$\begin{array}{c}\text { Beyond } \\
\text { Deta } \\
\text { (5) }\end{array}$} & \multicolumn{2}{|c|}{$\begin{array}{l}\text { Crude } \\
\text { Error } \\
(6)\end{array}$} \\
\hline & $\mathrm{D}$ & $\mathrm{J}$ & $D$ & $J$ & D & $J$ & $D$ & $\mathrm{~J}$ & D & $\mathrm{J}$ & D & $\mathrm{J}$ \\
\hline $\begin{array}{l}C \\
F \\
H \\
G \\
G \\
J \\
I \\
I \\
M \\
M \\
N \\
B^{\prime} \\
D^{\prime} \\
F^{\prime} \\
H^{\prime} \\
I^{\prime} \\
L^{\prime} \\
N^{\prime} \\
O^{\prime} \\
R^{\prime} \\
P^{\prime}\end{array}$ & $\begin{array}{l}62 \\
66 \\
68 \\
28 \\
52 \\
50 \\
74 \\
30 \\
56 \\
62 \\
42 \\
32 \\
38 \\
62 \\
34 \\
32 \\
78 \\
56 \\
68\end{array}$ & $\begin{array}{l}58 \\
84 \\
68 \\
28 \\
54 \\
66 \\
84 \\
18 \\
50 \\
62 \\
48 \\
52 \\
76 \\
68 \\
46 \\
58 \\
76 \\
70 \\
68\end{array}$ & $\begin{array}{l}72 \\
80 \\
68 \\
56 \\
56 \\
60 \\
72 \\
56 \\
64 \\
44 \\
40 \\
56 \\
68 \\
72 \\
28 \\
36 \\
72 \\
64 \\
80\end{array}$ & $\begin{array}{l}76 \\
72 \\
56 \\
52 \\
56 \\
64 \\
72 \\
20 \\
52 \\
44 \\
56 \\
44 \\
88 \\
64 \\
44 \\
56 \\
64 \\
64 \\
76\end{array}$ & $\begin{array}{r}52 \\
52 \\
68 \\
0 \\
48 \\
40 \\
76 \\
4 \\
48 \\
80 \\
44 \\
8 \\
8 \\
52 \\
40 \\
28 \\
84 \\
48 \\
56\end{array}$ & $\begin{array}{r}40 \\
96 \\
80 \\
4 \\
52 \\
68 \\
96 \\
16 \\
48 \\
80 \\
40 \\
60 \\
64 \\
72 \\
48 \\
60 \\
88 \\
76 \\
60\end{array}$ & $\begin{array}{r}8 \\
0 \\
8 \\
0 \\
20 \\
8 \\
0 \\
8 \\
4 \\
28 \\
12 \\
8 \\
8 \\
4 \\
32 \\
16 \\
16 \\
12 \\
8\end{array}$ & $\begin{array}{r}12 \\
8 \\
16 \\
8 \\
12 \\
20 \\
8 \\
24 \\
4 \\
16 \\
8 \\
24 \\
8 \\
12 \\
8 \\
4 \\
4 \\
8 \\
12\end{array}$ & $\begin{array}{l}48 \\
48 \\
32 \\
100 \\
52 \\
60 \\
24 \\
96 \\
44 \\
20 \\
56 \\
92 \\
92 \\
48 \\
60 \\
72 \\
16 \\
52 \\
44\end{array}$ & $\begin{array}{r}60 \\
4 \\
20 \\
96 \\
28 \\
32 \\
4 \\
84 \\
52 \\
20 \\
60 \\
40 \\
36 \\
28 \\
52 \\
40 \\
12 \\
24 \\
40\end{array}$ & $\begin{array}{l}20 \\
20 \\
24 \\
44 \\
24 \\
32 \\
28 \\
36 \\
28 \\
28 \\
48 \\
36 \\
24 \\
24 \\
40 \\
44 \\
12 \\
24 \\
12\end{array}$ & $\begin{array}{l}12 \\
20 \\
28 \\
40 \\
32 \\
16 \\
20 \\
56 \\
44 \\
40 \\
36 \\
32 \\
4 \\
24 \\
48 \\
40 \\
32 \\
28 \\
12\end{array}$ \\
\hline $\begin{array}{l}\text { Highest } \\
\text { Score }\end{array}$ & 78 & 84 & 80 & 88 & 84 & 96 & 32 & 24 & 100 & 96 & 48 & 56 \\
\hline Median & 56 & 62 & 64 & 56 & 48 & 60 & 8 & 8 & 52 & 36 & 28 & 32 \\
\hline Mean & 52 & 60 & 60 & 59 & 44 & 60 & 11 & 11 & 56 & 38 & 29 & 30 \\
\hline $\begin{array}{l}\text { Lowest } \\
\text { Score }\end{array}$ & 28 & 18 & 28 & 20 & 0 & 4 & 0 & 4 & 16 & 4 & 12 & 4 \\
\hline
\end{tabular}


TABLE 38

Scores On Interpretation of Data Test By Girls December 1950 and June 1951

\begin{tabular}{|c|c|c|c|c|c|c|c|c|c|c|c|c|}
\hline \multirow{3}{*}{ student } & \multicolumn{6}{|c|}{ Percentage of Accuracy } & \multicolumn{3}{|c|}{ Percentage } & \multicolumn{3}{|c|}{ of Errors } \\
\hline & \multicolumn{2}{|c|}{$\begin{array}{c}\text { General } \\
(1)\end{array}$} & \multicolumn{2}{|c|}{$\begin{array}{l}\text { True- } \\
\text { False } \\
(2)\end{array}$} & \multicolumn{2}{|c|}{$\begin{array}{l}\text { Insuffi- } \\
\text { cient } \\
\text { Data(3) }\end{array}$} & \multicolumn{2}{|c|}{$\begin{array}{c}\text { Over } \\
\text { Caution } \\
(4)\end{array}$} & \multicolumn{2}{|c|}{$\begin{array}{c}\text { Beyond } \\
\text { Data } \\
\text { (5) }\end{array}$} & \multicolumn{2}{|c|}{$\begin{array}{l}\text { Crude } \\
\text { Error } \\
(5)\end{array}$} \\
\hline & $\mathrm{D}$ & $J$ & $D$ & $\mathrm{~J}$ & $D$ & $J$ & $D$ & $\mathrm{~J}$ & $\mathrm{D}$ & $\mathrm{J}$ & $D$ & $J$ \\
\hline $\begin{array}{l}A \\
B \\
D \\
E \\
K \\
O \\
P \\
A: \\
C: \\
E^{\prime} \\
G^{\prime} \\
J^{\prime} \\
K^{\prime} \\
\mathbb{N}^{\prime} \\
Q^{\prime}\end{array}$ & $\begin{array}{l}60 \\
80 \\
38 \\
42 \\
44 \\
64 \\
48 \\
30 \\
52 \\
44 \\
42 \\
62 \\
20 \\
64 \\
28\end{array}$ & $\begin{array}{l}72 \\
78 \\
44 \\
58 \\
46 \\
68 \\
72 \\
46 \\
60 \\
66 \\
58 \\
68 \\
26 \\
66 \\
28\end{array}$ & $\begin{array}{l}60 \\
68 \\
40 \\
56 \\
52 \\
76 \\
48 \\
40 \\
56 \\
52 \\
76 \\
68 \\
32 \\
64 \\
32\end{array}$ & $\begin{array}{l}76 \\
68 \\
56 \\
52 \\
64 \\
64 \\
64 \\
52 \\
64 \\
72 \\
84 \\
68 \\
28 \\
52 \\
48\end{array}$ & $\begin{array}{r}60 \\
92 \\
36 \\
28 \\
36 \\
52 \\
48 \\
20 \\
48 \\
36 \\
8 \\
56 \\
8 \\
64 \\
24\end{array}$ & $\begin{array}{r}68 \\
88 \\
32 \\
64 \\
28 \\
72 \\
80 \\
40 \\
56 \\
60 \\
32 \\
68 \\
24 \\
80 \\
8\end{array}$ & $\begin{array}{r}16 \\
16 \\
24 \\
12 \\
8 \\
12 \\
16 \\
24 \\
20 \\
12 \\
0 \\
8 \\
12 \\
8 \\
28\end{array}$ & $\begin{array}{r}12 \\
12 \\
20 \\
12 \\
0 \\
8 \\
12 \\
12 \\
20 \\
0 \\
0 \\
0 \\
12 \\
4 \\
8\end{array}$ & $\begin{array}{r}40 \\
8 \\
52 \\
72 \\
64 \\
48 \\
52 \\
80 \\
52 \\
64 \\
88 \\
36 \\
88 \\
36 \\
68\end{array}$ & $\begin{array}{l}32 \\
12 \\
68 \\
36 \\
68 \\
28 \\
20 \\
60 \\
44 \\
40 \\
68 \\
32 \\
76 \\
20 \\
88\end{array}$ & $\begin{array}{l}24 \\
16 \\
28 \\
32 \\
40 \\
12 \\
36 \\
36 \\
24 \\
36 \\
20 \\
16 \\
56 \\
28 \\
48\end{array}$ & $\begin{array}{l}12 \\
20 \\
24 \\
36 \\
40 \\
24 \\
24 \\
36 \\
16 \\
28 \\
24 \\
32 \\
60 \\
40 \\
44\end{array}$ \\
\hline $\begin{array}{l}\text { Highest } \\
\text { Score }\end{array}$ & 80 & 78 & 76 & 84 & 92 & 88 & 24 & 20 & 88 & 88 & 56 & 60 \\
\hline Median & 44 & 60 & 56 & 64 & 36 & 60 & 12 & 12 & 52 & 40 & 28 & 28 \\
\hline Mean & 48 & 57 & 55 & 61 & 4.1 & 53 & 14 & 9 & 57 & 46 & 30 & 30 \\
\hline $\begin{array}{l}\text { Lowest } \\
\text { Score }\end{array}$ & 20 & 26 & 32 & 28 & 8 & 8 & 0 & 0 & 8 & 12 & 12 & 12 \\
\hline
\end{tabular}


Amons the 20 "poor readers" were 7 students with intelligence quotients above 85 . Five of these students registered great gains on the second test.

An inspection of Table 36 which lists the significance of gains by good readers and Table 32 which lists similar information for students with low $I$. Q.'s, is revealing. All of the good readers were also members of the "superior" group, and all of the "Inferior" group except 1, were poor readers. Hence, it is posigible to compare students with high I. Q.'s and good reading ability with students of low I. $Q$ 's and poor reading ability. The significant gains of the good readers (all with high I. Q.'s) were all near the 1\% level of confidence. The gignificant gains of the students With low I. Q.'s (and poor reading ability) were all near the $5 \%$ level of confidence. Apparent Influence of Sex on Interpretation of Data

Tables 37 and 38 list the scores of students by sex and the mean gains of these two groups are shown in Table 39.

\section{TABLE 39}

Mean Ga1ns on Interpretation of Data Test

\begin{tabular}{l|c|c|c|c|c|c}
\hline \hline $\begin{array}{l}\text { Stu- } \\
\text { dents }\end{array}$ & $\begin{array}{c}\text { General } \\
\text { Accuracy }\end{array}$ & $\begin{array}{l}\text { True- } \\
\text { False }\end{array}$ & $\begin{array}{l}\text { Insuf- } \\
\text { ficient } \\
\text { Data }\end{array}$ & $\begin{array}{r}\text { Over } \\
\text { Caution }\end{array}$ & $\begin{array}{c}\text { Beyond } \\
\text { Data }\end{array}$ & $\begin{array}{c}\text { Crude } \\
\text { Error }\end{array}$ \\
\hline $\begin{array}{l}\text { Boys } \\
\text { Girls }\end{array}$ & $\begin{array}{r}7.6 \\
9.2\end{array}$ & $\begin{array}{r}-1.3 \\
6.1\end{array}$ & $\begin{array}{l}16.4 \\
12.3\end{array}$ & $\begin{array}{c}0.8 \\
5.1\end{array}$ & $\begin{array}{l}17.1 \\
10.4\end{array}$ & $\begin{array}{r}-0.9 \\
0.1\end{array}$ \\
\hline
\end{tabular}


The mean $I . Q$. and the mean reading percentile of the boys were respectively 91 and 38, and for the girls, 85 and 27. The median reading percentile for each group was 24 .

The mean gains by the girls were greater in all categories except "Insufficient Data" and "Beyond Data". The slgnificance of these gains is summarized in Table 40 .

TABLE 40

Significance of Differences In Means

\begin{tabular}{|c|c|c|c|c|}
\hline \multirow{2}{*}{ Behaviors Evaluated } & \multicolumn{2}{|c|}{ Boys } & \multicolumn{2}{|c|}{ Girls } \\
\hline & $\begin{array}{l}\text { Value } \\
\text { of } t\end{array}$ & $\begin{array}{l}\text { Level of } \\
\text { Confidence }\end{array}$ & $\begin{array}{l}\text { Velue } \\
\text { of: } t\end{array}$ & $\begin{array}{c}\text { Level of } \\
\text { Confiderice }\end{array}$ \\
\hline $\begin{array}{l}\text { General Accuracy } \\
\text { True-False } \\
\text { Insufficient Data } \\
\text { Over-Caution } \\
\text { Beyond Data } \\
\text { Crude Error }\end{array}$ & $\begin{array}{l}2.69 \\
\text { Neg. } \\
3.75 \\
0.335 \\
3.8 \\
\text { Neg. }\end{array}$ & $\begin{array}{l}2 \%+ \\
0.1 \%- \\
80 \%+ \\
0.1 \%- \\
-\end{array}$ & $\begin{array}{l}4 \cdot 44 \\
2 \cdot 22 \\
3 \cdot 17 \\
4 \cdot 45 \\
2.54 \\
-\end{array}$ & $\begin{array}{l}0.1 \%+ \\
5 \%+ \\
1 \%+ \\
0.1 \%+ \\
2 \%-\end{array}$ \\
\hline Number of Students & & 19 & & 15 \\
\hline
\end{tabular}

The gains of the girls were statistically significant in all categorles except "Crude Error". The gains of the boys were statistically significant in three categories -General Accuracy, Insufficlent Data, and Beyond Data. The gain in general accuracy by the girls was very significant, and by the boys, significant. The gain in the "Beyond Data" category by the boys was very significant, and by the girls, significant. A striking fact disclosed by Tables 39 and 40 
is that the girls generally reduced their tendency to require more qualifications than necessary when evaluating statements based on given data, while the boys, generally, made no progress in this respect. In fact, all of the girls except 3, made lower scores in this category. There was no change in the scores of the three who did not make lower scores in June. On the other hand, ten of the boys made higher scores in June, while only 7 made lower scores. There was no change in the scores of two boys. Conclusions

Th1s analysis has included a study of the gains in ability to interpret data by the students of each section, and gains in relation to intelligence, reading ability and sex. The conclusions as subgested by the data are summarized as follows:

1. Generally, students made significant improvement in ability to perceive various types of relationships in data. The types of relationships evaluated included those involving:

I.I Comparison of points in the data.

1.2 Identification of common elements in the data.

1.3 Recognition of or comparison of trends.

1.4 Juagment of statements which cannot be Justified without the use of information from other sources. Students showed greatest improvement in evaluating this tyoe of relationship.

2. Students made significant improvement in recognizing the limitations of the data, as shown by:

2.1 Their general accuracy scores. In June, more 
true statements were rated as true, false as false, and the like, than in December.

2.2 The reduction in tendency to ascribe truth or falsity to interpretations which the data would not justify, $1 . e .$, students tended to over-generalize less in June than in December.

3. One section made significant improvement in recognizing the limitations of the data as shown by the over-caution score. Students tended less toward requiring more qualifications than necessary on the basis of the siven data.

4. Students with intelligence quotients ranging from 85 to 116, made more significant progress than students having intelligence quotients ranging from 84 to 67, in the following abilities:

4.1 Perceiving relationships in data as shown by their general accuracy scores and their ratings: of statements which cannot be justified without additional information.

4.2 Recognizing the Iimitations of the data as shown by their general accuracy scores and their more accurate ratings of statements in which more trutin or falsity was ascribed than the data would justify.

5. Apparently, reading ability is not as significant a factor as intelligence in the potential improvement of ability to interpret data.

6. Good readers with intellisence quotients above 84 made much more progress in the interpretation of data than the poor readers with intellicence quotients below 85 .

7. Girls achieved outstanding gains, in comparison with boys, in the following abilities:

7.I Perceiving relationships in data through the comparison of points in the data and the recognition of trends.

7.2 Recomizing the limitations of the data by not requiring more qualifications than necessary on the basis of the given data. Girls tended to recognize the limitations of data by reducing their tendency to over- 
generalize.

Discussion of Individual students

Pupil scores on the Interpretation of Data Tests can be used to diagnose the strengths and weaknesges of the indlvidual pupil. Many teachers and administrators use the results of this test and similar tests as a basis for making a yearly log or record of pupil achievements. The writer pregents the following analyses to illustrate how the test results can be used for diagnostic purposes and for enlargins the cumulative records of individual pupils.

This discussion will be concerned with the recoras of two students selected at random--one from each section. An analysis will be made of each student's status on the first administration of the Interpretation of Data Test and the changes in status shown in the final administration of the test.

Student $F$ of Section 1 ranked above the class median in reading ability and intelligence. As shown in Table 41, Student $F$ in December was above the class average in ability to recognize the limitations of data, for he was 12 points above the class median in general accuracy and made no errors in evaluating statements in which there were more qualifications than necessary on the basis of the given data. However, he was only 2 points below the class median in "going beyond diata" or over-generalizing--a weakness shown by 
student $F$ as well as by the class. In June, student $F$ continued to rank above the class median in desirable qualities. In fact, his gain in general accuracy was 18 points while the gain of the class was 8 points. Although in June, Student $F$ made more errors in over-caution (and so did the class generally), he made phenomenal progress in

\section{TABLE 41}

Gains By Student $F$ In Ability To Interpret Data

\begin{tabular}{|c|c|c|c|c|c|c|}
\hline \multirow{2}{*}{$\begin{array}{l}\text { Behaviors } \\
\text { Evaluated }\end{array}$} & \multicolumn{2}{|c|}{ December score } & \multicolumn{2}{|c|}{ June Score } & \multicolumn{2}{|c|}{ Gain } \\
\hline & Student $_{\mathrm{F}}$ & $\begin{array}{r}\text { Class } \\
\text { Median }\end{array}$ & $\underset{F}{\text { Student }}$ & $\begin{array}{r}\text { Class } \\
\text { Median }\end{array}$ & $\begin{array}{l}\text { Stu- } \\
\text { dent }\end{array}$ & Class \\
\hline $\begin{array}{l}\text { General Accuracy } \\
\text { True-False } \\
\text { Insuficient Data } \\
\text { Over-Caution } \\
\text { Going Beyond. Data } \\
\text { Crude Error }\end{array}$ & $\begin{array}{r}66 \\
80 \\
52 \\
0 \\
48 \\
20\end{array}$ & $\begin{array}{r}54 \\
60 \\
48 \\
8 \\
50 \\
28\end{array}$ & $\begin{array}{r}84 \\
72 \\
96 \\
8 \\
4 \\
20\end{array}$ & $\begin{array}{l}62 \\
64 \\
66 \\
12 \\
32 \\
24\end{array}$ & $\begin{array}{r}18 \\
-8 \\
44 \\
-\quad 8 \\
44 \\
0\end{array}$ & $\begin{array}{r}8 \\
4 \\
18 \\
-\quad 4 \\
18 \\
4\end{array}$ \\
\hline Reading Percentile & 65 & 42 & & & & \\
\hline $\begin{array}{l}\text { Intelligence } \\
\text { Quotient }\end{array}$ & 99 & 90 & & & & \\
\hline
\end{tabular}

controlling his tendency to over-generalize. While he gained 44 points in controlling that tendency, the class' median gain was only 18 points.

In December, student $F$ ranked above the class median in perceiving various relationships in the data. His score in evaluating statements involving the recognition of trends 
(True-False) was farther above the median than was his score for judging statements which required additional data before validation (Insufficient Data). His score was below the class median in "crude errors". In June, Student F had lost 8 points in rating true-false statements, while the class median gain was 4 points. His gain in rating statements based on insufficient data was 44 points, more than double the 18 point-median-gain of the class. Student F did not reduce his tendency toward careless reading (marking true statements false and vice versa) but the class improved slightly•

Student $A^{\prime}$ in section 2 had an intellizence quotient of 67 and was at the first percentile in reading ability. The median intelligence quotient and reading percentile for the class were 86 and 17 respectively. As shown in Table 42 , student $A^{\prime}$ in December ranked below the class median in the three desirable qualities associated with the interpretation of data. (General Accuracy, True-False, Insufficient Data). She ranked above the class median in the three qualities for which a low score is considered degirable (over-caution, golng beyona data, and crude error). Student A' 's most obvious wealrnesses were her inability to perceive relationships in data as shown by her low general accuracy score and her low score in comparine points in the data and the recognition of trends (insufficient data). Student $A^{\prime}$ also made a large number of crude errors which doubtless was due to 
TABIE 42

Gaing By Student $A^{\prime}$ In Ability To Interpret Data

\begin{tabular}{|c|c|c|c|c|c|c|}
\hline \multirow{2}{*}{$\begin{array}{l}\text { Behaviors } \\
\text { Evaluated }\end{array}$} & \multicolumn{2}{|c|}{ December Score } & \multicolumn{2}{|c|}{ June Score } & \multicolumn{2}{|c|}{ Gain } \\
\hline & $\underset{A}{\text { Student }}$ & $\begin{array}{r}\text { Class } \\
\text { Median }\end{array}$ & $\underset{A}{\text { Student }}$ & $\begin{array}{r}\text { Class } \\
\text { Hëdian }\end{array}$ & $\begin{array}{l}\text { Stu- } \\
\text { dent } \\
A^{\prime}\end{array}$ & Class \\
\hline $\begin{array}{l}\text { General Accuracy } \\
\text { True-False } \\
\text { Insufficient Data } \\
\text { Over-Caution } \\
\text { Golns Beyond Data } \\
\text { Grude Error }\end{array}$ & $\begin{array}{l}30 \\
40 \\
20 \\
24 \\
80 \\
36\end{array}$ & $\begin{array}{l}43 \\
56 \\
42 \\
12 \\
58 \\
28\end{array}$ & $\begin{array}{l}46 \\
52 \\
40 \\
12 \\
60 \\
36\end{array}$ & $\begin{array}{r}59 \\
60 \\
60 \\
8 \\
40 \\
32\end{array}$ & $\begin{array}{l}16 \\
12 \\
20 \\
12 \\
20 \\
0\end{array}$ & $\begin{array}{r}16 \\
4 \\
18 \\
4 \\
18 \\
-\quad 4\end{array}$ \\
\hline Reading Percentile & 1 & 17 & & & & \\
\hline $\begin{array}{l}\text { Intelligence } \\
\text { Quotient }\end{array}$ & 67 & 86 & & & & \\
\hline
\end{tabular}

her poor reading ability.

She failed to recognize the limitations of data not so much from over-caution but more because she has a strong tendency to over-generalize (go beyond data). During the year the teacher gave much individual attention to student $A^{\prime}$. She frequently worked on the study guides during study periods and the teacher tried to give her many hints on improving her reading ability.

From Table 42 it can be seen that student $A$ 'outsained the class in all categories except "general accuracy" and even in this category her gain equalled the median class gain. Her most noteworthy gaing were in her ratings of 
241

statements which were definitely true or false, and in reducing the tendency toward over-caution. Apparently student A' can do very well in recognizing relationships which are derived from sufficient data as shown by her gains in the categories of true-false and over-caution.

Although she gained 20 points each in the categories of "insufficient data" and "going beyond data", her June scores do not indicate unusual ability in these two categories. (She rated as true or false, 60 per cent of the statements which the data would not justify. She rated as uncertain, only 40 per cent of the statements which could not be justified without the use of information from other sources.). Hence, her improvement in curbing the tendency to over-generalize though commendable, indicates that she should be given continued training and help in this direction.

\section{Inventory of Behaviors Evaluated}

In chapter 2 the process of interpretine data was analyzed in detail. An important question which now needs consideration is this, "Have all of the understandings associated with the ability to interpret data been evaluated?" This question will be discussed through the following summary of the behaviors which were shown to be associated with the interpretation of data in chapter 2 and a summary of the behaviors evaluated by the instrument, Interpretation of 


\section{Data Test, Lower Level.}

Behaviors Associated with the Interpretation of Data

1. Perceives and expresses possible relationships between

Items in a set of data as evidenced by ability to:

1.I See the existence or non-existence of a relation between elements or variables in a set of data.

1.2 Make appropriate expressions of such relationships.

1.3 Compute values of a variable from known values of a related variable.

1.4 Relate like characteristics in different types of data.

1.5 Attach appropriate meanings to various symbols.

2. Recognizes the limitations of the data as evidenced by ability to:

2.I Decide how far to go in drawing inferences from data.

2.2 Use appropriate procedures for identifying tendencies or trends in a given set of data.

2.3 Qualify statements when interpolating.

2.4 Qualify statements when extrapolating.

2.5 Congider the representativeness of a set of data preparatory to making interpretations.

2.6 Recognize and use data appropriate for a particular situation.

2.7 Make interpretations which are within the domain and range of the data.

2.8 Realize that inferences cannot apply to a single individual or item.

2.9 Recognize the fact that many interpretations have only probability in their favor.

3. Understands the fact that the validity of a statement depends upon the value attached to the variables as evidenced by the followings behaviors: 
3.1 Understands that the degree of truth in a declaration is dependent upon the extent to which the related variables approach non-variability.

3.2 Realizes that many relations are propositional

3.3 Recognizes statements which are neither true nor false because of the non-specificity of the variables.

4. Evaluates conclusions and generalizations reached by others in their interpretation of data as evidenced by the following behaviors:

4.I Looks for the number of cases cited jn an argument.

4.2 Looks for the variety of sampling.

4.3 Considers the qualifications of persons making testimonials.

4.4 Distinguishes between relevant and irrelevant data.

5. Draws valid generalizations consistent with relationships recognized.

Behaviors Evaluated. By Interpretation of Data Test

1. Ability to perceive relationships in data.

1.I Ability to make comparisons.

1.2 Ability to see common elements in the data.

1.3 Ability to recognize prevailing tendencies in the data. This ability is dependent upon the following related abilities:

1.31 To read the given data.

I.32 To make simple computations.

1.33 To understand the symbol1sm used.

2. Ability to recognize certain limitations of the data.

2.I Recognizes what other information in addition to that which is given, is necessary in order to be reasonably sure of certain types of interpretations. 
2.2 Refrains from making judgments relative to implied causes, efrects, or purposes until the necessary facts are at hand.

2.3 Recognizes situations requiring qualified conclusions because of insufficient facts.

2.31. Does not require more qualifications than necessary on the basis of the given data.

2.32 Does not ascribe truth or falsity to interpretations which the data does not justify.

It can be seen that Behaviors 1,2 and 5 described in this study are practically the same as those described by the authors of the test. Behaviors 1,2 and 5 are concerned with the student's ability to make his own interpretations from a set of data, while behavior 4 is concerned with the student's ability to evaluate interpretations made by others. Behaviors 1,2 and 5 can be considered as the behaviors of the "producer" of interpretations, and behavior 4 as that of the "consumer" of interpretations.

The authors of the test make the following cornment concerning itg validity:

The two main aspects of the validity of the Interpretation of Data Test are (1) the validity of the test as a measure of the student's ability to judge interpretations formulated by others, and (2) the validity of the test as an inder to the student's ability to write original interpretations.

A directed essay form of the Interpretation of Data Test was prepared for use as the criterion for the validity of the test as a. measure of the ability of students to make orieinal interpretations. In a study conducted in a lerge public junior high school, 193 students in the seventh, elghth and ninth grades were given the sets of data used in the Interpretation of Data Test (Form 2.71) and 
were asked to make free essay responses to such directions as:

Write five statements that you are sure are true according to the facts given in these data.

Write three statements based on the data which you are not quite sure are true according to these data.

Scores for this essay form obtained independently by experienced scorers using well-derined criteria for scoring, when correlated by the product-moment method, yielded reliability coefficients ranging between .92 and .96 indicating high objectivity.

The product-moment correlation coefficients obtained by correlating the general accuracy scores on the essay form with the same scores on the objectlve form ...... are in all cases positive and are sufficiently large to indicate considerable overlap in measurement by the two test forms. One factor which may have decreased the correlations is that the free responses made by any one student involved a narrow range of relationships and did not sample adequately his ability to make various types of interpretations.?

From this explanation the writer concludes that all behaviors except No. 3 were evaluated by the test.

The third behavior was not evaluated through a formal test. Included in the Appendix is a copy of an instrument which was used to secure some measure of pupil reactions to statements involvine variables. However, the instrument must be subjected to tests of reliability, validity and other tests, before any claims can be made for its effectiveness in evaluating the behavior.

7. Manual of Directions, Interpretation of Data Test, Lower LeveI, pp. 9-10. 


\section{Chapter 7}

\section{Implications For General Education}

\section{General Summary}

In this report, the intimate relationship between relational thinking and the interpretation of data has been shown, and the understandings associated with the interpretation of data have been listed and 1llustrated.

Proposals for a course in algebra for developing the ability to interpret data have been presented, and a detailed description has been given of activities and student achievements in a course modeled from these proposals.

The results of student progress in the course were presented and evaluated. From this evaluation, the following conclusions were reached:

1. Students improved significantly in certain behaviors associated with the ability to interpret data.

2. Students with high intelligence quotients showed more significant growth in the behaviors associated with the interpretation of data than those with low intelligence quotients.

3. Reading apparentIy is not as important a factor as intelligence in developing behaviors associated with the interpretation of data.

4. Girls seemed to be more amenable than boys, to improvement in two behaviors associated with interpretation of data, (true-false and over-caution).

There is no conclusive evidence proving that these students improved in their ability to interpret data as a 
direct result of the limited controls exercised by the teacher in the activities which he planned for their ninth Grade mathematics course. The most significant kinds of control exercised by the teacher were in the planning of teaching activities and the provision of opportunities for students to learn to behave in certain ways when placed in a mathematios situation requiring the interpretation of data. However, it has been shown that the changes by students in their ability to interpret data could not have been by chance alone.

Recommendations

At the conclusion of this study for promoting student ability to interpret data, the following recommendations are made:

1. Algebraic skills shoula become subordinate in importance to skills involved in: (a) reasoning by induction and (b) the interpretation of data. The efforts of teachers and students should be focused on refining student reasoning abilities, rather than the accumulation of a stock-pile of manipulative skills with algebraic symbols, many of which will never be used again by the students generally.

This recommendation is presented because of the static nature of the research which is done seneraliy in the teaching of algebra, and because of the many promising posgibilities for student growth disclosed in the few reports in aleebra devoted to the development of reasoning abilities. The implementation of this recommendation should liberate 
the ninth grade student from the bonds of low-level thinkine to those higher levels of thining which stimulate one to seek the answers to such questions as: "Why is this statement valid?", "What is wrong with this generalization?" and "What additional information is needed to reach a conclusion?"
2. Operation, the slrill commonly taught in ele- mentary algebra, should be supplemented and enriched with an understanding of the con- cepts of relationship, number, symbolism, proof, and measurement. The concept of rela- tionship should be given precedence over the concept of operation, thus becoming the hub from which other concepts radiate.

The majority of high school students have an incomplete and depressing picture of the contribution of algebra to their education, because of the undue emphasis upon the concept of operation. Wj.th a more equitable digtribution of emphasis upon these additional concepts, more opportunities will be available for encourasing a wider variety of thought processes

3. The mathematics teacher should plan activities involving the interpretation of data which are commensurate with the native intelligence of the student.

In this study it was found that the students with higher intelligence quotients made more significant progress in the interpretation of data than the students of lower intelligence. If students of lower intelligence were given simplified materials, then their progress might be more percept- 
Ible.

4. Textbooks should be written in a manner which w111 encourage student thinking, by stimulating student-teacher development of alsebraic principles.

Textbook writers often have circumscribed the thinlkine of teachers and students through their method of presenting algebraic subject matter. Thinking on the part of the reader is not stimulated when each algebraic principle is developed for him. Textbooks could be written so that specific facts are presented relative to a given principle from which the student, under guidance of the teacher, could infer the principle.

5. Teacher training institutions should give concerted attention to planning the experiences of prospective mathematics teachers which will make them competent for training students to become better thinkers.

The first four recommendations have been concerned with one objective, the sugsestion of definite ways to improve the reasoning abilities of students as they study elementary algebra. This concluding recommendation is a necessity, for one cannot expect a change in the thinking of students generally without enlightened teachers of mathematics. Much of the fruitless efforts in the teaching of albebra can be related to the fact that we tend to teach ais we were taught.

\section{New Studies}

In chapter 1 of this report, the type of research 
commonly assoclated with the teaching of elementary algebra was discussed. The circumscribing of research within the narrow limits of techniques for teaching the skills of algebra was shown in this chapter. In chapter 2, summaries of studies were presented which are a potential means of broadening the horizong of student thinking. This study was designed to onlarge these horizons and its results guggest the following types of studies which would enhance the research done in the teaching of elementary algebra:

1. Studies similar to this study, on a wider scale, enlarging the behaviors evaluated and involving a larger student population.

The potentialities of this study for improving student reasonlng abilities, have not been exploitea completely. This is true especially for that phase of interpreting data which was concerned with the study of variables in daily language and in the language of mathematics. Much more evidence for or against the hypothesis of this study can be brought to light through wide scale classroom experimentation.

2. Compilation of a source book of materials for planning activities and exercises to develop the ability for interpreting data.

One of the hardest tasks facing a teacher desirous of embarking upon a mathematics program designed to improve student reasonine abilities, is the securing of appropriate learning materials. Doubtless, many teachers desiring to 
make such departures from traditional programs, have foregone this type of teaching because they lacked the time and energy to ferret out appropriate materials from the newspapers, periodicals and pamphlets which are so prevalent today. A source book would make available such information to be worked into appropriate study guides and other learning activities.

3. Follow-up studies of the Daily study. This study was summarized in chapter 2 of this report.

The Daily study, and other studies emphasizing the development of reasoning abilities by students of elementary algebra, have not been repeated by other researchers as has the pioneer study by Fawcett in the teaching of geonetry. Wuch will be gleaned from the conducting of similar studies with other student groups in varied school situations.

4. Studies involving the problem-solving (reflective thinking) process as applied to algebra. Activities involving: the definition of problems by students, proposing hypotheses, gathering data to verify or disprove hypotheses, and reaching conclusions.

Studies similar to the Wllits study as described in chapter 2 of this report depict the type of study desired. Such studies would emphasize the logic ot algebra and not its subject matter. So far the general emphasis in the teachine of algebra has been upon the subject matter of algebra with little attention Elven to Its logic. 
5. Studies concerned with clarifying arithmetic through algebra by relating algebraic processes to those of arithmetic. Understanding the operations associated with aigebra.

Most students never see the relation between arithmetic and algebra. If students were enabled to see that algebra is Beneralized arithmetic, the practical and concrete nature of algebra would be realized. Through such a study the knowledge that most algebraic principles are supported by innumerable specific number relations, would become a valuable motivation for students to Generalize specific number relations with which they have contact.

6. Stiudieg designed to aevelop an understanding of the significance and efficiency of symbolism through elementary algebra.

Much of our thinking is communicated to others through the use of written symbols. For the higin school student, elementary algebra can represent the acme of symbolic thinking if his attention is directed to the thoughts conveyed by mathematical and non-mathematical symbols. Comparisong of the precise and limited meanings of algebraic symbols with the indefinite and ambiguous meanings of some non-mathematical symbols would motivate a respect for the efriclency of algebraic symbolism which the student generally does not have.

7. A study of measurement and approximate computation through the channel of algebra. 
The concept of measurement and approximate computation is probably the most neglected concept in the teaching of secondary mathematics. This study could emphasize the logic involved in the rounding of numbers secured through measurement, and the principles used to determine the accuracy of products, quotients, sums and differences resulting from the use of approximate numbers.

8. Studies considering methods which illustrate how the number system has been and can be expanded to meet new demands and conditions in modern living.

Elementary algebra is characterized by piece-meal teaching. Operations with directed numbers are taught without relation to operations with arithmetic numbers, and without justification for their use. Exponential numbers are considered as a separate unit without conscious effort to relate them to other types of numbers. In like manner, other numbers and operations are considered as discrete and isolated units. If each student were stimulated to build his own number system with each new principle as an outgrowth of the known facts and principles our students would become more alert to number relations.

9. Proposals for content of courses designed for prospective mathematics teachers which will make them qualified to guide students in the improvement of their reasoning abilities.

This proposal, as the fifth recommendation, is necesgary if we are to have prospective teachers assume their tasks con- 
fidently and efficiently. Revising and enlarging the present plans for training mathematics teachers must parallel any plans for enlarging and revitalizing instruction in elementary algebra. 


\section{BIBLIOGRAPHY}

I Books, Booklets, Yearbooks, Bulletins

Aiken, WiIford M., The Story of the Eight Year Study. New York: Harper and Brothers, 1942.

Bennett, A. A., and Baylis, C. A., Formal Logic. New York: Prentice-Hall, 1939.

Chase, Stuart, The Tyranny of Words. New York: Harcourt, Brace and Company, 1938.

Cooley, H. R., Introduction to Mathematics. Boston: Houghton-Miffin Company, 1937 .

Daily, Benjamin D., The Ability of High School Pupilg to Select Essential Data in Solving Problems. New York: Bureau of Publications, Teachers College, Columbia Univeraity, 1925.

Everett, John P., The Fundamental Skills of Algebra. New York: Bureau of Publications, Teachers College, Columbia University, 1928.

Glaser, E. M., An Experiment in the Development of Critical Thinking. New York: Bureau of Publications, Teachers College, Columbia University, 1941.

Guilford, Joy P., Fundamental Statistics in Psychology and Education. New York: McGraw-H1ll Book Company, 1950 .

Hamley, Herbert R., Relational and Functional Thinking in Mathematics. New York: Bureau of Publications, Teachers College, Columbia University, 1934.

Hartung, Maurice L., Interpretation of Data Bulletin No. 3, Progressive Education Association, Evaluation in the Eight Year Study, Columbus: Ohio State University, October, 1935.

Hogben, Lancelot, Mathematics for the Million, New York: W. W. Norton and Company, 1937.

Jepson, R. W., Clear Thinking: An Elementary Course of Preparation for Citizenship. New York: Longmans, Green, 1936. 
Joint Commission of the Mathematical Association of America and the National Council of Teachers of Mathematics, The Place of Mathematics in Secondary Education. New York: Bureau of Publications, Teachers College, Columbia University, 1940.

Johnson, Palmer O., Statistical Methods in Research. New York: Prentice-Hall, 1949.

Judd, Charles H., Education as Cultivation of the Higher Mental Processes. New Yorls: The Macmillan Company, 1936.

Keyser, C. J., Mole Phllosophy and Other Essays. New York: E. P. Dutton and Company, 1927.

National Committee on Mathematical Requirements. The Reorganization of Mathematics in Secondary Education. Boston: Houghton-Mifflin Company, 1923.

National Council of Teachers of Mathematics, Seventeenth Yearbook, A Source Book of Mathematical Applications. New York: Bureau of Publications, Teachers College, Columbia University, 1942.

National Council for the Social Studies, Thirteenth Yearbook, Teaching Critical Thinking in the Soclal Studies. Washingtoni The Council, 1942.

National Society for the Study of Education, Forty-fifth Yearbook, Part 1, The Measurement of Understanding. Chicago: University of Chicago Press, 1946.

Orata, P. T., Theory of Identical Elements. Columbus: Ohio State University Press, 1928.

Progressive Education Association, Commission on Secondary Curriculum, Mathematics in General Education. New York: D. Appleton-Century, 1940.

Materials Prepared by Participants of the Mathematics Group, Progressive Education Association Workshop, Ohio State University, 1936.

Quilien, I. J., and Hanna, I. A., Education for Social Competence. Chicago: Scott, Foresman and Comnany, 1948. 
Smith, Eugene R., and Tyler, Ralph W., Appraising and Recordins Student Progress. New York: Harper and Brothers, 1942 .

Thouless, R. H., How to Think Straisht. New York: Simon and Schuster, 1939 .

Young, J. W., Lectures on the Fundamental Concepts of Alsebra and Geometry. New Yorls: The Macmilian Company, 1925 .

II Periodical References

Anderson, H. C., Marcham, F. G., and Dunn, S. B., "An Hxperiment in Teaching Certain Skills of Critical Thinking": Journal of Educational Research, XXXVIII (December, 1944)

Betz, William, "Whither Algebra? - -a Challenge and a Plea", The Mathematics Teacher, XXIII (February, 1930).

Bingham, N. E., and West, J. Y., "Aims and Purposes of Sclence Teaching", Review of Educational Research, XVIII (October, is48).

Fawcett, Harold P., "Language and Mathematics", Educational Method, XXI (March, 1942).

"Gallup Poll", Time, LI (May 3, 1948).

rinsella, John J., "Research in Mathematics Education", The Mathematics Teacher, XIIII (December, 1950).

Ratcliff, J. D., "The Hullabaloo About Hadacol", Reader's Digest, IIX (JuIy, 195I).

Richardson, J.S, and Barnard, J. D., "Methods and Materials in the Teaching of Science", Review of Educational Research, XVIII (October, 1948).

West, R. I. and Shuster, Carl N., "The Teaching of Approximate Computation", The Mathemat1cs Teacher, XXXVI (Apri1, 1942).

Willits, W. M., "New Objectives for Ninth Grade Mathematics: an Exposition and Appra1sal", Journal of Experimental Education, XIII (September, 1944). 
Wren, F. Lynwood, "A Survey of Research in the Teaching of Secondary Algebra", Journal of Educational Research, XXVIII (ApriI 1, 1935).

\section{Unpublished Materials}

Green, Helen L., "Developing an Understanding of the Nature of Relationships Through the Medium of Elementary Algebra". Unpublished Master's Thesis, Ohio State University, 1946.

Lewis, Harry, "An Experiment in Developing Critical Thinking Through The Teaching of Plane Demonstrative Geometry", Unpublished Doctor's Dissertation, New York: University, 1950.

Weisman, Leah I., "Some Factors Related to the Ability to Interpret Data in Biological Sclences, Unpublished Doctor's Dissertation, UnIversity of Chicago, 1946.

Willits, W. M., "New Objectives for Ninth Grade Mathematics", Unpublished Doctor's Dissertation, Temple University, 1944. 
259.

APPENDIX.

Complete Set of Study Guides Used In Experimental Course 
Name

Study Guide No. I

Symbols

What do the following symbols refer to?

1. Ai red light

2. A. D.

3. The sound of a siren

4. Jan.

5. H

6. Yellow traffic light

7. C. O. D.

8.

9. The sound of a door bell IO. M. D.

11. VII

12. E. S. T.

13.

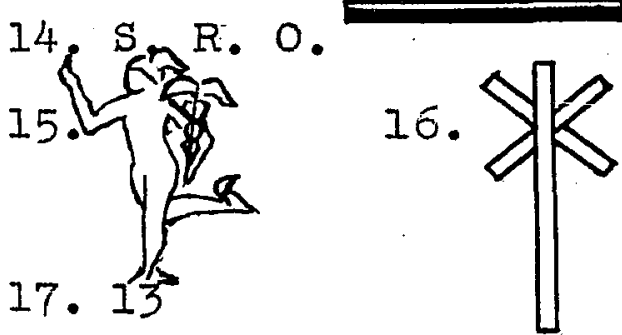

15.

16.

18. A No. 1

19. T. N. T.

20. $\div$

21. 45

22. $v=1 w h$ 


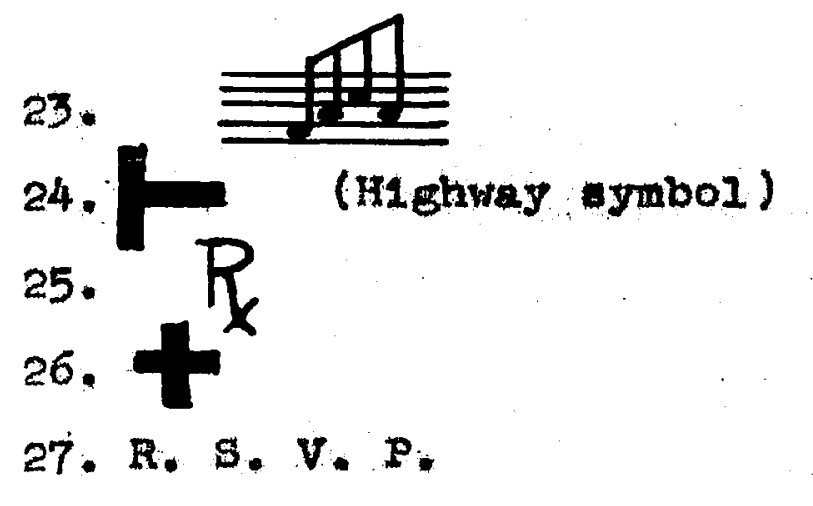

1. Which ymbols are warninge?

2. Wrich symbols are symbols of other symbols?

3. Liat nome other symbols and deseribe the thoughts they convey.

4. LIat all the gymbols which you can think of thet are used in mathemat 20 and ohow whet they mean.

5. Why do we use symbols? 
Name

\author{
Study Guide No. 2 \\ The Meaning of Symbols
}

In previous discussions we have agreed that words are one of man's most useful symbols. Consider the following statements noting how the underlined word is used in each set of statements.

1. a. We cast away useless things.

b. Her face had a bluish cast.

c. I could see by the cast of her eye that she was angry.

2. a. A newsboy needs a lot of change.

b. A change of scenery is necessary for the third act of the play.

3. a: Doctors are very cool when faced with an emergency.

b. Gool beverages are refreshing.

4. The price for dressed chickens was When Mary had dressed she rushed downstairs for breakfast.

5. a. Dry ginger ale does not taste very sweet.

b. Cactus plants flourish in dry air.

6. a. Did you see him edge away from the car?

b. The edge of thig knife is very sharp.

7. a. The speed of an airplane is very fast.

b. The screw held the hinge fast.

8. a. This hoslery is of fine quality.

b. Each club member must pay a fine when late to a meeting.

A. What observations can you make concerning the use or meaning of the underlined word in each set of statements?

B. For the following words, construct at least two statements for each to show the different meanings that the word can convey. 


$\begin{array}{lllll}\text { vice kind } & \text { mark } & \text { long hall light } \\ \text { plot lock } & \text { general rent hide }\end{array}$

C. What conclusions can you make concerning the uses that can be made of word symbols? 
Name

Study Guide No. 3

Using Symbols to Express Relations

We have seen that a symbol (word) may serve many purposes: and that its meaning is determined by the situation in which it is used as well as many other factors. The meaning of a word may change within a: situation because of the changed meanings of other words. Hence, 1ts meaning may depend upon the meaning of another word. Consider the following illustrations of dependence:

a. Blood pressure depend upon age. (As one increases in age blood pressure increaseg.)

b. Distance traveled dependa upon the rate at which you move and how long you travel. (Two things determine the distance that is traveled--the rate and the time).

c. The price of an article depends upon the amount on hand and the demand for it. (The price of sugar is high because there is not mush sugar avatlable and because every family needs (demands) it.)

d. A student's grade in a subject depends upon his attendance, the quality of his work, and other factors.

e. A person's appetite depends upon such factors as his age, the present state of his health, and the type of work that he does.

f. John's decision to buy a sweater may depend upon such factors as: his friend's purchase of a similar sweater, the cost of the sweater, its: color and styling.

8. The amount of floor area in a room depends upon its dimensions. (1ts length and width).

1. In the statements above, underline the words whose meanings are dependent as has been done in statement $a$.

2. Give other 1llustrations of dependence.

2.1 
2.2

2.3

2.4

3. In a short paragraph give your ideas concerning the Importance and value of dependence in our everyday living. 
Name

Study Guide No. 4

Reaching Conclusions

We can accurately state the nature of some of the examples of dependence in Study Guide No. 3. For example, the area of the floor of a rectangular room equals the product of the length by the width.

Other illustrations of dependence can only be expressed approximately. For example, we cannot measure a person's appetite in terms of related factors. There are so many variables. Which may or may not be present in each person. In addition to the variables listed in Study Guide No. 3 one person may be affected by the odor of food and the appearance of the food, while another would not. Some older pergons may have heavier appetites than 'teen agers because of the action of certain glands in the body. Hence, this relation cannot be expressed accurately because of the many variables which cannot be measured or which are not consigtent in their effect upon the relation.

Let us study the following table of data to discover possible relationships. These data on accidents are from school systems having a total enrollment of 936,000 pupils.

Where School Accidents Happen Apri1, 1942-March, 1943

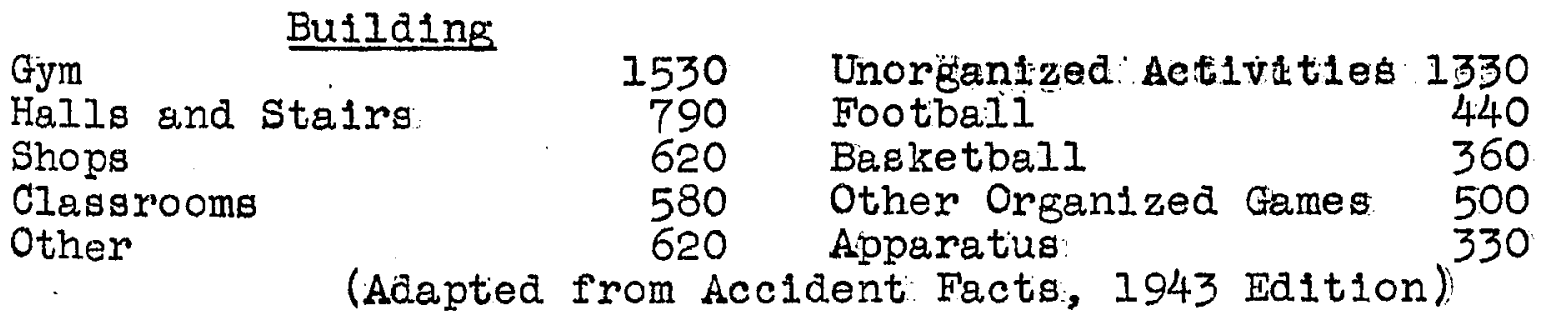

What observations can you make concerning school accidentis?

(For example: Where did the greatest number of accidents occur? in school buildings? on school grounds?

Where are the safest: places in the bullalngs?

In what type of activity is there greatest protection on school grounds?: 
Name

Study Guide No. 5

Reaching Conclusions

In Study Guide No. 4 we saw that the table represents one method for presenting information. The graph represents another method for presenting information. Try to make a. sraph of the information given on Study Guide No.4.

Using the graph, what observations can you make concerning school accident's?

From which illustrations can you make your observations best, the table or the graph? Why? 
Name

Study Guide No. 6

Rèrching Conclusions

The data below gives information concerning the number of dwelling units in Covington and the years in which they were built.

Dwelling Units In Covingtion By Year Bullt

\begin{tabular}{|c|c|c|c|c|c|c|c|}
\hline \multirow[b]{2}{*}{ Year Built } & \multicolumn{6}{|c|}{ Wards: } & \multirow[b]{2}{*}{ Trotal } \\
\hline & $I$ & $\overline{2}$ & 3 & 4 & 5 & 6 & \\
\hline $\begin{array}{l}1899 \text { or earlier } \\
1900 \text { to } 1919 \\
1920 \text { to } 1929 \\
1930 \text { to } 1940\end{array}$ & $\begin{array}{r}865 \\
243 \\
29 \\
3\end{array}$ & $\begin{array}{r}1406 \\
290 \\
52 \\
13\end{array}$ & $\begin{array}{r}1352 \\
382 \\
269 \\
37\end{array}$ & $\begin{array}{r}1361 \\
321 \\
45 \\
17\end{array}$ & $\begin{array}{r}1313 \\
2572 \\
1558 \\
236\end{array}$ & $\begin{array}{r}1862 \\
1819 \\
914 \\
110\end{array}$ & $\begin{array}{r}8159 \\
5627 \\
2867 \\
416\end{array}$ \\
\hline Totals & 1140 & 1761 & 2040 & 1744 & 5679 & 4705 & 17069 \\
\hline
\end{tabular}

Source: 3.6 th Censug of the U. S., Housing, Supplement to the First Series Housing Bulletin for Kentucky.

1. Make appropriate graphs of the data given in the table or portions of it. (For example, graph the data for city as: a whole and for Ward 1 ).

2. What observations can you make concerning dwelling units in the entire city and in the various wards?

(For example:: Describe the houses in Ward 1; in Ward

5. Is Covington a city of old homes or new homes?)

3. We can also reach conclusions by making a series of statements in the following manner:

Before 1900 the number of dwelling units in Ward 1 was 10.6\% of the total dwelling units in Covington. or $w_{1 a}=.106 n_{1} .$, where $w_{1 a}=$ the number of dwelling units

$$
n_{1}=\begin{aligned}
& \text { the total number of dwelling } \\
& \text { units in covington before } 1900
\end{aligned}
$$


Using this system of symbolism, what would the following symbols represent?

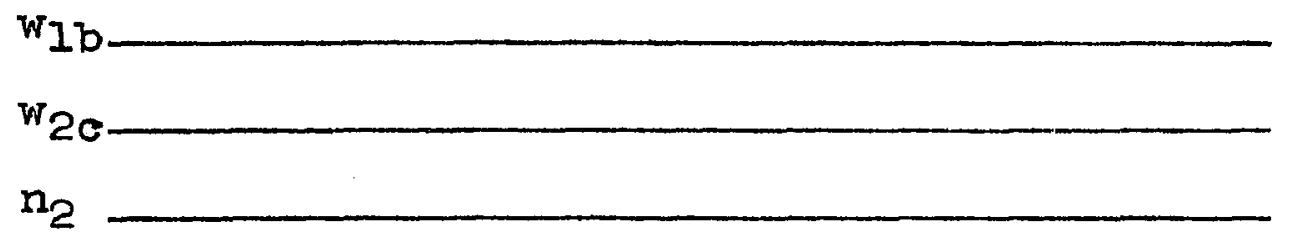

4. Make a few conclusions of the type described in question 3 above. 
Name

Study Guide No. 7

Interpreting Data

Workins For The Government

United States; 1900 - 1949

(Fèderal, State, Local)

Total

Employment

in Militions

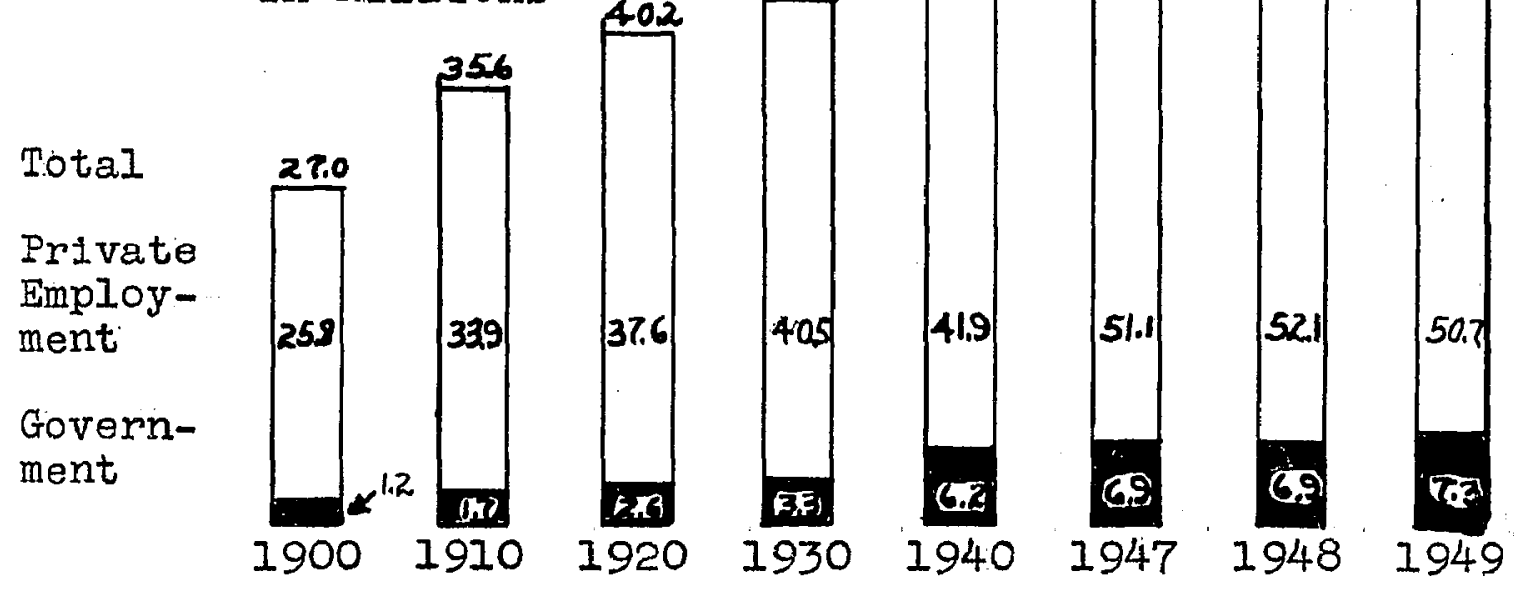

(Adapted from "Road Maps of Industry, May 19, 1950)

The following statements are conclusions that have been reached from a study of the graph above. However, some of the statements are valid while some are not justified. On the basis of the facts presented in the graph:

Write an $A$ to the left of the statement if you accept it as valid.

Write R to the left of the statement if you reject it.

Write U: to the left of the statement if you are unable to decide because of insufficient data.

1. The number of government employees has increased steadily since 1900.

2. There should be more than 10 million government employees in 1950.

3. The number of persons in private employment during 1949 is almost double the number employed in 1900 .

4. Since the total number of employed persons decreased 
in 1949 to 57.9 million, the number in 1960 should be lesg: than 50 million.

5. There were probably $\cdot 5$ million government employees in 1890.

6. In 1935 there was a total of 45.9 million employed persons in the United States.

7. In 1949 about one out of every eight employed persons was employed by the government.

8. There are too many people holding government jobs now.

9. In 1900 about one out of every 23 employed persons was. employed by the government.

10. If we are to have efficient government, we must employ many people to perform the duties that must be taken care of by government.

1.1. In 1907 there was a total of 33 million people employed in the United States.

12. There were no government employees in 1870. 
Name

Study Gulde No. 8

Int'erpreting Datia:

The grophs below peesent information on spendins by the average family in the United States:

How The Consumer Spent His Dollar

United States, 1901 -. 1949

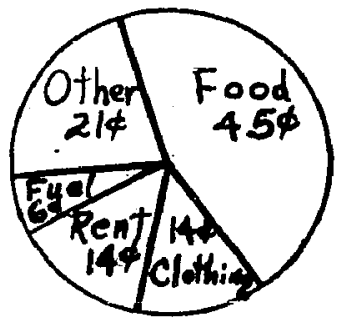

1901

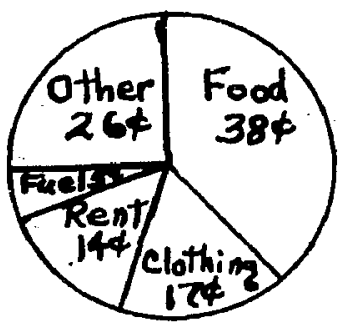

$1918-1919$

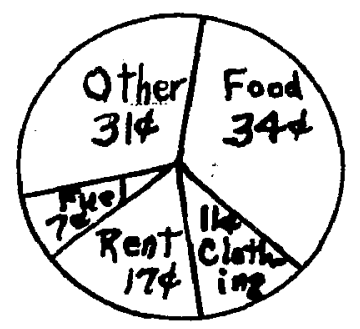

$1934-1936$

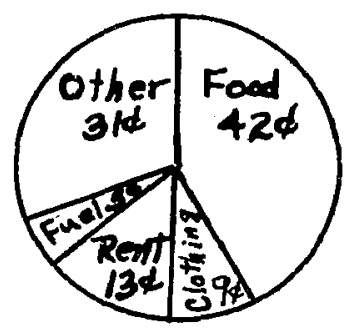

Oct., 1949

Study the graphs carefully then state as many conclusions as you can concerning spending by the average family. 
Name

Study Guide No. 9

Reaching Conclusions

The following table lists death rates per 100,000 people in the Unitied States::

1941 Death Rates

\begin{tabular}{l|r|r|r}
\hline Causes: & Male & Female & Doth Sexes \\
\hline Heart Disease & 338 & 241 & 290 \\
Cancer & 114 & 126 & 120 \\
Cerebral Hemorrhage: & 88 & 90 & 89 \\
Accidents: & 108 & 44 & 76 \\
Nephrit1s: & 80 & 70 & 75 \\
Pneumonia & 55 & 41 & 48 \\
Thuberculosis: & 52 & 37 & 45 \\
\hline
\end{tabular}

1. Make appropriate graphs of the data bobre.

2. From the table or from the: graph, what conclusiong can you reach concerning death rates?

(For example: What factor causes most deaths?

What factor causes least deaths?

What factor affects: men more than women?

What factor affectis women more than men? Are death rateg higher among males or females? )

3. From which 1liustration can you make your conclusions best,. the graph or the table?

Why? 


\section{Name \\ Study Gu1de No. 10 \\ Study ing Data}

The table below gives information on accidental deaths from motior vehicles in the United States.

Accldental Deaths. From Motor Vehicles

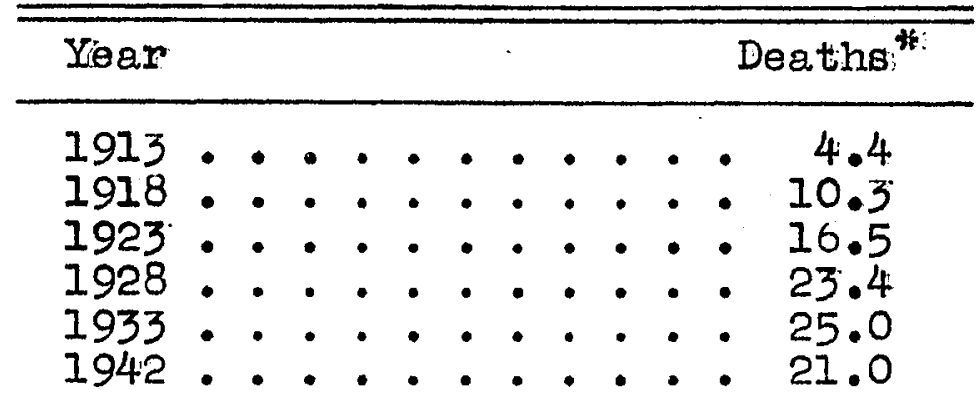

(Adapted from Accldent Facts, "43 ed.)

We can study the table by comparing the change in time with the change in the number of deaths. For example, from 1913 to 1918 there 1s: a change, which 18: an increase of 5 years. The corresponding change in deaths is 5.9 (10.3 4.4.). Is this change an increase or decrease?

Find the other changes in years and the corresponding change in deaths. Record your results in the table below placing a plus algn $(t)$ before numbers which represent increases: and a minus sign (-) before numbers which represent decreases.

\begin{tabular}{c|c|c|c}
\hline Years & $\begin{array}{c}\text { Change in } \\
\text { Years }\end{array}$ & $\begin{array}{c}\text { Change in } \\
\text { Deaths }\end{array}$ & $\begin{array}{c}\text { Rate of } \\
\text { Change }\end{array}$ \\
\hline 1913 to 1918 & 5 & 5.9 & \\
\hline 1918 to 1923 & & & \\
\hline 1923 to 1928 & & & \\
\hline 1928 to 1933 & & & \\
\hline 1933 to 1938 & & & \\
\hline 1938 to 1942 & & & \\
\hline
\end{tabular}


At the end of the first 5 years (In 1918) there was an increase of 5.9 deaths over the number of deaths in 1913 . As suming that the number of deaths increased regularly each year, what is the change per year during this period? This increase is called "rate of change".

Find the rate of change for the other periods and record them In the last column of the table above.

That conclusions can you make concerning the rates of change in accidental deaths due to motor vehicles? 
Stúdy Gúdre No. 11

Studying Data

The following table shows the relation between wages received by a worker and the number of hours he worked:

\begin{tabular}{c|c|c|c|c}
\hline Hours & Wages & $\begin{array}{c}\text { Change in } \\
\text { Hours }\end{array}$ & $\begin{array}{c}\text { Change in } \\
\text { Wages }\end{array}$ & $\begin{array}{c}\text { Rate of } \\
\text { Change }\end{array}$ \\
\hline 0 & $\$ 0.00$ & & & \\
\hline 5 & 4.50 & & & \\
\hline 15 & 13.00 & & & \\
\hline 20 & 18.00 & & & \\
\hline 25 & 22.50 & & & \\
\hline 30 & 27.00 & & & \\
\hline 35 & 31.50 & & & \\
\hline 40 & 36.00 & & & \\
\hline 45 & & & & \\
\hline 50 & & & & \\
\hline$n$ & & & & \\
\hline
\end{tabular}

Compute the change in hours for each interval and record in the table above.

Compute the change in wages for each interval and record in the table above.

Compute the rate of change for each interval and record in the table above. 
You will note that when the rate of change for the firgt interval is multiplied by the total number of hours, the answer $(\$ 4.50)$ represents the total wages. Is this true for every interval in the table?

What is the relation between hours worked and wages earned? 


\section{Study Guide No. 12 \\ Graphing Data}

Construct vertical bar graphs of the data given in the two preceding study guides on accidental deaths and on wages. Prepare each graph so that no spaces are between the bars.

How do the two graphs differ?

What observations can you make concerning the appearance of the graph on accidents and the rate of change in accidental deaths?

What observation can you make concerning the appearance of the graph on wages and the rate of change in wages? 
Name

Study Guide No. 13

Stopping Distances

This chart prepared by the Police Accident Investigation Unit of Washington, D. C., lists the distance an automobile goes before the ariver can apply his brakes after seeing danger.

\begin{tabular}{l|c|l|l}
\hline $\begin{array}{c}\text { Driving at } \\
\text { This Speed }\end{array}$ & $\begin{array}{l}\text { After Seeing The Danger } \\
\text { You Go This Far Before } \\
\text { Applying the Brakes }\end{array}$ & $\begin{array}{l}\text { Changes } \\
\text { In Re- } \\
\text { action } \\
\text { Distance }\end{array}$ & $\begin{array}{l}\text { Rate of } \\
\text { Change }\end{array}$ \\
\hline $\begin{array}{c}\text { Miles Per } \\
\text { Hour }\end{array}$ & $\begin{array}{c}\text { Reaction Distanoe } \\
\text { Feet: }\end{array}$ & & \\
\hline 10 & 11.0 & & \\
\hline 20 & 22.0 & & \\
\hline 30 & 33.0 & & \\
\hline 40 & 44.0 & & \\
\hline 50 & 55.0 & & \\
\hline 60 & 66.0 & & \\
\hline
\end{tabular}

(Adapted from the Washington Evening Star, Aug. 13, 1946)

1. As the speed increases what happens to reaction distance?

2. If the speed. is increased from 10 to $20 \mathrm{mph}$ what happens to reaction distance?

Then the speed is increased from 20 to $40 \mathrm{mph}$ what happens to the reaction distance? 
When the speed is increased from 30 to $60 \mathrm{mph}$ what happens to the reaction distance?

If the speed is doubled, what effect does this have upon the reaction distance?

3. Compute the differences between successive reaction distances and record them in the table.

4. That are the "changing quantities" or "variables" in this problem?

5. Which variable in this problem could not change without a change in the other vartable? Such a variable is called a dependent variable.

6. What is the rate of change or the rate of increase in reaction distance as speed increases? This ratio is known as slope.

7. Thenever the rate of change in a table involving two variables is constant, it is possible to state the relation between the two variables as a formula, State the formula.

8. Make a line graph of the data on reaction distance. Use the horizontal line for the independent variable giving each block a value of 10 . Use the vertical line for the dependent variable, Biving each block a value of 11.

9. That is the reaction distance when the speed is $25 \mathrm{mph}$ ? 45 mph?

10. Do the results obtained in problem 9 by using the graph, check with the results you get when using the formula?

11. What would be the reaction distance if the speed were $70 \mathrm{mph}$ ? $90 \mathrm{mph}$ ? 
Name

Study Guide No. 14

Studying Data

Let us study the following tables of data to discover possible relationships:

Student Accidents By Grade

\begin{tabular}{|c|c|c|}
\hline Grade & $\begin{array}{l}\text { Rate (per } \\
1,000,000 \\
\text { school days) }\end{array}$ & $\begin{array}{l}\text { Rate of } \\
\text { Change }\end{array}$ \\
\hline $\begin{array}{l}\text { Kinder- } \\
\text { garten }\end{array}$ & 45 & \\
\hline 1 & 84 & \\
\hline 2 & 104 & \\
\hline 3 & 108 & \\
\hline 4 & 125 & \\
\hline 5 & 125 & \\
\hline 6 & 149 & \\
\hline 7 & 152 & \\
\hline 8 & 138 & \\
\hline 9 & 129 & \\
\hline 10 & 117 & \\
\hline 11 & 100 & \\
\hline 12 & 104 & \\
\hline
\end{tabular}

Cost of Gasoline

\begin{tabular}{c|c|c}
\hline Gallons & $\begin{array}{l}\text { Cost in } \\
\text { Cents }\end{array}$ & $\begin{array}{l}\text { Rate of } \\
\text { Change }\end{array}$ \\
\hline 1 & 30 & \\
\hline 2 & 60 & \\
\hline 3 & 90 & \\
\hline 4 & 120 & \\
\hline 5 & 150 & \\
\hline 6 & 180 & \\
\hline 7 & 210 & \\
\hline 8 & 240 & \\
\hline 2 & 270 & \\
\hline 10 & 300 & \\
\hline 11 & 330 & \\
\hline 12 & 360 & \\
\hline 13 & 390 & \\
\hline
\end{tabular}

(Adapted from Accident Facts, 1943 edition, p. 49)

1. These tables represent one method for showing relations between variables. What are the other methods used for showing relations between variables? 
2. What are the variables in each table of data?

3. What are the dependent variables?

4. Choose a symbol for each variable.

5. Compute the rate of change in each table above.

6. What do you observe concerning the rate of change in each table? What type of line graph will each produce -- a broken or a straight ine?

7. Construct line graphs for each set of data to determine whether or not your answers to question 6 are true. Use the vertical axis to represent the dependent variable.

8. Try to make seneral statements concerning:

a. the relation between the number of student accidents and grade level.

b. the relation between cost of gasoline and the number of gallons purchased.

9. Using the symbols you chose in question 4, make formulas which will replace the statements bove. 
Name

\section{Study Guide No. 15 \\ Exploring The Value of $P_{1}$}

Is there any relationship between the distance around a circle and the distance across it?

1. In answering the question above, what data will you need?

2. How could you obtain the information which you listed in answer to question (I)?

3. Secure the data according to the plan which you described and record it in the table below:

\begin{tabular}{l|l|l|l}
\hline \hline & & & \\
\hline & & & \\
\hline & & & \\
\hline & & & \\
\hline & & & \\
\hline
\end{tabular}

4. In the last column of the table, record the ratio of the "digtance around" to the greatest distance across each clrcle.

5. The value of "pi" can be found by computing the average of the values in the last column of your table. What is its value? 
7. From a study of your data, you will note some relation between the distance around a circle and the distance across it. State at least one relation.

8. What name do we give to the "distance around a circle"?

What name do we $\mathrm{g}^{\mathrm{f}} \mathrm{ve}$ to the "greatest distance across a circle"l?

9. Using these terms restate your conclusion in question 7 .

10. Using appropriate aymbols restate your conclusion above as a formula.

11. In the past and even how there has been much argument concerning the value of $\pi$. The following problems lilustrate how man has attempted to arrive at an exact value for $p i$.

a. Boys and girls of Biblical times used oi. What was its value to them? See II Chronicles 4:2.

b. In 1897 some members of the Indiana state legislature attempted to enact a law which would make the ratio of the circumference of a circle to its diameter equal the ratio of four to five fourths. What does the ratio of 4 to $5 / 4$ equal? $(4 \div 5 / 4)$

c. In your arithmetic and algebra textbooks you were given the number $3 \quad I / 7$ as the value of $r$. How much does it differ from your value? 
Name

Study Guide No. 16

Interpreting Data

Tire Wear Vs. Car Speed

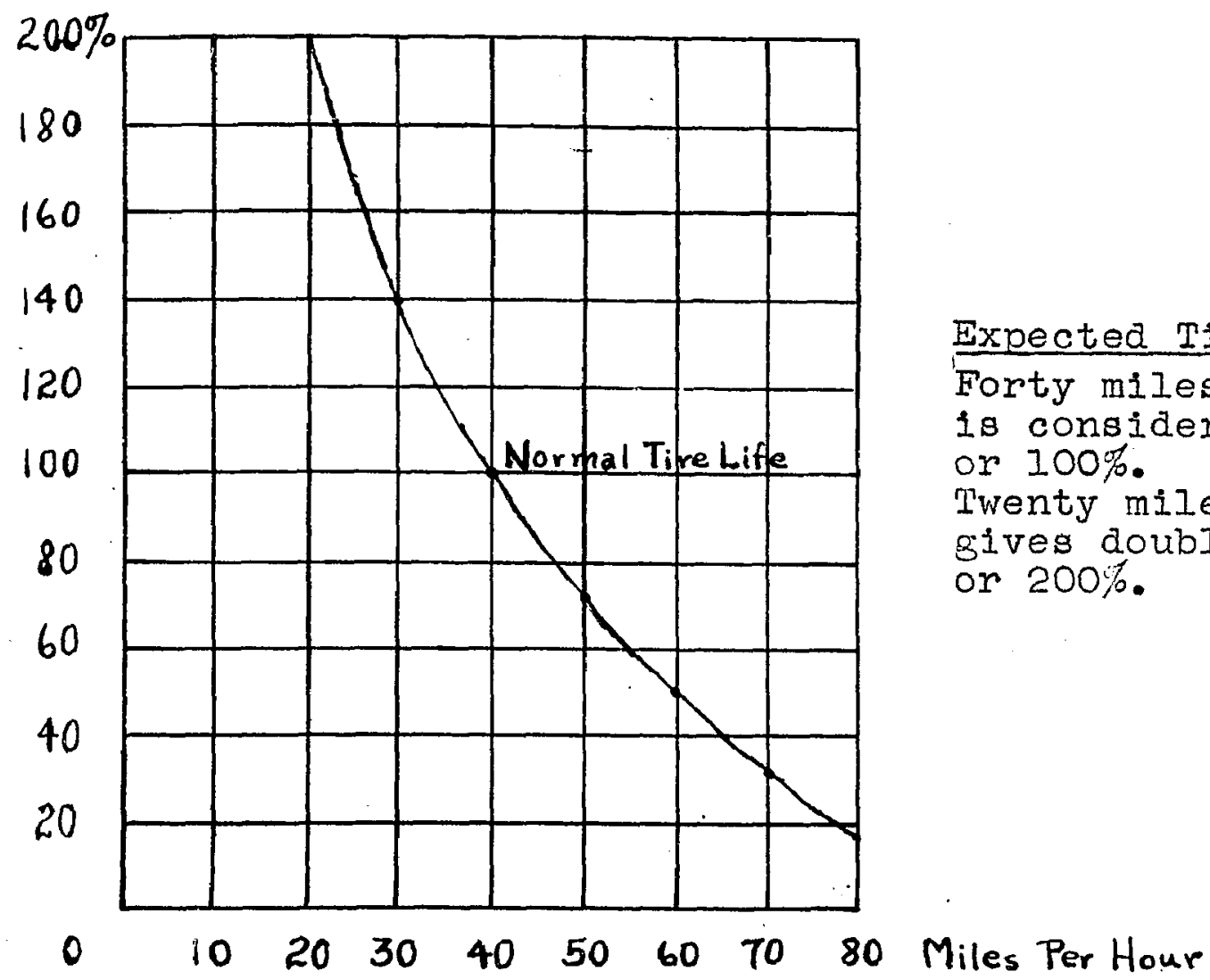

The line graph above deals with the problem of car speed and tire wear. It was prepared by the Society of Automotive Engineers of the War Engineering Board for the purpose of encouraging motorists to drive at lower speeds.

1. Johnny was very carerul as he drove his father's car. He said to his sweetheart, "Mary, I must dirive so that the tires will last longer". Mary replied, "Johnny, why don't you drive faster?" What do you think Johnny's reply was? 
2. Mr. James, the huckster, arives his truck at 20 miles per hour. Will his tires last longer than Iur. Hamilton's the taxicab ariver, who drives usually at 35 miles per hour? Why?

3. Is the following statement true? When the speed is doubled from 20 to $40 \mathrm{mph}$, the per cent of tire wear is halved. Why?

4. What per cent tire wear does a person get who drives his car at 30 mph? $60 \mathrm{mph}$ ?

5. What per cent tire wear does a person get, who drives his car at 25 miles per hour?

6. At what speed does a person drive his car when he gets $80 \%$ tire wear?

7. As speed increasea, what happens to tire wear?

8. What would you expect the tire wear to be when a car is driven at 90 miles per hour?

9. At what speed would you drive a car if you used this. graph as your guide? Why?

10. At what speed should you drive to get more than $200 \%$ tire wear? Why? 
Name

Study Guide Nọ: $17 a$

Interpreting Data

The graphs below present information on spending by the average family in the United States:

How The Consumer Spent His Dollar United States, 1901. - 1949

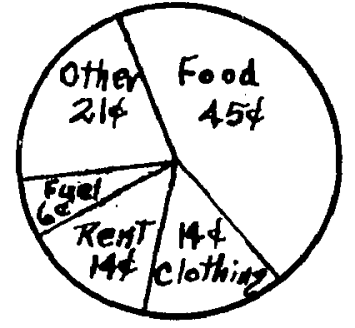

1901

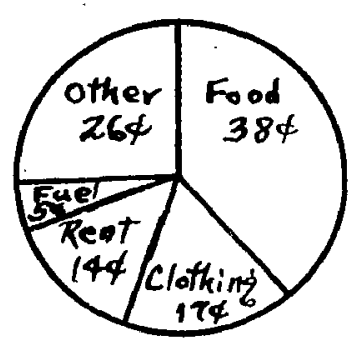

$1918-1919$

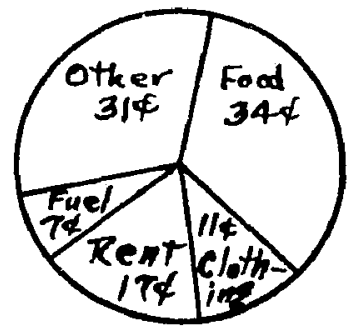

$1934-1936$

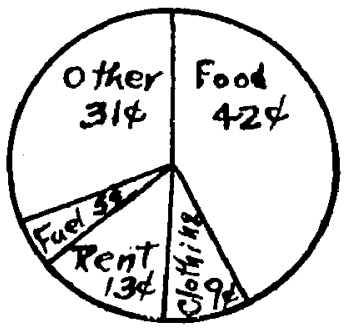

Oct. 1949

The following statements are conclusions that have been reached from a study of the graphs above. However, some of the statements are valid while some are not justified. On the basis of the facts presented in the graphs:

Write an A to the left of the statement if you accept it as vaIid.

Write an $R$ to the left of the statement if you reject it.

Write a U to the left of the statement if you are unable to decide.

1. During these times the consumer has spent his money wisely.

2. Clothing was cheaper in 1934-36 then in 1901 .

3. Food prices went down until the shortage, then they went up again.

4. In October, 1949, the consumer spent out of each dollar earned, 2\& less for clothing and $4 \not$ less for rent than he did in 1934-36.

5. Due to rent control, there were very little changes in rent.

6. The amount spent for food is more than the amount spent for rent, clothing and fuel combined. 
288

- 7. The average family spent less for fuel than any other thing.

8. Each year the average family spends more for food than any of the other family needs.

- 9. Prices were higher than ever in 1949. $10.5 \%$ 1ess for food than in 1918-19.

11. The standard of living went up from 1901 to 1949.

12. In October, 1949, more was spent for fuel than any other time.

13. In 1918 a person spent more for clothing out of his dollar than in 1949. 
289

Name

Study Guide No. 170

Interpreting Data.

The graphs below present information on spending by the average family in the United States:

How The Consumer Spent His Dollar

United States, 1901 - 1949

(See Graphs For Study Guide No. 17a.)

The following statements are conclusiong that have been reached from a study of the graphs above. However, some of the statements are valid while some are not justified. On the basis of the facts presented in the graphs:

Write an $A$ to the left of the statement if you accept it as valid.

Write an $\underline{R}$ to the left of the statement if you reject it.

Write $a$ U to the left of the statement if you are unable to decide.

1. Food cost more than the rest of the spendings by the average family.

2. More money was spent for food in 1901 than the

present day.

4. The average family spent more money for food than anythins else.

5. In 1949, the average family spent less for clothing than in the other years.

6. Food purchased during each year $1934-36$ cost $77 \%$ of the money spent for food in 1949.

7. In 1950 the amount spent for fuel will increase to about $3 \phi$ per dollar more than the amount spent for fuel in 1949 . 
8. During the 48 year period each family spent too much for "other things".

9. In 1934-1936 the family spent more for rent. The average man spent most of his money for food in 1949, so he had no money to buy clothing for his family.

11. Less was spent for clothing in 1949 than at any other time during the 48 year period.

12. Less was spent for fuel than for anything else.

13. From 5 to 8 times as much money was spent for food a.s for fuel.

14. In 1934-1936 the average family spent $11 \%$ of its income for clothing.

15. In October, 1949, more was spent for food than any other time.

16. Food was cheapest in 1934-1936.

17. The average family in 1901 gpent as much for clothing as it did for rent. 
Name

Study Guide No. 18

Studying Opposites

Consider the following terms which have opposite meanings (antonyms).

courage - cowardice
lengthen - shorten
accept - reject
love
happy - hate

$\begin{array}{ll}\text { accumulate } & \text { - waste } \\ \text { beautiful } & - \text { ugly } \\ \text { question } & - \text { answer } \\ \text { help } & - \text { hinder } \\ \text { start } & - \text { stop }\end{array}$

Now for each of the following words, give a word which has an opposite meanine in the space provided. Do not use words having the prefixes in-, im-, or un-.

1. up

2. right

3. rich

4. wet

5. soft

6. east

7. large

8. straight

9. take

10. work

11. grief

12. stupia
13. hole

14. apology

15. holy

16. add

17. rewara

18. part

19. withdraw

20. divide

21. reverse

22. midnight

23. 1950 A.D.

24. 1000 feet above sea level 
List at least ten pairs of words which have opposite meanings.
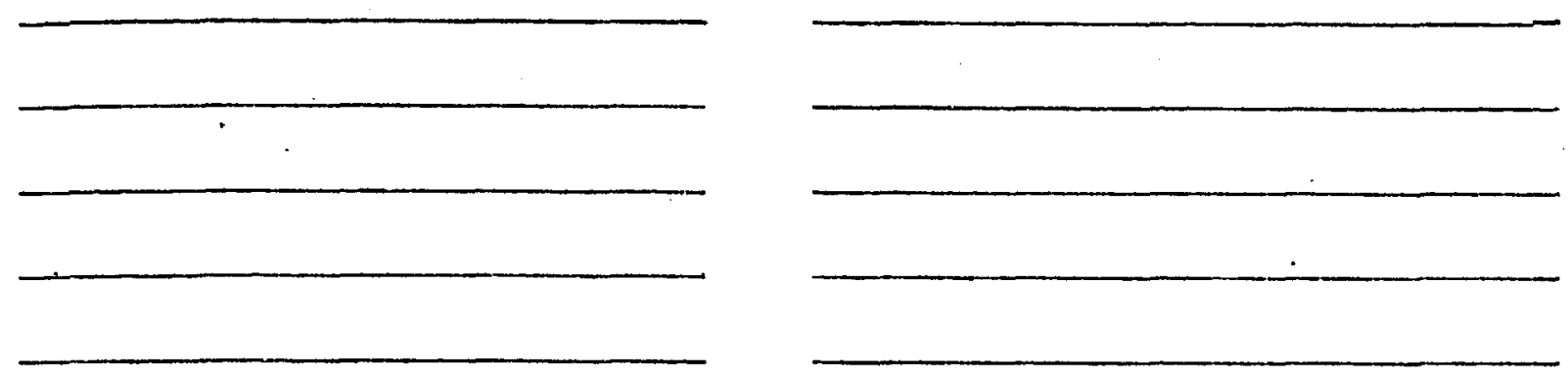

Can you think of any pairs of numbers which have opposite meanings? If so, list them below. 
293

Name

Study Guide No. 19

The Power of Well-Selected Symbols

Many years ago when number systems were more awkward, the results of counting and nessuring were recorded only with Roman numerals. As you have learned in your earlier work, the following basic symbols are used in the Roman system:
I for 1
$X$ for 10
$V$ for 5
I for 50
C for 100
$D$ for 500
M for 1000

Children of the Romans had to use these symbols when they learned to add subtract, and multiply. Imagine two Roman boys, "Caesar" and "Augustus" trying to write Roman numerals. How did they write the following numbers?

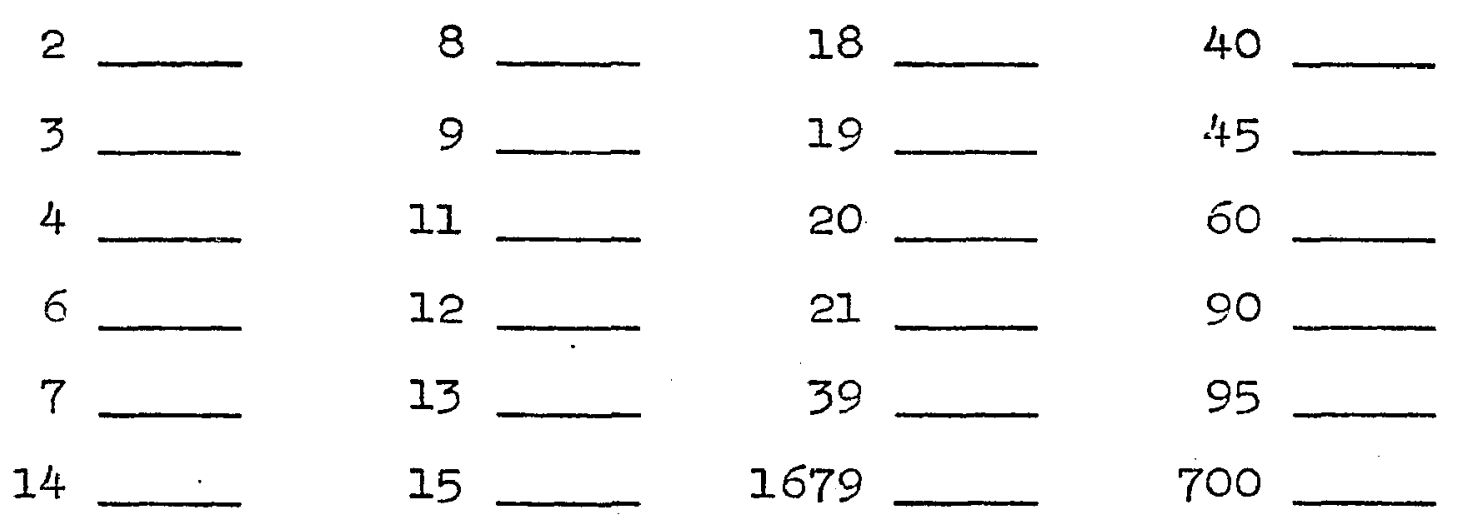

Perform the operations indicated below, then work each problem as you think Caesar and Augustus would have with Roman numerals.

Add

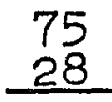

Subtract:

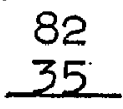

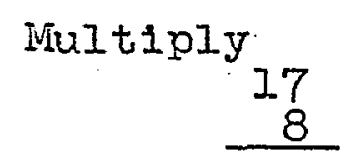

Multiply
61

Do you think that Caesar and Augustus and other children using Roman numerals could work such problems as easily as can we? Why? 
Name

Study Guide No. 20

Relations Between Operations

Perform the following operations:

Add:

(a)

(b)

(c)

(a)

\begin{tabular}{l}
39 \\
16 \\
\hline
\end{tabular}

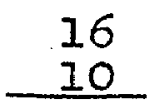

\begin{tabular}{l}
$8 a$ \\
$7 a$ \\
\hline
\end{tabular}

$13 \mathrm{x}$

$12 \mathrm{x}$

Now subtract: 16

10

$7 \mathrm{a}$

$12 x$

Difference:

What observations can you make concerning the relation of the final answers to the first number in each problem?

What seems to be the effect of subtracting the same amount that has been added previously to a number?

What then is the relation between the operation of addition and the operation of subtraction?

Now, perform the following operations:

(a) 'Divide 95 by 5, then multiply the answer by 5 .

(b) Divide 72 by 9, then multiply the answer by 9 .

(c) Divide 144 by 4, then multiply the answer by 4 .

(a) Divide $42 n$ by 3, then multipiy the answer by 3 .

(e) Multiply 36 by 9, then divide the answer by 9.

(f) Mutiply 256 by 16, then divide the answer by 16 .

(8) Multiply 39 by 13, then divide the answer by 13 .

(h) Multiply $17 x$ by 8 , then divide the answer by 8 .

What is the relation between multiplication and division? 
295

Name

Study Guide No. 21

New Problems In Subtraction

Consider the following problems:

1. James and Jack were playing a game. James had scored 5 points and Jack had scored 8 points. On the next round James lost 6 points and Jack lost 8 points. What wes each boy's score?

2. Last Christmas Day the thermometer registered $10^{\circ}$ and on the following day there was a decrease of $12^{\circ}$ in the reading. What was the temperature on that day?

3. If Mr. Jason had deposited in the bank 75 and was permitted to withdraw $\$^{2} 100$, how much did he have left in the bank?

4. An elevator operator stationed at the 6th floor of a bullding ran the elevator down 8 floors and stopped. At what floor did he stop?

5. If circular coins were first used as money 2250 years ago, in what year were they introduced?

6. In each of the following problems subtract the lower number from the top number:

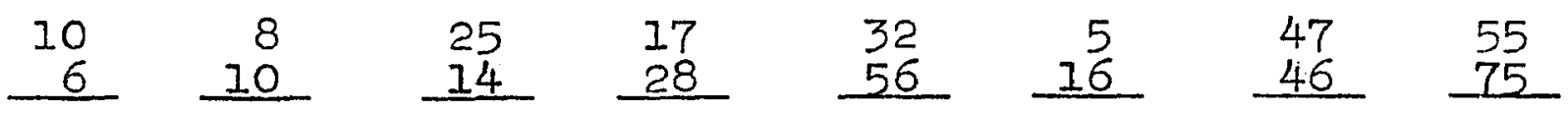

7. Is it always possible to subtract one number from another?

Explain your answer above. 
Name

Study Gu1de No. 22

Number Scales

000

1. A centigrade thermometer is pictured on the left. Imagine that the following readings have been taken.

Freezing point of water ....... $0^{\circ}$ Normal body temperature .......37 above zero Temperate weather ..........16 above zero Melting point of parafin wax $.53^{\circ}$ above zero Temperature of dry ice .......7. below zero Freezing point of alcohol ....ilis below zero Boiling point of water ......100'above zero

Arrange the readings in order from highest to lowest.

2. Following are some jmportant dates in history:

Birth of Christ ................ 0 Signing of Declaration of Independence .... 1776 A.D. World War I - War declared by U.S. on Germany 1917 A.D. Franklin D. Roosevelt inaugurated President 1933 A.D. U. S. declares war on Germany and Japan .... 1941 A.D. Abraham, patriarch of Hebrews, entered Caraan.2250 B.C. Exodus of Israelites under Moses .......... 1220 B.C. Rome founded ..................... 753 B.C. David becomes king of Israel ............ 1000 B.C. Crucifixion of Jesus Christ ............. 30 A.D. Widespread use of Hindu-Arabic numerals .... 1000 A.D. Ahmes wrote first book on mathematics ...... 1600 B.C. Diophantus wrote first algebraic equations. 275 A.D. Introduction of zero into number system by Hindus ...................... 500 A.D. First use of $t$ and - signs in a German arithmetic book .................. 1489 A.D.

Arrange the dates in order beginning with the most recent one. 
3. Following are some addresses in Covington:

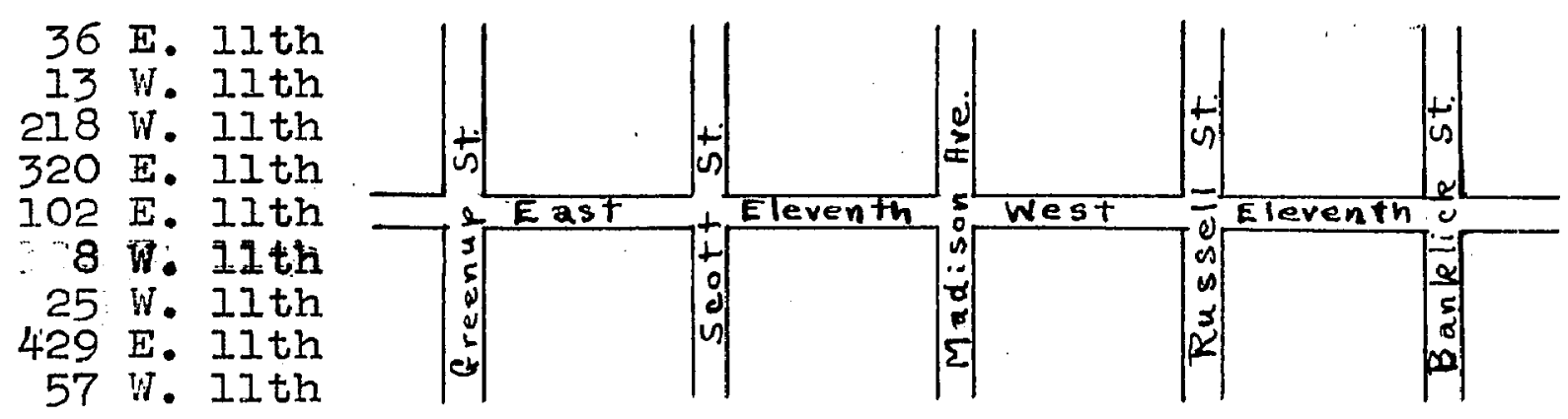

What street divides east from west?

List the addresses in order beginning with the one farthest east.

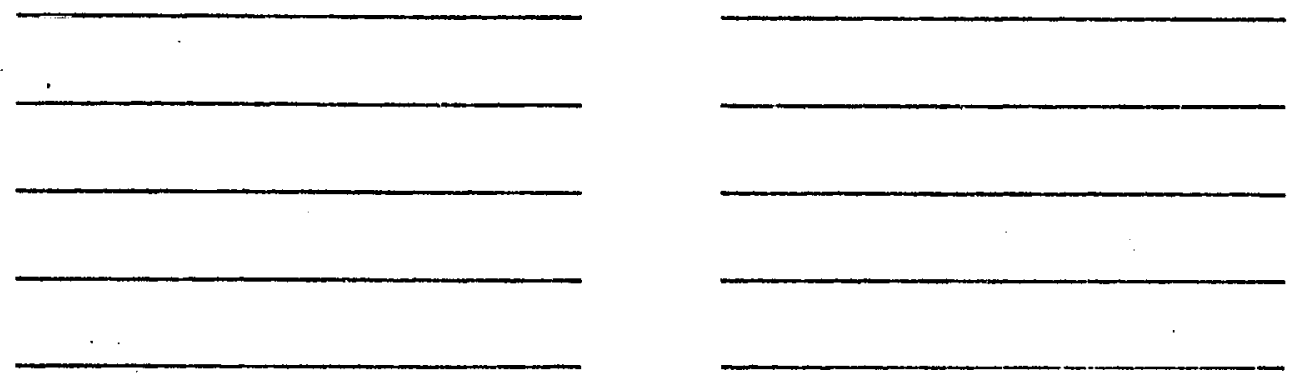

4. Following are the altitudes of various localities:

New Orleans, La. ............ $5 \mathrm{ft.} \mathrm{below} \mathrm{sea} \mathrm{level}$ Death Valley, California ........280 ft. below sea level Atlantic Ocean ................................. sea level Dead Sea, Palestine .............286 ft. below sea level Libian Desert, Africa .........436 ft. below sea level Lalre Erie, Michigan ......... 572 ft. above sea level Big Black Mountain, Kentucky ...4I50 ft. above sea level Ohio River (Hamilton County, Ohio) $425 \mathrm{ft}$. above sea level Caspian Sea, U.S.S.R. .......... $85 \mathrm{ft.} \mathrm{below} \mathrm{sea} \mathrm{level}$ Lake Eyre, South Australia ..... $39 \mathrm{ft}$. below sea level Bear Mountain, Connecticut .....2355 ft. above sea level Iron Mountain, Florida .........324 ft. above sea level Big Stone Lake, South Dakota ....992 ft. above sea level

Wich locality is closest to sea level?

Which locality is farthest below sea level?

Wich tocality is farthest above sea level?

If all points above sea level are indicated by a plus sign, how could we indicate those below sea level? 
Arrange the localities in order beginning with the one farthest above sea level, giving each the proper sign.

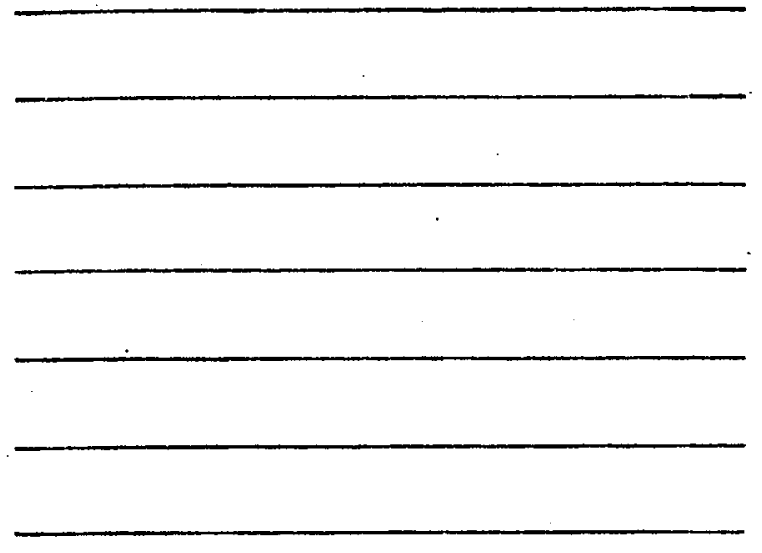


Name

Study Guide No. 23

Comparing Numbers

Using your number scale, complete the following table:

\begin{tabular}{c|l|l}
\hline Pairs of Numbers & $\begin{array}{l}\text { Greater of the } \\
\text { Two Numbers }\end{array}$ & $\begin{array}{l}\text { Position (To the } \\
\text { Right or Left of } \\
\text { Smalier Number) }\end{array}$ \\
\hline+2 and -2 & & \\
\hline 0 and -1 & & \\
\hline+5 and +3 & & \\
\hline 0 and +6 & & \\
\hline-3 and +1 & & \\
\hline-10 and -4 & & \\
\hline-3 and -9 & & \\
\hline+8 and -10 & & \\
\hline-7 and +4 & & \\
\hline$-n$ and +1 & & \\
\hline$-n$ and $+n$ & & \\
\hline
\end{tabular}

ilth respect to the smaller number, what is the position of the larger number in each example above?

\begin{tabular}{c|l|l}
\hline Pairs of Numbers & $\begin{array}{l}\text { Smaller of the } \\
\text { Two Numbers }\end{array}$ & $\begin{array}{l}\text { Posicion (To the } \\
\text { Right or Left of } \\
\text { Larger Number) }\end{array}$ \\
\hline-1 and 0 & & \\
\hline-4 and +10 & & \\
\hline+2 and -2 & & \\
\hline+3 and +5 & & \\
\hline-9 and -3 & & \\
\hline-10 and +8 & & \\
\hline+4 and -7 & & \\
\hline+6 and 0 & & \\
\hline+1 and -3 & & \\
\hline+1 and $-n$ & & \\
\hline$+n$ and $-n$ & & \\
\hline
\end{tabular}

With respect to the larger number, what is the position of the smalier number in each example above? 
In comparing a negative number and a positive number, what do you need to know to decide which is greater?

What are the numbers less than +4 ?

What are the numbers less than -4 ?

That are the numbers greater than +4 ?

That are the numbers greater than -4 ?

Name any number that is negative with respect to $+5 ?$

Thich is the greater of two numbers generally?

Which is the smaller of two numbers generally? 
Name

Study Guide No. 24

Positive Numbers

Inagine that you are operating an elevator in an office building and that you move as shown in the table below. Complete the table:

\begin{tabular}{c|c|c|c|c}
\hline \multicolumn{1}{c|}{$\begin{array}{c}\text { Deginning } \\
\text { Floor }\end{array}$} & $\begin{array}{c}\text { Foors } \\
\text { Moved }\end{array}$ & $\begin{array}{c}\text { Direction } \\
\text { Moved }\end{array}$ & $\begin{array}{c}\text { Fioor } \\
\text { Arrived At }\end{array}$ & $\begin{array}{c}\text { Indicated } \\
\text { Operation }\end{array}$ \\
\hline 2 & 3 & up & & \\
\hline 4 & 2 & up & & \\
\hline 1 & 3 & up & & \\
\hline 0 & 4 & up & & \\
\hline 7 & 2 & up & & \\
\hline 5 & 1 & up & & \\
\hline 3 & 6 & up & & \\
\hline
\end{tabular}

I. What sign would you use to show the direction in which the elevator moved in each instance?

2. What effect does the airection as indicated in each case in column 3 have upon the corresponding value in column 2 ?

3. The indicated operation in column 5 involves the corresponding values of what two columns?

4. Assuming that the operation indicated in column 5 is performed what is the relationship between the result and the corresponding value in column 4 ?

5. What Beneral statement could you make with regard to the sign of the addends and the sign of the sum? 
Name

Study Guide No. 25

Positive and Negative Numbers

Again imagine that you are operating an elevator in an office bullaing and that you move as shown in the table below. Complete the table below. (Consider the main floor as floor No. O and that the building has five basement levels):

\begin{tabular}{c|c|c|c|c}
\hline $\begin{array}{c}\text { Beginning } \\
\text { Floor }\end{array}$ & $\begin{array}{c}\text { Floors } \\
\text { Moved }\end{array}$ & $\begin{array}{c}\text { Direction } \\
\text { Moved }\end{array}$ & $\begin{array}{c}\text { Floor } \\
\text { Arrived At }\end{array}$ & $\begin{array}{c}\text { Indicated } \\
\text { Operation }\end{array}$ \\
\hline+2 & 3 & down & & \\
\hline+4 & 2 & down & & \\
\hline+1 & 3 & down & & \\
\hline 0 & 4 & down & & \\
\hline+7 & 2 & down & & \\
\hline+2 & 2 & down & & \\
\hline+5 & 1 & down & & \\
\hline+6 & 4 & down & & \\
\hline+3 & 6 & down & & \\
\hline
\end{tabular}

1. In what direction has the elevator moved in each of the above cases? (positive or negative)

2. When in the indicated operation of column $\overline{5}$ the numbers in column 2 are used, what sign is placed before each of these numbers from column 2 ?

3. This sign corresponds to the direction given in which column?

4. In each indicated operation (column 5), which of the two addends' signs agrees with the sign of the angwer?

5. Which sign is affixed to the values in column 4--the sign of the number in column 1 or column 2 ? 
6. How do your answers in columns 4 and 5 compare?

7. Would this suggest any principle to you which might be applied when adding values having unlike signs? If so, state it. 
Name

Study Guide No. 26

Subtracting Directed Numbers

We have reached agreements concerning the addition of directed numbers. Suppose we have a given number (say +9 ) and a second number $($ say +4$)$ and we want to know how much must be added to +4 to give us +9 . The number is +5 . This number represents the difference between +9 and +4 .

Using the number scale, we can locate 4 and count the number of units required to reach+9 and note the direction In which we go. The direction from +4 to +9 is positive, so the difference is +5 .

Using the number scale answer the following questions:

Answer. Indicated Operation

1. What number added to +3 gives +8 ?

2. What number added to +2 gives $+7 ?$

3. What number added to 0 gives +4 ?

4. What number added to +5 gives +9 ?

5. What number added to +7 gives +12 ?

6. What number added to +8 gives -3 ?

7. What number added to +9 gives -1 ?

8. That number added to +6 gives -5 ?

9. What number added to +4 gives -2 ?

10. That number added to +10 gives -6 ?

11. What number added to -8 gives +3 ?

12. What number added to - 9 gives $+I$ ?

13. That number added to -6 gives +5 ?

14. What number added to -4 gives +2 ?

15. What number added to -10 gives $+6 ?$ 
16. What number added to -3 gives - 5 ? 17. What number added to -7 gives -10 ? 18. What number added to 0 gives -8 ? 19. What number added to -5 gives -6 ? 20. What number adaed to -12 gives -15 ? 21. That number added to +5 gives +2 ? 22. What number added to +9 gives +4 ? 23. What number added to +5 gives 0 ? 24. What number added to +7 gives +6 ? 25. What number added to +4 gives +18 26. What number added to -5 gives -4 ? 27. What number added to -10 gives -5 ? 28. What number added to -6 gives -18 29. That number added to - 9 gives -3 ? 30. That number added to -12 gives -8 ?

Some of the problems which you have just solved, involved only positive numbers, some involved only negative numbers, while others involved a positive number and a negative number. Study carefully the results for each class and complete the table below:

\begin{tabular}{c|c|c}
\hline Class & Sign of Result & $\begin{array}{c}\text { Absolute Value of } \\
\text { Result }\end{array}$ \\
\hline Positive Numbers & & \\
\hline Negative Numbers & & \\
\hline $\begin{array}{l}\text { Positive Number } \\
\text { and } \\
\text { Negative Number }\end{array}$ & & \\
\hline
\end{tabular}


Using the information in the above table, write a general statement concerning the nature of the result when finding the difference between:

(a) Two positive numbers

(b) Two negative numbers

(c) A positive number and a negative number 
Name

Study Guide No. 27

Using Signed Numbers

Imagine that you have a set of piatform scales with the pans balanced by the sets of weights listed below. That would you have to do in order to find the value of the unknown weight and yet keep the pans balanced in each case?

\begin{tabular}{|c|c|c|c|c|}
\hline $\begin{array}{l}\text { Weights } \\
\text { On Left } \\
\text { Pan }\end{array}$ & $\begin{array}{l}\text { Weights } \\
\text { On Right } \\
\text { Pan }\end{array}$ & $\begin{array}{l}\text { Statement } \\
\text { of } \\
\text { Equality }\end{array}$ & $\begin{array}{l}\text { Value of } \\
\text { Unknown } \\
\text { Weight }\end{array}$ & $\begin{array}{l}\text { Operation Necessary } \\
\text { In Order To Find } \\
\text { Value of Unknown } \\
\text { Weight }\end{array}$ \\
\hline a $\begin{array}{r}\text { 3-gram } \\
5-\text { gram } \\
2 \text {-gram }\end{array}$ & 10-gram & & & \\
\hline b $\begin{array}{r}5 \text {-fram } \\
\text { 2-gram } \\
1 \text {-gram }\end{array}$ & 8-gram & & & \\
\hline 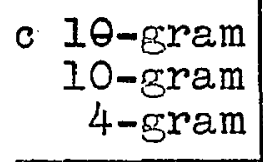 & 24-gram & & & \\
\hline d $\begin{array}{c}\text { p-gram } \\
5 \text {-gram }\end{array}$ & 10-8ram & & . & \\
\hline 15-gram & $\begin{array}{l}\text { 5-gram } \\
\text { 7-gram } \\
3 \text {-gram }\end{array}$ & & & \\
\hline f 7-gram & $\begin{array}{l}x-\text { gram } \\
\text { 3-gram }\end{array}$ & & & \\
\hline B $\begin{array}{l}\text { y-gram } \\
4-g r a m\end{array}$ & 6-gram & & & \\
\hline${ }^{\mathrm{h}}$ 2l-gram & $\begin{array}{r}11-\text { gram } \\
\text { r-gram }\end{array}$ & & & \\
\hline
\end{tabular}

1. What operation has been performed on the unknown welght in examples $d, f, g$, and $h$ above? 
308

2. When welghts are removed from one pan of the balance to find the value of the unknown weight, what else must be done in order to keep the pans balanced?

3. To what mathematical operation does the removal of the weight correspond--addition, subtraction, multiplication or division?

4. How do your answers to questions $I$ and 3 compare?

5. In equations (statements of equality) like $d, g, f$ and $h$ above, what must be done to find the value of the unknown term? 
Name

Study Guide No. 28

Multiplying Signed Numbers

When we multiply +4 by +3 , we are really adding 4 , three times beginning at zero. In fact, multiplication is rapid addition. Starting at zero on the number scale, we add +4 once by moving over to +4 . Adding +4 two more times, we move to +8 and then to +12 , which is the product of $(+4) \times(+3)$.

Similarly, what does $(-3) \times(+2)$ mean? Starting at zero on the number scale, we add moving over to Adaing one more time, we move to , which is the product of $(-3) \times(+2)$.

Using the number scale, try to solve the following problems. The first problem has been solved as an 1liustration of. What you are to do.

Equivalent Product Explanation Addition

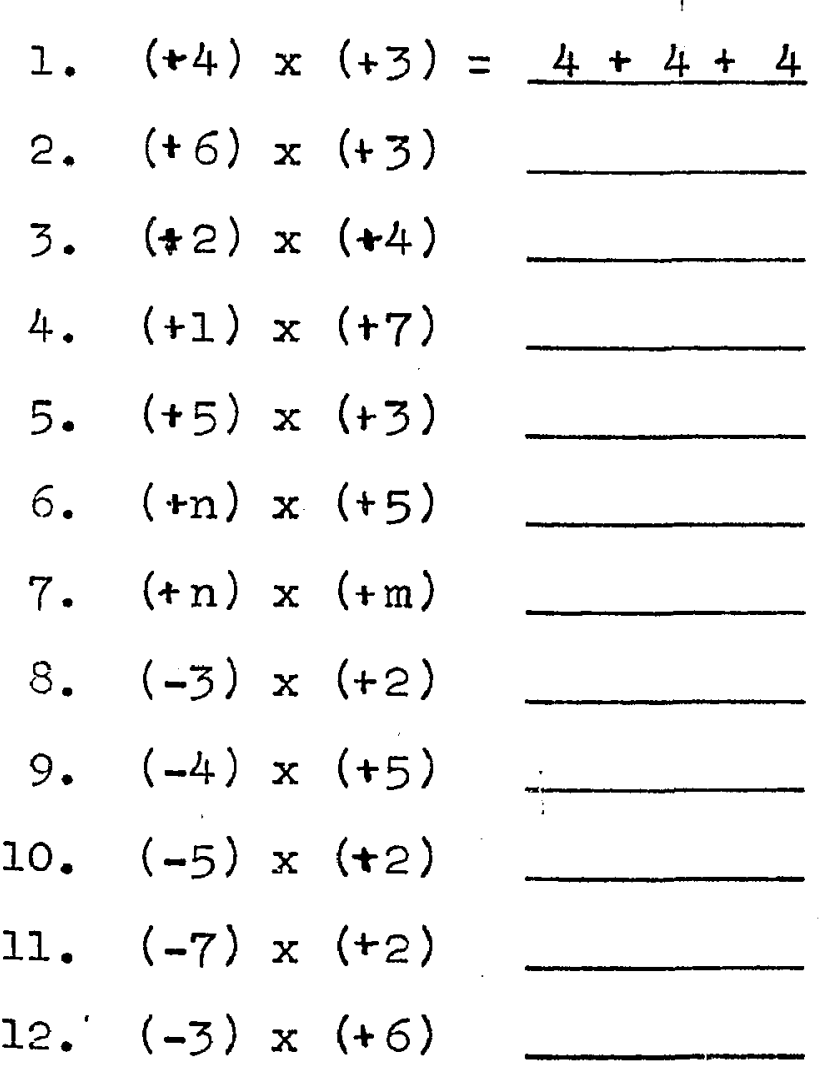
Four has been +12 added 3 times. 
13. $(-n) \times(+7)$

14. $(-n) \times(+m)$

Study the results in the problems above and try to make general statements concerning a rapid method for multiplying:

(a) Two positive numbers

(b) A negative number by a positive number 
Name

Study Guide No. 29

Multiplying Signed Numbers

Last week we investigated the multiplication of a positive nuinber by a positive number and the multiplication of a negative number by a positive number. If we let $+a$ and tb represent positive numbers and $-a$, any negative number, we can say that the product of ta by to is equivalent to adding $+a, b$ times. The product of $-a$ by the to is equivalent to adding $-a, n$, times.

If the statements above are valid, what is the product of $(+4) \times(-3)$ equilvalent to?

Starting at zero on the number scale, we once by moving over to two more times, we move to is the product of $(+4) \times(-\overline{3})$. and then to $+4$ $+4$

Similarly, what does $(-4) \times(-3)$ mean? problems :

Using the number scale, try to solve the following

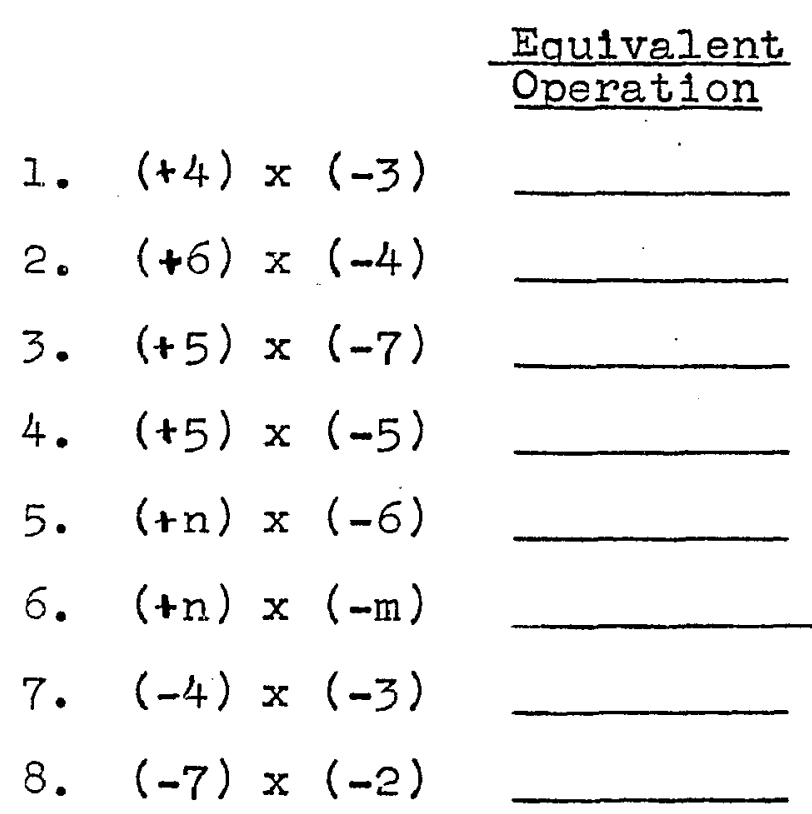

Product

Explanation Operation

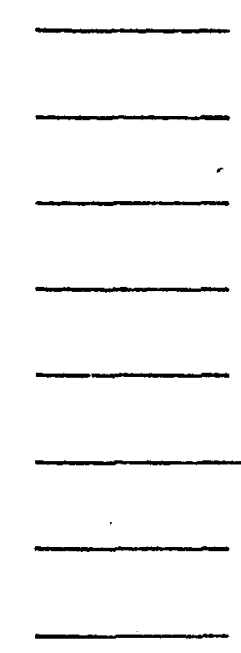


$312 c$

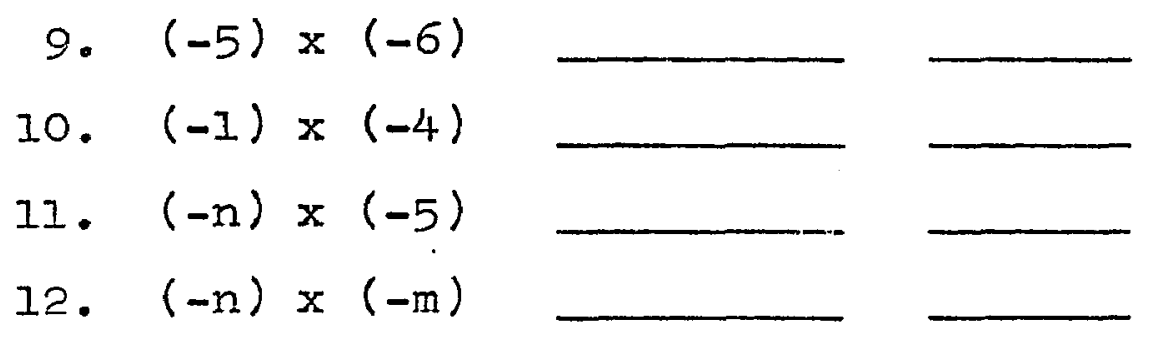

Study the results in the problems above and try to make general statements concerning the multiplication of:

(a) a positive number by a negative number

(b) a negative number by a negative number 
Study Guide No. 30

Dividing Signed Numbers

We have agreed that $(+5) \times(+3)=+15$. From this it follows that if we divide the product $(+15)$ by either of two factors, $(+5)$ or $(+3)$, our quotient will be the other factor. That is, $\frac{+15}{+3}=+5$, or $\frac{+15}{+5}=+3$.

Conslder the following problems in multiplication and give the corresponding division checks:

1. $(+5) \times(+3)=+15$.
2. $(+3) \times(+2)=+6$.
3. $(+8) \times(+4)=+32$.
4. $(-5) \times(+3)=-15$.
5. $(-7) \times(+2)=-14$.
6. $(-9) \times(+5)=-45$.
7. $(+4) \times(-2)=-8$.
8. $(+5) \times(-3)=-15$.
9. $(+6) \times(-1)=-6$.

10. $(-5) \times(-3)=+15$.

11. $(-7) \times(-3)=+21$.

12. $(-4) \times(-6)=+24$.

13. $(+a) x(+b)=+a b$.

14. $(-a) \times(+b)=-a b$.

15. $(+a) \times(-b)=-a b$.

16. $(-a) \times(-b)=+a b$.

Study your results above in division and try to make general statements concerning the quotient obtained by:

(a) Dividing a positive number by a positive number 
(b) Diviaing a negative number by a positive number

(c) Dividing a positive number by a negative number

(a) Diviaing a negative number by a negative number 
Name

Study Guide No. 31

The Conditional Equation

Consider the unknown term " $n$ ".

1. Multiply $n$ by 5 .

2. Divide this expression by four

3. Add 2 to the expression in (2)

4. Let the expression in (3) be equal to twelve.

5. The expression in (4) represents a conditional equation. The conditions are expressed in statements ( $1--4$ ) above. The conditions are that $\frac{5 n}{4}+2$ has a value of twelve, provided we do certain things to $n$. What are these things?

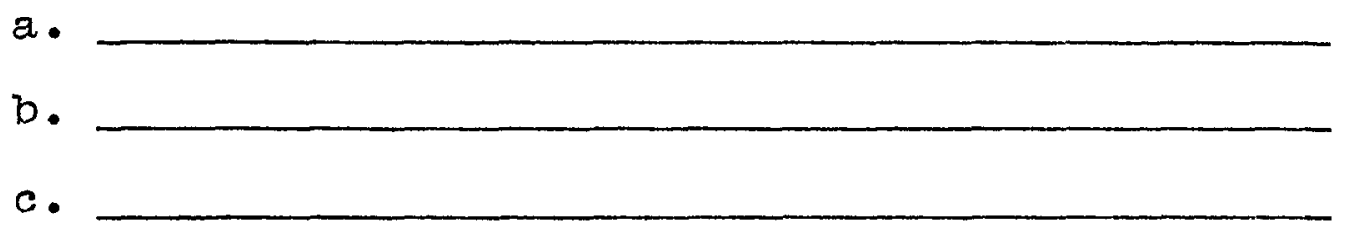

6. In order to determine the value of " $n$ " we would have to perform the inverses (opposites) of those operations listed in (5) above. What are the inverses of the operations which you listed above?

The inverse of $5 \mathrm{a}$.

The inverse of $5 \mathrm{~b}$.

The inverse of $5 \mathrm{c}$.

7. Try to perform the inverse operation of " $c$ " on the equation listed in (4). (Note: You must perform the same operation to both members, if the equality of the two members is to be maintained).

8. Perform the inverse of " $\mathrm{b}$ " on the above answer. 
9. Perform the inverge of " $a$ " on the above answer.

10. What then is the value of $n$ ?

11. What general statement can you make concerning the procedure to follow in solving a conditional equation? 
Name

Study Guide 32

The Relationship Between Age and Weight

The following data give the actual monthly welght in pound of a baby boy from birth until he is $2 \frac{1}{2}$ years of age:

\begin{tabular}{|c|c|c|c|}
\hline $\begin{array}{l}\text { Age in } \\
\text { Monthg }\end{array}$ & $\begin{array}{l}\text { Weight in } \\
\text { Pounds }\end{array}$ & & \\
\hline 0 & $7^{\frac{1}{2}}$ & & \\
\hline$I$ & $8 \frac{1}{2}$ & & \\
\hline 2 & 10 & & \\
\hline 3 & $11 \frac{1}{2}$ & & \\
\hline 4 & 13 & & \\
\hline 5 & $14 \frac{1}{2}$ & & \\
\hline 6 & 16 & & \\
\hline 7 & 163 & & \\
\hline 8 & $17 \frac{1}{2}$ & & \\
\hline 9 & I8 $\frac{1}{2}$ & & \\
\hline 10 & $19 \frac{1}{2}$ & & \\
\hline 11 & $20 \frac{1}{2}$ & & \\
\hline 12 & 21 & & \\
\hline 13 & $27 \frac{1}{2}$ & & \\
\hline 14 & 22 & & \\
\hline 15 & $22 \frac{1}{2}$ & & \\
\hline 16 & 23 & & \\
\hline 17 & $23 \frac{1}{2}$ & & \\
\hline 18 & 24 & & \\
\hline 19 & $24 \frac{1}{2}$ & & \\
\hline 20 & 25 & & \\
\hline 21 & $25^{\frac{1}{2}}$ & & \\
\hline 22 & 26 & & \\
\hline 23 & $26 \frac{1}{2}$ & & \\
\hline 24 & 27 & & \\
\hline 25 & $27 \frac{1}{2}$ & & \\
\hline 26 & 28 & & \\
\hline 27 & $28 \frac{9}{2}$ & & \\
\hline 28 & 29 & & \\
\hline 29 & $29 \frac{1}{2}$ & & \\
\hline 30 & 30 & & \\
\hline
\end{tabular}

1. Prepare a line graph of the data, plotting values for age along the horizontal axis.

2. Add two columns to the table and record opposite the weight, $8 \frac{1}{2}$ pounds, the increase in weight during the first month. Call this column "Increase in Weight". 
3. In Iike manner, record the increase in weight for each month.

4. Between what months are the increases constant (the same)?

Between age mo. and age mo.

Between age mo. and age mo.

Between age mo. and age mo.

Between age mo. and age mo.

5. How does the graph appear in each of these intervals?

6. In problem 2, what is the ratio of the increase in weight to the increase in age? Record this ratio in the last column. (Give this column the heading, $\Delta \mathrm{w} / \Delta \mathrm{a}$, where $\Delta W$ stands for increase in welght and $\Delta a$, increase in age.

7. In Iike manner, record the corresponding ratios for the other ages.

8. Nathematicians often analyze data by computing ratios similar to these which you have computed. When dealing with tables of values, they define such ratios as rates of chanse, and they broaden the definition as follows:

Rate of change $=$ ratio of change of dependent variable to corresponding change of independent variable.

Which of the variables in the table (weight and age) is dependent on the other for its value?

9. When dealing with line graphs, the mathematician also denotes the rate of change by another term. This term is "slope". He defines slope in exactly the same way that he defines rate of change.

Using your graph, note that when "a" changea from two to three, w changes from IO to 11․ㅜㄹ. This can be illustrated by first, drawing a line parallel to the "a" axis between 2 and 3 and intersecting the Iine graph. Label this segment, $\Delta a$. Second, draw al Iine parallel to the $w$ axis between the graph and the end point of $\Delta a$. Label this segment, $\Delta w$. Note that 
$\Delta W / \Delta a$ equals $1 \frac{1}{2} / 1$ or $3 / 2$. Compare this value with the corresponding value of $\Delta \mathrm{w} / \Delta a$ in the table.

10. Illustrate on the graph how you would determine the slope between the following points on the a axis:

a. Between 2 and 3. Computed value of slope $1 \frac{1}{2} \div 1=\frac{3}{2}$

b. Between 3 and 4. Computed value of slope

c. Between 4 and 5. Computed value of slope

d. Between 5 and 6 . Computed value of sIope

e. Between 7 and II. Computed value of slope

f. Between 11 and 30. Computed value of slope

11. What can you conclude about the slope of the graph between $I$ and 6 on the "a" axis?

12. Using your answers to questioil 4, 5, and II, state your reactions concerning the relation between a straight line graph and its slope.

13. Using the age interval, $1--6$ in the table, try to express the relationship between age and weight for this baby boy as a formula.

14. That does this formula state?

15. Whenever a relationship exists between two variables such that the change in the dependent variable is a constant multiple of the change in the independent variable, it is said to be a linear relationship.

How would you recognize a Iinear relationship in your formula?

16. In the graph between $I$ and 6 on the "a" axia?

17. In the table of values between age $I$ and age 6 ?

18. Using the age interval 7 to 11 , state the relationship 
between age and weight as a formula; for 11 to 30 .

19. Would you be able to predict the weight of this baby boy when he becomes 3 years old?

Why?

20. Would you be able to predict the weight of any 3 year old boy? Why?

21. What was the age of the baby when he weighed 20 pounds?

22. How did you determine this answer?

23. Is the age of any baby the same at 20 pounds? Why?

24. To what extent should one use caution when using a table of data to determine values of a dependent variable not given in the table?

25. Would these same restrictions apply to the use of a graph? Why?

26. Would these same restrictions apply to the use of a formula? ihy? 
Name

Study Guide No. 33

Comparing Pupils By Type of Body Build

There are many ways to compare the age, height and weight of people. For instance, there is a close relationship between weight and height of 15 year old pupils, 16 year old pupils and similarly for other ages. We might assume that there is a functional relationship between the weight and height of tall-slender girls in a certain age range. However, if we are to study such a relationship, we must control the two variables, body build and age. Suppose now we consider the relation between weight and height of:

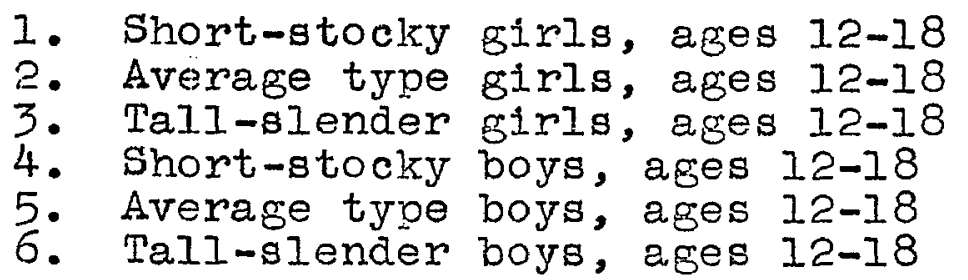

1. Which of these relationships would you like to investigate?

2. Using the suegested table below, tabulate in order of increasing height, the average weights of your group. (You will need to use the original table of raw data for this).

Average Weight - Height Table

For

Ages $12-18$

\begin{tabular}{l|l|l|l|l|l}
\hline Height & $\begin{array}{l}\text { Average } \\
\text { Weight }\end{array}$ & Height & $\begin{array}{l}\text { Average } \\
\text { Weight }\end{array}$ & Height & $\begin{array}{c}\text { Average } \\
\text { Weight }\end{array}$ \\
\hline & & & & & \\
\hline & & & & & \\
\hline & & & & & \\
\hline
\end{tabular}


322

3. Make a line graph of the data. Which variable will you use as the independent variable?

4. Is the Iine thus obtained a curved or straight Iine?

5. What slope does it appear to have?

6. Where does it meet the vertical axis?

7. Assuming that the equation is Iinear, sugejest the probable equation of this line.

8. Use the equation to predict the weight of a friend who is of the proper body build and sex.

9. How accurate is your result? 
Name

\section{Study Guide No. 34}

Comparing Pupils By Type of Body Build

Your equation on study guide 33 for predicting weights gave a rough estimate. You can derive a more precise equation by studying the average weight differences. Transfer the data from study guide 33 to columns 1 a.d 2 in the table below:

Average Weight-Height Table For Ages 12-18

\begin{tabular}{l|l|l|l|l|l|l|l}
\hline He1ght & $\begin{array}{l}\text { Average } \\
\text { Weight }\end{array}$ & $\Delta$ & $\mathrm{b}$ & Height & $\begin{array}{l}\text { Average } \\
\text { Weight }\end{array}$ & $\Delta$ & $\mathrm{b}$ \\
\hline & & & & & & & \\
\hline & & & & & & & \\
\hline & & & & & & & \\
\hline & & & & & & & \\
\hline
\end{tabular}

1. Compute the differences between successive weights and record the results in column 3. We customarily use the symbol, $\Delta$, (pronounced delta) to denote such differences.

2. That is the average difference between successive weights?

3. How does the average compare with the slope of the line graph that you made in study guide 33 ?

4. State the general Iinear equation using $w$ as the dependent variable and $\mathrm{h}$ as the independent variable. 
5. For which terms in this equation do we have values?

6. Knowing these values, find the corresponding values of the unknown term. Use a separate sheet for these computations.

7. List these values in column 4 of the table.

8. What is the average of these values? Place this average in the table at the bottom of column 4 .

9. What does this findicate as to the best equation for showing the relation between height and weight?

10. Use this equation to predict the weight of a friend who is of the proper sex and body build.

11. How precise is it in comparison with the equation used in study Guide No. 33 ? Are your answers more or less accurate? How much? 
Name

Study Guide No. 35

Comparing Pupils By Type of Body Build

You can further test the precision of your equation by the plar which follows:

1. Transfer the data from stuay guide 34 to the first columns of the table below.

Average Welght-Height Table For

, Ages 12-18

\begin{tabular}{|c|c|c|c|c|c|c|c|c|c|c|c|c|}
\hline \multirow[b]{3}{*}{ Helght } & \multirow{3}{*}{ 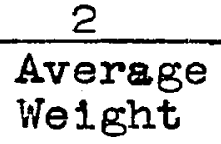 } & \multirow[b]{3}{*}{$\Delta$} & 4 & 5 & 6 & 7 & 8 & 9 & 10 & 11 & 12 & 13 \\
\hline & & & \multirow[b]{2}{*}{$\mathrm{b}$} & \multicolumn{3}{|c|}{ For $b=$} & \multicolumn{3}{|c|}{ For $b=$} & \multicolumn{3}{|c|}{ For $b=$} \\
\hline & & & & $\mathrm{w}$ & $\mathrm{d}$ & $a^{2}$ & $\mathrm{w}$ & $\bar{a}$ & $\mathrm{~d}^{2}$ & $\mathrm{~W}$ & $\bar{d}$ & $\overline{d^{2}}$ \\
\hline & & & & & & & & & & & & \\
\hline & & & & & & & & & & & & $\ldots$ \\
\hline & & & & & & & & & & & & 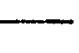 \\
\hline & & & & & & & & & & & & 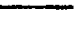 \\
\hline & & & & & & & & & & & & 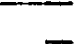 \\
\hline & & & & & & & & & & & & \\
\hline & & & & & & & & & & & & \\
\hline & & & & & & & & & & & & \\
\hline & & & & & & & & & & & & - \\
\hline & & & & & & & & & & & & \\
\hline & & & & & & & & & & & & \\
\hline
\end{tabular}

2. Using one value of $b$ with each value of $h$ and the equation of problem 4, study guide 34, solve for w.

3. Record your answers in column 5 of the table.

4. How do these computed values for $w$ compare with the average $w$ in column 2 ?

5. Find the differences, $d$, between the w's in columns 2 and 5 and record them in column 6 . If the computed $w$ (column 5) is greater than the average w (column 2), assume the difference to be positive $(t)$. If it is less, assume it to be negative $(-)$.

6. Now complete column 7 .

7. Repeat steps $2-6$ for the other values of b. Record your 
results in table, labeling your columns:

8. The method for testing the exactness of vour equation is concluded by using the formula, $A=\frac{\sqrt{5 d^{2}}}{N}$ to find the set of $\mathrm{d}^{2}$ 's giving the smallest value for $A$. The value for $b$ giving this smallest answer is the one that will be used in the equation of problem 9, sheet 34. The symbol, $\Sigma$, (pronounced sigma) means the "sum of ${ }^{\prime \prime}$ and $N$ equals the number of $w^{\prime} s$ in column 2. Use the formula to find the value of A for each set of $d^{2}$ 's. Record your results in the table below.

\begin{tabular}{l|c|c|c}
\hline $\begin{array}{l}\text { When b is } \\
\text { equal to }\end{array}$ & $\begin{array}{c}\Sigma \mathrm{d}^{2} \\
\text { equals }\end{array}$ & $\begin{array}{c}\mathbf{M} \\
\text { equals }\end{array}$ & $\begin{array}{c}\text { A } \\
\text { equals }\end{array}$ \\
\hline & & & \\
\hline & & & \\
\hline & & & \\
\hline
\end{tabular}

9. For what value of $b$ is $A$ smallest?

10. What change would you make in your equation of problem 4, study guide 34 ?

11. Use this equation to predict the weight of some one who is of the proper body build and sex.

12. Use the equation to predict the weight of any person in the group which you studied. (As a check, use the table of average weights for the entire country).

13. What is your per cent of error? 
Name

Study Guide No. 36

Predicting Weights

1. Write the formula which you developed on your last study guide.

2. This formula can be used to predict the weight of certain people. For what group of people can it be used to predict weights?

3. Write a sentence which explains what your formula states.

4. Prepare a table of values which corresponds to your formula.

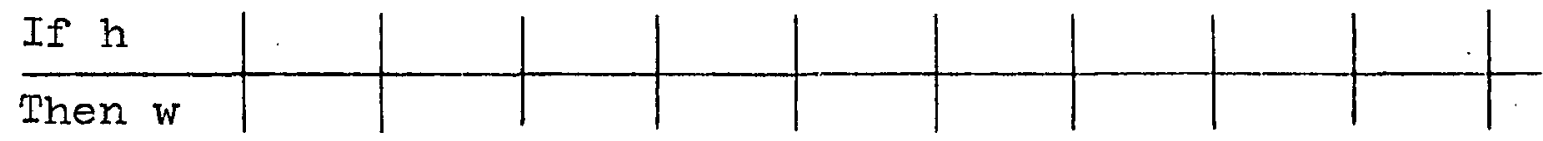

5. From the table prepare a line graph of your formula.

6. Using the formula

find the weight

of a person

inches high.

7. Do the same thing using the sentence in question 3 above.

8. Now use the table and the graph. Explain how you got your answer when you used the table and when you used the graph.

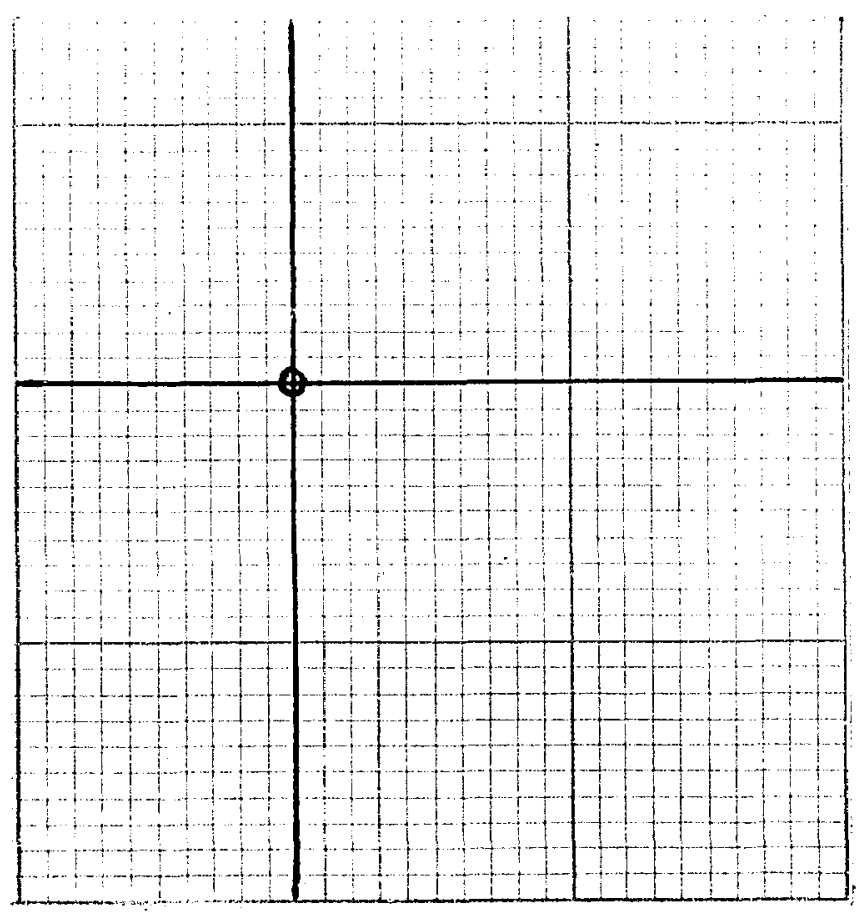


9. In how many ways can you predict a person's weight when you know his height? List them. 
Study Guide No. 37
Slopes and Intercepts

I. On one set of axes graph the following formulas:
(a) $c \equiv 308$
(b) $c=70 \mathrm{~g}$
(c) $c=108$

2. On one set of axes graph the following formulas:
(a) $c=30 \mathrm{~g}$
(b) $c=30 \mathrm{~B}+10$
(c)
$c=308-20$

3. On one set of axes graph the following formulas:
(a) $a=40 t$
(b) $a=-40 t$
(c) $a=-10 t$

(d) $d=-80 t$

Asgign only negative values to $t$ in (b), (c) and (d).

4. Which graph has the greatest slope?

5. Which graph has the least slope?

6. Which graphs pass through the origin?

7. How can you find out from the formula whether a graph will pass through the origin?

8. Give an example of a formula whose graph crosses the vertical axis below the origin. above the origin.

9. When the slope of a formula is negative, how does its graph slant----from lower left to upper right or from upper left to lower right? 
Name

Study Guide No. 38

Relating Change In SIope To Change In Rate

This graph represents the income of John, who sells newspapers for the Daily Tattler. According to the graph, he receives a basic salary of $\$ 2.00$ per week plus a commission of lic per paper sold.

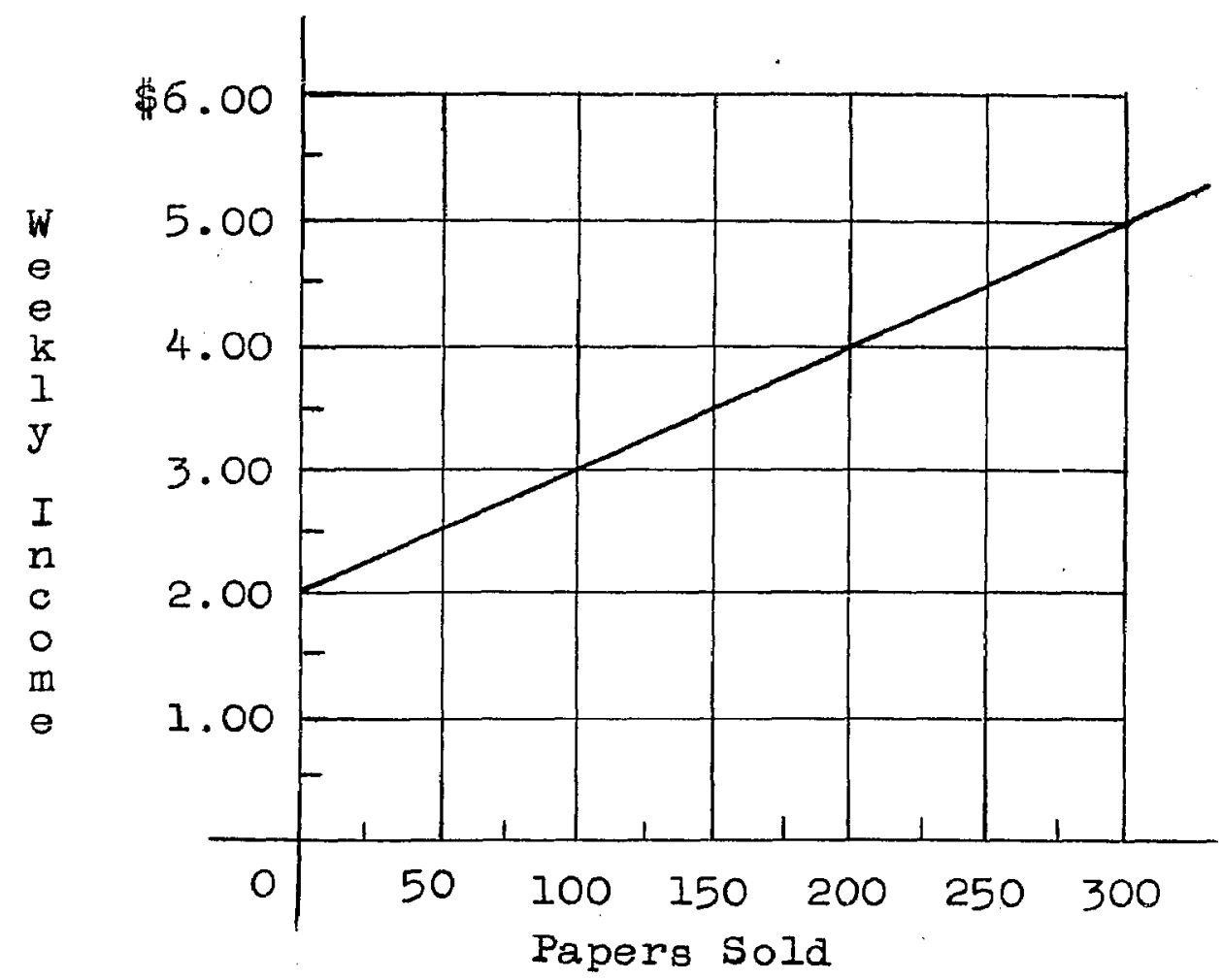

1. Construct a table to accompany the graph.

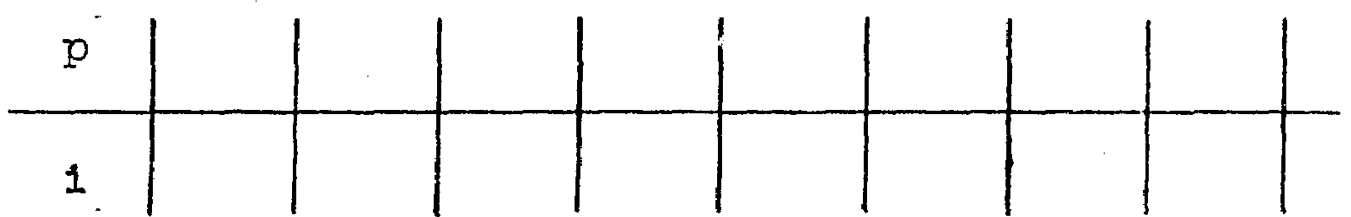

2. State the formula. which gives the same information as. the graph.

3. Suppose John's employer decides to raise his basic salary to 3.00 per week giving him the same commission 
on the number of papers sold. Would a graph of John's new salary (using the same scale) be any different from the above graph? Yes () No (.

If so, how?

Where would the graph begin?

4. Suppose his basic salary is not increased but he is Given a commigsion of lite per paper sold. Would a Graph of John's salary based on this change (using the same scale) be any different from the above graph? Yes ( ) INo ( )

If so, how?

5. Suppose John stops selling papers ane gets a job delivering the monthly bills of the Electric Power Company to its customers. For this work the company will pay him a salary of 13.00 per week plus a commission of I $\not$ per bill delivered. Would a graph of John's salary be any aifferent from the graph on the first page of this study guide? Yes () No ()

If so, how?

6. Suppose his salary is doubled and his commission remains at Id per paper sold. Would a graph of his salary be any different from the original Braph? Yes $(;$ No ()

If go, how?

There would the graph begin?

7. Suppose his salary is not increased but lis commission is reduced to $\frac{1}{2} \phi$ per paper sold. Would a graph of this salary be any different from the original graph? Yes () No $($ )

If so, how?

Where would the graph begin? 
Name

Study Guide No. 39

Relating Like Characteristics In Different Types of Data

The tables, graphs and formulas below give information on the cost of tomatoes per pound during different seasons of the year.

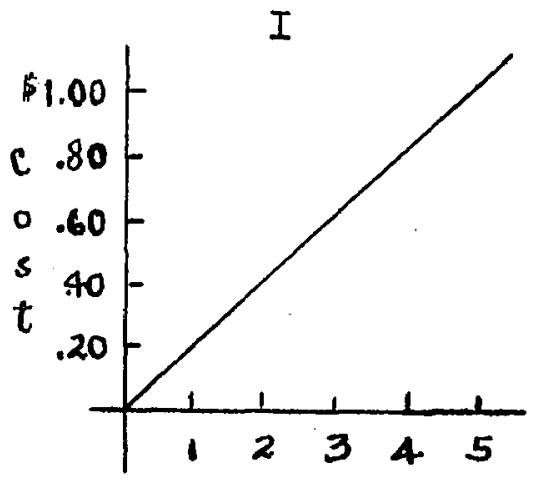

No. of Pounds

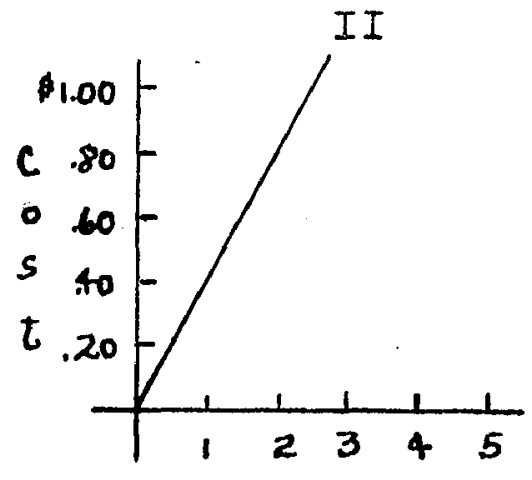

No. of Pounds

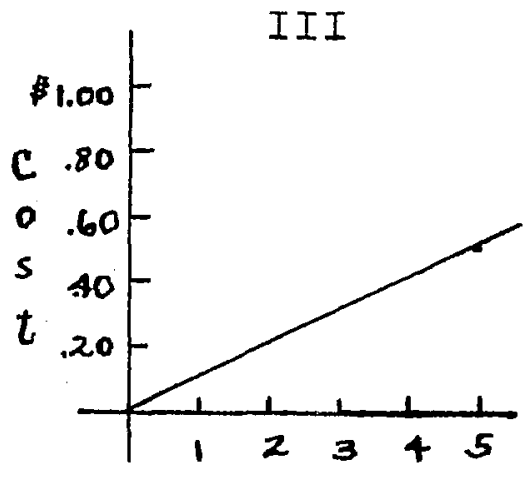

No. of Pounds

\begin{tabular}{c|r}
\multicolumn{2}{c}{$I$} \\
\hline No. of & Cost \\
\hline Pound.s & \\
\hline 0 & 0.00 \\
1 & .40 \\
2 & .80 \\
3 & 1.20 \\
4 & 1.60 \\
5 & 2.00 \\
\hline
\end{tabular}

$I$

$c=.20 n$

\begin{tabular}{c|r}
\multicolumn{2}{c}{$I I$} \\
\hline No. of & Cost \\
Pounds & \\
\hline 0 & 1.00 \\
1 & .10 \\
2 & .20 \\
3 & .30 \\
4 & .40 \\
5 & .50 \\
\hline
\end{tabular}

II

\begin{tabular}{c|r}
\multicolumn{2}{c}{$I I I$} \\
No. OI & Cost \\
Pounds & \multicolumn{1}{|c}{0.00} \\
\hline 0 & .20 \\
2 & .40 \\
3 & .60 \\
4 & .80 \\
5 & 1.00 \\
\hline
\end{tabular}

III

$c=.10 n$

( c represents cost and $n$ represents number of pounds).

The price of tomatoes is determined by the season of the year. Suppose that the seasons are: (I) the growins (spring-summer) season. (2) the fall season, and (3) the 
winter season.

1. Which graph corresponds to each season?

Graph I corresponds to the season.

Graph II corresponds to the season.

Graph III corresponds to the season.

2. That caused you to put the graphs and seasons together a.s you did?

The information that one can secure from each of the graphs is the same as the information obtained from one of the formulas and one of the tables.

3. Which formula corresponds to each graph?

Graph I corresponds to formula:.

Graph II corresponds to formula:.

Graph III corresponds to formüla:.

4. What caused you to put these formulas and graphs together as you did?

5. Which table corresponds to each graph?

Graph I corresponds to Table lNo.

Graph II corresponds to Table No.

Graph III corresponds to Table No.

6. Whit caused you to put these graphs and tables together as: you did?

7. Which formula corresponds to each table?

Table I corresponds to the formula:

Tabie II corresponds to the formula: 
Table III corresponds to the formula:

8. What caused you to put these tables and formulas together as you did? 
Name

\author{
Study Guide No. 40 \\ Symmetric Relations
}

As we read advertisements and listen to the radio or make decisions on various problems we often do not consider the relations between variables. Frequently we overlook the additional relations which are not stated but which are implied in a statement. Consider the following as a true statement: "Covington is the second largest city in Kentucky". Is it true that: "The second largest city in Kentucky is Covington"?

Now consider this statement as valid: "If Jane uses Bond's Cold Cream, her skin will be beautiful". Is the following statement valid? If Jane has beautiful skin, then she uses Bond Cold Cream".

From the two 1llustrations above, it has probably occurred to you that we often rate false statements as true when they are reversed or "Turned around". In fact, many merchants want us to rate such statements as true, then we will purchase only one particular brand of face cream or cereal.

In the statements which follow, assume that the first statement of each pair is true. Rate the second statement as true (T), false (F), or Insufficient data (I).

1. John is Tom's nephew. Tom is John's nephew.

2. Cincinnati is north of Covington. Covington is north of Cincinnati.

3. Ice is lighter in weight than water. Water is lighter in weight than ice.

4. -7 is less than -3 . -3 is less than -7 .

5, Life magazine is a weekly magazine. If the magazine is a weekly it is Life magazine.

6. Paul is married to Jane. Jane is married to Paul.

7. John is the tallest boy in the class. The tallest boy in the class is John.

8. James is taller than John. John is taller than 
James.

9. Mary Ioves Harry. Harry loves Mary.

10. $-8+4=-7+3 \cdot-7+3=-8+4$.

11. Workers are treated fairly by their employers. Employers are treated fairly by their workers.

12. a is greater than $b . \quad b$ is greater than $a$.

13. The building which extends the highest in the air from the ground is the tallest building in the world. The tallest building in the world extends the highest in the air from the ground.

14. $m$ equals $r . \quad r$ equals $m$.

15. General MacArthur disagrees with the foreign policy of President Truman. President Truman disagrees 'with the foreign policy of General MacArthur.

Try to construct at least five sets of statements which are converses of each other and indicate whether the second statement is true or false. 
Name

Study Guide No. $4 I$

Transitive Relations

Some of the statements which follow are true (T), some are false (F) and some are neither true nor false because of insufficient data (I). Read and consider each statement carefuliy, then rate 1 t.

1. If John is taller than James and Robert is taller than John, then Robert is taller than James.

2. If Walter is Harry's brother and Harry is Helen's brother, then Walter is Helen's brother.

3. If James is in the same class as John and John is taller than Albert, then James is taller than Albert.

4. If $c=n$ and $n=b$, then $c=b$.

5. The population of Cincinnati is greater than the population of Loulsvilie, and the population of Detroit is greater than the population of Cincinnati, therefore the population of Detroit is greater than Louisvilie's population.

6. Alabama is south of Kentucky, and Kentucky is south of Ohio, therefore Ohio is north of Alabama.

7. $-6 \div 2=-3$ and $-6 \div 2=x$, therefore $x=-3$.

8. If the Ohio river is wider than the Kentucky river and the Kentucky river is wider than the Licking river, then the Ohio river is wider than the Ilcking river.

9. If the Grant High basket ball team defeated the East High basket ball team and East High's team defeated Lockland Wayne's basket ball team, then Grant will defeat Lockland.

10. If Arthur is Hector's father and Hector is Mortimer's father, then Arthur is Mortimer's father. 11. If $-2=2-4$ and $-4+2=-1+a$, then $-I+a=-2$. 12. If Jane's ball 1s latger than Alice's and Alice's 
338

ball is larger than Mary's, then Jane's ball is larger than Mary's.

13. If a is parallel to $b$ and

$b$ is parallel to $c$, then

c is parallel to a.

8

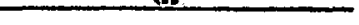

$\mathrm{b}$

\section{c}

14. If $X$ 1s east of $Y$ and $Z$ is east of $X$, then $Z$ is east of $Y$.

15. If Mary's books are lighter (in weight) than John's books and John's books are lighter than Paul's books, then Paul's books are lighter than Mary's.

16. If $a$ is perpendicular to $b$ and $c$ is perpendicular to $b$, then a is perpendicular to $c$.

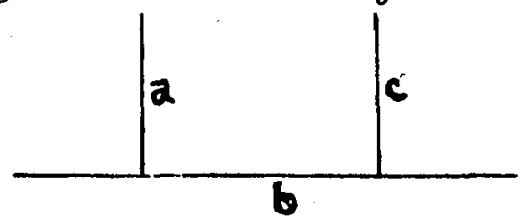

Try to construct at least five statements in which you compare three things as was done in the above statements, then indicate whether each statement is true, false or neither true nor false. 
Name

Study Guide No. 42

Reflexive Relations

Sometimes, we do not realize what relations we are assuming when we solve problems and make decisions. The following questions and statements are designed to make you more conscious of some simple relations. Fill in the blanks and answer the questions.

1. To solve the equation, $4 \mathrm{y}=16$, both members of the equation must be divided by - This is a valid procedure because _. equals_. Thus, both members of the equation are divided by equals.

2. If $a$ is greater than $b$, then $a+c$ is greater than $b+c$. This statement is valid because c equals Thus, equals are being added to unequals and the relationship still holds.

3. Does $5+9$ always equal $9+5$ ?

4. If your principal excuses you from school to go to see a doctor this Thursday afternoon, will he excuse you to do the same thing next Thurgday afternoon?

5. The claim that Mary Ann Evans wrote whatever George Ellot wrote is valid if

6. If John Brown, alias Jim Smith, was arrested last night, was Jim Smith, alias John Brown, arrested last night?

7. Does $a+b$ alvays equal $b+a$ ?

3. If Mark Twain is the pseudonym of Samuel Clements, is Samuel Clements the pseudonym of Mark Twain?

9. If the cost of mailing two packages to the same place was six cents each, did the packages have identical weights? 
Study Guide No. 42 was taken from:

Helen I. Green, "Developing an Understanding of the Nature of Relationghips through the Medium of Elementary Algebra", Inpublished Master's Thes1s, Ohio State University, 1946, pp. 133-34. 
Name

Study Guide No. 43

General Solution of a Gonditional Equation

Solve the following equations for the value of " $n$ ":

(I) $2 n+4=8$

(3) $n+9=12$

(5) $12 n-3=45$

(7) $6 n+b=c$

In the equations above, what operations were performed on the unknown term before its solution?

Equation no. 1

Equation no. ?

Equation no. 3

Equation no. 4

Equation no. 5

Equation no. 6
(2) $3 n-7=11$

(4) $5 n+2=22$

(6) $5 n+b=7$

(8) $a n+b=c$ 
Equation no. 7

Equation no. 8

What did you do in order to find the value of the unknown term in each equation?

Equation no. I

Equation no. 2

Equation no. 3

Iquation no. 4

Equation no. 5

Equation no. 6

Equation no. 7

Equation no. 8

What conclusions can you make concerning the operations that one must perform in order to solve equations of this type? 
Name

Study Guide No. 44
Products Of Numbers To Same Base

1. a. What is the product of 1000 and 100 ?

b. Express the factors and the product above with the base;...10.

In like manner,

(a) find the following products, and

(b) express the factors and product with

the indicated base::

2. 216 and 36 Base 6

3. 2500 and 50 Base 50

4. 144 and 144 Base 12

5. 64 and 512 Base 8

6. 125 and 125 Base 5

7. 16 and 32 Base 2

8. 1,600 and 64,000 Base 40

9. 27,000 and 810,000 Base 30

10. 10,000 and

$10,000,000,000$ Base 100

11. Notice carerully the "b" answers above, studying the relations between the exponents. What is this relationship?

12. Using your generalization, multiply the following expressions:
(a) $10^{3} \times 10^{5}=$
(c) $3 \times 3^{3}=$
(e) $a^{2} \cdot a^{3}=$
(b) $5_{4}^{2} \times 5^{8}=$
(d) $10^{4} \times 10^{4}=$
(f) $b^{2} \cdot b^{4}=$ 
Name

Study Guide No. 45

Quotlents Of Numbers To The Same Base

1. What is the quotient of 1728 divided by $12 ?$

Express the problem above using the base,12

In like manner,

(a) find the following quotients, and

(b) express each problem with the indicated base:

2. $1331 \div 121 \longrightarrow$ Base 11

3. $2401 \div 49$ Base 7

4. $3200000 \div 400$ Base 20

5. $625 \div 25$ Base 25

6. $3125 \div 125$ Base 5

7. $4096 \div 16$ Base 4

8. $81 \div 81$ Base 9

9. $729 \div 81$ Base 3

10. $256 \div 32$ Base 2

11. Notice carefully the "b" answers above, studying the relationg between the exponents. What is this relationship?

12. Using your generalization, divide the following expressions:
(a) $\frac{10^{5}}{10^{3}}=$
(b) $\frac{5^{8}}{5^{2}}=$
(c) $\frac{3^{3}}{3}=$
(a) $\frac{10^{4}}{10^{4}}=$
(e) $\frac{a^{3}}{a^{2}}=$
(f) $\frac{\mathrm{b}^{4}}{\mathrm{~b}^{2}}=$
(8) $\frac{x^{a}}{x^{3}}=$
(h) $\frac{y^{2}}{y^{b}}=$
(i) $\frac{10^{2}}{10^{3}}=$ 
Name

Study Guide No. 46

A study Of Squares

1. Draw squares having sides respectively: I inch, 2 inches, 3 inches, 4 inches, 5 inches and 6 inches long.

2. Record the area of each square in the table below:

\begin{tabular}{l|l|l|l|l|l|l|l|l}
\hline $\mathrm{s}$ (length of side) & 0 & 1 & 2 & 3 & 4 & 5 & 6 \\
\hline $\mathrm{A}$ (area) & & & & & & & \\
\hline
\end{tabular}

3. Graph the data above, plotting "s" on the horizontal axis.

4. Describe the graph.

This type of graph. is known as a parabola.

5. In the table below record the changes in area of the squares. Label the column as " $\mathbf{\Delta A}$ ". Are the changes regular or varying?

6. Record the second differences by finding the changes in $\Delta A$. Label the column " $\Delta^{2} \mathrm{~A}^{\prime}$.

\begin{tabular}{l|l|l|l}
\hline s: & A & & \\
\hline & & & \\
\hline & & & \\
\hline & & & \\
\hline & & & \\
\hline & & & \\
\hline & & & \\
\hline
\end{tabular}


346

7. Are the second differences regular or varying?

8. When the second differences are constant, the equation for the graph is a quadratic equation. --.-The dependent variable equals the square of the independent variable.

What is the independent variable?

What is the dependent variable?

9. State the equation using statement (8) as a guide. 
347

Name

Study Guide No. 47

The Crash of A Speeding Car

"If a moving automobile hits a stationary object, such as a solid wall, a tree, or a telephone post, the force of the impact is equivalent to that force with which it would strike the ground when falling from a certain height. If $s$ represents this height in feet and $r$ is the speed of the car in miles per hour, then

$$
s=.0336 r^{2} . " 17 t h \text { Yearbook, NCTM }
$$

1. Using the formula, complete the following table of values:

\begin{tabular}{l|l|l|l|l|l|l|l}
\hline When $r$ equals & 0 & 10 & 20 & 30 & 40 & 50 & $60 \mathrm{mph}$ \\
\hline Then s: equals & & & & & & & $\mathrm{ft.}$ \\
\hline
\end{tabular}

2. Plot and graph these values in the chart to the right.

3. Suppose the speed of a car is doubled from 20 miles per hour. How does the height change?

4. How does the height change when the speed is tripled from 20 miles per hour?

5. Suppose the speed of another car is hallved from 60 miles per hour. How does the height change?

6. What is the equivalent force of impace of a car moving at the rate of 45 miles per hour?

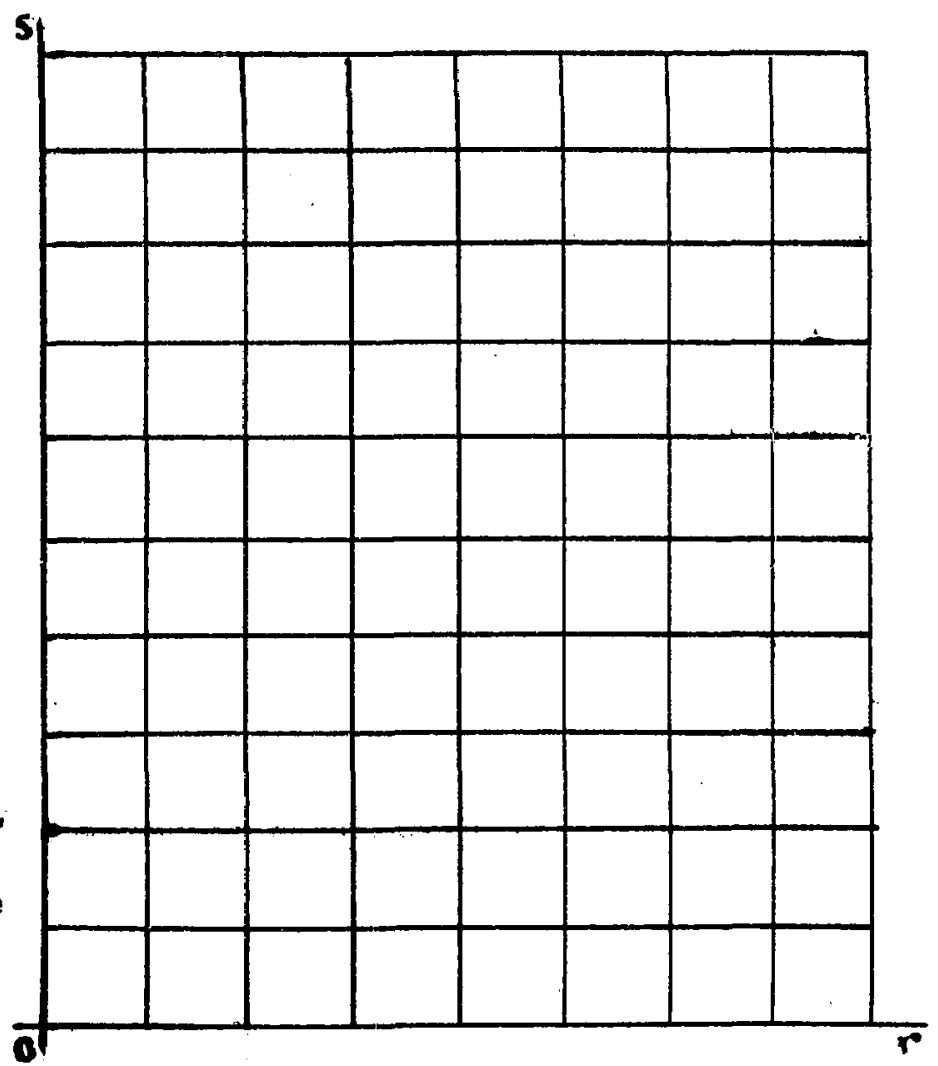


348

7. If a motoristi is driving at the rate of 90 miles per hour, the crash of his car would be equivalent to it falling how many feet?

8. What conclusions can you make concerning speed and safe driving? 
349?

\section{Name}

Study Guide No. 48

Stopping Distance And Speed

"How soon can a car be stopped in the face of danger? The answer to this question depends upon the speed at which the car is being ariven, the length of time necessary to start applying the brakes, and the rate at which the car slows down after the brakes are applied. For a car being driven at the rate of $r$ miles per hour the minimum number of feet, d, necesaary for stopping the car after danger is realized, is given approximateiy by the formula,

$$
d=.045 r^{2}+1.1 r \text {. }
$$

"This is for a dry road with the best braking conditions". It is also assumed that the average reaction time necessary before a driver can set his foot on the brakes is .75 second.

(Adapted from 17th Yearbook, NCTM, p. 95)

Using the formula, complete the following table to show the stopping distances for cars moving at the indicated rates.

\begin{tabular}{l|l|l|l|l|l|l|l|l|l}
\hline$r$ & 0 & 10 & 20 & 30 & 40 & 50 & 60 & 70 & 80 \\
\hline $\mathrm{d}$ & & & & & & & & & \\
\hline
\end{tabular}

Using the table, construct a graph to show the relation between speed and stopping distance.

1. How many feet are required to stop a car moving at the rate of 55 miles per hour? (Dry road, good brakes, average reaction time)

2. If a driver's reaction time is .9 second or above the average, what is his stopping distance when moving at the rate of 40 mph?

3. What is the stopping distance of a car moving at the rate of 90 miles per hour? The car has good brakes, the road is dry and the driver's reaction time is average. 
350

4. What is the stopping distance of a car moving at the rate of 35 miles per hour on a wet road?

5. According to the table, what change occurs in stopping distance when the speed is doubled from 30 miles per hour?

6. That change occurs in stopping distance when the speed is haived from 80 miles per hour? 


\section{Name \\ Study Guide No. 49 \\ The Value of $\mathrm{Pi}$}

Earlier in the year, we computed the value of $P_{1}(\pi)$ by finding the ratio of the distance around (circumference) to the distance across (diameter) in a number of circles. We can use a second method by studying the relations between the areas of circles of varying radi1.

On a piece of graph paper which has been given to you is drawn a circle. If we agree that each small block has an area of 1 square unit, how could you get the area of the circle?

What is the length of each small block?

What is the length of the radius of the circle?

What is the area of the circle?

Class Results

\begin{tabular}{l|l|l|l}
\hline $\begin{array}{c}\text { Radius } \\
(\mathrm{x})\end{array}$ & $\begin{array}{c}\text { Area } \\
(\mathrm{A})\end{array}$ & $\Delta \mathrm{A}$ & $\Delta^{2} \mathrm{~A}$ \\
\hline & & & \\
\hline & & & \\
\hline & & & \\
\hline & & & \\
\hline
\end{tabular}

Compute the first and second differences.

From the data in the table, what is the approximate formula for the area of a circle?

We can find the value of $P_{1}$ by substituting values in the formula from the table. Do this and find the average of the answers which you get from the substitution.

What is the relation between the area and radius of a circle? 
352

Test 5.4 P.E.A.

Name

\section{PROBLEMS RELATING TO FUNCTIONAL THINKING}

a. Verbal Statement:

The distance traveled during reaction time in feet is equal to one and a half times the speed in miles per hour.

b. Table

\begin{tabular}{c|c}
\hline $\begin{array}{c}\text { Speed in } \\
\text { Miles per } \\
\text { Hour }\end{array}$ & $\begin{array}{c}\text { Distance } \\
\text { in } \\
\text { feet }\end{array}$ \\
\hline 10 & 15 \\
20 & 30 \\
30 & 45 \\
40 & 60 \\
50 & 75 \\
60 & 90 \\
\hline
\end{tabular}

d. Formula c. Graph

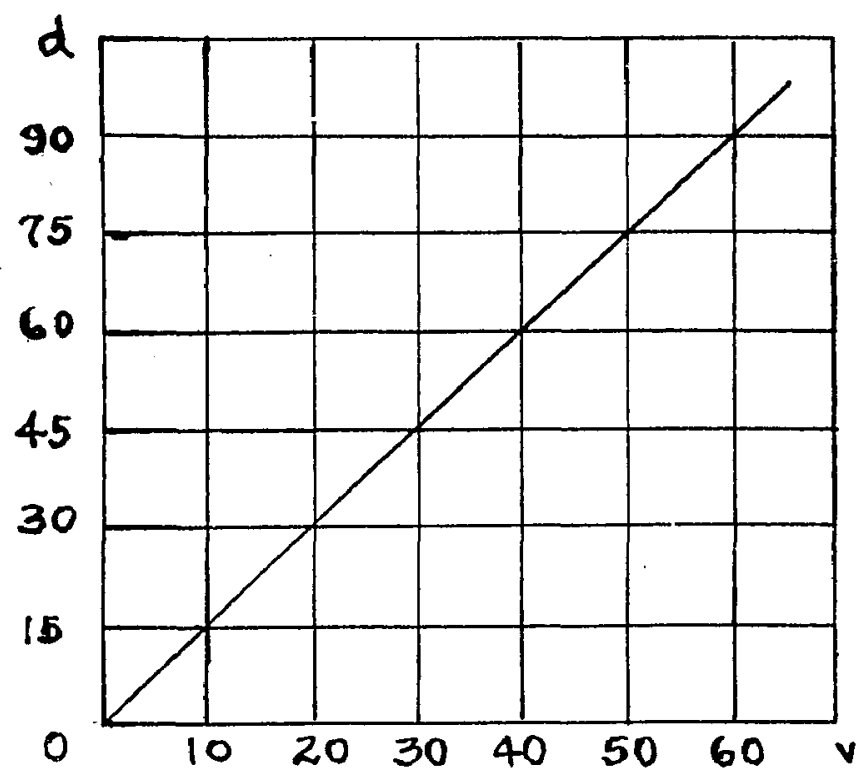

$d=1.5 v$, when $d=$ the distance in feet: $v=$ the speed in miles per hour.

Read the following exercises and answer the questions asked.

Automoblle accidents are often caused by carelessness. A ariver is not paying close enough attention to the road or to the cars on the road. He forgets that he needs a certain time to react and that during this time his car travels some distance. After an accident, such a driver was sentenced to attend a police school for drivers. During a study of the distance that a car travels between a person's seeing the danger and stepping on the brakes, the policeman in charge of the class asked. "If you were driving at a speed of 45 miles per hour when it became necessary to put on the brakes, how far would the car go before your foot could be put on the brake pedal?" 
353

a. How would you answer the question? _a.

b. Which of the above ways of representing the data did you use in order to arrive at your answer?

c. Below are Iisted statements which support the possible answers to (b). Check those which seem to be most closely in aympathy with your choice.

1. The formula is conclse and useful for exact prediction.

2. If the data are themselves subject to error, the graph will give an accurate enough answer to the question.

3. In order to go beyond the scope of the data

$\therefore$ It is usually best to use the formula.

4. The verbal statement is used because it is the easiest to remember.

5. In a table of such regular data it is a simple matter to interpolate.

6. I do not know how to work out an answer to the question but if I did I would use the

Suppose the police instructor had said, "There is one important aspect of this data which every driver should keep in mind, 'What happens to the distance as the speed increases from 50 to 60 to 70 miles per hour?

a. How would you answer this question? a.

b. Which of the above ways of representing the data did you uae in order to arrive at your answer?

c. Below are listed statements which support the possible answers to (b). Check those which seem to be most closely in sympathy with your cholce.

1. A table of such regular data clearly indicates the trend.

2. The graph vividly pictures the relationship of distance and speed.

3. The formula is of little use because it is hard to find from it how the. distance varies with speed.

4. The verbal statement indicates the relationship of distance and speed. 
5. Since the table of data is so regular, it is easy to see how to go beyond it; that is, to fill in correspondins distances and speeds above 60 miles per hour.

6. The graph is a straight Iine; for that reason one can easily extend it and see the relationship between distance and speed.

7. Since the formula is of such a simple type, one can discover without much difficulty how the distance varies with speed.

If the police instructor had said, "In order to make clear to you the importance of remembering that your car covers a considerable distance during your reaction time, imagine yourself behind the wheel of Malcolm Campbell's Bluebird, tearing down the salt flats of Utah at a speed of 200 miles per hour. In case of some danger, how inuch distance would you have to allow for your reaction time?"

a. How would you answer this question? a.

b. Which of the above ways of representing the data did you use in order to arrive at your answer? b.

c. Below are listed statements which support the possible answers to (b). Check those which seem to be most closely in sympathy with your choice.

1. I would make a new graph, using a smaller scale, and from it read the distance.

2. The table can be extended to a speed of 200 miles per hour.

3. Using the verbal statement I would mentally work out the aistance.

4. The formula is easier to use in this case because it is of a simple type.

5. In order to go beyond the scope of the data it is easier to use the formula.

6. Since the graph is a straight line, all one has to do is extend it and read the required âstance.

7. Since the table is very regular, one can estimate the distance for a speed of 200 
miles per hour.

The police instructor went on to investigate more completely the relationship of speed and the distance traveled during the reaction time. He said, "Suppose your speed doubles, what happens to the distance?"

Of the possible answers given below, check the one you would make.

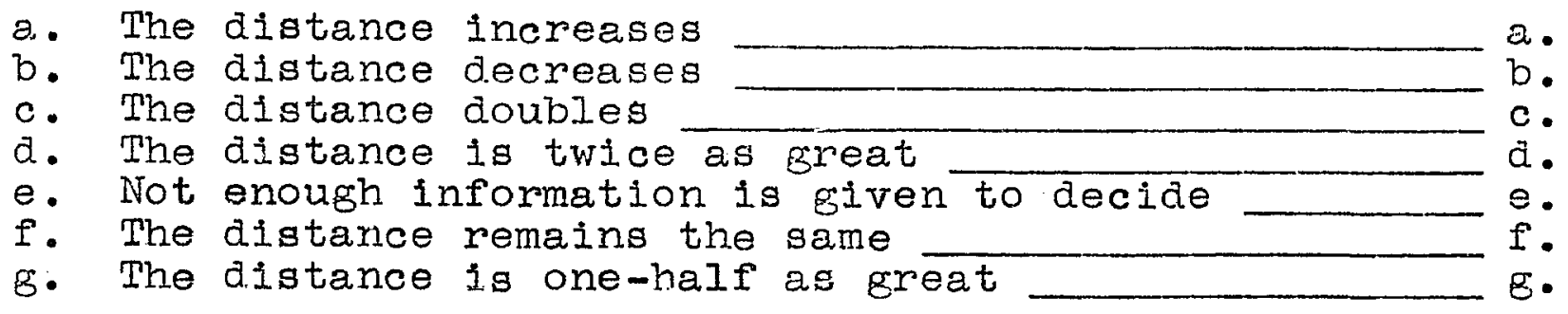

The psychology class at school was asked to write an article on lts activities for the school paper. One part of its work consisted of a study of reaction time. In order to show the importance of the concept to everyone the class decided to use the above data and then had to decide on a way of presenting it in the paper.

If you were a member of the class which way would you choose to present the data?

After the article prepared by the psychology class appeared in the paper, the science teacher asked if it would be possible to have a member of the class lecture to his physics students. In the laboratory there are blackboards and you could hang up charts.

If you were the member chosen to talk to this group made up of physics and mathematics students, how would you present the data to them?

In the course of your lecture you wished to give an illustration of the way in which the distance changed with speed. You chose the following problem. If the speed is increased by one-half of it-self, how does the distance change?

Thich of the possible answers listed below do you think to be the correct one?

a. The distance is half as great:

c. is $1 \frac{1}{2}$ times as great

e.

is 3 times as great

b. is twice as great d. Is unchanged 
356.

Interpreting Data and Reaching Conclusions

The students in a health class were studying the number of hours of sleep needed by boys and girls. One student brought in the table at the right showing the number of hours of sleep needed at several different ages. The students noticed some definite relationships between pairs of numbers.

Directions: Study the table and the statements below. Suppose the facts in the table are true. If you agree with a statement which follows, put $A$ on the Iine by the statement. If you dieagree with a statement, put $D$ on the line. If You can nejther agree nor disagree, but are uncertain, put $U$ on the line by the statement.

1. As the age increases from 6 to 16 ,

\begin{tabular}{c|c}
\hline $\begin{array}{c}\text { Age } \\
(\mathrm{A})\end{array}$ & $\begin{array}{c}\text { No. of } \\
\text { Hours } \\
(\mathrm{H})\end{array}$ \\
\hline 6 & 14 \\
\hline 8 & 13 \\
\hline 10 & 12 \\
\hline 12 & 11 \\
\hline 14 & 10 \\
\hline 16 & 9 \\
\hline
\end{tabular}
hours of sleep needed. increases.

2. The number of hours of sleep needed at any age is greater than the age.

3. In this table the ratio of the number of hours of sleep to the age is constant.

4. A four-year-old should have 15 hours of sleep.

5. A twelve-year-old only needs half as much sleep as a six-year old.

6. From age 6 to age 16, for every 2 years that your age increases you need one haur less sleep.

7. A person 30 years old needs very few hours of sleep.

8. If the number of hours of sleep needed is subtracted from 17, the result is half the age.

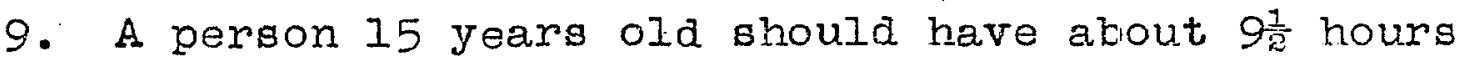
of sleep.

10. If the number of hours of sleep needed is subtracted from 17, the ratio of the result to the

(45th Yearbook, N.S.S.E., The Measurement of Understanding.) 
Intexpretation of Data and Application of Principles

Part I

Statement: During a campaign to reduce automobile accidents a class in the Iincoln School was studying some of the factors involved. Data were studied to find out whether there is a relationship between speed and the number of accidents. A question arose as to how far a car travels before coming to a stop after the brakes are applied. The following data were found in a magazine article. The speed is given in miles per hour and the distance required for a car to come to a stop after the brakes are applied is measured in feet.

$$
\begin{aligned}
& s=\text { speed in miles per hour } \\
& d=\text { distance in feet }
\end{aligned}
$$

\begin{tabular}{r|r}
$\mathrm{s}$ & $\mathrm{d}$ \\
\hline 20 & 28 \\
30 & 63 \\
40 & 112 \\
50 & 175 \\
60 & 252 \\
70 & 343 \\
80 & 448
\end{tabular}

It was decided to study these data in order to understand more completely the way in which stopping distance depends upon speed.

Directions: Assuming that the data given in the aforementioned table are correct, mark in accordance with the following statements:

Mark with an $\mathrm{R}$ - every statement which is a reasonable interpretation of the data.

Mark with a $U$ - every statement which may be true but for which ingufficient facts are given to justify the interpretation.

Mark with an F - every statement which cannot be true because it is contradicted by the data.

1. The number of feet in which a car can be stopped after the brakes are applied has no relationship to the speed of the car.

2. The distance in which a car can be brought to a stop when going at a speed of 30 miles an hour is the same for all cara.

3. The distance in which any car can be stopped after the brakes are applied has some relationship to 
the square of the speed at which the car is traveling.

4. If the speed of the car is increased from 30 to 60 miles an hour, the distance required to stop a car is then approximately four times as great.

5. A car going 50 miles an hour can be stopped in less than twice the distance required when going 30 miles an hour?

6. There is no relationship between the distance required to stop a car soing at 40 miles an hour and its weight.

- 7. High speeds cause accidents.

8. The distance required to stop a car when the speed is increased from 40 to 70 miles an hour does not increase any more than when the speed is increased from 30 to $60 \mathrm{miles}$ an hour.

9. A car moving at 45 miles an hour can be stopped in about 142 feet.

10. A car moving at the rate of 100 miles per hour can be stopped after the brakes are applied in less than 600 feet:

11. The increase in the distance required to stop a car when the apeed is doubled from 40 to 80 miles an hour, is not any greater than the increase in distance when the speed is doubled from 30 to 60 miles an hour.

Part 2

Given the graph below with the vertical and horizontal axes labeled $A$ and $e$ regpectively.

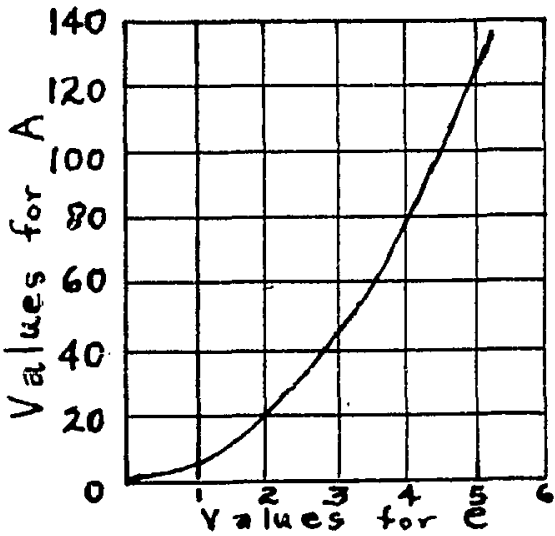


1. From the graph make a table of values for $A$ and $\theta$.

2. From a study of the table, show how you could be sure of the degree of the equation from which the graph was drawn.

3. What value must be given to the constants of variation?

4. Write the equation from which the graph could be drawn.

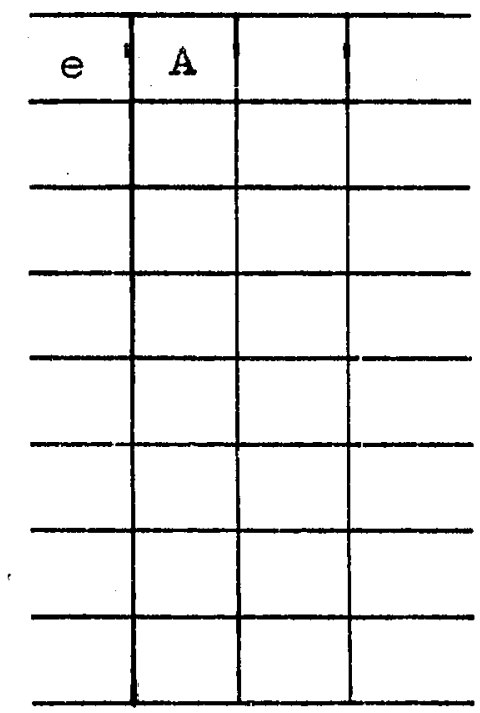

5. Express the meaning of the formula in worda.

Part 3.

Galileo, an Italian mathematician and astronomer, discovered certain laws of falling bodies by dropping heavy objects from the Leaning Tower of Pisa. One of the laws is that the distance through which an object falls is equal to the square of the number of seconds it falls, multiplied by one-half the gravitational constant, The gravitational constant is approximately 32.

1. Write the above statement in equation form.

2. Using the formula you have just made, make a table in which the time varies from $I$ second to $\sigma$ seconds inclusive.

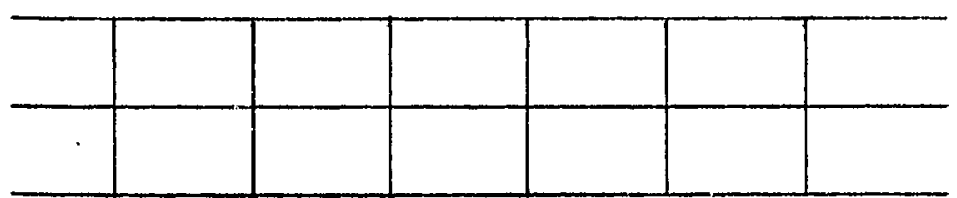

3. Draw a graph from the table you have just made.

4. From your graph tell what relationship there is between 
360

the distance a body falls in three seconds and the distance it falls in six seconds.

5. From your graph determine the distance a body falls when the time is 3.5 seconds.

6. Determine how far a body will fall in eight seconds.

(Materials prepared by the Mathematics Group, Progressive Education Association Workshop, Ohio State University, 1936). 
P.E.A. Test 5.5

I A manufacturer of leather goods uses many square pleces of leather. To make them fit, a narrow strip must be trimmed off two edges until the remaining piece is 3 inches square. The trimmings are worthless and must be thrown away. The number of square inches thrown away depends upon the width of the atrip cut off. Assume both strips are the same width and that the area of the small corner may be ignored.

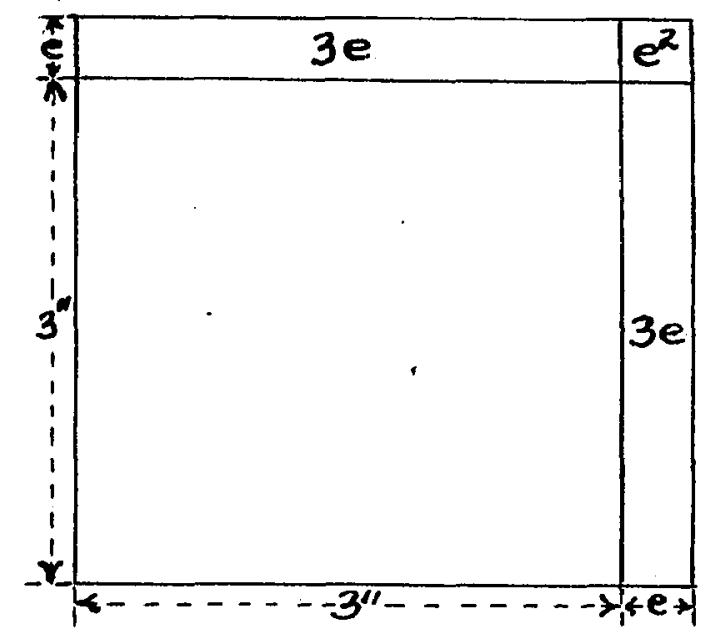

Let $W=$ the approximate number of square inches of leather thrown away--i.e., waste leather.

Let $e=$ the number of inches in the wiath of the small strips cut off.

Then the following formula may be used: $W=6 e$.

Check $(\checkmark)$ any of the following statements with which you asree.

1. More leather is thrown away when the strip cut off is wide than when it is narrow.

2. If the width of the strip cut off is made twice as wide, the amount of waste will be four times as great.

3. If $e$ is increased by 0.2 inch, the waste is increased by 1.2 square inches.

4. If the width of the strip cut off could be made half its usval size, then the maste would also be reduced to half its former amount.

5. If the width of the strip cut off is doubled, the amount of waste is also doubled.

6. If the width of the strip cut off is decreased by $60 \%$ of its regular size, the amount of waste would be only $60 \%$ of 1 ts former value.

7. If the width of the strip cut off is decreased 


\section{2}

by $60 \%$ of 1 ts regular size, the amount of waste would be only $40 \%$ of $1 \mathrm{ts}$ former value.

8. If the width of the strip cut off is decreased by $60 \%$ of $1 \mathrm{tg}$ regular size, the amount of waste would be reduced $36 \%$.

9. If the width of the strip cut off is made 2 times as wide, the waste is 12 times as great.

II. The following quotation is talen from an article printed in a daily newspaper:

"......George I. Smith, an automotive engineer of the national capital, has made a study of the (automobile) brake situation in relation to speed fatalities and is far from being content.

"He points out that 10 years ago the usual stock passenger automobile sold to the general public rarely had a speed capacity in excess of 50 miles an hour. That, of course, is a high rate of speed, and the great weight of a motor car, striking at such a, speed, creates an impact which is bound to cause severe results. But Mr. Smith asserts that while today the speed of stock motor cars has been stepped up to 70 miles an hour, there has not been a comparable advance in braking power. The destructive power of a car going 70 miles an hour is almost exactly twice that of the same car going 50 miles".

Columbus Dispatch, Jan. 7, 1936.

The "destructive power" referred to in the article comes from the kinetic energy of the car, and this may be computed from the formula

$$
\begin{aligned}
\mathrm{K} & =\frac{1}{2} \mathrm{mV}^{2} \\
\text { where } \mathrm{K} & =\text { kinetic enersy } \\
\mathrm{m} & =\text { mass (sometimes called "weight") } \\
\mathrm{V} & =\text { of the car }
\end{aligned}
$$

The article says "the destructive power of a car going 70 miles an hour is almost exactly twice that of the same car going 50 miles." "Note that 70 is 1.4 times a.s great as 50$)$. 
Check $(\mathscr{d})$ any of the following statements with which you agree.

10. The article id incorrect. The destructive power of a car going 70 miles an hour cannot be almost twice that of the same car going 50 miles an hour.

11. The destructive power of a certain car bought ten years ago was less than 1t would be today.

12. If one of two cars of the same weight is moving twice as fast as the other, its kinetic energy is four times as great.

13. If one of two cars of the same weight 1s $10 \%$ heavier than the other, its destructive power will be $10 \%$ greater provided both are moving at the same speed.

14. Since 70 is not twice 50 , the "destructive power" at 70 miles per hour cannot be twice as great. -

15. Since $\overline{70}^{2}$ is almost twice $\overline{50}^{2}$, the kinetic energy of a car going. 70 miles an hour will be about twice that of one going 50 miles per hour.

16. The kinetic energy of a car moving 50 miles an hour is 100 times as great as that of the same car moving 5 miles an hour.

17. The article is correct. The destructive power of a car going 70 miles an hour is almost exactly twice that of the same car going only 50 miles an hour.

18. Not enough information has been given to enable one to decide whether the newspaper article is accurate or not.

19. The destructive power of two cars with the same "horgepower" w1II" be the same.

20. The kinetic energy of a car moving 40 miles an hour will be four times as great as that of the same car moving 20 miles an hour.

21. The destructive power of a car weighing 4000 pounds will be twice as great as that of a car weighing 2000 pounds. 
22. If the weight of one car is twice that of a second car, the "destructive power" of the first is four times that of the second.

23. The destructive power of a car does not depend upon its weight.

24. The destructive power of one car which is 1.4 times as heavy as a second car w1Il be 1.4 times as great.

25. Car A is twice as heavy as car B, but is moving only half as fast when it strikes. How will the destructive power of the two cars compare?

a. It will be the same.

b. Car A will be twice as destructive as car B. c. Car A will be half as destructive as car B. d. No definite answer is possible.

IV One of the measurements often made during a health examination is the circumference of the chest. The circumference changes with the age of the person approximately according to the formula:

$$
\begin{aligned}
C & =A+15 \\
\text { where } C & =\text { circumference of chest in inches } \\
A & =\text { age of person in years }
\end{aligned}
$$

This formula holds reasonably well for persons less than 18 years of age.

Check $(\checkmark)$ any of the following statements with which you agree.

42. The circumference of the chest increases as the age increases up to the age of 18 .

43. If one small boy is twice as old as another, the circumference of the first boy's chest should be about twice the circumference of the younger boy's chest.

44. If a girl is 3 years older than her sister, the distance around the older girl's chest should be 
about three inches greater.

45. When a small boy is twice as ola as he is now, the circumference of his chest then will be twice what it is now, minus 15 inches.

46. When a child's age has doubled a former age, the circumference of his chest is four times as great.

47. The c1rcumference of the chest of a man 40 years old should be 5 inches greater than the chest circumference of $\dot{a} 35$ year old man.

48. The chest circumference of a normal boy increases about one inch a year.

49. Chest circumference changes at about the same rate for very young children as for older boys and girls. 
366.

Recosnition of Variables and Constants:

Directions: In each of the following statements, does the underlined word have a meaning or value which changes? Does it have a meaning or value which does not change?

Write $C$ to the left of the statement if the word has a changing value.

Write $N$ to the left of the statement if the word has a value which does not change.

Write U to the left of the statement if you cannot decide.

1. $A+3=16$.

2. $A+B=16$.

$\bar{A}$ is the first letter of the alphabet.

$\underline{A}$ and $B$ Stores sell for less.

2. Athletes are healthy.

Five athletes are on a basketball team.

The Philadelphia Athletes won the 1935 baseball championship.

John had athiete's foot.

3. A boy who walks at the rate of two blocks per minute is a fast walker.

The baby was fast asleep.

The nails held the board fast.

Ash Wednesday is a fast day for Catholics.

4. One-half equals five-tenths.

The Johnson family rented one-half of their house. The area of a triangle equals one-half the product of its base by its altitude or height.

The class in history covered one-half of the text book in ten weeks.

5. The president travels.a lot.

President Roosevelt wielded much power. The president of our class should be a good leader. A president is usualiy over 45 years of age. 
6. The cost of six pencils seling at five cents each is thirty cents.

The cost of several things of the same kind equals the number of things multiplied by the price for one of the things.

The product of the price per ton of Pocahontas coal (节14) by the number of tons purchased ( 5 tons) shows Mr. Sutton the cost of his coal. When we divide the price for one bar of Mounds ( $10 \phi)$ into the cost for five Mounds ( $50 \phi)$, we know that Arthur purchased five bars.

7. Since Mr. James couldn't wrste, he marked an $\underline{X}$ for his signature.

When using Roman numerals, we indicate ten by an $x$. $4 \underline{X}=28$.

Mary ends all her letters to George with a row of $\underline{X}^{\prime} \theta$.

8. Henry is the bright student in the class. Wednesday was a bright day.

Pure copper is bright before it corrodes. Martha gave a bright smile as she passed Harry.

9. Elach boy accepted into the club must be a regular fellow.

Only students in regular attendance were given Ifnot Hole tickets.

A healthy person has a regular heart beat.

A figure with a regular shape appeals to the eye.

10. Small screws must be used to fasten the strips of metal to the edge of the book case. The clerk placed a small piece of cheese upon the scales. Most of the rooms in apartment houses are small. A small number of people were at the basketball same.

11. Thirty-two students are enrolled for the class in speech. Water freezes at thirty-two degrees Fahrenheit. Walter's father has been employed at the post office for thirty-two years. Each boy earned an average of thirty-two dollars per week during the summer. 
12. A city hospital covers a wide area. This school building covers an area of 20,000 square feet. The area of a rectangle equals the product of the width by the length. The parking area for customers of this super market is behind the building.

13. The one-fourth note in music is not sounded as long as a half note.

In mixing the cake batter, Mrs. Johnson added one-fourth cup of sugar. Twenty-five cents is one-fourth of a dollar. One-fourth of the merchandise in the store was refrigerated.

14. A person's interest in photography might prompt him to seek regular employment in a studio. The interest on a loan of fifty dollars at six per cent is $\$ 3.00$ per one year. Most steel manufacturers have an interest in coal mines. Motion pictures are of interest to many people.

15. The price of food is hish during wars. High bridges usually are very long. Television stations can operate best from high hills. The weather bureau forecast high ceilings during the month of July. 


\section{Autobiography}

I, William Nichols Jackson, was born in Lyerly, Georgia, December 27, 1912, I received my secondary education at the Howard High School in Chattanooga, Tennessee. My undergraduate training was received at Morehouse College, Atlanta, Georgia, from which I received the defree Bachelor of Science in 1933. In 1938, I received the degree Master of Science from the Atlanta University, my field of specialization being mathematics. While in residence at Atlanta University, I served as assistant to Professor C. B. Dansby of the Department of Mathematics. I have held continuous employment as a secondary school teacher since my sraduation from college and have served as mathematics and science instructor in the following school systems: Chattanooga Public Schools; Atlanta Public Schools; Atlanta University Laboratory Schools and the Covington, Kentucky Public Schools. During the summers beginning in 1940, I have had numerous worlshop experiences either as participant or consultant on various college campuses. I was a participant in the following workshops: Secondary School Study, Atlanta University, 1940; University of Chicago, 1941; Ohio State University, 1945. I served as consultant in the following workshops: Secondary School Study, INorth Carolina College, Durham, 1942; South Georgia Forkshop of Secondary School Study, Albany State College, 1943; Science Workshop, 